Portland State University

PDXScholar

\title{
Multi-Perspective Technology Assessment to Improve Decision Making: A Novel Approach Using Fuzzy Cognitive Mapping for a Large-Scale Transmission Line Upgrade
}

Richard Chad Sperry

Portland State University

Follow this and additional works at: https://pdxscholar.library.pdx.edu/open_access_etds

Part of the Technology and Innovation Commons

Let us know how access to this document benefits you.

\section{Recommended Citation}

Sperry, Richard Chad, "Multi-Perspective Technology Assessment to Improve Decision Making: A Novel Approach Using Fuzzy Cognitive Mapping for a Large-Scale Transmission Line Upgrade" (2014).

Dissertations and Theses. Paper 1822.

https://doi.org/10.15760/etd.1821

This Dissertation is brought to you for free and open access. It has been accepted for inclusion in Dissertations and Theses by an authorized administrator of PDXScholar. Please contact us if we can make this document more accessible: pdxscholar@pdx.edu. 
Multi-Perspective Technology Assessment to Improve Decision Making: A Novel Approach Using Fuzzy Cognitive Mapping for a Large-Scale Transmission Line Upgrade

by

Richard Chad Sperry

A dissertation submitted in partial fulfillment of the requirements for the degree of

\author{
Doctor of Philosophy \\ in \\ Technology Management
}

Dissertation Committee:

Antonie J. Jetter, Chair

Tugrul U. Daim

Thaddeus Miller

Wayne Wakeland

Portland State University

2014 
(C) 2014 Richard Chad Sperry 


\section{ABSTRACT}

The objective of the technology assessment (TA) process is to understand problematic and undesirable consequences from the development and application of technology. TA advocates for the engagement of technology experts and stakeholders to understand the effects of technology. However, TA is often criticized that the decision-making process is not transparent - leaving stakeholders wondering if their contributions were heard. Furthermore, the methods have limited capability for conducting tradeoff analysis between the organizational objectives and conflicting stakeholder perspectives that can result in unintended consequences. Finally, these methods are static making it difficult to update and reassess decision alternatives when new information about issues becomes available.

This dissertation research addresses these problems by developing a new technology assessment methodology using Fuzzy Cognitive Mapping (Fuzzy Cognitive TA - FCTA). This novel approach supports both stages of the process: capturing expert and stakeholder perspectives in cognitive maps, and then using FCM for assessment and decision-making. The methodology shows how experts and stakeholders perceive the value or harm of a technology alternative, which stakeholders share the same perspectives, and how these perspectives change over time. The methodology also shows the degree to which expert and stakeholder perspectives are in support or in conflict with the organizational objectives to help avoid the direct and indirect 
consequences associated with the decision. Finally, the methodology shows how new or changing perspectives by experts and stakeholders affect the outcome of the decision to improve system knowledge.

The research applies the FCTA methodology with a real-world Environmental Impact Study conducted by the Bonneville Power Administration (BPA). BPA is a U.S. federal agency that provides about a third of the electric power and 75 percent of the highvoltage electric transmission in the Pacific Northwest. 


\section{ACKNOWLEDGEMENTS}

First and foremost, I would like to express my sincerest gratitude to my dissertation committee chair and my academic advisor, Dr. Antonie J. Jetter, who challenged and guided me with her knowledge and wisdom. Without her invaluable guidance and persistent support, this dissertation would not have been possible. I also express gratitude to my dissertation committee members, Dr. Tugrul U. Daim, Dr. Thaddeus Miller, and Dr. Wayne Wakeland (Graduate Representative), whose valuable comments and guidance enabled this dissertation to be the best it could be.

I am truly indebted and thankful to all of the professors at the Department of Engineering and Technology Management, Portland State University, especially the department chair, Dr. Dundar F. Kocaoglu, whose encouragement, leadership, support and vision provided me with the inspiration to reach this plateau.

I am thankful to my classmates, colleagues and friends at Portland State University for their friendship and support during my studies.

Finally and most importantly, I would like to dedicate this dissertation to my family. To my daughters Alyssa and Christa: Their support made me realize how my studies inspired them and that this endeavor was a special opportunity to bond with them in a very meaningful way. To Sharon, my wife, for her patience, understanding and unconditional love. Her insights and questions on the environment and society not only challenged me, but also made me think out of the box. 


\section{TABLE OF CONTENTS}

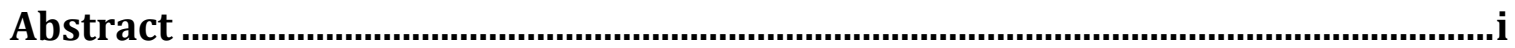

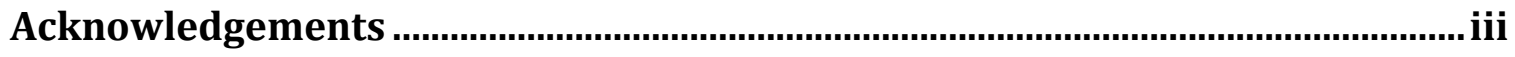

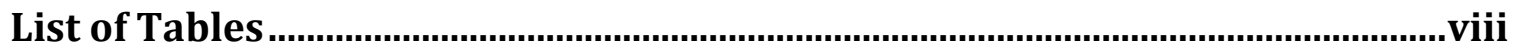

List of Figures

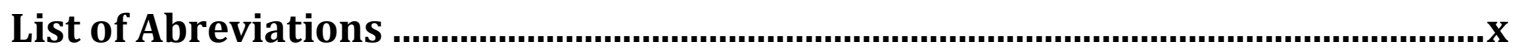

1 Introduction

1.1 Problem Background .................................................................................. 1

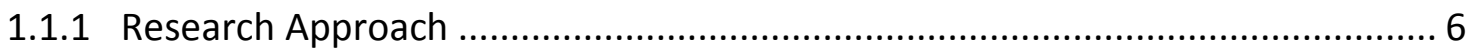

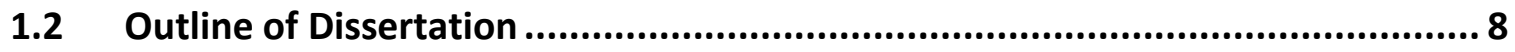

1.3 Publications Arising from this Dissertation ................................................. 10

2 Literature Review: Technology Assessment and selection ..........................11

$2.1 \quad$ Literature Review Overview ....................................................................... 11

2.2 Methods for Technology Assessment ............................................................... 13

2.2.1 Office of Technology Assessment (OTA) ...................................................... 14

2.2.2 Constructive Technology Assessment (CTA) .................................................. 16

2.2.3 Discussion on Merits and Limitations ......................................................... 18

2.3 Methods for Environmental Impact Assessment (EIA).................................... 20

2.3.1 EIA according to NEPA and European Community ........................................ 20

2.3.2 Discussion on Merits and Limitations ........................................................ 22

2.4 Methods for Green Technologies and Products............................................... 23

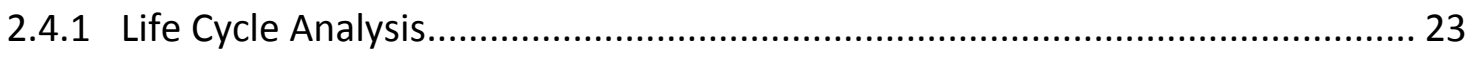

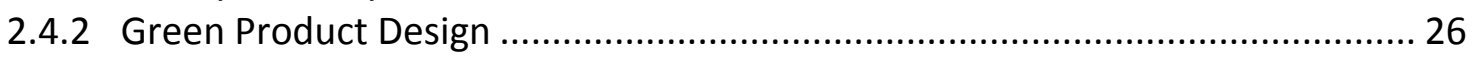

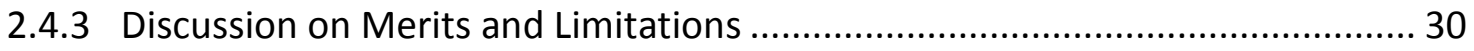

2.5 Methods for Stakeholder Engagement/CSR ................................................. 31

2.5.1 Over view of Stakeholder Engagement/CSR …............................................ 31 


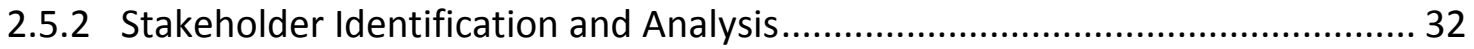

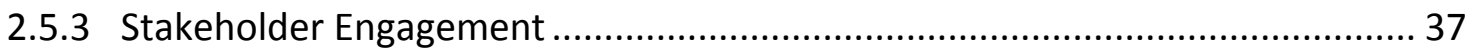

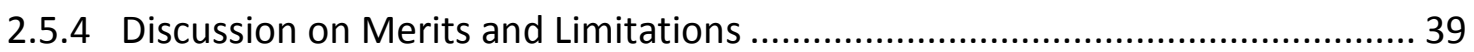

2.6 FCM-Based Approaches for Stakeholder Analysis...................................... 42

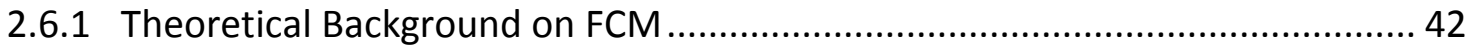

2.6.2 FCM Research Studies and Application Domains .......................................... 50

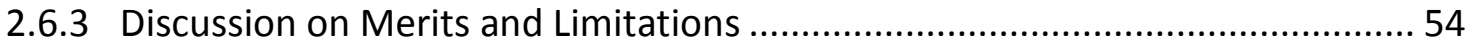

2.7 Method Requirements and Gap Analysis .................................................. 55

3 Research methdology

3.1 Research Objectives and Questions ................................................ 61

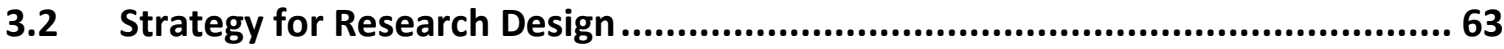

3.3 Strategy for Data Collection, Model Building and Analysis ............................. 64

3.4 Strategy for Evaluation and Assessment ............................................. 65

3.4.1 Strategy for Validation and Quality Control of Methods Used .........................66

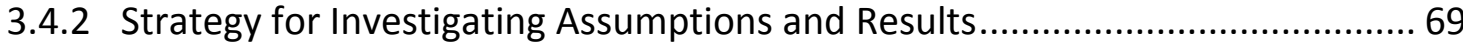

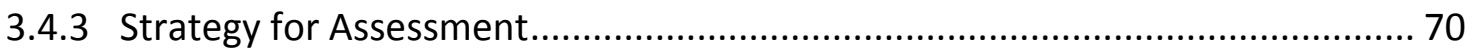

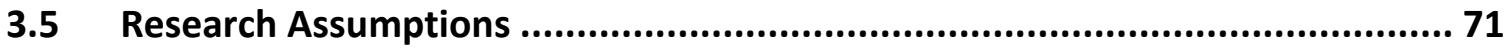

4 State of the Art FCM Research Methods.......................................................... 72

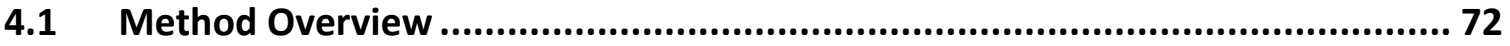

4.2 Step 1 - Knowledge Capture in Causal Cognitive Maps ................................. 72

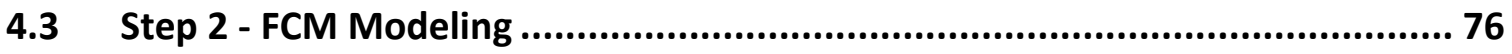

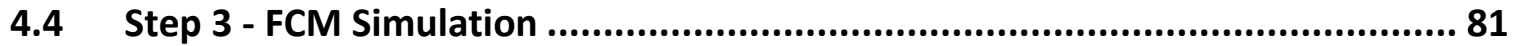

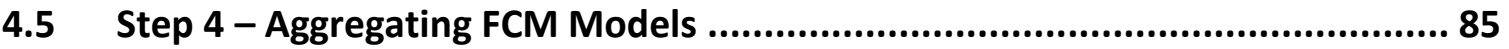

4.6 Step 5 -Identify New or Changing Knowledge.......................................... 86

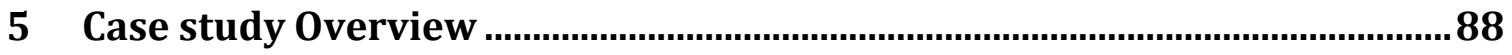

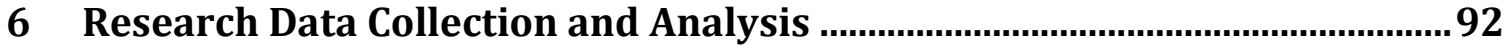




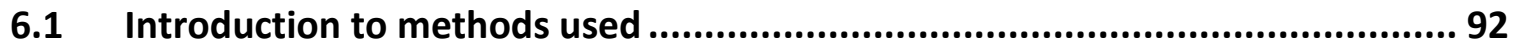

6.2 Stakeholder and expert knowledge capture in cognitive maps ..................... 93

6.2.1 Methods for Knowledge Capture ................................................................ 93

6.2.2 Libby to Troy Knowledge Capture ................................................................ 95

6.3 Translate Cognitive Maps in FCM Models ................................................ 111

6.3.1 Methods for Translation to FCM Models ........................................................ 111

6.3.2 Development of Stakeholder and Expert FCMs ......................................... 112

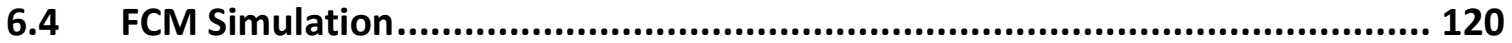

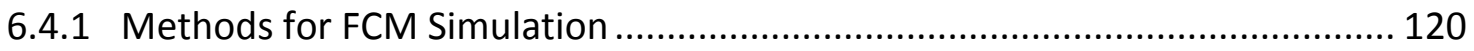

6.4.2 FCM Simulation for Libby to Troy............................................................ 122

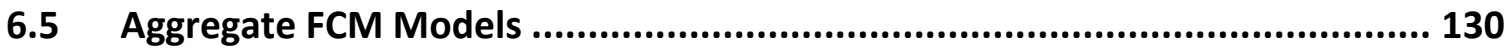

6.5.1 Methods for Aggregating FCMs ................................................................ 130

6.5.2 Aggregating Stakeholder Group FCMs ................................................... 131

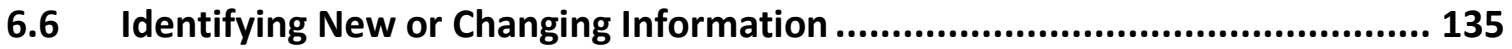

6.6.1 Methods for Identifying New or Changing Information ................................. 135

6.6.2 Identifying New or Changing Information in Libby to Troy .......................... 135

6.7 Summary of Case Insights............................................................. 141

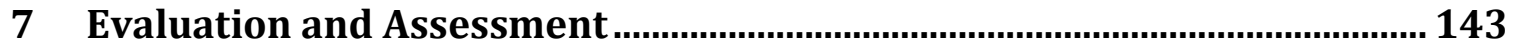

7.1 Evaluation of Methodology .................................................................. 143

7.1.1 Validation and Quality Control of Research Methods ................................... 143

7.1.2 Investigation into the Assumptions and Results of the Model ....................... 147

7.2 Assessment of the Methodology .................................................... 155

8 Summary of Findings and Limiations ..................................................... 159

8.1 Introduction to Summary of Findings.................................................... 159

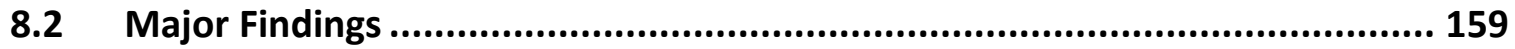

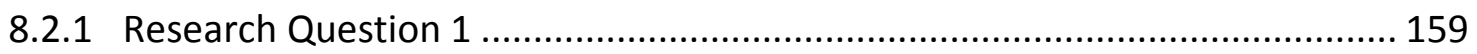

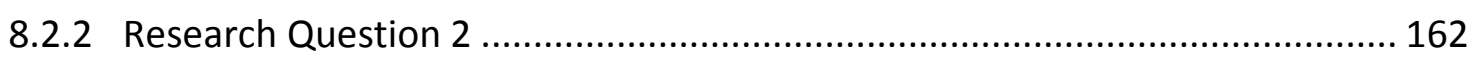

8.2.3 Research Question 3 .............................................................................. 163

8.2.4 Research Question 4 ................................................................................. 165

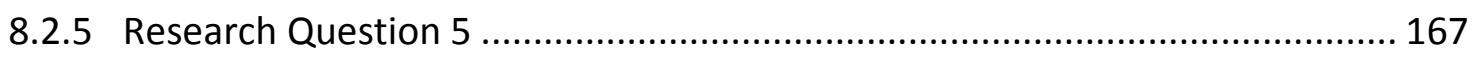


8.3 Limitations ............................................................................................ 168

9 Conclusion, Contributions and Future Research …….................................. 170

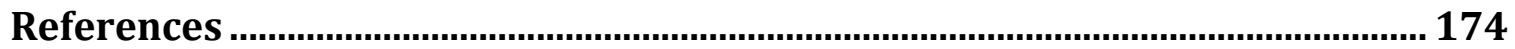

Appendix A - Libby to Troy Upgrade Project …................................................... 183

Purpose and Need for Action ................................................................................. 183

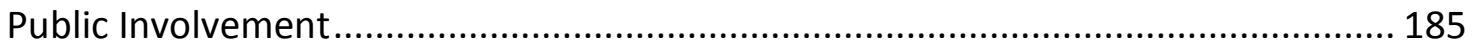

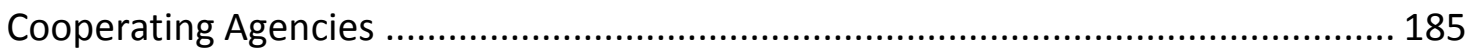

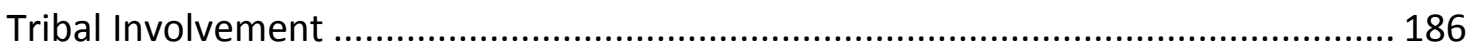

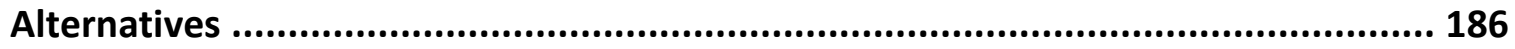

Proposed Action - 115-kV Single-Circuit Rebuild ................................................. 187

Alternative 1 - 230-kV Double-Circuit Rebuild ....................................................... 195

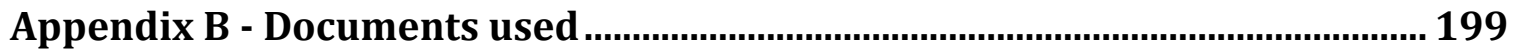

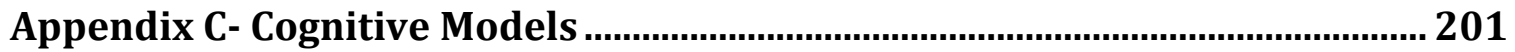

Appendix D - Common Ontology ……............................................................ 209

Appendix E - Interview Script for EvalUation of the research ............................ 211

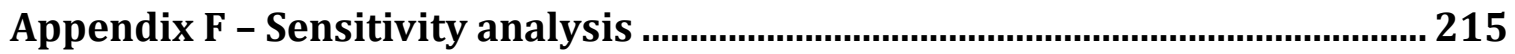




\section{LIST OF TABLES}

Table 1: Topology of Resource Relationships - source (Frooman, 1999,P.199) .............. 34

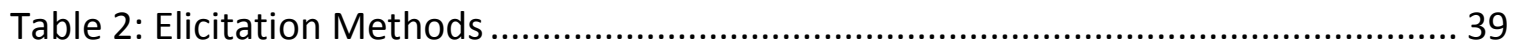

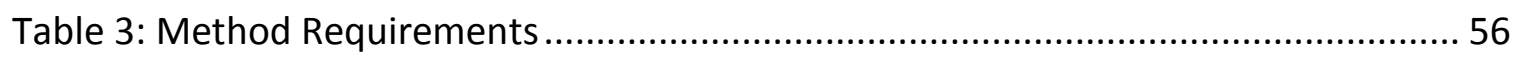

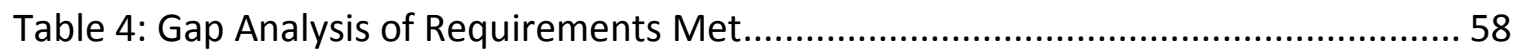

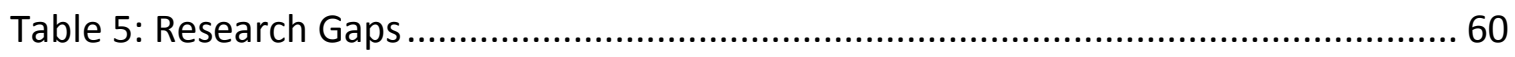

Table 6: Research Validation Framework Adapted from (Yin, 2003, p. 34) .................... 66

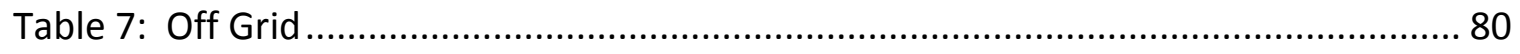

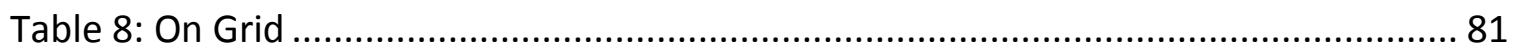

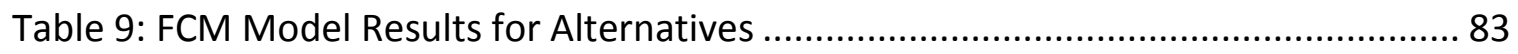

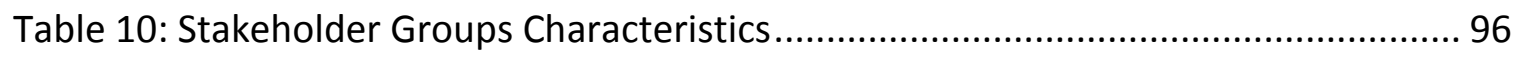

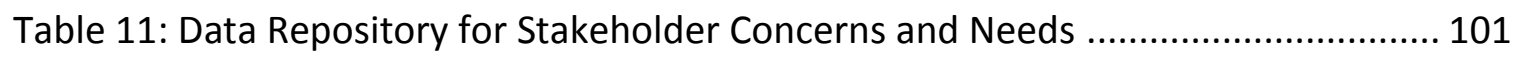

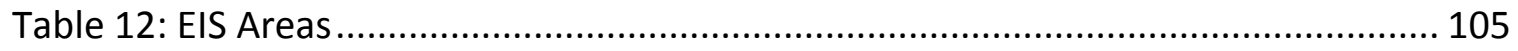

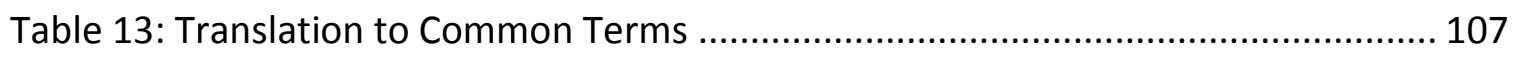

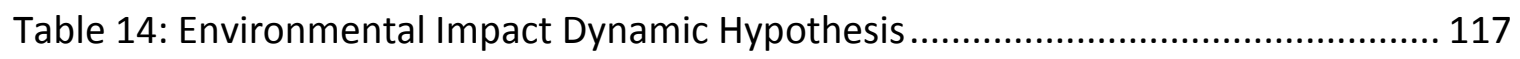

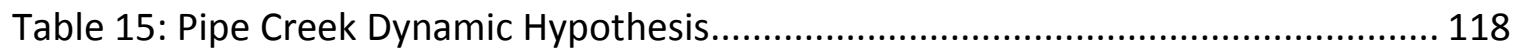

Table 16: Quartz Creek Dynamic Hypothesis.......................................................... 119

Table 17: Kootenai River Dynamic Hypothesis ....................................................... 120

Table 18: Stakeholder Perceptions on Impacts of Alternatives .................................. 123

Table 19: Central Concepts that Affect Utility ......................................................... 126

Table 20: How Experts View Affects BPA Objectives............................................... 128

Table 21: How the Experts View Impacts on Stakeholders ......................................... 130

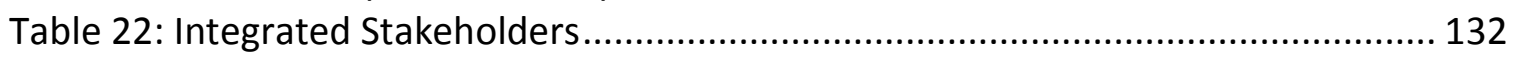

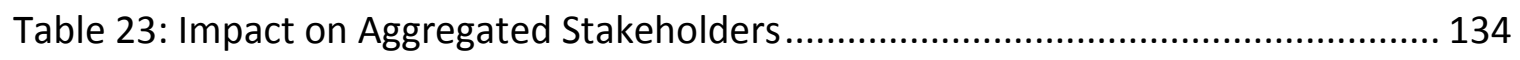

Table 24: Stakeholder Preferences over Time.............................................................. 137

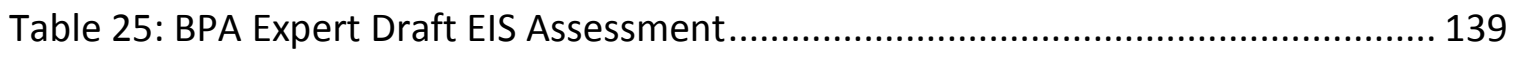

Table 26: BPA Expert Final EIS Assessment ............................................................. 140

Table 27: Policy Sensitivity Analysis for Dynamic Hypothesis 1 ................................... 150

Table 28: Policy Sensitivity Analysis for Dynamic Hypothesis 2 ................................. 151

Table 29: Policy Sensitivity Analysis for Dynamic Hypothesis 3 .................................. 152

Table 30: Policy Sensitivity Analysis for Dynamic Hypothesis 4 ................................... 154

Table 31: Policy Sensitivity Analysis with Best Alternative - 115kV ............................. 155

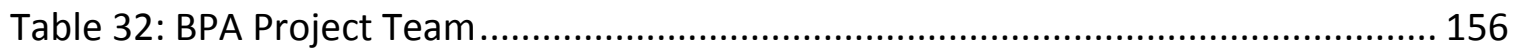

Table 33: Summary of Research Contributions ..................................................... 172 


\section{LIST OF FIGURES}

Figure 1: Conceptual Framework for the Literature Research ...................................... 11

Figure 2: Ackerman and Eden (2011,p. 184) Power-Interest Grid ................................. 35

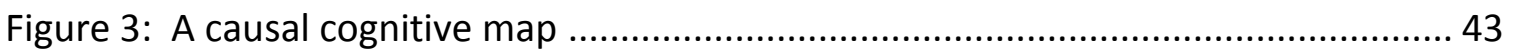

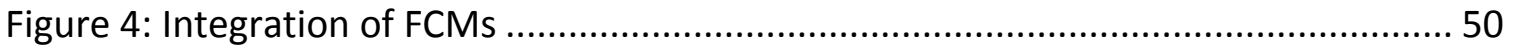

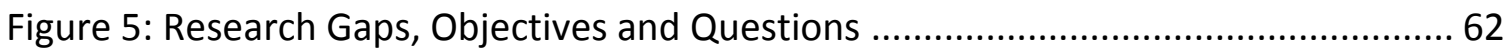

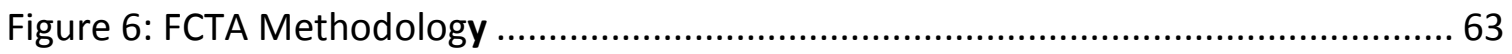

Figure 7: Cognitive Map of Stakeholder Perceptions ................................................... 79

Figure 8: Rebuild of Libby to Troy System Upgrade Project ......................................... 88

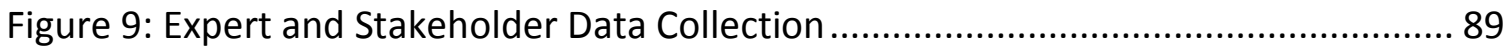

Figure 10: Methodology for Knowledge Capture \& Developing Causal Cognitive Maps. 94

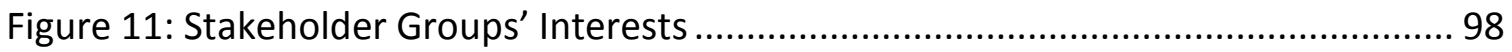

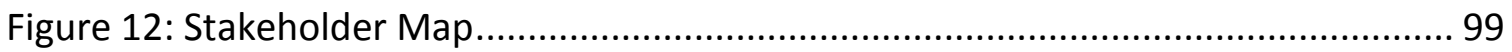

Figure 13: Textural Document Snippet of Stakeholder Concerns and Needs ................ 100

Figure 14: Pipe Creek Residents Cognitive Map ...................................................... 108

Figure 15: Three EIS Areas Define by the BPA Expert.............................................. 110

Figure 16: Methodology for FCM Modeling .............................................................. 111

Figure 17: Common FCM Structure ................................................................... 114

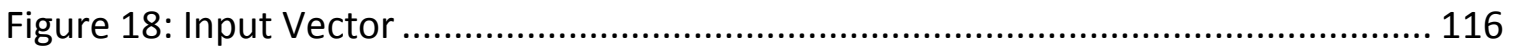

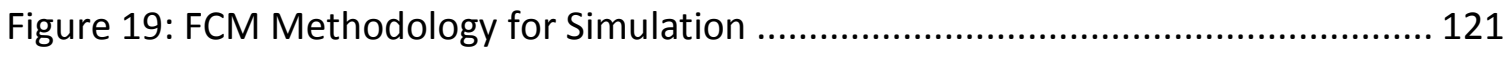

Figure 20: FCM Methodology for Integrating FCMs ................................................ 131

Figure 21: FCM Methodology for Soliciting Feedback............................................ 135 


\section{LIST OF ABREVIATIONS}

$\begin{array}{ll}\text { AD } & \text { Axiomatic Design } \\ \text { BPA } & \text { Bonneville Power Administration } \\ \text { CH } & \text { Cost Hose } \\ \text { CSR } & \text { Corporate Social Responsibility } \\ \text { CTA } & \text { Constructive Technology Assessment } \\ \text { DFES } & \text { Design for Energy Saving } \\ \text { DfE } & \text { Design for Environment } \\ \text { EIA } & \text { Environmental Impact Assessment } \\ \text { EIS } & \text { Environmental Impact Study } \\ \text { EC } & \text { European Community } \\ \text { FCTA } & \text { Fuzzy Cognitive Technology Assessment } \\ \text { FCM } & \text { Fuzzy Cognitive Mapping } \\ \text { HoQ } & \text { House of Quality } \\ \text { GH } & \text { Green House } \\ \text { ISO } & \text { International Standards Organization } \\ \text { kV } & \text { Kilovolt } \\ \text { LCA } & \text { Life Cycle Assessment } \\ \text { LCC } & \text { Life Cycle Costing } \\ \text { LCIA } & \text { life cycle impacts } \\ \text { NEPA } & \text { National Environment Policy Act } \\ \text { NGO } & \text { Nongovernmental Organizations } \\ \text { OTA } & \text { Office of Technology Assessment } \\ \text { ORV } & \text { Over the Road Vehicles } \\ \text { QFD } & \text { Quality function deployment } \\ \text { ROD } & \text { Record of Decision } \\ \text { ROW } & \text { Thecht of Way } \\ \text { SETAC } & \text { Toice of the Customer of Environmental Toxicology and Chemistry } \\ \text { TA } & \\ \text { TRIZ } & \text { VOC }\end{array}$




\section{INTRODUCTION}

\subsection{Problem Background}

Technology plays an important role in improving the way humans live and interact in society; however, technology has also created some harmful effects on society and the environment (Carroll, 1979; D'Arcy, 2009; Hart, 1997; Linstone, 1999; Stitzhal, 2011; Wartick \& Cochran, 1985). Technology assessment (TA) is a process that assesses early warnings about problematic and undesirable consequences arising from the development and application of technology (Schot \& Rip, 1997; J. C. M. Van Eijndhoven, 1997). TA promotes participatory assessments during which technology experts communicate with stakeholders (e.g., nonscientists or lay people) to understand beneficial or harmful effects of technology (Fisher, 2005; D. Guston, 2013; D. H. Guston, 2001; Lengwiler, 2008; Linstone, 1999). Broad public participation has been recognized as a critical success factor for TA, but commonly used forums (e.g., consensus conferences and dialogue workshops) are not conducive to eliciting diverse perspectives among the experts and stakeholders and therefore provide limited input and little feedback on policy decisions (Grin \& van de Graaf, 1996; D. H. Guston, 1999; Schot \& Rip, 1997). Furthermore, the assessment findings are static: once an assessment has been made, it is typically passed onto the decision makers who are expected to become aware of stakeholder issues and concerns by reading summary reports and interacting with the organizational units that conducted the assessment (F. B. Wood, 1997). Consequently, policy decisions have been criticized for being bureaucratic and 
ineffective (Fisher, 2005; D. H. Guston, 2001). Moreover, the use of static assessment attributes has made it difficult to predict the consequences of technology innovation because the environment is constantly changing (D. H. Guston \& Sarewitz, 2002).

TA does not only assess the potential benefits and harms of future technologies but also evaluates the effects of technology development activities that result in the actual construction of the technology though design, development and implementation (Genus, 2006; D. H. Guston \& Sarewitz, 2002; Schot \& Rip, 1997). It thus not only supports policy decisions but also technology planning and selection (Linstone, 1999). For example, an environmental impact assessment (EIA) (Bass \& Herson, 1993; Hildebrand \& Cannon, 1993; Modak \& Biswas, 1999) engages with stakeholders and experts to assess the socio-economic and environmental impacts of proposed technology alternatives prior to their selection and implementation. The assessment is separated from the decision-making process, and as a result, EIA decisions are criticized for being political and lacking public involvement (Brooks \& Harris, 2008; Dresner \& Gilbert, 1999; Wilkins, 2003).

An evolving stream of literature proposes the use of Fuzzy Cognitive Mapping (FCM) to capture stakeholder and expert input in causal cognitive maps, integrate them, and translate them into FCM simulation models. The models test alternatives using different assumptions about the evolving needs and issues of experts and stakeholders to understand the effects of a decision (Mouratiadou \& Moran, 2007; Uygar Özesmi, 1999; Uygar Özesmi \& Özesmi, 2003). However, most studies to date are limited in the scope 
of the stakeholder and expert engagement, do not show how stakeholder interests affect organizational objectives, and provide little guidance on how to avoid unintended consequences of decisions (A. J. Jetter \& Sperry, 2013). Furthermore, no studies specifically address the TA process for environmental impact studies, even though about 400 of these studies take place annually under NEPA law ${ }^{1}$. It is therefore largely unclear how FCM can be used by technology planners, and whether or not FCM methods lead to improved system knowledge.

This dissertation addresses these problems by developing a novel TA methodology using FCM (fuzzy cognitive TA - FCTA). The approach supports both the knowledge capture from experts and stakeholders in cognitive maps, and using FCM modeling and simulation to assess alternative technologies and decision support make the technology planning and decision-making process transparent. It does this by showing how stakeholders and experts perceive the value or harm associated with technology alternatives, which stakeholders and experts share the same perceptions, and how strongly the perception of value or harm differs with regard to different aspects of the technology alternatives and at different points in time (Brooks \& Harris, 2008; Glasson, Therivel, \& Chadwick, 1994; J. C. M. Van Eijndhoven, 1997). Furthermore, the methodology shows the degree to which expert and stakeholder perspectives are in support or in conflict with the project objectives, and the direct and indirect consequences associated with the decision (Hart \& Sharma, 2004; Linstone, 1999).

\footnotetext{
${ }^{1}$ http://ceq.hss.doe.gov/
} 
Finally, the methodology shows how new or changing perceptions by experts and stakeholders affect the outcome of the decision to improve system knowledge (J. D. Sterman, 2000b).The lack of a systematic approach for capturing a wide range of expert and stakeholder perspectives during the assessment, and integrating both the expert and the stakeholder perspectives into the decision-making process, pose considerable practical problems. First, it makes it difficult to show transparently how stakeholder input influences the decision, leaving stakeholders to wonder if their concerns were ever heard, and the value of stakeholder engagement activities. Second, without the capability of conducting tradeoff analysis amongst the various organizational objectives and conflicting stakeholder perspectives, decision makers may create unintended consequences because they are unaware of the long-term indirect effects of their decisions. Third, it is difficult to assess decision alternatives not known during the stakeholder/expert engagement activities or to reassess known decision alternatives when new information about issues becomes available.

Technology assessment is a methodology that analyzes the potential impacts from the use of technology through multiple stakeholder and expert perspectives. Several methodologies have been developed and are currently being used. One approach assesses the impacts arising from scientific research and development (R\&D) (Fisher, 2005; D. H. Guston, 2001; Schot \& Rip, 1997). Other approaches assess ecological, social and economical impacts arising with proposed build projects (e.g., roads, bridges) or with the use of a product, and the processes used to manufacture, distribute and 
dispose of the product (Pennington, et al., 2004; Rebitzer, et al., 2004; Zhang, Wang, \& Zhang, 1999). The assessment process encourages public stakeholder and expert participation. However, the assessments are often criticized: the boundaries are too narrow, there is missing information, the assumptions are incorrect, the decisionmaking process lacks public involvement (Brooks \& Harris, 2008; Dresner \& Gilbert, 1999; Wilkins, 2003), and stakeholder perceptions are not transparent in the decision (Fisher, 2005; D. H. Guston, 1999).

The research objective is to develop an FCM-based technology assessment and decisionsupport methodology that uses a wide range of stakeholder and expert input to assess and anticipate the effects of the technology on individual and aggregated stakeholders; analyze conflicting interests with organizational objectives; and dynamically adjust its conclusions when learning about new or changed stakeholder and expert perceptions.

Five research questions guide the research. First, how can FCM be used to systematically integrate a wide range of stakeholder and expert input into the technology assessment and decision-making process and preserve their perceptions? Second, how can FCM models be used to assess the positive or negative effects of alternative technologies on stakeholders? Third, how can FCM be used to identify the potential for stakeholder coalitions? Fourth, how can FCM be used to resolve conflicts between stakeholder interests and organizational objectives? Fifth, how can new or 
changing stakeholder and expert input be integrated into the FCM model to reassess technology alternatives?

\subsubsection{Research Approach}

The research investigates the feasibility and usefulness of a new methodology for assessing alternatives and decision support using a real-world environmental impact study conducted by the Bonneville Power Administration (BPA). BPA is a U.S. federal agency that provides about a third of the electric power and 75 percent of the highvoltage electric transmission in the Pacific Northwest, and it must comply with the environmental policies as set forth by the National Environmental Policy Act (NEPA). The NEPA process is designed to ultimately help public officials make informed decisions based on the understanding of environmental and social consequences and available alternatives.

BPA goes through a lengthy stakeholder engagement process and considers the impact of multiple technology alternatives on all stakeholders. The process, which stretches out over several years, starts with a notice of intent (NOI) as part of the scoping phase. A NOI includes a brief discussion of the need for the proposed project, a listing of alternatives, possible environmental impacts of the projects, and a listing of agencies and persons consulted. Scoping is an open and early process phase that elicits stakeholder input to understand what issues need to be evaluated, potential environmental impacts that need to be studied, and the alternatives to be considered. If 
the impact is still unclear after the scoping, the agency conducts an environmental assessment $(E A)$ to determine the significance of impact using experts and public opinions. If the impact is significant, an environmental impact statement (EIS) is required, which is a more in-depth analysis of environmental impacts conducted by experts. It elicits additional stakeholder input on the draft assessment before making a final decision. An EIS describes the short-term, long-term, and cumulative impacts of the proposed solution on the environment and on stakeholders, including any adverse impacts that cannot be avoided should the proposal be implemented. The EIS also proposes reasonable alternatives and mitigation activities to reduce the impact. Moreover, it describes any irreversible and irretrievable commitments of resources that would be involved in the proposed action.

Because the NEPA process stretches over multiple years, it is impossible to test all steps of the FCM-based methodology for environmental analysis and decision support in real time; therefore, the research uses publically available documents to model a completed transmission upgrade project from Libby to Troy, Montana. The documents used include project scoping comments from stakeholders, the draft EIS, comments from stakeholders regarding the draft EIS, and the final EIS. FCM models are used to assess the potential impacts of the technology alternatives from the stakeholders' perceptions as well as the experts' perceptions. 


\subsection{OUTLine OF Dissertation}

The dissertation is organized into nine chapters, including this chapter, which presents the introduction and overview of the research, plus references and appendices.

Chapter 2 provides a comprehensive literature review of five methodologies that are relevant for assessing technology with regard to environmental, economic, and social impacts. At the end of the chapter, a gap analysis is performed against a set of requirements for each of the methodologies reviewed.

Chapter 3 introduces the research objective and questions. It further describes the research strategy for developing FCTA, as well as the approaches for assessing and evaluating the method, using the case study.

Chapter 4 develops the FCTA framework. Based on a discussion of the state-of-the-art FCM methods, it proposes steps for capturing stakeholder and expert perceptions into causal cognitive maps, for translating causal cognitive maps into the FCM model, and for assessing the beneficial and harmful effects from the technology on individual stakeholders. It also describes how to integrate multiple stakeholder perceptions to understand holistically the beneficial and harmful effects from the technology. Finally, it describes how to used FCMs to assess how technology alternatives best achieve objectives and how to incorporate new and changing information into the FCTA approach. 
Chapter 5 provides an overview of the case study and the publically available documents from BPA that are used in the research.

Chapter 6 discusses the research data collection and analysis. It describes how FCTA was applied to the specifics of the case study to elicit and model stakeholder and expert knowledge. Furthermore, it describes how FCM simulation was used to gain understanding of the technology alternatives' impacts on individual aggregated stakeholder groups and of experts' perceptions about stakeholder impacts and organizational objectives.

Chapter 7 discusses the assessment and evaluation of the FCTA methodology, including the validation of the research methods used. The evaluation and assessment determine whether the methodology is consistent with the approaches taken in an EIS study and if the FCTA outputs are relevant for real-world decision making.

Chapter 8 summarizes the findings from the research. It discusses how stakeholder and expert input are systematically integrated into the FCM technology assessment and decision-making process. It also discusses how FCM is used to assess the technology alternatives to anticipate the effects on individual and aggregated stakeholders. Lastly, it discusses how FCM is used to analyze conflicting interests with organizational objectives.

Chapter 9 discusses the conclusion, limitations, research contribution, and future research projects. 


\subsection{Publications Arising fRom this Dissertation}

- "Corporate Social Responsibility and the Sustainable Product Development: A

Review and Research Model," for International Conference on Sustainability,

Portland State University, 2011

- $\quad$ "Fuzzy Cognitive Maps for Product Planning: Using Stakeholder Knowledge to Corporate Responsibility," in 46th Hawaii International Conference Maui, Hawaii: System Sciences (HICSS), 2013, pp. 935-934.

- “Incorporating Stakeholder Input for Assessing Alternatives: A Novel Approach Using Fuzzy Cognitive Mapping" for the PMI Research and Education Conference 2014, July 2014. Portland, Oregon. 


\section{LITERATURE REVIEW: TECHNOLOGY ASSESSMENT AND SELECTION}

\subsection{LITERATURE REVIEW OVERVIEW}

The following literature review discusses current methods for capturing stakeholder and expert perspectives, for assessing the impact of technology, and for supporting the selection of technology alternatives that fulfill organizational objectives while considering impacts on society and the environment. The framework of the literature review is presented in Figure 1.

Steps for capturing a wide range of expert and stakeholder input, and integrating their input into the assessment and decision-making process

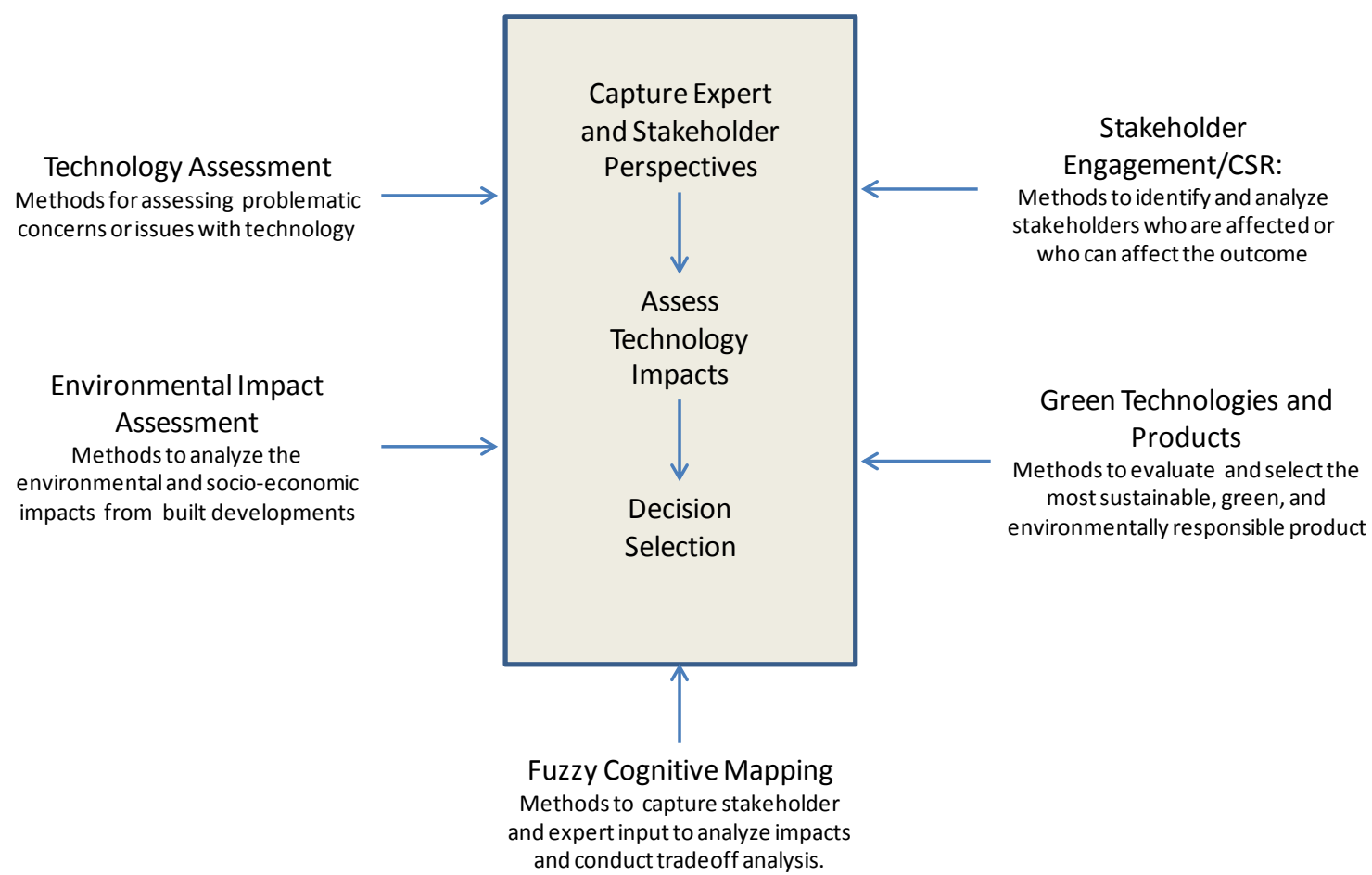

Figure 1: Conceptual Framework for the Literature Research 
The literature review covers four long-established literature streams, namely TA, Stakeholder Engagement, Green Technologies and Products, and Environmental Impact Assessment, as well as one emerging research area, Fuzzy Cognitive Mapping. TA proposes methods for conducting internal and external reviews with experts, and discursive elicitation methods with stakeholders to understand the early warnings about possible problematic and undesirable consequences (Fisher, 2005; D. H. Guston \& Sarewitz, 2002). Environmental Impact Assessment (EIA) is a methodology for assessing ecological, social and economic impacts of a project with proposed build alternatives (e.g., roads, bridges) that encourages public stakeholder participation in its early phases (Bass \& Herson, 1993; Hildebrand \& Cannon, 1993; Modak \& Biswas, 1999). The Green Technologies and Products methodology assesses the environmental impacts associated with a product's use and process used to manufacture, distribute and dispose of the products and selects products that meet the sustainable engineering objectives (Pennington, et al., 2004; Rebitzer, et al., 2004; Zhang, et al., 1999). Finally, Stakeholder Engagement/Corporate Social Responsibility (CSR) advocates identifying and analyzing stakeholders who ethically have a legitimate claim on the organization (Carroll, 1979; ISO, 2010; Wartick \& Cochran, 1985), i.e., those who are powerful and have a strategic interest in the organization's operations, products or services (Fran Ackermann \& Eden, 2011; Freeman, 2004; Harrison \& Freeman, 1999; King, 2007; Mitchell, Agle, \& Wood, 1997). The review also examines an evolving stream of literature that proposes the use of fuzzy cognitive mapping (FCM) to capture stakeholder and expert input in causal 
cognitive maps, integrate them, and translate them into FCM simulation models to assess impacts and conduct tradeoff analysis.

At the conclusion of the review, a set of requirements are defined that address the issues found with the methods. Then a gap-analysis is performed comparing the traditional methods and the FCM methods against the methods requirements identified in the literature.

\subsection{Methods for TeChNology Assessment}

Technology assessment is a methodology that analyzes the legal, ethical, and social and impacts of scientific technology research and development (R\&D) (Fisher, 2005; D. H. Guston, 2001; Schot \& Rip, 1997). The assessment process proposes to predict the early warnings about possible problematic and undesirable consequences resulting from scientific R\&D before making policy decisions to govern future developments and applications used by society (Schot \& Rip, 1997; J. e. C. M. Van Eijndhoven, 1997). In the 1960s, the topic of social responsibility in the context of technology development was getting considerable attention, which resulted in the United States federal government establishing the Office of Technology Assessment (OTA) in 1972 (Fisher, 2005). In the 1980s several European countries, namely France, Netherlands, Denmark, UK, and Germany, also started conducting TA through their own institutions (D. H. Guston, 2001; J. e. C. M. Van Eijndhoven, 1997). Each TA organization played a major role in shaping how experts and the public were involved when conducting technology assessments over time. 


\subsubsection{Office of Technology Assessment (OTA)}

The OTA managed the development of scientific R\&D using a complex process that included several federal agencies, boards, and councils to determine which projects would be assessed and how policy recommendations would be implemented (Fisher, 2005; F. B. Wood, 1997). The OTA conducted approximately 755 studies, where each full assessment lasted between 18 to 24 months at a cost of about $\$ 500,000$ USD (D. H. Guston, 2001; F. B. Wood, 1997). The OTA placed emphasis on producing a technology assessment report running approximately 200-400 pages in length using outside contractors and advisory panelists (Fisher, 2005; F. B. Wood, 1997). Later, the assessment methodology included internal and external reviews with experts, and workshops and other methods with stakeholders, to assure the assessment considered a wider range of stakeholder perspectives (F. B. Wood, 1997); however, the literature was not very clear on how stakeholders were identified.

As described by Wood (1997), the OTA methodology consisted of the following steps. In the pre-request stage, informal discussions about the scope of the assessment and timing took place between committee staff members and the OTA. The committee chair and/or ranking minority member prepared a formal request outlining the key issues for the study. The process continued with a study proposal identifying the technologies to be studied, which had to be approved before the assessment began. Once approved, a project advisory panel was selected, which ranged in size from 12 to 24 people 
representing stakeholder perspectives: academic, research, consumer, business, educational, technology, policy and others. This panel advised the OTA study team on key issues based on their own perspectives that were relevant to the topic. The OTA study team conducted the actual assessment, which generally consisted of the project director and three or four people. The data collection, analysis and synthesis did not use a standardized process; rather, the methods used by the study team were left up to each individual project director. Data collection techniques included a mix of literature reviews, interviews with technical and policy experts, agency and stakeholder briefings, and a variety of workshops that focused on specific technical or policy issues with stakeholders. Site visits, an occasional survey, and quantitative analyses were also used when appropriate, though the use of a quantitative computer model was rare. The advisory panel always reviewed the findings. The assessment process used general frameworks to understand the stages of technology development and their potential application use. The draft study identified potential direct and indirect impacts that were weighed against a spectrum of policy options to understand intervention and consequences on generic types of stakeholders, and the study team went through several reviews before releasing the report for publication. Although the report identified the impacts, the study team was distant from the policy makers who actually made the decisions. 


\subsubsection{Constructive Technology Assessment (CTA)}

In 1984, the Dutch called for a broader political and societal process for TA than the OTA (Schot \& Rip, 1997), which provided the foundation for constructive technology assessment (CTA), though the Dutch never used the term. CTA aims to broaden stakeholder participation and discourse and occurs with some variations, sometimes called ethical and real-time TA (Azzone \& Manzini, 2008; D. H. Guston \& Sarewitz, 2002; Palm \& Hansson, 2006; J. C. M. Van Eijndhoven, 1997) in many different contexts. CTA is employed by Norway, Germany, the Organization for Economic Cooperation and Development (OECD), and the Netherlands Organization of Technology Assessment (NOTA), now called the Rathenau Institute (Schot \& Rip, 1997). In contrast to the OTA, CTA emphasized bridging macro-level policy with micro-level activities through early involvement of experts and lay people to enhance social learning about the technology and to anticipate the potential societal impacts early on (Genus, 2006; D. H. Guston \& Sarewitz, 2002; Schot \& Rip, 1997). However, the CTA literature was not very clear on how stakeholders were identified to participate in the assessment process.

CTA uses a variety of discursive retrospective and prospective elicitation methods to increase participation: socio-technical mapping that combines stakeholder analysis and plotting of recent technical dynamics, anticipatory agenda building, and dialogue between innovators and the public using consensus conferences, citizen panels, and workshops (D. H. Guston \& Sarewitz, 2002; Schot \& Rip, 1997). An underlying principle of these activities is democratic discursive participation, which requires that 
stakeholders and experts freely exchange information and are open to criticism and that stakeholder-focused activities are aligned with the decision-making process (Genus, 2006). Practical challenges to these approaches are discussed in the literature. When the U.S. used a citizens' panel to assess the issue of "Telecommunications and the Future of Democracy," there was no legislative sponsorship and no direct participation of key decision makers on the panel, and as a result the panel had no substantive impact on policy decisions (D. H. Guston, 1999). Also, the CTA approach used to assess wind power in Denmark fostered broad public participation through consensus conferences, but it nevertheless had difficulty in successfully negotiating points of transition because it did not fit the parliamentary decision-making processes (Genus, 2006). A contributing factor was that consensus conferences and dialogue workshops were often distant from technology development. Also, forums are temporary and therefore limited in their ability to influence policy decisions and provide feedback on them (Grin \& van de Graaf, 1996; D. H. Guston, 1999; Schot \& Rip, 1997). Moreover, broadening the participation of lay people can impede some participants from freely expressing the values held closely by them: influential experts can be discouraged from reflecting on or making explicit their own deep-seated values about the technology (Genus, 2006). Furthermore, trying to unify experts and lay people on one particular issue runs the danger of closing the issue too early (Palm \& Hansson, 2006).

A principle of CTA is the understanding that the consequences of technology innovation cannot be understood by employing pre-defined, static attributes. Instead, continuous 
reflexive capacity is needed to make decisions, observe technology and societal outcomes, and design informed incremental responses to improve outcomes (D. H. Guston \& Sarewitz, 2002). As a result, CTA evolved to understand and evaluate technology development by including societal feedback into the actual construction of technology though design, development and implementation (Genus, 2006; D. H. Guston \& Sarewitz, 2002; Schot \& Rip, 1997). This was achieved through concurrent engineering during the product's design and development (Schot \& Rip, 1997). The evolution of the process became more stakeholder oriented and eventually firms, consumer organizations, and other non-government organizations (NGO) outnumbered the governmental and parliamentarian bodies (Schot \& Rip, 1997). Technology assessments were viewed as an ongoing learning process where technology change is incorporated as a feedback into the process of learning (D. H. Guston \& Sarewitz, 2002). However, the CTA literature was not specific on what methods were used to assess tradeoffs among alternatives.

\subsubsection{Discussion on Merits and Limitations}

Although the purpose of a TA is to understand early warnings about possible problematic and undesirable consequences of technology developments before making policy decisions, both OTA and CTA initially had little or no influence on actual policy (Hildebrand \& Cannon, 1993; Schot \& Rip, 1997; J. e. C. M. Van Eijndhoven, 1997). A key reason cited was that the decision-making process was not integrated with technology assessment (Fisher, 2005; D. H. Guston, 1999). The OTA identified consequences and 
offered options, but it never made policy recommendations (Fisher, 2005; Palm \& Hansson, 2006). Moreover, OTA served a committee of chairs that had relatively weak positions with policy makers from the congressional agencies (D. H. Guston, 2001). Furthermore, there was no clear focus as to who was responsible for the integration of the research with societal concerns and the direction of the technology R\&D (Fisher, 2005; F. B. Wood, 1997). CTAs were conducted using democratic consensus; however, the approach was not aligned with parliamentary decision-making and relied on ad-hoc and temporary institutions, such as consensus conferences and dialogue workshops, which had little means to continuously impact decisions (Grin \& van de Graaf, 1996; D. H. Guston, 1999; Schot \& Rip, 1997).

Moreover, stakeholder and expert participation only pays off if participants are engaged, willing to communicate, reflexive, and capable of dealing with differences and ongoing disagreements (Genus, 2006; D. H. Guston \& Sarewitz, 2002). Experts tend to adopt an instrumental role when rationalizing their views, whereas lay members tend to play a more cooperative role when it comes to rationality and the need to feel a positive self worth when participating in the discourse (Dresner \& Gilbert, 1999; Genus, 2006). Success of participatory processes therefore depends on identifying the correct stakeholders and understanding their interests and role in the assessment process (Palm \& Hansson, 2006). However, the TA literature was very scant on identifying and understanding stakeholders other than advertising to the public about when and where the discourse will take place. 
It was also noted that predicting various consequences of innovation is not achievable using static attributes because consequences unfold as the technology is being developed (D. H. Guston \& Sarewitz, 2002). As CTA evolved, incremental decisions were made using feedback, thus the decision-making process became continuously reflexive (Genus, 2006; D. H. Guston \& Sarewitz, 2002; Schot \& Rip, 1997). However, critics argued that building this reflexive capacity into R\&D required having effective communication among stakeholders and experts; understanding their capabilities, preferences and values; and modulating the innovation though continuous analysis and feedback (D. H. Guston \& Sarewitz, 2002; Palm \& Hansson, 2006).

\subsection{Methods FOR EnVIRONMENTAL ImPACt ASSESSmENT (EIA)}

In parallel with the emergence of TA approaches, governments and the public became concerned about how build projects, such as construction, would impact the ecological

environment and society. In response, the U.S. formed the National Environmental Policy Act (NEPA) (founded 1969) to oversee the national policy that encourages harmony between man and the environment (Eccleston, 2001; Hildebrand \& Cannon, 1993). In 1985, a similar mission was adopted in as a European Community Directive (Glasson, et al., 1994), resulting in a wide-spread use of EIA as a tool to achieve this harmony.

\subsubsection{EIA according to NEPA and European Community}

The US EIA process follows a uniform set of requirements as defined by the National Environment Policy Act (NEPA) (Glasson, et al., 1994). The ElA has spread to other 
countries: for example, in 1985 the European Community (EC) directive introduced uniform requirements for an EIA to all EC member states (Eccleston, 2001; Glasson, et al., 1994). Unlike OTA and CTA, an EIA is not about predicting the implications of scientific R\&D developments for society, but rather about assessing the probable implications for society and the environment of known technology alternatives that are proposed for development projects, such as construction of dams and bridges (Bass \& Herson, 1993; Hildebrand \& Cannon, 1993; Modak \& Biswas, 1999). An EIA uses experts to conduct the actual assessment. Consultation with the public occurs to assure the quality, scope and effectiveness of the assessment, and to assure that stakeholder views are known and can be taken into consideration when decisions are being made (Eccleston, 2001; Glasson, et al., 1994).

The EIA methodology includes several steps, as described by Glasson et al. (Glasson, et al., 1994). A public notice of intent is prepared and sent to the public advertising the proposed project. Public hearings solicit information regarding their issues and concerns, which are used to define the scope of the EIA. Other stakeholder forums include joint planning sessions using advisory committees and structured workshops conducted by delegated authorities, including citizens review boards and planning commissions. In the scoping phase, alternatives are considered, including taking no action. The discussions are generally between the developer and the authorities. Alternatives have different costs and affect the environment and society in different ways. There is no one method used for comparing and presenting alternatives; however, 
the methods used in the technical analysis generally span from simple non-quantitative descriptions to quantitative translation of impacts, using techniques such as weighted matrix, scoring models, and monetary value. A draft assessment is prepared and reviewed internally before sending it out to the public for comments. The draft assessment establishes a baseline of impacts and mitigation procedures. Once comments are reviewed and addressed, a final assessment is prepared, and the lead planning agency as the decision maker is required to consider the environmental and socio-economic impacts of the alternatives, including the cumulative impact on past, present and future projects. Once the decision record is made, it is sent out for public review, and the public has a limited period of time (e.g., 90 days) to dispute the final decision.

\subsubsection{Discussion on Merits and Limitations}

The purpose of EIA is to understand the environmental and socio-economic impacts of uniform requirements to assure credibility of the process (Glasson, et al., 1994). However, it is often criticized that the evaluations are politicized, the boundaries are too narrow, there is missing information, the assumptions are incorrect, and the decisionmaking process is distant and lacks public involvement (Brooks \& Harris, 2008; Dresner \& Gilbert, 1999; Wilkins, 2003). Levels of public involvement vary from where the public is beings informed and manipulated, to consultation and active involvement; however, the later is not the norm and requires citizens to get involved in governmental groups and panels (Brooks \& Harris, 2008). Moreover, the EIA is subject to the same issues with 
democratic discussion groups and bureaucratic decision-making processes as discussed in the TA review (Dresner \& Gilbert, 1999).

\subsection{Methods for Green Technologies and Products}

Methods for green technologies and products are used in engineering to select the most sustainable, green, or environmentally responsible product that fulfills engineering objectives (Brezet \& van Hemel, 1997; Fiksel, 1996a; Saling, et al., 2002).

\subsubsection{Life Cycle Analysis}

Life cycle assessment (LCA) analyzes the environmental impacts associated with a product's lifecycle from production to end-of-life by referring to a life-cycle inventory (LCI) that shows all exchanges of pollutants and resources with the natural environment (Pennington, et al., 2004; Rebitzer, et al., 2004). The impact of each resource or pollutant flow on the natural environment is estimated using common equivalence units, and the total impact scores are used to identify products and technologies with the least negative impacts. There are many ways to perform a LCA, such as Design for Environment (DfE), Society of Environmental Toxicology and Chemistry (SETAC), and BASF Eco-efficiency index; but ISO 14040 is the standard commonly referred to in all of these methods (Pennington, et al., 2004; Rebitzer, et al., 2004; Saling, et al., 2002; Schmidt, et al., 2004; Shonnard, Kicherer, \& Saling, 2003).

ISO 14040 defines the framework and principles for a LCA: ISO 14041 defines the goal, scope definition and inventory analysis; ISO 14042 defines the mandatory and optional 
elements; and ISO 14043 defines interpretation (Pennington, et al., 2004; Rebitzer, et al., 2004). The critical elements of the LCA are the inventory compilation and tabulation of the life-cycle impacts (LCIA), which is then followed with an impact assessment to interpret the indicators associated with exchanges with the natural environment during production, distribution, utilization and end-of-life (Brezet \& van Hemel, 1997; Pennington, et al., 2004; Rebitzer, et al., 2004). For example, $\mathrm{CO}_{2}$ is an impact substance that is emitted during the production phase, and its calculated effect is based on the greenhouse emissions it emits (Brezet \& van Hemel, 1997).

ISO 14042 defines three broad groups of impact categories-resource use, human health consequences, and ecological consequences-and includes categories such as climate change, stratospheric ozone depletion, photooxidant formation (smog), eutrophication (excess plant growth in water), acidification, and noise (Pennington, et al., 2004; Rebitzer, et al., 2004). There are many models available for calculating characterization factors that linearly express the relationship between the inventory data and the impact category indicators in relationship to the accumulated risks or the potential impacts attributed to different product options (Pennington, et al., 2004). Often, government sponsored databases are used in the calculation (Thorn, Kraus, \& Parker, 2011), and the resulting impacts are typically mapped and compared using a spider chart (Brezet \& van Hemel, 1997). Research and consensus building are still occurring at the national and international level, such as through AA1000 (AccountAbility Institute, 2008) and GRI (GRI, 2000-2011). 
Traditional LCA does not discuss costs, which are important in understanding and building a business case for evaluating and conducting tradeoff analysis (Fiksel, 1996b). Life cycle costing (LCC) provides an alternative. LCC is a process that defines the total cost of ownership, not just the initial capital to develop and produce the product such as the discount rate or operating and maintenance costs (Woodward, 1997). BASF's ecoefficiency is an example of a methodology that uses both LCA and LCC by computing eco-efficiency as a ratio of environmental performance to total cost of ownership (Saling, et al., 2002).

Another aspect that traditional LCA does not address very well is social life-cycle impacts. BASF's SSEbalance, developed in 2004, extends its eco-efficiency methodology to assess the social impacts over the life cycle of the product by calculating socioefficiency as a ratio of social benefits to total cost of ownership (Schmidt, et al., 2004). Social categories include human health, nutrition, living condition, education and research, work and working conditions, and other aspects of corporate social responsibility. SEEbalance identifies social impacts as a fingerprint using a spider graph, much like the environmental impacts. The process includes a sensitivity analysis that changes assumptions and recalculates the eco-efficiency and/or socio-efficiency based cost, environmental impacts and social impacts. 


\subsubsection{Green Product Design}

LCA/LCC, including SEEbalance, typically evaluate the negative effects of products that already exist, whereas green or sustainable product designs seek the most environmentally responsible product while being developed (Zhang, et al., 1999). To this end several green design approaches have extended the traditional product design methodologies to include LCA/LCC in order to reflect environmental requirements. Quality function deployment (QFD) was found to be the predominate methodology: it has been successfully used in numerous companies because it assesses product requirements (what the customer wants) and correlates them to technical specifications (how engineering does it) using relationship matrices to identify conflicts and assess tradeoffs (Hauser \& Clausing, 1988). Furthermore, the Theory of the Solution of Inventive Problems (TRIZ) is used in green product design because of its ability to resolve conflicts using the inventive design principles (Chen, Liu, \& Chih-Chen, 2001; Runliang \& Hui, 2009). The focus of this review is not to describe the traditional aspects of these methodologies, but rather to highlight the extensions.

Cristofari et al. (1996) developed "Green QFD" as a method to evaluate product concepts by combining environmental impacts indentified in the LCA and using QFD as a means to assess quality requirements (voice of customer - VOC). QFD is a methodology that translates customer requirements into product specifications and actions using a hierarchy of houses that correlates requirements to technical measures, competitive assessments and product performance, which are represented as rooms in the House of 
Quality (HoQ) (Rahimi \& Weidner, 2002). Zhang et al. (1999), motivated by life-cycle cost, extended Green QFD to include LCC as a means to assess costing requirements throughout the product development lifecycle, which they called "Green QFD-II." Customer benefits and weighted tradeoff analysis are conducted through the concept comparison house $(\mathrm{CCH})$. The objective in Green QFD-II is to identify the quality, environmental and cost technical requirements, which are listed in Quality House (QH), Green House $(\mathrm{GH})$, and Cost House $(\mathrm{CH})$ respectively. The $\mathrm{QH}$ is the product-planning matrix used in the house of quality (HoQ) in the traditional QFD. The purpose of the GH is to analyze life-cycle inventory (LCAI) and CH is to identify those LCC cost items that can be reduced in each of the life-cycle stages. Another objective is to assess alternative product concepts in conjunction with the existing product to satisfy the critical quality, environmental and cost of technical requirements. At this stage, the quality, environmental and cost requirements are grouped together so they can be assessed concurrently with the product concepts. The product concepts are evaluated based on total satisfaction, which is a weighted derivation over the product life cycle.

Rahimi \& Weidner (2002) also develop a method using QFD; but unlike Zhang et al., they introduce the ability to assess tradeoffs between functional objectives and design by redefining the traditional sequence in QFD into a multi-objective decision hierarchy. The first step is to identify value-based or fundamental objectives as the HoQ requirements and assess them against the customer quality, environmental and cost requirements, which are the technical specifications of a new house. The purpose is to understand how 
requirements fulfill the objectives. The next step carries forward the quality, environmental, and cost requirements into product house, and decomposes them into lower-level operational requirements (e.g., service use and end-of-life disposal). An assessment is then made using the component level specifications, which are the technical specifications. These component specifications are then carried forward as requirements in the component house and assessed against the performance attributes, which are defined as technical specifications. The final step is the creation of a new house, which is called the augmented "ends-alternatives-attributes." The fundamental objectives and design choices are the requirements for the new house, and they are assessed against the performance attributes, which were carried forward from the component house to assess the fundamental objectives against design alternatives, thereby achieving multi-objective decision analysis.

Masui et al. (2003) develop a method similar to Rahimi and Weidner. The first step was to list VOC as the requirements and engineering metrics (EM) as technical specifications in the HoQ. They assigned weights to the VOC requirements assembled from a market survey or a LCA. An overall relative-strength is determined for each EM using the associated weight based on each VOC/EM pairing. The second step carries forward the EM and relative strength index as the requirements into the next lower house and compares them against the alternative components, which are defined as the technical specifications. Using a similar process as in step 1, a relative ranking weight is determined for each component. Next, the detail design effects are assessed on each of 
the high-ranking components to determine an improvement rate. The final step re-uses the HoQ from step 1 and the EM metric to determine the overall improvement effect on each VOC requirement, thereby indicating the most effective design changes. It is this last step that supports the multi-objective decision analysis similar to Rahimi and Weidner.

The next two approaches utilize the design principles from TRIZ. Runliang and Hui (2009) developed a Design for Energy Saving (DFES) method using Axiomatic Design $(A D), Q F D$ and TRIZ. The AD domain boundaries discriminate amongst the various design activities, which are 1) consumer attributes, 2) function requirements, 3) design parameters and 4) process variables. AD domain is not capable of correlating between domains; therefore, QFD is used. For example, consumer attributes are the requirements, and the function requirements are the technical specifications. Conflict resolution uses the contradiction matrix from TRIZ to isolate those design inventive principles that will resolve the contradiction. The process is repeated though each of the layers in the AD domains.

Chen et al. (2001) also use TRIZ; however, they do not use the contradiction analysis as defined by TRIZ. Chen et al. argue a contradiction matrix is useless if the designer does not know or cannot predict the contradictions, which is the case with innovation. Chen et al. categorized the 39 engineering parameters by the seven sustainable elements as defined by the World Business Council for Sustainable Developments (WBCSD). They 
then mapped the appropriate inventive design principles to each of the desirable and undesirable engineering parameters. The design inventive principles that appeared most frequently were considered to have the best chance of solving the eco-efficiency design problem. The LCA was used to identify the environmental impacts, and the design problem was solved by identifying which of seven sustainable elements are most applicable. For those high environmental impacts identified, the engineering parameters and inventive principles that appear the most frequently become the highest priority when designing concepts.

\subsubsection{Discussion on Merits and Limitations}

LCA/LCC and the methods for evaluating green products aim to provide decision support for selecting a course of action that best fulfills sustainable product requirements and engineering objectives (Pennington, et al., 2004; Rebitzer, et al., 2004). LCA/LCC is the primary input for estimating and assessing the environmental impacts that are attributable to the lifecycle of a product and it is also used in evaluating priorities, and identifying quantifiable opportunities (Pennington, et al., 2004; Rebitzer, et al., 2004). LCA/LCC is static and uses databases that are criticized for being outdated and inaccurate (Brezet \& van Hemel, 1997; Thorn, et al., 2011). Moreover, the focus is on product life-cycle impacts and falls short in providing decision makers a dynamic and holistic view of social impacts (Saling, et al., 2002), nor do these methods make transparent how stakeholder and expert inputs impact decisions (Fiksel, 2003). 
QFD was the primary tool used in eco-design; the process is sequential and is carried out only in the forward direction (Prasad, 1998). TRIZ was used for its design principles and features to resolve design conflicts (such as tradeoff between different environmental goals) within existing products (Chen, et al., 2001; Runliang \& Hui, 2009); however, as Chen et al. (2001) observed, conflicts concerning an innovation are not always known or fully understood in the product's planning phase. Both QFD and TRIZ use static data and do not provide simulation capabilities. The only way to assess multiple sustainable objectives is to carry forward redundant data, which makes analysis static (Masui, et al., 2003; Rahimi \& Weidner, 2002). Finally, data is static and it is it is not possible to assess changing stakeholder perspectives (Fiksel, 2003).

\subsection{Methods for Stakeholder Engagement/CSR}

\subsubsection{Over view of Stakeholder Engagement/CSR}

The goal of stakeholder engagement is to understand how organizations engage with stakeholders to recognize their issues and concerns with the organization's products and supporting business processes, and then take action that best meets the sustainability and business objective (AccountAbility Institute, 2005a, 2005b). Social responsibility is terminology adopted by the International Standards Organization (ISO) and its origins are grounded in the Corporate Social Responsibility (CSR) policy (ISO, 2010).

There are primary stakeholders, such as customers, suppliers and employees, that exchange resources with the organization (Clarkson, 1995). Secondary stakeholders, 
such as consumer organizations, government agencies, and environmental groups, influence or affect the organization and visa-a-versa, but they are not directly involved in the organizational activities (Clarkson, 1995). All technology planning activities impact or are impacted by various primary and secondary stakeholders (Freeman, 1984; Freeman, Harrison, Wicks, Parmar, \& deColle, 2010; Porter \& Kramer, 2006). For example, environmental pollution can lower brand image and employee morale, thus affecting primary stakeholders, and it can also lead to government intervention and reactions by environmental groups, which are examples of secondary stakeholders (Agle, Micthell, \& Sonnedfeld, 1999). Furthermore, all organizations face the same generic stakeholder groups, such as customers, suppliers, and regulators, but specific stakeholders vary from organization to organization depending on the technology and innovation paths. Over time, stakeholders can lose or gain interest in issues, or shift their power to influence through coalitions (Fran Ackermann \& Eden, 2011). Therefore, stakeholder engagement is dynamic in nature and needs to be an ongoing activity, customized to the reality of each organization and linked to a particular problem.

\subsubsection{Stakeholder Identification and Analysis}

Stakeholder literature is vast and diverse in its approach to identifying stakeholders and analyzing their interests. Stakeholder identification identifies stakeholders who are critical to the organization's operation or are affected by the operations, and stakeholder analysis aims at understanding the stakeholders' interests and narrowing down the resulting, oftentimes extensive list of stakeholders to those that are (or will 
be) important to the organization (Agle, et al., 2008; Agle, et al., 1999; Mitchell, et al., 1997). Strategic management literature focuses on identifying those stakeholders who are directly involved in business activities (Freeman, 1984; Harrison \& St. John, 1996; B. Jones, 1995; S. R. H. Jones, 1997; King, 2007; Williamson, 1979) and those stakeholders who have the power and interest in the organization's strategy (Fran Ackermann \& Eden, 2011; Clarkson, 1995; Frooman, 1999; Porter, 1980). The CSR literature and standards organizations advocate identifying stakeholders with environmental and social issues, communicating with them, and engaging with them to develop an empathetic sensitivity for their concerns and interests (AccountAbility Institute, 2008; Agle, et al., 2008; Carroll, 1974; Clarkson, 1995; Donaldson \& Dunfee, 1994; GRI, 20002011; ISO, 2010; Mitchell, et al., 1997; Wartick \& Cochran, 1985; D. J. Wood, 1991).

\subsubsection{Strategic Management}

Primary stakeholders are analyzed based on trust, their ability to influence the organization's strategy, and reciprocal benefit between the organization and the stakeholder. Reciprocal benefit goes beyond the traditional transactional relationship between the organization and the stakeholder (Coase, 1998; S. R. H. Jones, 1997). It creates a utility value in the form of demand, innovation, and stability and, as a result, value is distributed through a stakeholder network more widely than just viewing the relationship as transactional (Harrison, Bosse, \& Phillips, 2010), thereby maximizing value (Jensen, 2002). 
Frooman (1999) illustrates utility value using a resource dependency strategy, as shown in Table 1. In this example, maximization of wealth is distributed when both the stakeholder and the organization are interdependent on one another, as shown in the lower right quadrant. Furthermore, in this type of relationship the power over each other is neutralized. The premise is that resource dependency creates a power situation, and when the organization is dependent on the stakeholder, the stakeholder has power and is able to influence the organization. If the resource dependency is reversed, then the organization has the power over the stakeholder. In either case, the entity with the power can choose to withhold the resource, creating an imbalance and ultimately diminishing the distribution of wealth. However, when stakeholders are managed using a utility value such as resources, the needs and demands of both are satisfied through willful participation (Harrison, et al., 2010).

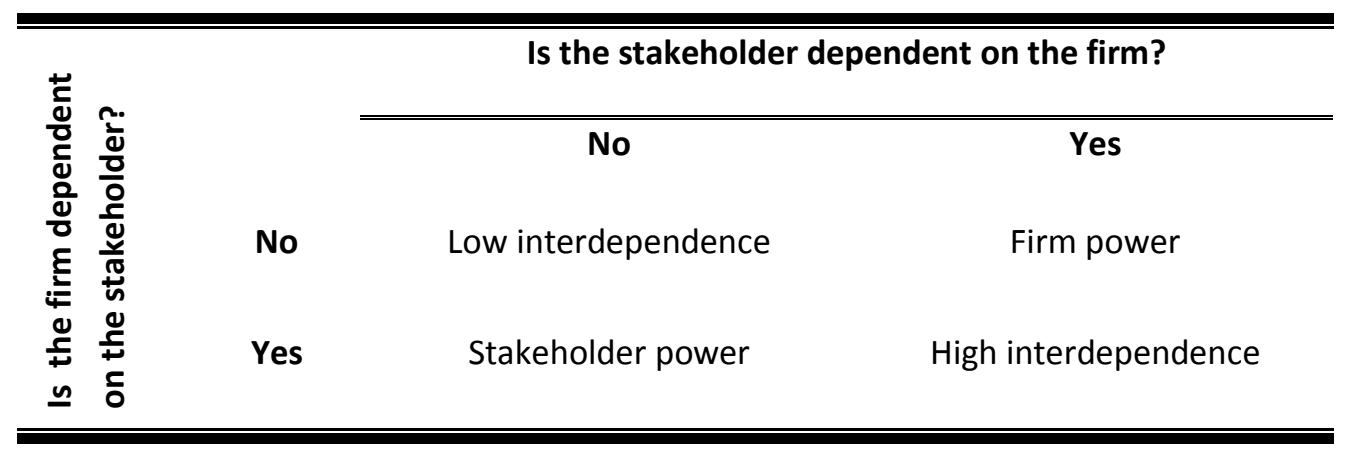

Table 1: Topology of Resource Relationships - source (Frooman, 1999,P.199)

Stakeholders may also influence the organization carrying out its strategy (Fran Ackermann \& Eden, 2011; Freeman, et al., 2010; King, 2007). Ackermann and Eden 
(2011) analyze stakeholders according to stakeholder power (high vs. low) and interest (high vs. low) in the organization's strategy, as shown in Figure 2.

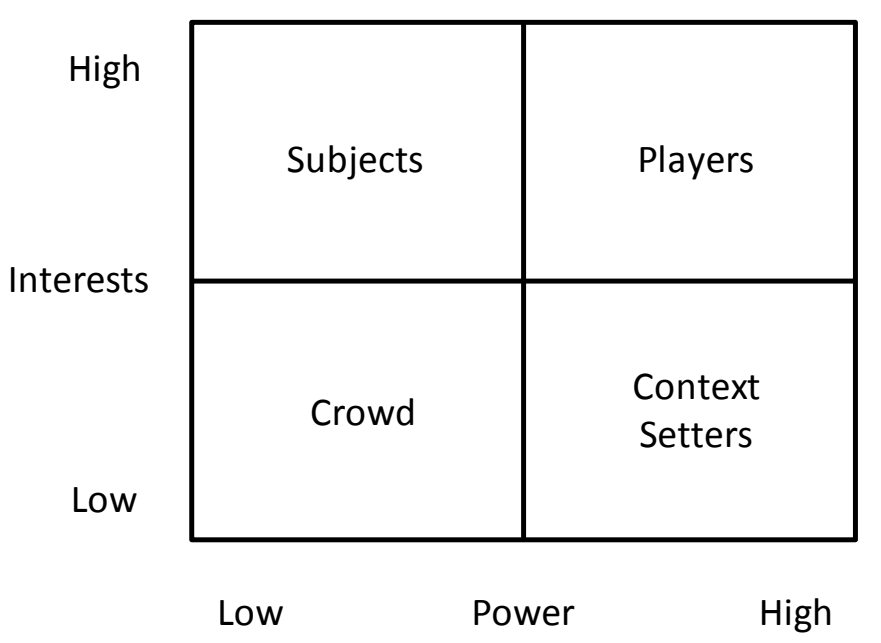

Figure 2: Ackerman and Eden (2011,p. 184) Power-Interest Grid

Only three stakeholder categories are considered of interest: Players, Context Setters, and Subjects. Crowds are not considered important at this time and, therefore, do not warrant management's attention. Players (high power and high interest) require management's top attention. Context Setters (high power and low interest) need to be considered because they could increase their interests by influencing the future (e.g., regulatory standards). Subjects (high interest and low power) deserve attention because they could encourage coalitions to increase their power. Coalitions are formed though stakeholder relationships, which may be of particular interest, especially when a Subject has a relationship with a Player and thus, the Subject's power increases. However, the analysis stops short of indicating the aggregated effect of the coalition's interests, thereby warranting a different strategy. 
Mitchell et al. (1997) classify stakeholders using the attributes of "legitimacy" of the stakeholder's standing in the society or claim on the organization (e.g., contract or moral interest); the degree of "power" a stakeholder has in the relationship with the organization; and "urgency," as in the attention required in the capacity of their claim. Power and legitimacy formulate the core attributes for salience (i.e., prioritization), and the inclusion of urgency adds the catalytic or dynamic component so that in the mind of the manager a stakeholder attains salience (Agle, et al., 1999). Using these attributes, salience is determined by the cumulative presence or absence of legitimacy, power, and urgency. Mitchell et al. indicate that stakeholders with all three attributes are highly salient and require management's attention, while those with two attributes are expectant (i.e., potential) stakeholders and need to be considered, and those with one attribute are latent and do not require management's immediate attention.

Although discretionary stakeholders have a legitimate claim, Mitchell et al. indicate that they have no power to influence and have no urgency in their claim; therefore, from a manager's view, there is no pressure and if the manger chooses to act in such a relationship, it is most likely to be in the form of philanthropy. As for demanding stakeholders, Mitchell et al. indicate that they appear to the manager as noise, and dormant stakeholders have little or no interaction with the organization; however, dormant stakeholders can become more salient if they have a legitimate claim and/or urgency. Furthermore, Mitchell et al. indicate that when stakeholders have legitimacy and are powerful, such as dominate stakeholders, their influence should matter to a 
manager. Dependent stakeholders who have legitimate and urgent claims also need to be considered by management because they depend on other stakeholders for the power, thus forming a coalition (Mitchell \& Agle, 1997). Lastly, stakeholders who have urgency and power but lack legitimacy are considered dangerous because they may use coercion as a means to advance their claim even though it may not be legitimate (Mitchell \& Agle, 1997).

AccountAbility (2005a, 2005b) is a practitioner's guide for stakeholder engagement that adapted Mitchell et al.'s approach. The guide does not use urgency, but rather analyzes stakeholders who affect the organization's business operations. Unlike Mitchell et al., AccountAbility does not prioritize stakeholders based on salience but rather identifies and groups all stakeholders and then prioritizes issues for the engagement.

\subsubsection{Stakeholder Engagement}

The purpose of engaging with stakeholders is to exchange perspectives and understand the concerns and issues of stakeholders regarding the positive and negative impacts from the business operations and its products (Freeman, 1984). By proactively seeking stakeholders' perspectives, the organization may avoid unnecessary harm to the environment and society, and avoid costs for both the organization and stakeholder, thereby creating a sense of optimization and value (AccountAbility Institute, 2005b; Jensen, 2002). 
AccountAbility (2005a) organizes engagement methods according to four types of relationships between the organization and the stakeholder. First, an organization communicates with stakeholders by conveying information about itself and the products it provides using methods such as company brochures, web sites, open houses, and press releases. When the organization begins to educate stakeholders, it does so through consultation and dialogue. Consultation is the second type of relationship, which is achieved by gathering information or advice from stakeholders using methods such as surveys, focus groups and advisory forums. Dialogue, the third type, is similar to consultation, but it involves seeking different perspectives and requires using methods such as forums, advisory panels and summits. The fourth type is when the organization seeks a partnership, it is sharing its resources as well as risks with stakeholders to seek bi-lateral synergies using methods such as joint ventures and alliances.

Table 2, which is an adaption of commonly used participatory methods, depicts a variety of methods used for learning as categorized by Pretty (1995, p. 1254). These methods include numerous secondary methods for eliciting the stakeholder identified by researchers (Chambers, 1994a, 1994b; Genus, 2006; D. H. Guston \& Sarewitz, 2002; F. B. Wood, 1997). Secondary methods do not actually engage with stakeholders but rather establish one-way communication, whereas participatory methods establish a two-way communication. 


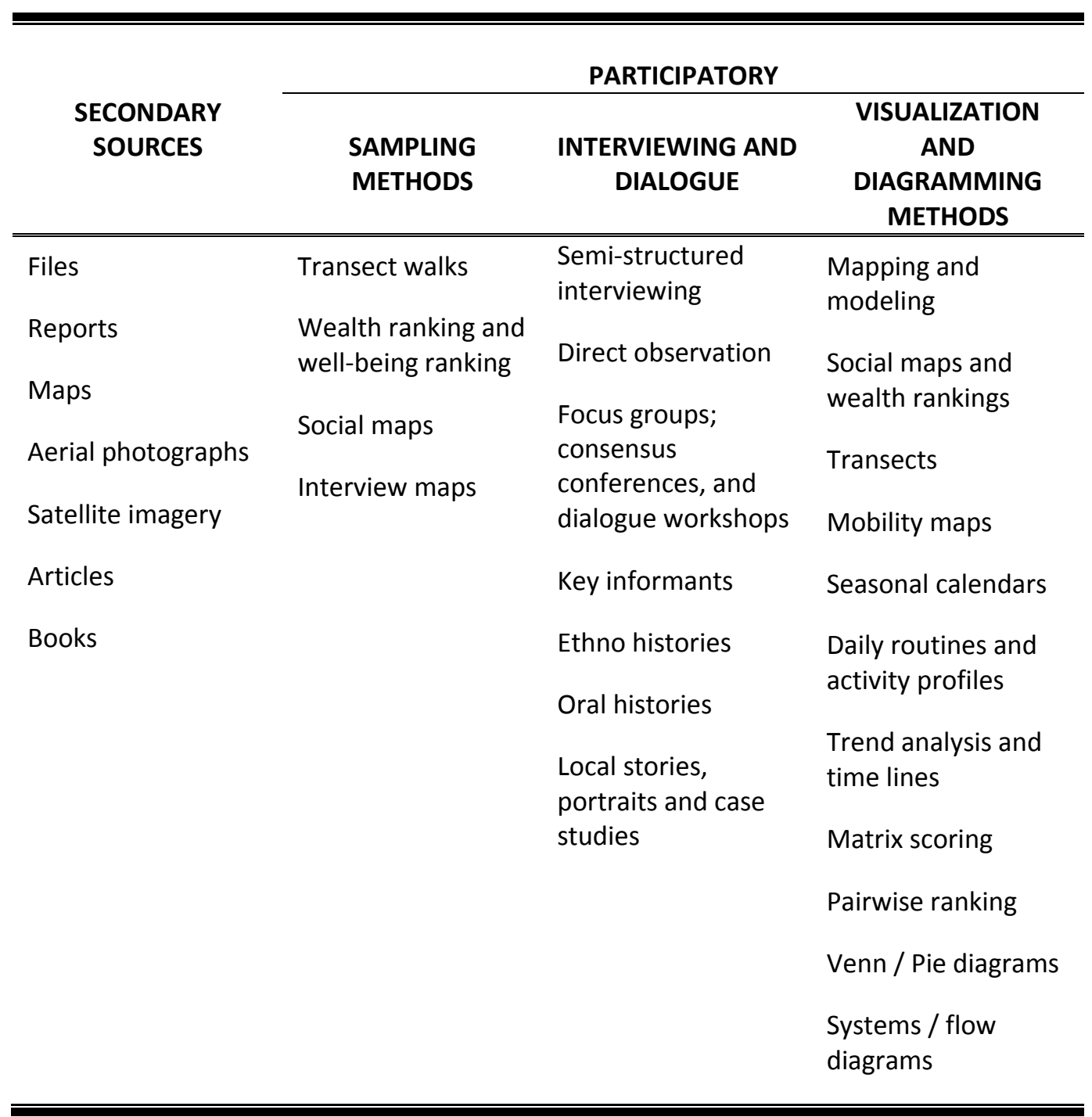

Table 2: Elicitation Methods

\subsubsection{Discussion on Merits and Limitations}

The Stakeholder/CSR methods presented numerous approaches for identifying and analyzing individual stakeholder relationships and eliciting stakeholder and expert input and are used in conjunction with TA, EIS and Green Technologies and Product 
methodologies to assess the impacts on stakeholders and determine the best course of action to meet sustainable and organizational objectives. The interpreting individual and aggregated stakeholders' issues requires sifting through the myriad of stakeholder signals by identifying those that are potentially problematic, interpreting the signals and constructing meaning as to how they affect organizational objectives (Kiesler \& Sproull, 1982). Common failures in sensing issues have been related to past learning experiences, especially when managers construct their explanations of the cause-andeffect relationships using their own mental models (Kiesler \& Sproull, 1982). They notice incoming signals based on past experience and then interpret whether the signal affirms the organizational activities (positive) or indicates a deviation from the organizational goals or objectives (negative) (John D. Sterman, 2001). Two factors that contribute to misinterpreting an incoming signal are social perception, which is how information is encoded and used for explanations, and gaps in the information (Kiesler \& Sproull, 1982).

Kiesler and Sproull (1982) argue that a person may wrongly assume events to be causally correlated because he or she receives and processes information about them in chunks. They also indicate that misinterpreting signals may occur because the information received was not relevant to the organization's schematic for change, or the person filled in the missing information and assumed the event occurred when it did not. Sensing stakeholder issues is further complicated in environments that are dynamic and complex because the numerous interactions among networks of feedback 
signals are constantly shifting (John D. Sterman, 2001). As a result, to gain a holistic view of stakeholder issues and concerns, it is necessary to capture a wide range of stakeholder input using multiple and disparate sources. Otherwise, a method for stakeholder analysis or CSR may fail to address the interest of some stakeholder groups, particularly those who are considered non-salient because they lack power or interest. Furthermore, the method may fail to assess impacts on interconnected stakeholders, who - when jointly facing a technology alternative - may alter their perception of issues. Consequently, stakeholder issues that were dismissed individually may be more severe or undertake a new meaning than originally thought when aggregated with other stakeholders (Hart \& Sharma, 2004).

To overcome these issues it is necessary to increase the range of stakeholder signals to ensure all relevant issues, interests and concerns are understood, thereby enabling the organization to have more information to spot new or shifting stakeholder problems they would have otherwise missed (Kiesler \& Sproull, 1982). Secondly, it is necessary to receive stakeholder signals relative to the rate of change so that current knowledge is not obsolete and the organization is able to make corrections sooner (J. D. Sterman, 2000b). Thirdly, it necessary to tie the received signals to organizational objectives to assess whether there is a problem (Kiesler \& Sproull, 1982). Lastly, it is necessary to reconstruct the relevant set of causal assertions to validate social perceptions from the elicited information in order to understand the impact on the organizational goals and objectives (Robert Axelrod, 1976). 


\subsection{FCM-BASED APPROACHES FOR STAKEHOLDER ANALYSIS}

\subsubsection{Theoretical Background on FCM}

Fuzzy cognitive maps were invented by Bart Kosko in 1986 (Bart Kosko, 1986). He proposed them as a means to make qualitative causal cognitive maps, which had originated in social science (see e.g. R. Axelrod, 1976; Eden, 1988; Huff, 1990), because they are computable and able to understand the dynamic behavior of the system they represent. Causal cognitive mapping is a technique to capture the mental models of decision makers and stakeholders (F. Ackermann, \& Eden, C. , 2005; Robert Axelrod, 1976; Bryson, Ackermann, Eden, \& Finn, 2004; K. Carley \& Palmquist, 1992; Nakamura, Iwai, \& Sawaragi, 1982). Causal cognitive maps were first invented by Axelrod (R. Axelrod, 1976), who used them to analyze and predict the decisions of political elites. They have also been used in strategy workshops to elicit how managers think about their business environment, to identify and discuss areas of agreement and disagreement in the management team, and to foster managers' understanding of the dynamic complexity of the problems they are facing (F. Ackermann \& Eden, 2005; Collin Eden \& Fran Ackermann, 2002; Probst \& Gomez, 1989).

Axelrod $(1976$, p. 5) asserts that "causation is vital to the process of evaluating alternatives" and "people evaluate complex policy alternatives in terms of the consequences a particular choice would cause, and ultimately of what the sum of all of these effects would be." The approach to learning in causal cognitive mapping is qualitative, and evaluating the alternatives is accomplished by understanding the 
causation of the consequences resulting from direct and indirect effects paths of positive or negative causal relationships (Robert Axelrod, 1976). As depicted Figure 3: Concepts (= "nodes" or "circles") are linked through arrows that represent causality. Concepts are described verbally and can represent hard-to-quantify phenomena such as "protectionism," "subsidies," and "free trade." The arrows are denoted with "+" or "-", depending on what type of causality exists. Positive arrows between two concepts (e.g., $C_{1}$ and $C_{3}$ ) imply that an increase in $C_{1}$ causes an increase in $C_{3}$. Negative arrows (e.g. $C_{2}$ and $C_{3}$ ) reflect a decrease in $C_{3}$ when $C_{2}$ increases (A. J. Jetter, 2006; J. D. Sterman, 2000b).

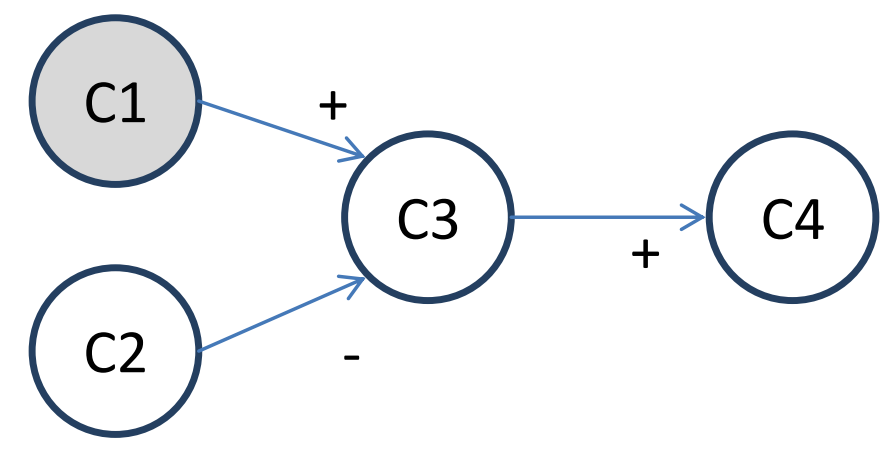

Figure 3: A causal cognitive map

Transmitter concepts have only outgoing arrows (e.g., assertions) and receiver concepts have only incoming arrows (e.g., goals and objectives). Ordinary concepts have both incoming arrows and outgoing arrows (e.g., benefits, consequences and requirements) (Bryson, et al., 2004; Eden, 1992; Harary, Norman, \& Cartwright, 1965; Uygar Özesmi \& Özesmi, 2004). Studies have shown that cognitive maps can get very complex and difficult to read once they include more than 30 concepts (Bryson, et al., 2004; A. J. 
Jetter, 2011; Uygar Özesmi \& Özesmi, 2004). Therefore, these complex individual stakeholder or group stakeholder maps need to be condensed into smaller normalized maps. This is achieved by combining "like" concepts into categories that represent them in an all-encompassing concept (Bryson, et al., 2004; A. J. Jetter, 2006; Nakamura, et al., 1982; Uygar Özesmi, 1999; Uygar Özesmi \& Özesmi, 2004).

To analyze the total effects on the graph, it is necessary to understand the individual effect of each indirect path, such as $C_{1}-C_{3}-C_{4}$. The indirect path is positive if the number of negative arrows in the path is even and negative if the number of negative arrows is odd (Robert Axelrod, 1976, p. 63). Moreover, the total effect of a path between two points is the sum of the indirect effects from all of the paths, and if the sum of all indirect paths are positive, then the overall effect on the path is positive (Robert Axelrod, 1976, p. 64). On the other hand, if all indirect effects are negative, the overall effect on the path is negative; and if some indirect effects are positive and negative, the effect is indeterminate (Robert Axelrod, 1976, p. 64).

Casual cognitive mapping has several drawbacks. In complex maps, it is difficult to assess how the network under investigation will behave dynamically and which concepts will increase or decrease as a result of environmental changes or actions taken by the decision makers; as a result, cognitive limitations make it impossible to keep track of cumulated direct and indirect effects (J. D. Sterman, 2000a). Also, if a concept 
has the same number of in-going positive and negative arrows, it is undetermined if it increases, decreases, or remains the same (R. Axelrod, 1976).

Kosko addressed these issues by applying principles of fuzzy set theory and neural networks to traditional cognitive maps (Bart Kosko, 1986, 1988; Kosko, 1993). Structurally, FCM is not that different from a traditional causal cognitive map, which represented in the form of an adjacency matrix $-\mathrm{N} \times \mathrm{N}$ matrix of concepts in the digraph shown in Figure 3. Kosko changed the way in which the graphs are analyzed; in particular, FCMs are regarded as a simple form of recursive neural networks, with concepts being the equivalent of neurons. Other than neurons in a neural network, concepts in FCMs are not either "on" (=1) or "off" (=0) but can take states in-between and are therefore "fuzzy." Fuzzy concepts are non-linear functions that transform the path-weighted activations directed towards them (their "causes") into a value in the range of $[-1,1]$. When a neuron "fires" (i.e., when a concept changes its state), it affects all concepts that are causally dependent upon it. Depending on the direction and size of this effect, and on the threshold levels of the dependent concepts, the affected concepts subsequently may change their state as well, thus activating further concepts within the network. Since FCMs allow feedback loops, it is possible that the newly activated concepts influence concepts that have already been activated before.

The FCM activation begins by multiplying an initial state vector of causal with the square of the connection matrix. The following example illustrates that if concept $C_{1}$ 
(highlighted in grey) in Figure 3 is activated while all other concepts are turned off, the initial state vector is:

$$
S=\left[\begin{array}{llll}
1 & 0 & 0 & 0
\end{array}\right]
$$

It is then multiplied with the adjacency matrix, which is equivalent to the signed digraph in Figure 3.

$\begin{array}{ccccc} & \mathrm{C}_{1} & \mathrm{C}_{2} & \mathrm{C}_{3} & \mathrm{C}_{4} \\ \mathrm{C}_{1} & 0 & 0 & +1 & 0 \\ \mathrm{C}_{2} & 0 & 0 & -1 & 0 \\ \mathrm{C}_{3} & 0 & 0 & 0 & +1 \\ \mathrm{C}_{4} & 0 & 0 & 0 & 0\end{array}$

Matrix multiplication and the application of a threshold function lead to a new state vector:

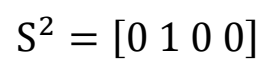

(In this particular example, a binary squashing function that converts inputs of $\leq 0$ to 0 and inputs of $>0$ to 1 is used.) The resulting new state vector is again multiplied with the connection matrix. The process is repeated until stability is reached, in this case after S4, or a stop criterion is met:

$$
\begin{aligned}
& S^{3}=\left[\begin{array}{llll}
0 & 0 & 0 & 1
\end{array}\right] \\
& S^{4}=\left[\begin{array}{llll}
0 & 0 & 0 & 0
\end{array}\right] \\
& S^{5}=\left[\begin{array}{llll}
0 & 0 & 0 & 0
\end{array}\right]
\end{aligned}
$$

The calculation is slightly different if the activation of concept $C_{1}$ is not a one-time impulse (e.g., an election or a natural disaster) but rather a change that lasts over 
extended periods of time (e.g., new tax laws). In this case, the concept is "clamped" and always set back to its initial activation level, as the following example, which already reaches a stable state after three cycles, will show:

$$
\begin{aligned}
& \mathrm{S}^{\prime 1}=\left[\begin{array}{llll}
1 & 0 & 0 & 0
\end{array}\right] \\
& \mathrm{S}^{\prime 2}=\left[\begin{array}{llll}
1 & 0 & 1 & 0
\end{array}\right] \\
& S^{\prime 3}=\left[\begin{array}{llll}
1 & 0 & 1 & 1
\end{array}\right] \\
& \mathrm{S}^{\prime 4}=\left[\begin{array}{llll}
1 & 0 & 1 & 1
\end{array}\right] \\
& \mathrm{S}^{\prime 5}=\left[\begin{array}{llll}
1 & 0 & 1 & 1
\end{array}\right]
\end{aligned}
$$

All FCMs have "meta-rules" associated with input vectors, also called input regions, which lead to the same final system state. The meta-rules of an FCM can be identified experimentally through simulation (J. Dickerson \& Kosko, 1994) and, if strict restrictions are met, analytically (Miao, Liu, Tao, Shen, \& Li, 2002). The normalization meta-rules (i.e., threshold function) controls the simulation to either a fixed state vector called fixed-point attractor or cycles between a number of fixed state values called a limit cycle (Stach, Kurgan, Pedrycz, \& Reformat, 2005).

The system's behavior depends on the structure of the causal map, the input vector, and the choice of squashing functions that determine the state of each activated concept: Commonly used squashing functions, such as bivalent, trivalent or logistic, restrict the weighted sum to a certain range to allow for comparisons between concepts (Stach, et al., 2005). FCMs with bivalent or trivalent squashing functions are discrete-output transformation (Stach, et al., 2005) and result in concept states that are considered 
"finite state machines" that result in either a fixed-state vector or in a limited cycle between a number of fixed state vectors (Stach, et al., 2005). The stable fixed point or limited cycle is typically reached in less than 30 cycles (Uygar Özesmi \& Özesmi, 2004) and oftentimes much sooner (A. J. Jetter, 2006). An example of a bivalent squashing function would convert any weighted sum greater than " 0 " to " 1 " and less than or equal to " 0 " to " 0 ". An example of a trivalent squashing function would convert any weighted sum greater than or equal to " 0.5 " to " 1 ", less than or equal to " -0.5 " to a " -1 "; otherwise, the result is " 0. " Although this type of normalization hinders quantitative analysis, it does provide for comparisons between concepts (Stach, et al., 2005) and reveals patterns hidden in the causal flow (J. A. Dickerson \& Kosko, 1993). More specifically, a bivalent can only represent an increase of a concept, whereas a trivalent can represent an increase or a decrease of a concept, and neither cannot represent any degree in increase or decrease (Tsadiras, 2008).

FCMs with logistic squashing functions are continuous-output transformation (Stach, et al., 2005) and are considered as "continuous state machines" that allow for better understanding and representation of activation levels, i.e., FCMs with concept values in the intervals $[-1 ; 1]$ (A. J. Jetter, 2006). A logistic squashing function is used when a degree of increase or decrease of a concept is required, such as strategic planning scenarios (Tsadiras, 2008). However, unlike a fixed state machine, a stable state may not be reached in less than 30 cycles; in fact, it is possible that it could lead to chaotic system behavior (J. A. Dickerson \& Kosko, 1993; Stach, et al., 2005), although it rarely 
occurs in real-world applications that are characterized by relatively small models with few interdependencies (A. J. Jetter, 2006; Taber, 1991).

An important feature of FCM is the capability of integrating FCMs to undercover hidden patterns not found in individual FCMs (B. Kosko, 1988). This can be achieved by augmenting each individual FCM to the total number of distinct concepts in all FCMs to create a new FCM (B. Kosko, 1988). To illustrate, in Figure 4, FCM-1 has four distinct concepts: $\mathrm{C} 1, \mathrm{C2}, \mathrm{C} 3$ and $\mathrm{C} 4$. FCM-2 has two additional distinct concepts: $\mathrm{C5}$ and $\mathrm{C} 6$. The total number of distinct concepts is now six. Each adjacency matrix is augmented by two concepts to bring them into mutual coincidence.

When an FCM does not have a concept that is included in another FCM, then the rows and columns of the new adjacency matrix are all zeros. The final step is combining the augmented matrices by adding point wise and normalizing them by dividing the total by the number of FCMs (A. J. Jetter, 2006; B. Kosko, 1988; Uygar Özesmi \& Özesmi, 2004). The usefulness of this approach has been debated because perceptions can be negated when one stakeholder has a positive view and another stakeholder has a negative view, thereby offsetting one another (A. J. Jetter \& Kok, 2013). However, it has also been stated that a large sample size will produce a more stable connection strength (B. Kosko, 1988). 


(C21)

Figure 4: Integration of FCMs

\subsubsection{FCM Research Studies and Application Domains}

FCM has the capability of capturing input from a wide range of stakeholders and experts using disparate knowledge sources, and systematically integrating the input into the assessment and decision support. Moreover, FCM is a systems thinking approach to understanding the stakeholder's problem, modeling the problem, assessing potential actions on all or portions of the problem, and evaluating feedback after the actions are 
implemented (Checkland, 2000; Salomon \& Seegers, 1996; J. D. Sterman, 2000b; Voinov \& Bousquet, 2010).

U. Özesmi and S. L. Özesmi are predominantly referenced in the literature. For his PhD Uygar Özesmi (1999) studied the harvest of aquatic vegetation in the Kizilirmark Delta wetlands and how human practices are an integral part of the ecosystem. He interviewed 31 stakeholders from 4 stakeholder groups: villagers, vacation home owners, nongovernmental organization (NGO) officials, and government officials. Stakeholder perceptions of ecosystems were captured in causal cognitive maps, which were then used to compare and contrast their understanding of the ecosystem. Some stakeholders drew their own maps, where others were constructed from the interview notes using textual analysis as defined by Carley and Palmquist (1992). The causal cognitive maps were transformed into adjacency matrices, thereby creating fuzzy cognitive maps. In the second study, U. Özesmi \& S. L. Özesmi (2003) used FCM to develop a participatory ecosystem management plan for the Uluabat Lake in Turkey. They interviewed 51 people.

In both studies, the individual maps were aggregated qualitatively first and then quantitatively. They used graph theory to identify dependent and independent variables in order to compare and contrast which variables were important to the stakeholder groups. They then used FCM simulation to run "what-if" questions to assess how policy decisions affect the stakeholder groups using a combined social map of all stakeholders. 
The first step in the simulation turned on all variables in the initial state vector to understand which steady state the system settles down to. To test different policy options, variables were subsequently turned off (activated with 0). Results were compared to the initial steady state to see the impact of polices.

Another study was conducted by Mouratiadou and Moran (2007) by which they wanted to understand the current state of and pressures on water resources to simulate the acceptance of alternative water management policies and their impacts on water resources and the economy. The study interviewed 30 stakeholders representing 5 stakeholder groups. The stakeholder views were combined into stakeholder group FCMs and then augmented into a social map FCM. FCM simulation was used to compare the effect of the different policy options using the same approach as U. Özesmi and S. L. Özesmi.

Giordano et al. (2007; 2005) used FCM to identify quality demand issues in water management of the Candelaro river basin in Italy. Their research was to define a community decision support system that would consider the opinions and conflicts resulting from the surrounding communities, local water agency and environmentalists as well as those communities that could create a coalition. Of particular interest was integrating conflict analysis and reaching consensus in a decision support system.

Soler et al. (2012) used FCM to understand the determinants of land cover change in the Brazilian Amazon. They codified the determinants as concepts into an FCM and used a 
cross-analysis between the Pearson correlations values and literature to determine the strength of the relationships for building FCM. They also conducted interviews with experts to capture their interpretation of significant concepts and relationships. FCM simulation was used to conduct a sensitivity analysis to assess the rates of land cover change.

Jetter and Schweinfort (A. Jetter \& Schweinfort, 2011) used FCM as a method of scenario development for photovoltaic cells. Their focus was to integrate a worldview of seven experts. Each expert's worldview was captured in causal cognitive maps. All seven maps were then qualitatively integrated into joint causal map and translated into an FCM. Another study by Jetter and Sperry (A. J. Jetter \& Sperry, 2013) used FCM to capture and integrate stakeholder mental models to understand social and environmental impacts of wind and solar systems for an urban eco-district. Each stakeholder's mental model was captured in a causal cognitive map. Cognitive maps were qualitatively integrated to create a joint causal map and then translated into an FCM to analyze impacts of multiple product designs.

Numerous FCM studies have demonstrated the process of capturing stakeholder and expert input in causal cognitive maps, translating and integrating these inputs into FCM simulation models, and testing decision alternatives to understand differing stakeholder perceptions. They have primarily been used in environmental analysis (R. Giordano, et al., 2005; Lopolito, Prosperi, \& Sisto, 2009; Mouratiadou \& Moran, 2007; Uygar Özesmi, 
1999; Uygar Özesmi \& Özesmi, 2003; Wildenberg, et al., 2010), scenario and strategic planning (A. Jetter \& Schweinfort, 2011; Kardaras \& Mentzas, 1997; Kok, 2009; Xirogiannis \& Glykas, 2004), and, to a limited extent, in social responsibility (A. J. Jetter \& Sperry, 2013; A. J. M. Jetter \& Sperry, 2011).

\subsubsection{Discussion on Merits and Limitations}

FCM research has demonstrated potential for integrating stakeholder and expert inputs into technology assessment and decision support: It has provided approaches for modeling how stakeholder perceptions impact the assessment of policy alternatives, such as water policies in the Pinos River Basin in Greece (Mouratiadou \& Moran, 2007). It has also demonstrated the capability to assess tradeoffs between renewable product energy alternatives based on conflicting stakeholder interests (A. J. Jetter \& Sperry, 2013). However, for the most part, these studies are limited in scope: they focus on environmental and societal impacts but fail to take the objectives of the decision makers into account, resulting in a poor link between FCM analysis and decision making. Studies frequently use a relatively small number of respondents and, with few exceptions (Mouratiadou \& Moran, 2007), either focus on stakeholder or expert views, which makes it impossible to understand where these groups are aligned and where they are in conflict. Moreover, many studies rely on qualitative aggregation of stakeholder inputs, either through a modeler who creates stakeholder FCM from what he or she has uncovered in stakeholder interviews or through stakeholder workshops, during which the participants jointly create social maps. In contrast to the computational approach as 
defined by Kosko (REF), this approach leads to poor traceability, and it is difficult to understand exactly how a particular stakeholder concern is reflected in the FCM model. Finally, current FCM studies do not show how to incorporate new or changing information to reassess decisions. Moreover, FCM approaches are not currently applied to the NEPA process for environmental impact assessment, even though this is a very commonly used and government mandated stakeholder engagement process.

\subsection{Method ReQUiRements ANd Gap AnAlysis}

The literature discussed provides a variety of different methods for capturing stakeholder and expert input, assessing the positive and negative impacts of the technology alternative on stakeholders, and determining the decision-making process. Based on the literature review, Table 3 lists the requirements to address the positive and negative aspects found with methods discussed in the literature review.

The basis for formulating requirement 1 was provided by the literature that has identified broadened public participation as a success factor for CTA (Fisher, 2005; D. H. Guston, 1999) and recommends assuring that stakeholder views are considered in the EIA decision-making process (Eccleston, 2001; Glasson, et al., 1994). Moreover, TA and EIA were criticized because the assessment was separated from the decision-maker . Requirement 2 is based on the insight gained from the literature that sensing and interpreting of all incoming signals are required to understand the far-reaching direct and indirect effects of decisions on stakeholders as indicated in the Stakeholder 
Engagement/CSR (Kiesler \& Sproull, 1982. Furthermore, aggregating multiple stakeholder groups is used to explore commonality in interests and willingness to join forces and exploit power (Nooy, Mrvar, \& Batagelj, 2005) (Fran Ackermann \& Eden, 2011; Hart \& Sharma, 2004).

\begin{tabular}{|c|c|c|}
\hline & REQUIREMENTS: METHODS SHOULD.... & LITERATURE STREAMS \\
\hline 1) & $\begin{array}{l}\text {... systematically integrate a wide range of } \\
\text { stakeholder and expert perceptions }\end{array}$ & $\begin{array}{l}\text { TA (Fisher, 2005; D. H. Guston, 1999); } \\
\text { EIA (Eccleston, 2001; Glasson, et al., } \\
\text { 1994), Stakeholder Engagement/CSR } \\
\text { (Kiesler \& Sproull, 1982) }\end{array}$ \\
\hline 2) & $\begin{array}{l}\text {... understand the consequences of decisions for } \\
\text { individuals and aggregated stakeholder groups }\end{array}$ & $\begin{array}{l}\text { Stakeholder Engagement/CSR (Fran } \\
\text { Ackermann \& Eden, 2011; Hart \& } \\
\text { Sharma, 2004; Kiesler \& Sproull, 1982), } \\
\text { EIA (Nourry, 2008) }\end{array}$ \\
\hline 3) & $\begin{array}{l}\text {... assess tradeoffs between organizational } \\
\text { objectives and stakeholder impacts }\end{array}$ & $\begin{array}{l}\text { Green Technologies and Products } \\
\text { (Rahimi \& Weidner, 2002) , FCM (A. J. } \\
\text { Jetter \& Sperry, 2013) }\end{array}$ \\
\hline 4) & $\begin{array}{l}\text {... make transparent how stakeholder and expert } \\
\text { perceptions influence decisions }\end{array}$ & $\begin{array}{l}\text { EIA (Brooks \& Harris, 2008; Dresner \& } \\
\text { Gilbert, 1999; Wilkins, 2003) }\end{array}$ \\
\hline 5) & $\begin{array}{l}\text {... reassess decisions when new stakeholder or } \\
\text { expert insights become available }\end{array}$ & $\begin{array}{l}\text { Stakeholder Engagement/CSR (Kiesler } \\
\text { \& Sproull, 1982) }\end{array}$ \\
\hline
\end{tabular}

Table 3: Method Requirements

Requirement 3 is based on the identified need to conduct tradeoff analysis among the different alternatives as indicated in Green Technologies and Products (Rahimi \& Weidner, 2002; Zhang, et al., 1999), and FCM (A. J. Jetter \& Sperry, 2013). Requirement 4 is based on the identified need to make decisions transparent by showing how stakeholder and expert perceptions influenced the decision, which again was a criticism 
of EIA (Brooks \& Harris, 2008; Dresner \& Gilbert, 1999; Wilkins, 2003). Requirement 5 is based on the need for information to spot new or shifting stakeholder problems that would have otherwise been missed, which is an extension of sensing and interpreting incoming signals as indicated in the Stakeholder Engagement/CSR (Kiesler \& Sproull, 1982).

Table 4 compares the requirements to each of the methods. For requirement 1 , Stakeholder/CSR provides numerous methods to a capture a wide range stakeholder and expert input using secondary and participatory methods. TA and EIA also attempt to capture a wide range of input, but the assessment is separated from the decisionmaking process, and the public involvement is distant from the technology development and is not always effective. While CTA attempts to resolve these issues by incorporating public feedback into the technology development process, it has difficulties providing these inputs concurrently and with true impact on decision making. FCM, however, demonstrates the ability to integrate the input into the assessment and decision-making process. Green Technologies and Products assessed the impacts in association with product lifecycle; however, they did not engage with stakeholders, but rather used databases to understand the impacts. Green Technologies and Products did integrate these requirements into the decision-making process; however, the decision-making process was limited to a small set of requirements. CSR had no decision support. 


\begin{tabular}{|c|c|c|c|c|c|c|}
\hline \multirow{2}{*}{\multicolumn{2}{|c|}{$\begin{array}{c}\text { REQUIREMENTS: METHODS } \\
\text { SHOULD ... }\end{array}$}} & \multicolumn{5}{|c|}{ RESEARCH STREAMS: DO METHODS FULFIL REQUIREMENTS? } \\
\hline & & TA & EIA & GREEN & STAKEHOLDER & FCM \\
\hline 1) & $\begin{array}{l}\text {... systematically integrate a } \\
\text { wide range of stakeholder } \\
\text { and expert perceptions }\end{array}$ & Partially & Partially & No & Partially & Yes \\
\hline 2) & $\begin{array}{l}\text {... understand the } \\
\text { consequences of decisions } \\
\text { for individuals and } \\
\text { aggregated stakeholder } \\
\text { groups }\end{array}$ & Partially & Partially & No & Partially & Partially \\
\hline 3) & $\begin{array}{l}\text {... assess tradeoffs between } \\
\text { organizational objectives and } \\
\text { stakeholder impacts }\end{array}$ & No & No & Partially & No & Partially \\
\hline 4) & $\begin{array}{l}\text {... make transparent how } \\
\text { stakeholder and expert } \\
\text { perceptions influence } \\
\text { decisions }\end{array}$ & No & No & No & No & Partially \\
\hline 5) & $\begin{array}{l}\text {... reassess decisions when } \\
\text { new stakeholder or expert } \\
\text { insights become available }\end{array}$ & Partially & Partially & No & Partially & No \\
\hline
\end{tabular}

Table 4: Gap Analysis of Requirements Met

For requirement 2, with the exception of the literature on Green Technologies and Products that does not investigate perceptions, all literature streams provide methods to capture and analyze differences among stakeholder and expert perceptions and to foster an understanding of the consequences of decisions on stakeholders. This is achieved through participatory methods (e.g., dialogue workshops and consensus conferences) and secondary analysis. FCM moves one step further and not only captures but also mathematically models the insights, which provides the capability of understanding far-reaching and indirect effects of decisions that are difficult to infer 
from the other methods. However, none of the methods analyze the effects on aggregated stakeholder groups who share interests or power.

For requirement 3, Green Technologies and Products and FCM demonstrated some capability for assessing tradeoffs. QFD was capable of isolating conflicts and making a decision that best fulfils engineering objectives, but it did not show how it best fulfills the positive and negative impacts on stakeholders (Rahimi \& Weidner, 2002). FCM showed the capability of understanding the impacts on stakeholders, but it did not demonstrate the capability of how it best fulfills organizational objectives in light of the positive and negative impacts on stakeholders (A. J. Jetter \& Sperry, 2013).

For requirement 4, only Green Technologies and Product were able to make transparent the decision, but it was not able to differentiate the sources input. This was a criticism of TA and EIA, and Stakeholder Engagement/CSR had no decision capability. FCM showed potential capability of making transparent how stakeholder and expert input impacts the decision, but the case studies were exploratory.

For requirement 5, the methods in Stakeholder Engagement/CSR are capable of capturing new or changing stakeholder or expert perceptions; however, there is no assessment or decision-making capability. EIA captured new or changing stakeholder perspectives between the scoping, draft and final EIS NEPA phases; however, the focus is on capturing what impacts stakeholders are concerned with and not about reassessing change in perceptions with individual or aggregated stakeholders. CTA did 
show the capability of using feedback. Green Technologies and Products methods did not show any research evidence of capturing new or changing stakeholder perceptions. None of FCM case studies showed this capability; however, in theory it is capable. As a result, Table 4 defines the research gaps in the literature research.

LITERATURE RESEARCH GAPS: CURRENT METHODS...

RG1-... do not preserve the perceptions of Stakeholders and experts

RG2 ... do integrate the assessment and decision-making

RG3 ... do not support decision makers in understanding far-reaching and indirect effects of their decisions on stakeholders

RG4 ... do not make transparent how stakeholder and expert inputs impact decisions

RG5-...do not assess tradeoffs between organizational objectives and stakeholder impacts

RG6 ... are static or have limited capacity to incorporate new or changing stakeholder perspectives

Table 5: Research Gaps 


\section{RESEARCH METHDOLOGY}

\subsection{Research OBJectives AND QUESTIONS}

This research develops a fuzzy cognitive technology assessment (FCTA) methodology that captures a wide range of expert and stakeholder perceptions, builds FCM models to assess effects of the technology on stakeholders, analyzes conflicting interests of stakeholders with organizational objectives, and dynamically adjusts the conclusions when learning about new or changing stakeholder perceptions and/or expert input. To achieve these objectives, the five research questions defined in Figure 5 are investigated, which correspond with the research gaps.

Research question 1 provides the needed guidance to meet the objective by clarifying how FCM can be used to systematically integrate a wide range of stakeholder and expert input into the assessment and decision making processes. Research questions 2 provides the needed guidance to understand how the effects of the technology alternatives positively and negatively affects on stakeholders. Research question 3 provides the guidance for understanding stakeholder collations. Research question 4 provides the needed guidance, which conducts analysis to understand how FCM can be used to resolve conflicts between conflicting stakeholder interests and organizational objectives. Research question 5 provides the needed guidance to answer how new or changing information can be incorporated into the FCM model to assess the new impact on the selected technology. 

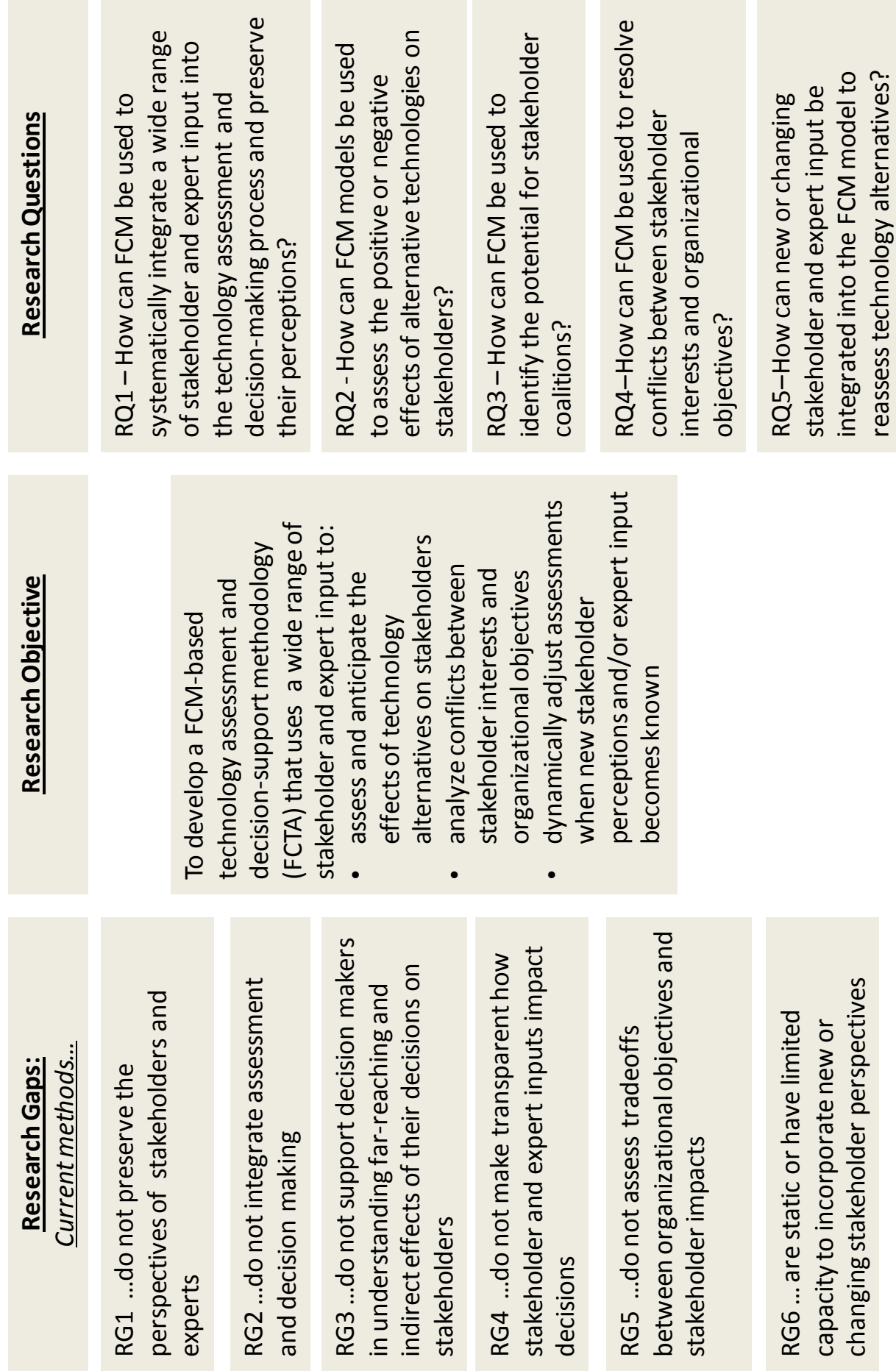

Figure 5: Research Gaps, Objectives and Questions 


\subsection{StRATEgY FOR RESEARCH DESIGN}

To develop FCTA and answer the five research questions, this research occurs in two phases. First, FCTA will be developed and applied to a real-world environmental impact analysis. This will cover steps 1-5 depicted in Figure 6: Knowledge Capture, FCM Modeling, FCM Model Aggregation, FCM Simulation, and Feedback Learning. Second, FCTA will be evaluated and assessed as a methodology for supporting decision-making in environmental impact assessment, as depicted in step 6. Both research phases are discussed in the following section.

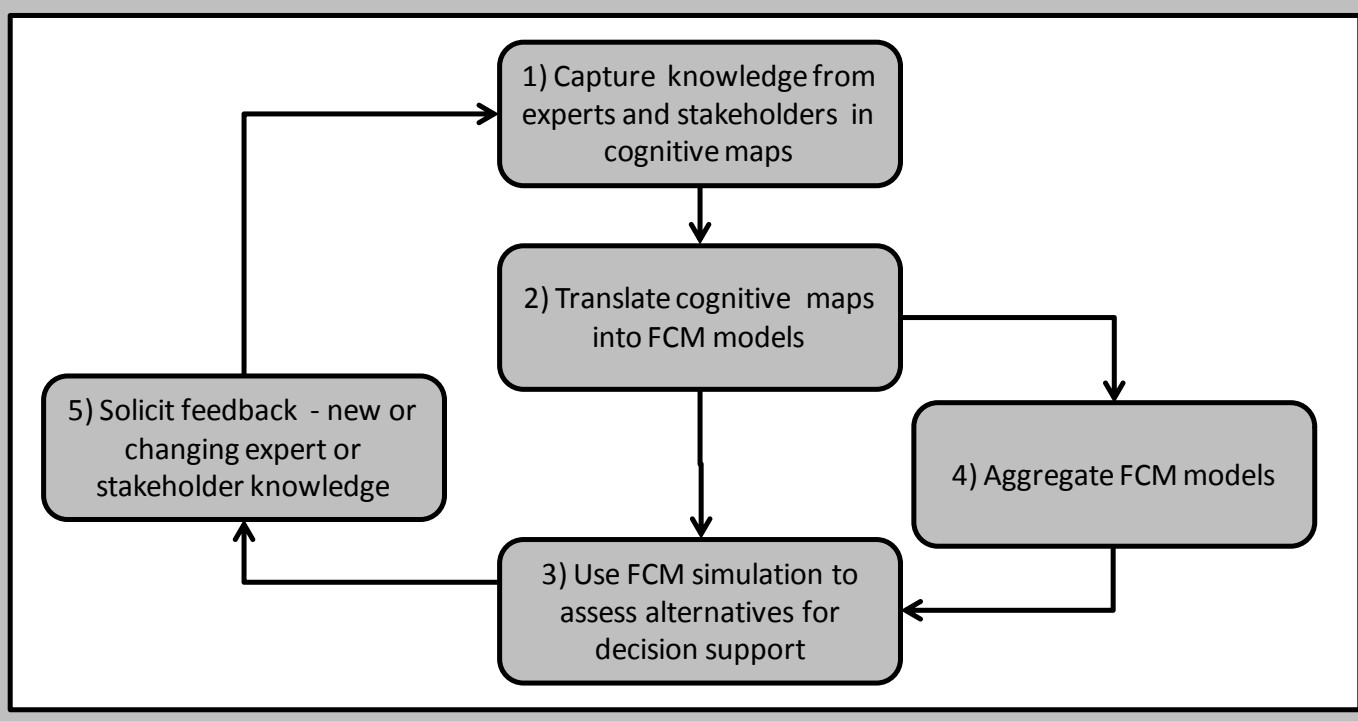

6) Evaluation /Assessment: Case Study

Figure 6: FCTA Methodology 


\subsection{Strategy for Data Collection, Model Building and Analysis}

Step 1 captures the subjective knowledge (factual knowledge, concerns, beliefs, values, etc.) of stakeholders and experts in causal cognitive maps. Step 2 translates each causal cognitive map into a FCM model (i.e., adamancy matrix). The FCM model is used to simulate the expected outcomes of technology alternatives in order to support decision-

making in Step 3. FCM simulation is expected to show similar or pluralistic interests for a technology alterative. Because multiple stakeholders and experts share differing perceptions about the beneficial or harmful effects, the approach does not identify a single preferred alternative, but rather provides decision makers with information about which alternatives are preferred by each expert and stakeholder group, thus preserving the plurality in perceptions.

Research shows that aggregating multiple stakeholder groups is used to explore a holistic understanding among common classes (Nooy, et al., 2005) and to exploit power when interests are the same (Bryson, et al., 2004). Step 4 aggregates FCM models to represent a holistic view among multiple stakeholder groups. When dealing with aggregated stakeholder groups, it is important to understand which aspects are critically important to these groups (Bryson, et al., 2004).

The impact assessments in Step 3 are not intended for static analysis. Instead, this new information is captured in Step 5 whenever new information becomes available. Over time, this may cause a shift in expert perceptions. In the case where new information is 
captured for an existing stakeholder group, the existing cognitive map is modified or additional cognitive maps are created (return to Step 1) and then translated into individual or integrated FCM models (Step 2 and 4, respectively) and analyzed through simulation (Step 3). Furthermore, additional experts or stakeholders may provide new perceptions, which need to be added to the study. In this case a new causal cognitive map is developed and translated into individual or integrated FCM models (Step 2 and 4, respectively) and analyzed through simulation (Step 3). The state-of-the-art practices for each of the five steps of the methodology are described in Chapter 4 of this dissertation.

\subsection{Strategy for Evaluation AND Assessment}

This research results in a new method, FCTA, which aims to improve TA decisionmaking. Two questions need to be answered: 1) Does FCTA result in a model that adequately describes a real-world context and thus can it support TA? 2) Does FCTA serve its intended purpose and improve the decision-making practice? These two questions are addressed through evaluation and assessment, respectively. Evaluation determines the validation and quality control for the methods used to build the model, and it investigates the model's assumptions and how they affect the results (Borenstein, 1998). Assessment, on the other hand, determines with some level of confidence that the results produced by the model can be used in decision-making (Borenstein, 1998). 


\subsubsection{Strategy for Validation and Quality Control of Methods Used}

This research uses a mixture of qualitative and qualitative methods for data collection, FCM model building, and FCM simulation in the context of a specific, real-world TA case, which is further described in Section 5. Quality control must therefore assure the continuity between the methods used (Collins \& Onwuegbuzie, 2007; Dellinger \& Leech, 2007; Johnson, Onwuegbuzie, \& Turner, 2007; Krefting, 1991). The logical tests described in Table 6 are used to assess the quality of the research methods employed for data collection, FCM model building, and FCM simulation.

\begin{tabular}{|c|c|c|}
\hline LOGICAL TEST & CRITERIA & RESEARCH STEP \\
\hline Construct & $\begin{array}{l}\text {-Establish chain of evidence } \\
\text {-Have key informants review results } \\
\text {-Dynamic hypotheses testing }\end{array}$ & $\begin{array}{l}\text { Knowledge Capture and Cognitive } \\
\text { Modeling }\end{array}$ \\
\hline Internal & $\begin{array}{l}\text {-Explanation building } \\
\text {-Address rival explanations }\end{array}$ & FCM Modeling and FCM Simulation \\
\hline External & $\begin{array}{l}\text {-Use replication of FCM methods from } \\
\text { previous FCM studies }\end{array}$ & FCM Modeling and FCM Simulation \\
\hline Reliability & -Case study protocol & $\begin{array}{l}\text { Knowledge Capture and Cognitive } \\
\text { Modeling, FCM Modeling and FCM } \\
\text { Simulation }\end{array}$ \\
\hline
\end{tabular}

Table 6: Research Validation Framework Adapted from (Yin, 2003, p. 34)

\subsubsection{Construct Validity}

The purpose of the construct validity is to establish the correct operational measures for the concepts under study and to confirm that the data collected is objective and interpretational (Yin, 2003). Two strategies have been defined: 1) establish a chain of evidence and 2) have key informants review the results. 
BPA used several methods for eliciting stakeholder input such as dialogue workshops, web-based portals and email. In addition, BPA experts conducted the impact assessments in accordance with the NEPA standard. Both the stakeholder comments and the impact assessments are publically available in secondary sources that include scoping, draft EIS and final EIS documents. Therefore, the research establishes a coding scheme to trace stakeholder comments back to the original source document. As for the impact assessments, the research constructed the FCM model so that it reflects the case study data by EIS area and BPA objectives, thereby allowing for traceability to the draft and final EIS documents.

Interpreting and encoding text is dependent on individual perspectives. Furthermore, the document may not provide enough stakeholder information to associate a stakeholder with a particular group. Therefore, provisions are made to interview the BPA project team and, if necessary, to associate a stakeholder with the appropriate stakeholder group and/or explain a concept being studied.

\subsubsection{Internal Validity}

Internal validity establishes confidence in the truth of the research analysis by establishing the causal relationships under study and that certain conditions that lead to other conditions can be shown (Yin, 2003). Three strategies are used: 1) dynamic hypotheses testing; 2) explanation building; and 3) addressing rival explanations. The research uses FCM models to represent a complex chain of events that are staged in 
repeated cause-and-effect patterns. The output of the FCM simulation is used for decision making. Therefore, is necessary to verify that the structure of the model represents the problem domain (Borenstein, 1998). The research validates the model structure by constructing the dynamic hypotheses (J. D. Sterman, 2000b) using the alternatives discussed in the Record of Decision (ROD). The ROD provides the justification for decision making (i.e., selecting or rejecting) as the basis for explanation building and addressing rival explanations.

\subsubsection{External Validity}

External validity establishes generalizations where the findings can be applied to other contexts and settings (Yin, 2003). The context of generalization is applicable to the methodology, not to actual models. Therefore, the strategy is to use the methods used by other researchers from previous FCM studies (A. Jetter \& Schweinfort, 2011; A. J. M. Jetter, 2003; Kok, 2009; Mouratiadou \& Moran, 2007; Uygar Özesmi, 1999; Uygar Özesmi \& Özesmi, 2003; van Vliet, Kok, \& Veldkamp, 2010), which are discussed in Section 4. The main differences between FCTA methods and the methods used by other researchers is in how the research integrates and interprets a diverse set of individual stakeholder groups and aggregated stakeholder group issues. In addition, FCTA indentifies how experts view the impacts of alternatives on the stakeholders, how stakeholders interest conflict with organizational objectives, and incorporating new and changing stakeholder and expert views into the FCM model. 


\subsubsection{Reliability}

Reliability measures the degree of consistency in the collection of the data to minimize error and biases so other researchers can repeat the same experiments and get the same results (Yin, 2003). The strategy is in the development of case study protocol that deals with the documentation and procedures for collecting data, building models, and conducting FCM simulation. The research uses publicly available documents and documents the steps taken to extract and identify the cause-and-effect concepts and to infer the degree of causality between two concepts, thus establishing the causal relationship. The research also documents the procedures for construction of the FCM models and the methods for conducting the FCM simulation.

\subsubsection{Strategy for Investigating Assumptions and Results}

A model is a simple representation of the real world (A. J. Jetter \& Kok, 2013; B. Kosko, 1986). Furthermore, the results produced by the model are dictated by the assumptions in the mental representations of the real world (J. D. Sterman, 2000b). Therefore, it is imperative to understand if the results from the FCM model change in a manner that is important to your purpose when assumptions are varied with a range of possibilities (J. D. Sterman, 2000b). Sensitivity analysis is a technique to assess whether the conclusions drawn from the model change when assumptions are varied over the possible range (Baird, 1989). The research will conduct numerical sensitivity analysis (J. D. Sterman, $2000 \mathrm{~b})$ to determine if the results of the model change when different squashing functions are used. In addition, the research will conduct policy sensitivity analysis 
(Gass, 1983; Moxnes, 2005; J. D. Sterman, 2000b) to understand if changing assumptions lead to different results that could affect how decisions are made.

\subsubsection{Strategy for Assessment}

A focus group is conducted with the BPA project team to determine the confidence in results produced by the research and whether or not the result helps in the decisionmaking process. A pre-defined script (refer to Appendix E - Interview Script for Evaluation of the Research for details) is used to understand the following:

1. Did FCTA adequately identify relevant stakeholders?

2. Did FCTA adequately aggregate stakeholder groups?

3. Did FCTA adequately capture stakeholder concerns?

4. Did FCTA adequately represent changes in stakeholder perception over time?

5. Did FCTA identify issues/problems that became apparaent during project execution?

The first question ensures the research did not miss a stakeholder group. The second question probes to understand stakeholder relationships and how they impact the decision-making. The third question determines whether causal cognitive maps are capable of capturing the stakeholder concerns and did the research correctly identify the concerns. The fourth question determines if the stakeholder concerns change from the time when the project was conducted during the scoping phase to when the Draft EIS was released. Finally, the fifth question determines if the research was able to predict potential issues with the implementation. 


\subsection{Research Assumptions}

The following assumptions are made for this research:

- The research assumes that the publically available information on stakeholder concerns and issues, elicited by BPA, is sufficient to create meaningful models of stakeholder perspectives.

- The research assumes that BPA is capable of assigning issues and concerns raised during the public involvement process to particular stakeholder groups, even if no author is identified.

- The research assumes that the direction and positive and negative causality between concepts raised by stakeholders can be extracted from publicly available documents.

- The research assumes BPA is capable of validating the FCM models. 


\section{STATE OF THE ART FCM RESEARCH METHODS}

\subsection{Method OvervieW}

Research has shown that FCM uses a mixture of qualitative and quantitative methods for the steps as shown in Figure 6. Research step 1 qualitatively captures a wide range of expert and stakeholder perceptions into causal cognitive maps. Research Step 2 translates these causal cognitive maps into individual stakeholder and expert FCM models. Research Step 3 uses quantitative methods to assess the technology alternatives and to understand the positive or negative effects of the alternative. Step 3 is also used to understand the direct and indirect effects of the alternative technologies to avoid unintended consequences associated with a decision and to understand supporting and conflicting perceptions with the organizational objectives. Step 4 aggregates stakeholder group perceptions and then uses Step 3 FCM simulation to assess alternatives using the aggregated stakeholders' perceptions to understand the positive or negative effects of the alternative technologies, and also to avoid unintended consequences associated with a decision, and to understand supporting and conflicting perceptions with the organizational objectives. Finally, research Step 5 uses a qualitative approach to identify changes or new information. Once identified, the new or changing information is incorporated in the new models using the original models as the baseline.

\subsection{Step 1 - Knowledge Capture in Causal Cognitive Maps}

Causal cognitive mapping is a visual modeling technique for capturing stakeholder and expert views on a particular problem. A view is represented by a collection of concept 
formulated by principles, general laws and relationships with other concepts to provide a deep-level knowledge for solving complex problems (Kim \& Courtney, 1988). Several methods have been used to study people's views in the form of cognitive maps, and there are advantages and disadvantages to each.

Stakeholder identification identifies stakeholders who are critical to the organization's operation or are affected by the operations, and stakeholder analysis aims at understanding the stakeholders' interests and narrowing down the resulting, oftentimes extensive, list of stakeholders to those that are (or will be) important to the organization (Agle, et al., 2008; Agle, et al., 1999; Mitchell, et al., 1997). There two approaches: identifying those stakeholders who are directly involved in business activities (Freeman, 1984; Harrison \& St. John, 1996; B. Jones, 1995; S. R. H. Jones, 1997; King, 2007; Williamson, 1979) and those stakeholders who have the power and interest in the organization's strategy (Fran Ackermann \& Eden, 2011; Clarkson, 1995; Frooman, 1999; Porter, 1980). The CSR standards organizations advocate identifying stakeholders with environmental and social issues, communicating with them, and engaging with them to develop an empathetic sensitivity for their concerns and interests (AccountAbility Institute, 2008; Agle, et al., 2008; Carroll, 1974; Clarkson, 1995; Donaldson \& Dunfee, 1994; GRI, 2000-2011; ISO, 2010; Mitchell, et al., 1997; Wartick \& Cochran, 1985; D. J. Wood, 1991). 
Knowledge can be extracted in real time by soliciting concepts individuals using individual or group modeling sessions. Individual and collective group mapping produces clusters of concepts that reveal how decisions are made. Furthermore, because the experts and stakeholders participate, they are able to validate the boundaries and structure of the map (F. Ackermann, \& Eden, C. , 2005; Fran Ackermann, Eden, \& Williams, 1997; Eden, 1992; C. Eden \& F. Ackermann, 2002; Eden, Ackermann, \& Cropper, 1992). However, consideration needs to be given to how people make sense of the world because you don't want to run the risk of changing someone's perception (Bryson, et al., 2004). Although collective group mapping benefits from new ideas and insights from the participants, it is also limited by group dynamics. For example, groupthink can constrain the participants' willingness to share their ideas within a democratic and discursive participation setting due to peer pressure (F. Ackermann, \& Eden, C. , 2005; Bryson, et al., 2004; 2006; A. J. Jetter \& Kok, 2013); attempting to unify the group on one particular issue runs the risk of closing the issue too early (Palm \& Hansson, 2006). Individual mapping, on the other hand, produces insights that are not constrained by group dynamics faced by collective group mapping. However, individual mapping is limited by one's perceptions of the domain (Eden, 1992; A. J. Jetter \& Kok, 2013; Uygar Özesmi \& Özesmi, 2004), and it is the predicted ability of the modeler not to create illusory correlated events when receiving and processing information in chunks (1982). 
Alternatively, concepts can be extracted from secondary sources, where the knowledge is transcribed into venues such as interview notes, surveys, books, and articles. Wellconstructed surveys provide consistency and yield good validation; however, a survey's capacity to derive concepts unique to each respondent is limited (Robert Axelrod, 1976).

Documents have been widely used because the concepts under study are traceable to the documents, they are flexible in categorizing people's thoughts, and they provide good validation (Robert Axelrod, 1976; K. Carley \& Palmquist, 1992; K. M. Carley, 1997; Nakamura, et al., 1982; Roberts, 1989). Mapping from secondary sources requires identifying the cause and effect concepts, which are the subject or object in a statement that can take on different values, and the relationship (positive or negative) between the two concepts as indicated by the verb/adverb (K. Carley \& Palmquist, 1992; K. M. Carley, 1997; Nakamura, et al., 1982; Roberts, 1989; Wrightson, 1966).

The use of these approaches is dependent on two critical factors: accessibility to the knowledge source and the approach for identifying concepts. Individual or group modeling sessions imply direct access to the knowledge sources, whereas extracting knowledge from documented sources implies no direct access to the knowledge sources. Furthermore, the approach for identifying the concepts depends on the researcher's understanding of the knowledge domain. A confirmatory approach assumes that the concepts and their semantics are identified independently and prior to the mapping, whereas an exploratory approach draws out concepts and their semantics from the knowledge source (1992). 
More often than not, concepts are not described using the same terminology. A technique for addressing this issue is to group similar concepts into categories and then assign a name to the category (i.e., affinity process). This process simplifies the coding and maintains continuity among the concepts across multiple stakeholders and experts. For example, "noise from construction equipment" and "blasting" and "drilling" could be categorized as "construction noise," or it could also be categorized as "construction disturbances" because "blasting" and "drilling" are more than noise since they actually affect the physical structure of the land.

Finally, when mapping causal relationships, careful attention needs to be given to causal reasoning because it is possible to represent a negative causality using the same relationship with a positive causality (B. Kosko, 1986). For example, the "construction disturbances decrease wildlife living in the area" is the same as "construction disturbances increase wildlife not living in the area." Therefore, it is important to maintain the same method, positive or negative causality, across domains.

\subsection{STEP 2 - FCM MODELING}

FCM modeling is the mechanism for integrating stakeholder input into the technology assessment and decision support. Assessing alternatives requires a decision support process that is transparent, unbiased and reproducible (Baird, 1989). Moreover, making socially responsible decisions requires a FCM structure that can not only assess the perceived actions of the decision on the organizational objectives, but also how the 
decision affects stakeholders', either positively or negatively (Agle, et al., 2008; Agle, et al., 1999; GRI, 2000-2011; ISO, 2010; Mitchell, et al., 1997).

The creation of the FCM is accomplished by translating the causal cognitive map into an adjacency matrix and applying a threshold squashing function as described in 2.6.1. Mathematically, an FCM represents each concept by a number $A_{i}^{t}$ at an activation level for the concept at step $t$, and an input vector $A_{i}^{t}=\left[A_{1}^{t}, A_{2}^{t} \ldots . A_{n}^{t}\right]$ activates the concepts in $W$ as described in $E Q(1)$ (Tsadiras, 2008). The result is the summation of all arc edge weights (positive or negative) in Wij, where $j$ is not equal to $i$ because FCM does not allow directions between a concept and itself (Tsadiras, 2008). Furthermore, threshold squashing function $f$, such as bivalent $\mathrm{EQ}(2)$, trivalent $\mathrm{EQ}(3)$ or hyperbolic tangent $E Q(4)$, restrict the weighted sum to a certain range between $[-1,1]$ to allow for comparisons between concepts (Stach, et al., 2005).

$$
\begin{gathered}
A_{i}^{t+1}=f\left(\sum_{\substack{j=1 \\
j \neq i}}^{n} W_{j i} A_{j}^{t}\right) \\
\int\left(A_{i}^{t}\right)=\left(1, A_{i}^{t} \geq 0 ; 0\right) \\
\int\left(A_{i}^{t}\right)=\left(1, A_{i}^{t} \geq 0 ;-1, A_{i}^{t} \leq 0 ; 0\right) \\
\int\left(A_{i}^{t}\right)=\frac{e^{2 x}-1}{e^{2 x}+1}
\end{gathered}
$$


When building the model it is necessary to analyze and refine the model because it may contain concepts and causal links that will affect or create computational problems, specifically model boundaries, definitional or overly detailed causal links, time-lags, conditional causality, and faulty variables (A. J. Jetter, 2006). Strict boundaries must be adhered to in order to maintain construct validity; otherwise, concepts from the results of the model may be skewed by concepts not under study. Definitional concepts result from over-defining the causal assertions of a concept, which may affect the timing of when concepts fire and activate, thus causing a delay (A. J. Jetter, 2006). Moreover, dummy concepts may need to be added to synchronize time frames (A. J. Jetter, 2006). Concepts that are dependent on two or more dependent concepts need to assure that the threshold of the activation of the dependent concept can only be met when the independent concepts fire (A. J. Jetter, 2006). Finally, all receiver concepts (e.g., objectives) need to be validated to ensure all concepts that are used to measure the objective are not incomplete or are synchronized when firing (A. J. Jetter, 2006; Uygar Özesmi \& Özesmi, 2004). Dynamic hypothesis testing is used to validate the structure of the model, which is described in detail in section 3.4.1.1.

Figure 7 is a causal cognitive map that represents the concerns and needs of residents who are environmentally conscious and want to install a renewable energy system in their home that is either wind, solar or a combination of both. Furthermore, they choose to go off the grid or stay on the grid; however, going off the grid requires a storage system such as batteries or a fly wheel. There are five alternative technology 
concepts: "Solar Panel," “Wind Turbine," "Bluenergy Solarwind" and "Battery Storage." The solar panels typically are installed on the roof, a wind turbine is a vertical structure with 3 blades that rise at least 30 feet, and the Bluenergy Solarwind ${ }^{\mathrm{TM}}$ is a novel technology that combines solar and wind in a double-helix structure that sits on the ground.

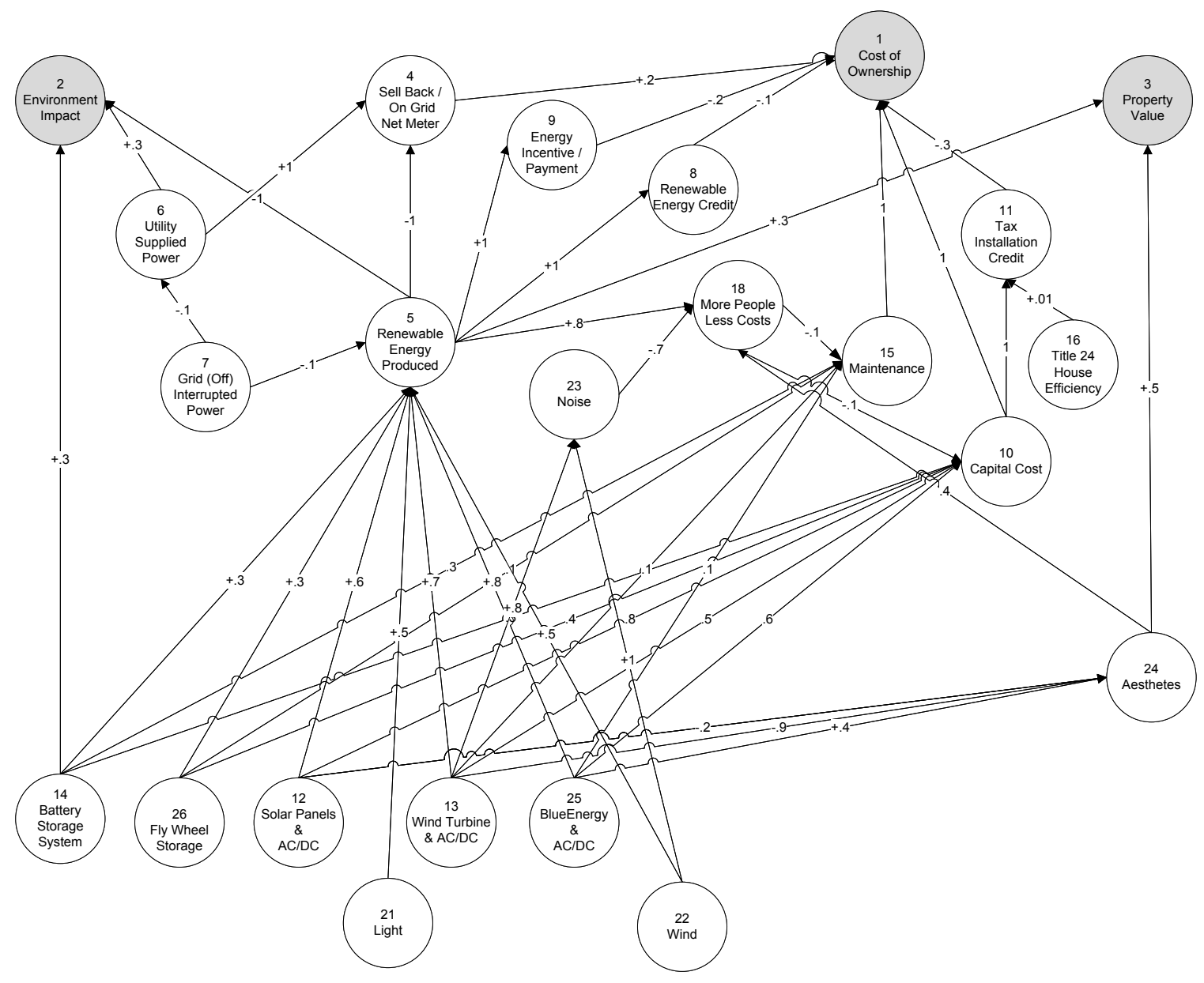

Figure 7: Cognitive Map of Stakeholder Perceptions

The hypothesis states that an off-grid renewable energy system with storage (e.g., battery) is capable of producing enough kW capacity for a residence to be independent 
of the utility. To test this, the model assumes that there is enough light and/or wind, depending on the system, and no energy is lost. Therefore, solar and wind renewable energy system concepts are activated and given an edge weight of " 1 " to indicate no loss of energy. Light and wind concepts are also set to " 1 " to indicate the maximum amount of sunlight and wind required by the systems, and they are activated accordingly based on the type of system. In addition, the storage system is activated and is given an edge weight of "1" because it is capable of storing energy and using that energy, even if the utility company interrupts the power; therefore, grid (off) interrupted power is not activated. As shown in Table 7, the on-grid meter is " 0 " and renewable energy is " 1, " indicating no utility power was used, thereby supporting this hypothesis.

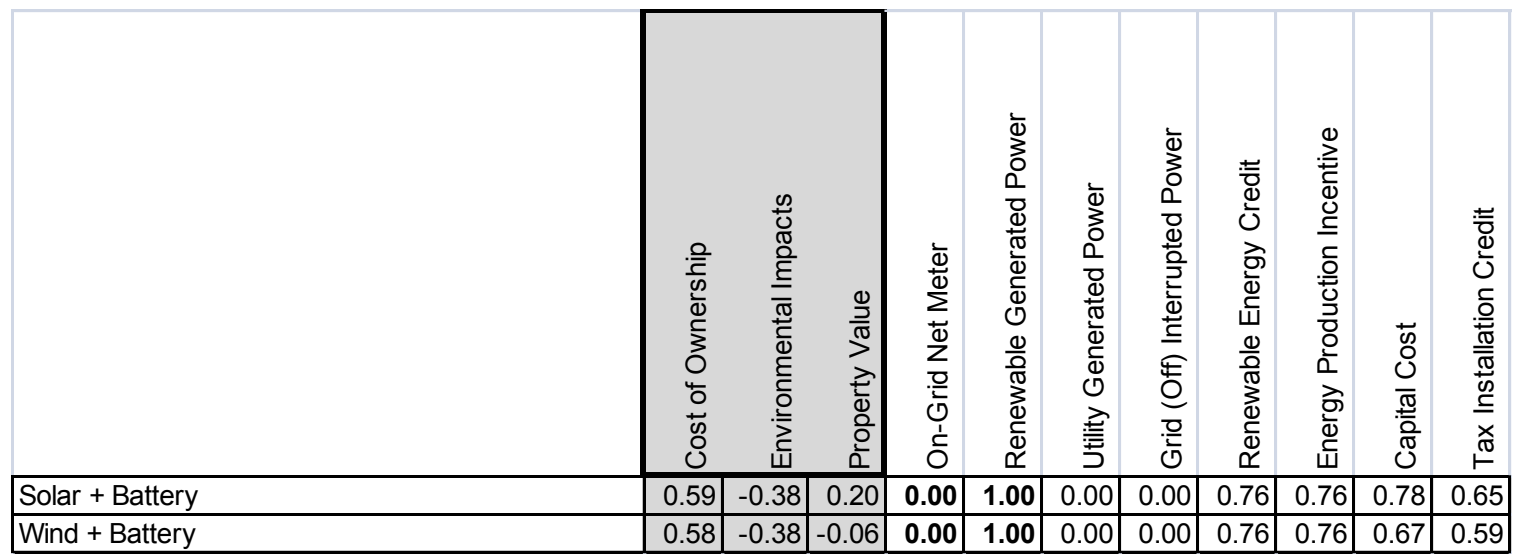

Table 7: Off Grid

The second hypothesis states that an on-grid renewable energy system without storage (e.g., battery) is not capable of producing enough $\mathrm{kW}$ capacity for a residence to be independent of the utility. The test is essentially the same as $\mathrm{H} 1$, except an on-grid 
system is susceptible to power interruptions because it has no storage system; therefore, the storage system is not activated, but the grid (off) interrupted power is activated. As shown in Table 8, the on-grid meter is " 0.04 " and renewable energy is "0.96" for both solar and wind, thereby supporting this hypothesis.

\begin{tabular}{|c|c|c|c|c|c|c|c|c|c|c|c|}
\hline & 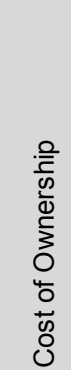 & 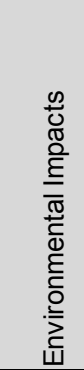 & 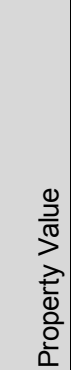 & 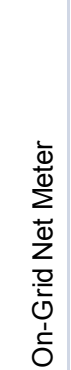 & 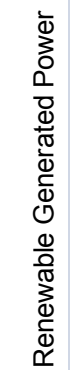 & 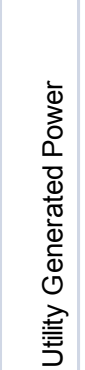 & 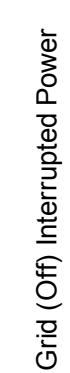 & 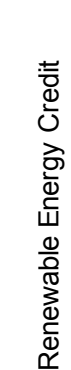 & 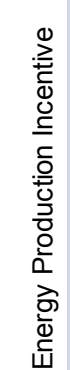 & 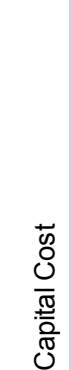 & 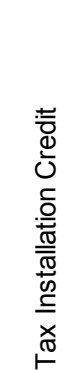 \\
\hline Solar & 0.28 & -0.58 & 0.19 & 0.04 & 0.96 & \begin{tabular}{|l|}
-0.10 \\
\end{tabular} & 0.00 & 0.74 & 0.74 & 0.63 & 0.56 \\
\hline \begin{tabular}{|l} 
Wind \\
\end{tabular} & 0.24 & -0.58 & -0.07 & 0.04 & 0.96 & \begin{tabular}{|l|}
-0.10 \\
\end{tabular} & 0.00 & 0.74 & 0.74 & 0.48 & 0.44 \\
\hline
\end{tabular}

Table 8: On Grid

\subsection{STEP 3 - FCM SIMULATION}

The technology assessment and decision support are achieved through FCM simulation. FCM models are used to assess the positive or negative effects of the alternative technologies on individual stakeholder groups and aggregated stakeholder groups. This is achieved by simulating the impacts of each technology alternative on each individual stakeholder group FCM model. The integrated FCM models are used to assess the positive or negative effects of the alternative technologies on aggregated stakeholders.

As previously discussed, the technology alternatives (i.e., transmitter concepts) form the input state vector by toggling them on (i.e., 1) or off (i.e., 0). The input state vector is 
then multiplied by the adjacency matrix, transforming path-weighted activation in a non-linear manner until the system settles down. Depending on the squashing function, the range of values in the new vector range from $[1,0]$ if a binary squashing function is used or $[-1,1]$ if a trivalent or logistic function is used. The FCM simulation leads to either a fixed state vector value, known as a hidden pattern or fixed point attractor, or cycles between a number of fixed state vector values, known as a limit cycle point (B. Kosko, 1988; Stach, et al., 2005). It is also possible that the FCM simulation with time varying edges continues to produce different state vectors values in successive cycles, known as chaotic attractor (B. Kosko, 1988; Stach, et al., 2005).

Unlike scoring models, FCM simulation can be used to examine the inputs on the basis of attitude for risk and (un)certainty to the organization and its preferences associated with consequences resulting from the alternative actions (Baird, 1989). The process involves identifying the concepts that will be used to measure stakeholder and organization objectives using those concepts that determine the perceived value. Common methods for establishing the relative importance of stakeholder issues and needs include but are not limited to eliciting stakeholder input or prioritization of organizational objectives (AccountAbility Institute, 2005b), or identifying the most central concepts and resulting consequences (Mouratiadou \& Moran, 2007; Uygar Özesmi \& Özesmi, 2004).

To illustrate and continue with the same example in the previous situation, three objectives have been defined: 1) lower the cost of ownership, 2) minimize 
environmental impacts, and 3) increase property value. Since the five product concepts can be used concurrently (e.g. "Solar Panel with Battery Storage"), there are actually 12 alternatives. For example, a battery storage system and a flywheel system both increase the independence from the utility company, but the flywheel is expected to have a longer lifetime than batteries and does not contain any problematic materials. The batteries, therefore, have a small negative impact on the environment, whereas the flywheel has no such link. Finally, there is another alternative: "do nothing" and just purchase the power from the utility company. Therefore, there are 13 alternatives that need to be assessed, as shown in lines 1-13 in Table 9.

\begin{tabular}{|c|c|c|c|c|c|c|c|c|c|c|c|c|}
\hline \multicolumn{2}{|r|}{ Alternatives } & 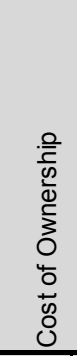 & 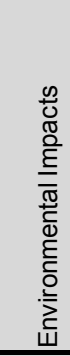 & 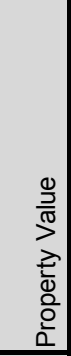 & 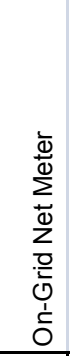 & 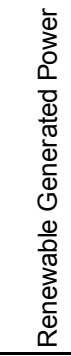 & 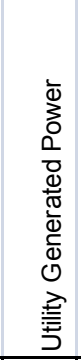 & 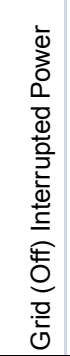 & 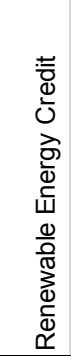 & 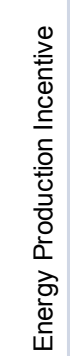 & 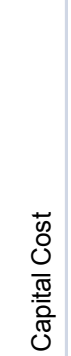 & 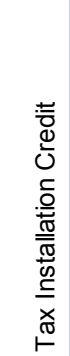 \\
\hline 1 & Baseline - All Utility & 0.20 & 0.38 & -0.03 & 0.80 & -0.10 & -0.10 & 0.00 & -0.10 & -0.10 & 0.01 & 0.01 \\
\hline 2 & \begin{tabular}{|l|} 
Solar \\
\end{tabular} & 0.36 & -0.43 & 0.13 & 0.23 & 0.76 & \begin{tabular}{|c|}
-0.10 \\
\end{tabular} & 0.00 & 0.64 & 0.64 & 0.64 & 0.56 \\
\hline 3 & Solar + Battery & 0.62 & -0.28 & 0.17 & 0.11 & 0.89 & 0.00 & 0.00 & 0.71 & 0.71 & 0.78 & 0.65 \\
\hline 4 & Solar + Flyw heel & 0.46 & -0.53 & 0.17 & 0.11 & 0.89 & 0.00 & 0.00 & 0.71 & 0.71 & 0.85 & 0.69 \\
\hline 5 & Wind & 0.31 & -0.46 & -0.12 & 0.20 & 0.80 & $\mid-0.10$ & 0.00 & 0.66 & 0.66 & 0.49 & 0.45 \\
\hline 6 & \begin{tabular}{|l|} 
Wind + Battery \\
\end{tabular} & 0.61 & -0.30 & -0.1 & 0.09 & 0.91 & 0.00 & 0.00 & 0.72 & 0.72 & 0.68 & 0.59 \\
\hline 7 & Wind + Flyw heel & 0.46 & -0.54 & -0.09 & 0.09 & 0.91 & 0.00 & 0.00 & 0.72 & 0.72 & 0.77 & 0.65 \\
\hline 8 & Solar \& Wind & 0.57 & -0.59 & -0.11 & 0.02 & 0.98 & -0.10 & 0.00 & 0.75 & 0.75 & 0.87 & 0.70 \\
\hline 9 & Solar \& Wind + Battery & 0.74 & -0.37 & -0.10 & 0.01 & 0.99 & 0.00 & 0.00 & 0.76 & 0.76 & 0.92 & 0.73 \\
\hline 10 & Solar \& Wind + Flyw heel & 0.62 & -0.60 & -0.10 & 0.01 & 0.99 & 0.00 & 0.00 & 0.76 & 0.76 & 0.95 & 0.74 \\
\hline 11 & Bluenergy Solarw ind ${ }^{\mathrm{TM}}$ & 0.22 & -0.56 & 0.44 & 0.06 & 0.94 & -0.10 & 0.00 & 0.73 & 0.73 & 0.51 & 0.47 \\
\hline 12 & Bluenergy Solarw ind ${ }^{\mathrm{TM}}+$ Battery & 0.57 & -0.35 & 0.45 & 0.03 & 0.97 & 0.00 & 0.00 & 0.75 & 0.75 & 0.70 & 0.60 \\
\hline 13 & \begin{tabular}{|lll} 
Blluenergy Solarw ind ${ }^{\mathrm{TM}}+$ Flyw heel \\
\end{tabular} & 0.41 & -0.59 & 0.45 & 0.03 & 0.97 & 0.00 & 0.00 & 0.75 & 0.75 & 0.79 & 0.66 \\
\hline
\end{tabular}

Table 9: FCM Model Results for Alternatives 
To model the "do nothing" situation, meaning homeowners do not own renewable energy systems and purchase all their electricity needs from the utility company concept 6 (Utility Generated Power) is activated and clamped (the initial state of the concept remains the same throughout the simulation). In addition, concept 7 (Grid "off"; some power interruptions) is also activated and clamped, which means that from time to time, the utility company may not be supplying power. The results in Table 9 show the cost of ownership is +0.20 (homeowners incur cost for power from the utility), negative environmental impacts are +0.38 (the utility company uses coal instead of renewable energy to produce electricity), and property value is -0.03 (slight negative impact because buyers value a renewable energy system in a house).

Rows 2-13 in Table 9 show the results for several alternative product configurations: the traditional solar panel and horizontal wind turbine have the highest cost of ownership, and Bluenergy Solarwind ${ }^{\mathrm{TM}}$ has the lowest, although it is still slightly higher than the baseline situation. The two concepts that produce the greatest amount of renewable energy are the combination of a traditional solar panel and a traditional wind turbine, as well as Bluengery Solarwind ${ }^{\mathrm{TM}}$. The increase in renewable energy production goes handin-hand with lower values for "negative environmental impacts." Furthermore, Bluenergy Solarwind ${ }^{\mathrm{TM}}$ has the best property value overall because it is more aesthetically pleasing than other designs. From a stakeholder needs perspective, Bluenergy Solarwind ${ }^{\mathrm{TM}}$ is the most desirable choice. 


\subsection{Step 4 - AggRegating FCM Models}

An important feature of FCM is the capability of modeling multiple perceptions to provide a holistic view (B. Kosko, 1988). It is potentially stronger than an individual (Taber, 1991) and it is less subject to biases (B. Kosko, 1988). There are two approaches: 1) qualitatively integrating cognitive models into one causal cognitive map prior to creating an FCM (Mouratiadou \& Moran, 2007; Nakamura, et al., 1982; Uygar Özesmi \& Özesmi, 2004) or 2) integrating individual stakeholder FCMs into a combined FCM (B. Kosko, 1988; Taber, 1991). Because of the uniqueness in the way people express their concepts, the number of individual concepts can be massive (Uygar Özesmi \& Özesmi, 2004). This requires defining a common meaning across all concepts, known as a common ontology. Defining a common meaning across all concepts is achieved by using the affinity process to group like concepts into categories and replacing the unique concepts with an all-encompassing concept, thereby providing a common meaning across all concepts (Nakamura, et al., 1982; Uygar Özesmi \& Özesmi, 2004).

Qualitatively integrating individual cognitive maps replaces each unique concept in the causal cognitive map with the common concept and then eliminating duplicate common concepts across all causal maps. Each unique causal relationship is then carried forward into the new causal cognitive map, thereby representing all the views in the form of a social cognitive map (Uygar Özesmi \& Özesmi, 2004). Alternatively, individual stakeholder FCMs can be integrated by augmenting each individual FCM to the total number of distinct concepts in all FCMs to create a new FCM (B. Kosko, 1988). Although 
integrating FCMs mathematically does not require defining a common ontology, it will encounter the same complexity as qualitative integration; therefore, it would make sense to do this before integrating FCMs.

Quantitative integration address two other aspects when integrating FCMs: (1) normalizing the weights and (2) applying creditability factor to the weight. As defined in $E Q(5)$, the next step is the additive weighted strength $A W_{i j}$ for the causal relationships in each matrix $W_{i j}$, which is then normalized by $e$, which is the number of adjacency matrices being integrated (Taber, 1991). This approach still preserves outlier perceptions, although they are given little weight (A. J. Jetter \& Kok, 2013). In addition, integrating quantitatively can make use of creditability weights $C$ for each adjacency matrix being integrated, thereby indicating a preference for one perception over another (B. Kosko, 1988). However, credibility judgment is subjective; therefore, its usefulness is questionable, and it is better to demonstrate creditability by agreement among FCMs (Taber, 1991).

$$
A W_{i j}=\left(\sum_{e=1}^{e} C_{e} W_{i j}\right) \div e
$$

\subsection{Step 5-IDENTIFY NeW OR Changing KNOWLEdGe}

This requires first identifying new and changing perceptions from the baseline documents originally used to capture stakeholder or expert knowledge. Research provided no FCM methods; however, a technique used in project management is to 
keep the original cognitive map as a baseline and make a copy for the new or changing information (Project Management Institute, 2013). Once identified, the new perceptions are added to a copy of the original cognitive map, and changes in perceptions modify information in the copy. 


\section{CASE STUDY OVERVIEW}

The research proposes to meet the research objective and answer the research questions using a historical BPA transmission upgrade project from Libby Montana to Troy Montana that is described in detail in Appendix A - Libby to Troy Upgrade Project. The project spanned over 17 miles as shown in Figure 8. BPA had to decide among eight alternatives that included replacing the existing $115 \mathrm{kV}$ with $115 \mathrm{kV}$ or increasing the voltage to $230 \mathrm{kV}$ in anticipation of future users. In addition, 3 alternative routings for the transmission lines were also considered for each voltage option (i.e., 115kV or 230kV): Pipe Creek, Quartz Creek and Kootenai River. Although, BPA considers "do nothing" as an alternative, BPA had determined that it was a viable alternative; therefore, it will not be modeled.

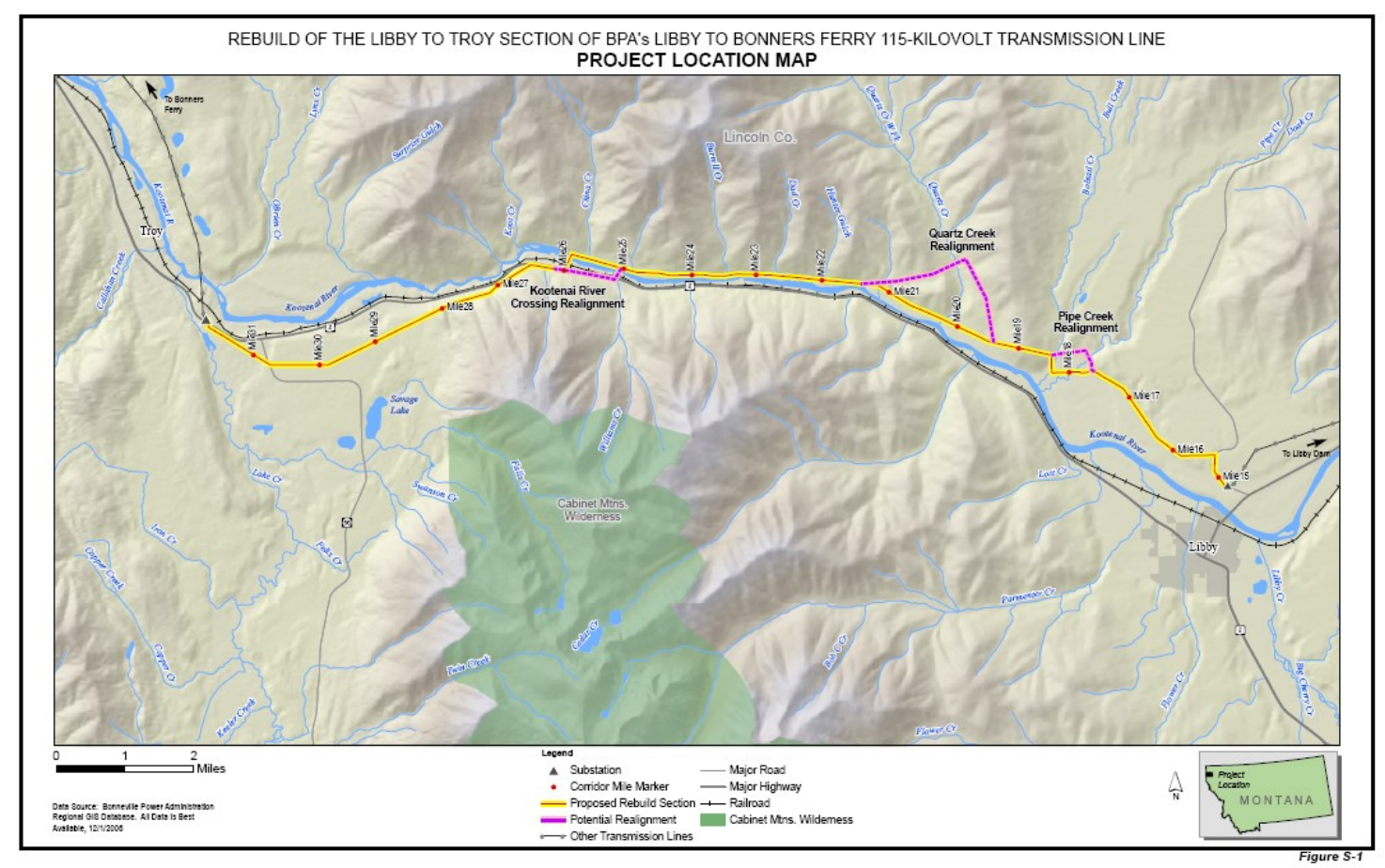

Figure 8: Rebuild of Libby to Troy System Upgrade Project 
BPA had four objectives: 1) Maintain transmission system reliability to industry standards; 2) continue to meet BPA's contractual and statutory obligations; 3) minimize environmental impacts; and 4) minimize costs. Objectives one and two are determined by the equipment and capacity of the transmission, which are assumed to be met by each alternative. Therefore, research will only model objectives three and four. The project followed the National Environmental Policy Act (NEPA) process, as shown in Figure 9. The process is to ultimately help public officials make informed decisions based on the understanding of environmental and social consequences and available alternatives. The research uses publically available documents that describe the project in detail for all phases of the project ${ }^{2}$, also as shown in Figure 9.

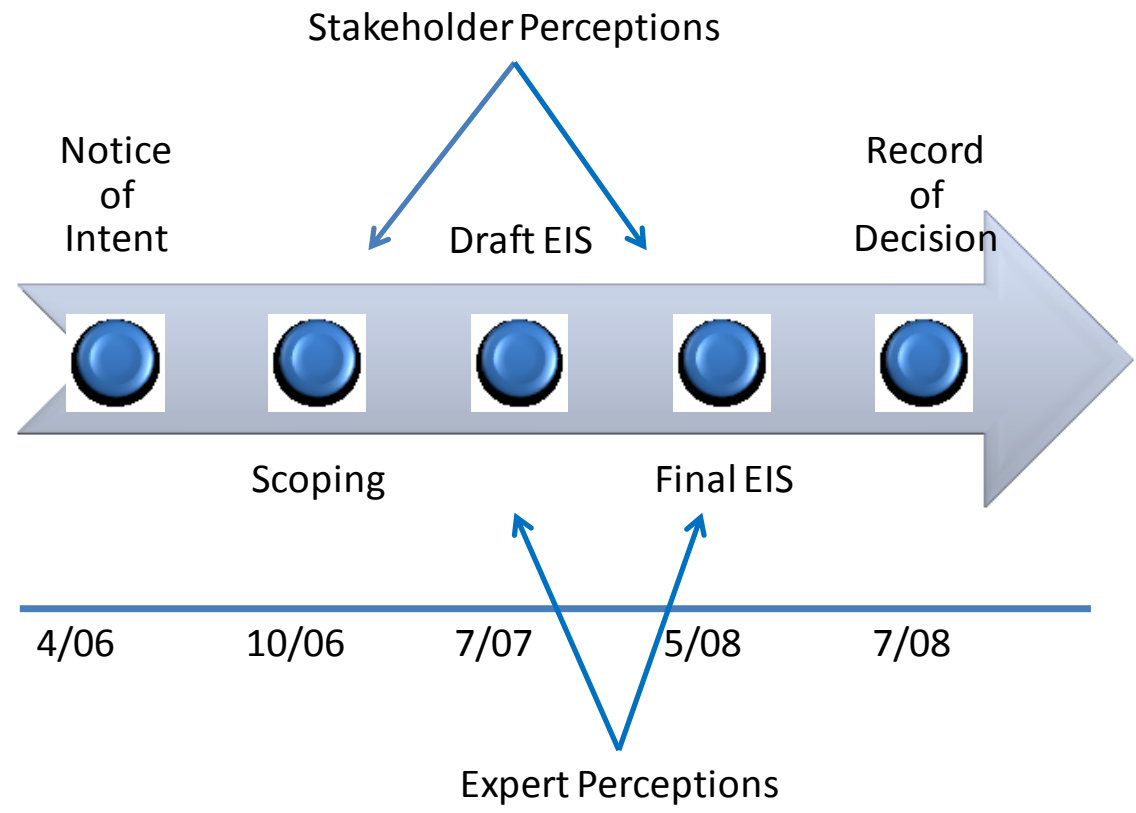

Figure 9: Expert and Stakeholder Data Collection

\footnotetext{
${ }^{2}$ All documents are located http://efw.bpa.gov/environmental services/Document Library/Libby/ with the exception of the stakeholder scoping comments. BPA scanned these comments and stored them on a CD that was provided for the research.
} 
BPA surveyed the project land site to determine those individual stakeholders who may be affected. In addition, BPA notified city, state and federal government agencies whose support would be required in implementing the project. A Notice of Intent (NOI) was sent to these stakeholders, as well as publishing the NOI in the Federal Register and local newspapers. The NOI included a brief discussion of the need for the proposed project, a listing of alternatives, possible environmental impacts of the projects, and a listing of agencies and persons consulted.

Scoping is an open and early process phase that elicits stakeholder input to understand what issues need to be evaluated, potential environmental impacts that need to be studied, and the alternatives to be considered. BPA identified approximately 300 stakeholders from whom they wanted to solicit comments regarding the 8 alternatives proposed as part of the Libby to Troy transmission upgrade project. During this phase, 58 individuals and 4 government agencies submitted comments, and 4 public town hall meetings were captured in 58 documents (see Appendix B - Documents Used). The concerns of the tribal communities are documented in Appendix-A of the Draft EIS.

After the stakeholder comments were submitted, BPA conducted a draft Environmental Impact Statement (EIS), which is an in-depth analysis of environmental and socioeconomical impacts conducted by experts. An EIS describes the short-term, long-term, and cumulative impacts of the proposed solution on the environment and on stakeholders, including any adverse impacts that cannot be avoided should the proposal 
be implemented. The EIS also proposes reasonable alternatives and mitigation activities to reduce the impact. Moreover, it describes any irreversible and irretrievable commitments of resources that would be involved in the proposed action. The experts take into account those specific concerns and needs as identified by stakeholders in the scoping comments when assessing the environmental, social and economic impacts associated with each alternative. The results of the experts' perceptions are documented in the draft EIS document.

After the draft is published, stakeholders are again encouraged to analyze how the experts have assessed their concerns and submit any new or changed concerns as a result of the draft EIS. An additional 10 individual stakeholders, 6 agencies and 2 stakeholder groups submitted their comments in 22 documents (see Appendix B Documents Used). The experts then take in account these comments and conduct a final EIS, which documents any new or changed perceptions by the experts. 


\section{RESEARCH DATA COLLECTION AND ANALYSIS}

\subsection{INTRODUCTION TO METHODS USED}

This section describes the steps taken to collect the data, create the causal cognitive maps, build the FCM models, and conduct the analysis. As described in Figure 6, the research makes use of five steps. Steps 1 through 2 are initially executed to capture stakeholder perceptions using stakeholder scoping comments and are grouped by type of entity and/or by geographic location to the transmission line. Steps 1 and 2 are again used to capture the expert perceptions using the draft EIS. Step 3 analyzes the impacts of the eight alternatives for each stakeholder group based on their perceptions of the impacts resulting from the alternatives. Step 3 is also used to understand how the expert perceives the impacts of the eight alternatives. Step 4 is then used to assess the impacts of the eight alternatives on aggregated stakeholders who share the same group characteristics or like interests. At the completion, the research has established a baseline for both stakeholder and expert point of view in the form of causal cognitive maps and FCM models.

After the draft EIS is released to the public, research Step 5 is executed to identify new or changing stakeholder and expert perceptions. Stakeholders submit new stakeholder comments regarding their concerns and needs as a result of the draft EIS. These new comments are captured and incorporated into a copy of the baseline model for each stakeholder group using Steps 1 and 2. The result is a new set of causal cognitive maps and FCM models for each stakeholder group identified previously or a new cognitive 
map and FCM model for any new stakeholder not previously identified using Steps 1 and 3. The revised expert perceptions are also captured and incorporated into a copy of the baseline model, thereby resulting in a new causal map and FCM model using the final EIS using Steps 1 and 2. Finally, these new FCMs are used to anticipate the effects of the technology on individual and aggregated stakeholders; analyze conflicting interests with organizational objectives; and dynamically adjust its conclusions when learning about new information or changes in stakeholder perception and/or expert input using steps 3 and 4.

\subsection{STAKEHOLDER AND EXPERT KNOWLEDGE CAPTURE IN COGNITIVE MAPS}

\subsubsection{Methods for Knowledge Capture}

Figure 10 depicts the methodology for capturing and developing domains of knowledge in the form of causal cognitive maps. The first step is to define and validate the project objectives. Next is to identify the stakeholders and experts, and the process for capturing the domains of knowledge (e.g., stakeholder perceptions). Research has shown that grouping stakeholders is generally along the lines of like entities or interests, such as farmers or residents (Mouratiadou \& Moran, 2007; Uygar Özesmi, 1999). Capturing these can be done either in real time using individual or group modeling sessions or after the fact using documented sources. The next step in the methodology is to identify the cause of an event and its consequence to establish a direction and determine whether the consequence is positive or negative (+ or -) relative to the event 
(Bryson, et al., 2004; J. D. Sterman, 2000b). In addition, the strength of the causal relationship is determined (A. J. Jetter \& Kok, 2013).

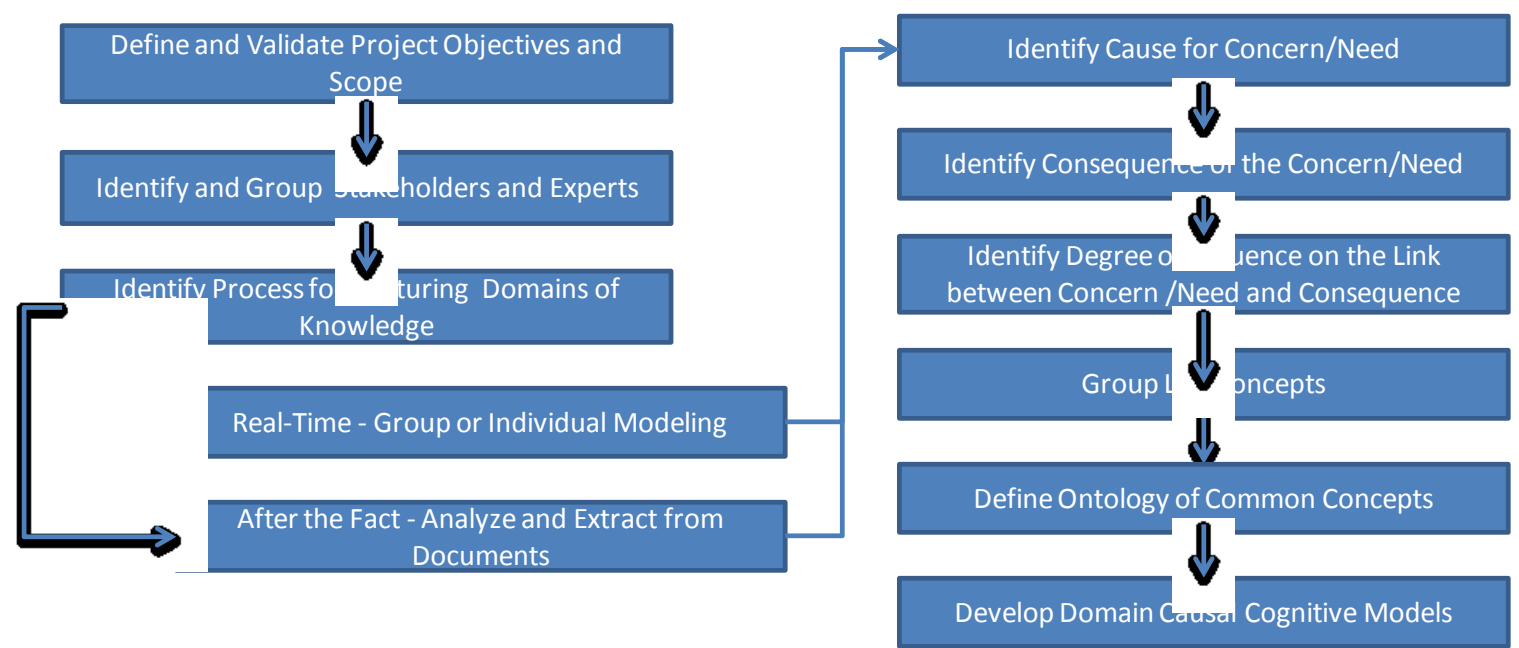

Figure 10: Methodology for Knowledge Capture \& Developing Causal Cognitive Maps

Once the domains of knowledge are captured, it is necessary to establish a common or shared meaning across multiple and often disparate stakeholder and expert concepts (A. J. Jetter \& Kok, 2013). The methodology groups like concepts within the domain of knowledge and then defines them(Bryson, et al., 2004; Uygar Özesmi \& Özesmi, 2004). Specific domain concepts are then translated into the common ontology, thereby establishing their exact meaning when comparing and contrasting stakeholder and expert views. 


\subsubsection{Libby to Troy Knowledge Capture}

\subsubsection{Stakeholder Identification and Knowledge Capture: Scoping Phase}

The Libby to Troy case study extracted stakeholder and expert perceptions from public documents. The research initially used an exploratory approach that draws out concepts and their semantics from the publically available documents (1992). The reason is that the researcher is not familiar with the specifics of the transmission upgrade project.

BPA conducted a series of town hall meetings where stakeholders voiced their concerns and could ask questions to BPA about the project. All town hall comments were documented in the form of meeting minutes by BPA. Alternatively, stakeholders could speak to a BPA associate and comment on their concerns and/or ask questions. These comments were documented in the form of an email. Furthermore, stakeholders could submit their issues or questions using BPA's website, or send them to BPA via mail or fax. These comments are contained in 58 documents that are listed in Appendix B Documents Used. In addition, the Confederated Salish and Kootenai Tribes comments were documented in an appendix of the draft EIS.

The next step is to identify stakeholder groups and then associate stakeholders with a specific group. Stakeholders submitted their comments with either contact information, geographic information about the area where they are affected by the transmission alternative, or the organization the stakeholder was affiliated with. Although there is no specific method for grouping stakeholders, research has shown that grouping of 
stakeholders was based on like characteristics (Fran Ackermann \& Eden, 2011;

Mouratiadou \& Moran, 2007; Uygar Özesmi \& Özesmi, 2004). Using this as the basis, the research identified three main stakeholder groups: residents, businesses, and government entities.

\begin{tabular}{|c|c|}
\hline STAKEHOLDER GROUPS & GROUP CHARACTERISTICS \\
\hline Pipe Creek Residents & $\begin{array}{l}\text { - Between mile markers } 17 / 13 \text { and } 18 / 11 \text {. } \\
\text { - } \quad \text { Thisting } 115 \mathrm{kV} \text { line is south of these residents. } \\
\text { of existing residents; however, the proposed realignment } \\
\text { line would cross through several properties. }\end{array}$ \\
\hline $\begin{array}{l}\text { Bighorn Terrace } \\
\text { Residents }\end{array}$ & $\begin{array}{l}\text { - Large subdivision between mile marker } 19 / 5 \text { and } 21 / 5 \\
\text { - Existing } 115 \mathrm{kV} \text { line runs through the subdivision and many } \\
\text { bought their property accepting these circumstances. } \\
\text { - The Quartz Creek realignment would move the existing line } \\
\text { north of the subdivision, thereby removing the structures } \\
\text { and giving back to those residents the use of their land } \\
\text { currently encumbered by the Row. }\end{array}$ \\
\hline Residents at Large & $\begin{array}{l}\text { - Span of the existing transmission line north or south of the } \\
\text { Kootenai River road } \\
\text { - Do not reside in the Bighorn Terrace or Pipe Creek }\end{array}$ \\
\hline Local Business & $\begin{array}{l}\text { - Established businesses whose locations are within the span } \\
\text { of the entire project area }\end{array}$ \\
\hline City of Libby & $\begin{array}{l}\text { - City of Libby represents a local government whose interest } \\
\text { is associated city owned land. } \\
\text { Entities whose services are affected by the transmission } \\
\text { line, such as the Fire Department. }\end{array}$ \\
\hline State of Montana & $\begin{array}{l}\text { - State government whose interests are associated with state } \\
\text { own land. } \\
\text { Entities whose services are affected by the transmission } \\
\text { line, such as the state recreational parks and services. }\end{array}$ \\
\hline Federal Government & $\begin{array}{l}\text { - City of Libby represents a local government whose interests } \\
\text { are associated with city owned land. } \\
\text { Entities whose services are affected by the transmission } \\
\text { line, such as the Fire Department. }\end{array}$ \\
\hline Tribal Community & $\begin{array}{l}\text { - Confederated Salish and Kootenai Tribes have interests and } \\
\text { concerns within the project area, primarily the Kootenai } \\
\text { River and Pipe Creek realignment. }\end{array}$ \\
\hline
\end{tabular}

Table 10: Stakeholder Groups Characteristics 
(Note: In the scoping, Pipe Creek residents, Bighorn Terrace residents, residents at large, state of Montana and tribal communities were identified. The city of Libby and the US Federal Government were identified as two new stakeholder groups after the Draft EIS was released - see section 6.6 for details).

These groups were further refined based on project geographical interest as shown in Table 10. Pipe Creek residents were primarily concerned with how the right-of-way (ROW) from either $115 \mathrm{kV}$ or $230 \mathrm{kV}$ and access roads would affect privacy, views, property values, recreational activities, bald eagles, construction noise and sediment in the Pipe Creek. Bighorn Terrace residents had similar interests as Pipe Creek residents but were also concerned about land use, electromagnetic fields (EMF) health issues, safety as well as the cultural impacts and views associated with the Kootenai River. However, Bighorn Terrace was in favor of moving the line to the top of the mountain in the Quartz Creek areas because it removes the existing line from their residential area. Residents were scattered at large across the project area. Their concerns such as safety, noise, fires, and the scenic views were associated with clearing of sites from the construction of $230 \mathrm{kV}$, as well as safety to aircraft from the larger towers. Local businesses were primarily concerned with the effects of the construction of the new structures on wildlife, views and safety. The city of Libby was concerned with potential fires from downed power lines (they did not comment during the scoping phase). The state of Montana had various concerns depending on whether it was $115 \mathrm{kV}$ or $230 \mathrm{kV}$. They were concerned about the toxicity of removing the existing poles. They were also 
concerned about how the new ROW associated with $230 \mathrm{kV}$ or the realignments would affect wildlife, naturalness of the areas, views along HW2 and cultural resources. Furthermore, they were concerned with EMF or GPS reception from the 230kV lines. Finally, they were in favor of moving the lines out of the Bighorn Terrace residential area because it increased the property values and returned the land back to the owners. The federal government was primarily concerned with the sediment, water quality, wetland functions, avian community, and aquatic life resulting from the construction of either the $115 \mathrm{kV}$ or $230 \mathrm{kV}$ lines and Kootenai River realignment. The tribal communities had cultural interests in Kootenai Falls and Pipe Creek areas.

Figure 11 pictorially depicts the stakeholder areas of interest geographically in relationship to the project. The smaller ovals in Figure 11 represent specific areas of interest, whereas the larger oval represents the entire project area.

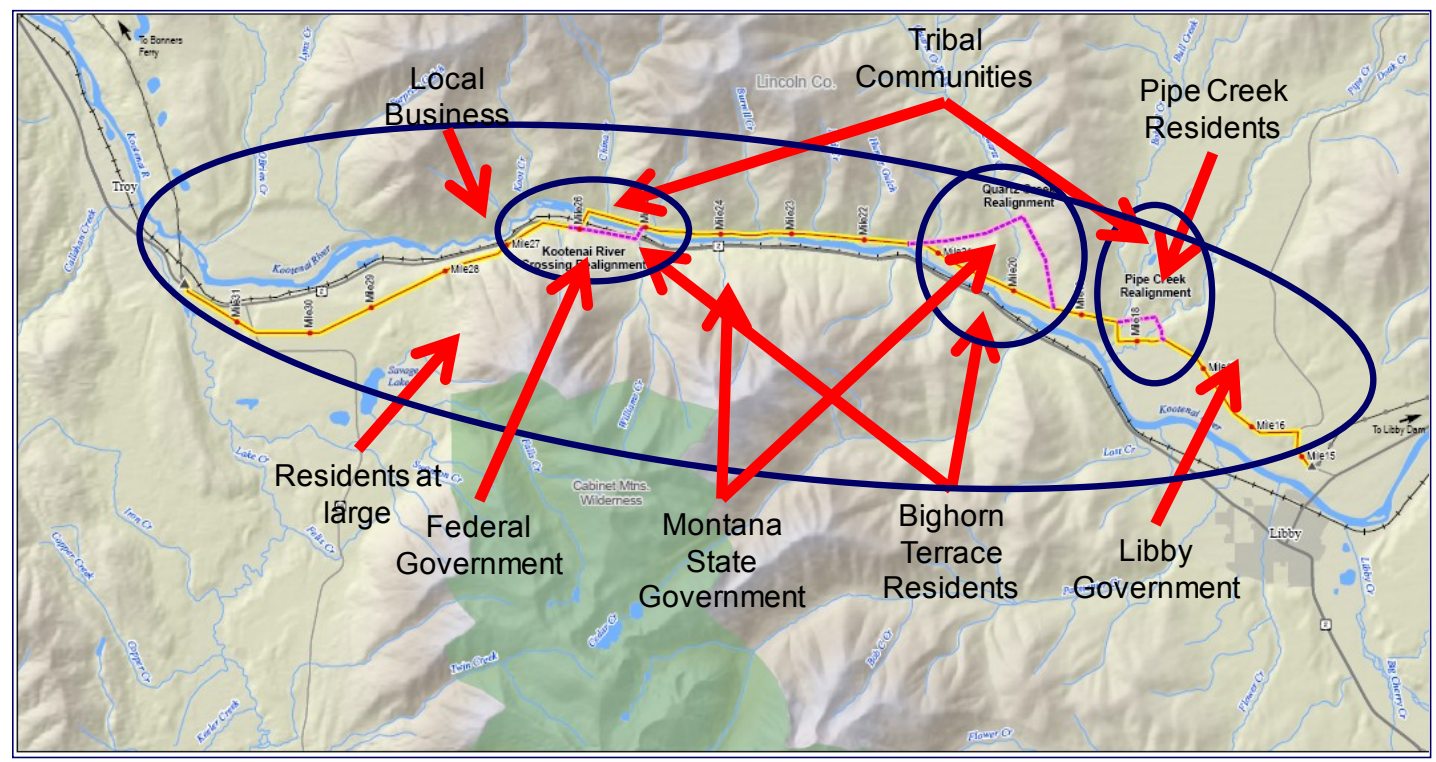

Figure 11: Stakeholder Groups' Interests 
There were times when the stakeholder did not provide their affiliation to a particular residential area. Therefore, the research used the address of the stakeholder to locate the stakeholder geographic location using a mapping tool such as Zillow.com or Google Maps, as shown in Figure 12. Between the two methods, it was not necessary to ask BPA resources, which group the stakeholder, belonged to.

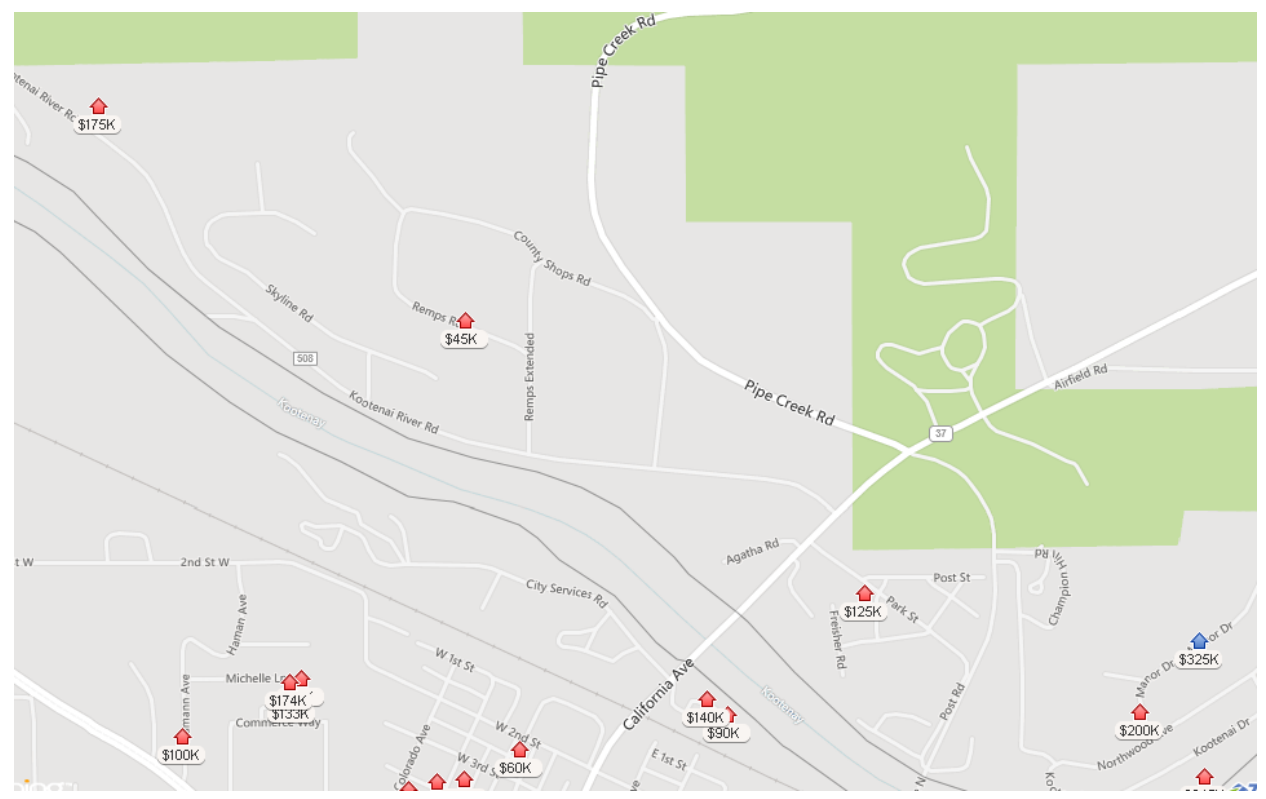

Figure 12: Stakeholder Map

Capturing the stakeholder concerns involved reading the comments and interpreting the causal concepts and the effect concepts. Figure 13 is a snippet from one of the stakeholders. This stakeholder indicates it is best to build the $230 \mathrm{kV}$ line in anticipation of future use. Furthermore, they were concerned about the "width of the easement for the power line" and "how the clearing of the land for the power line and roads to access the power lines" would attract people who used the area for parties or hunting. This situation could cause fires, the firing of stray bullets, and an increase of noise. 


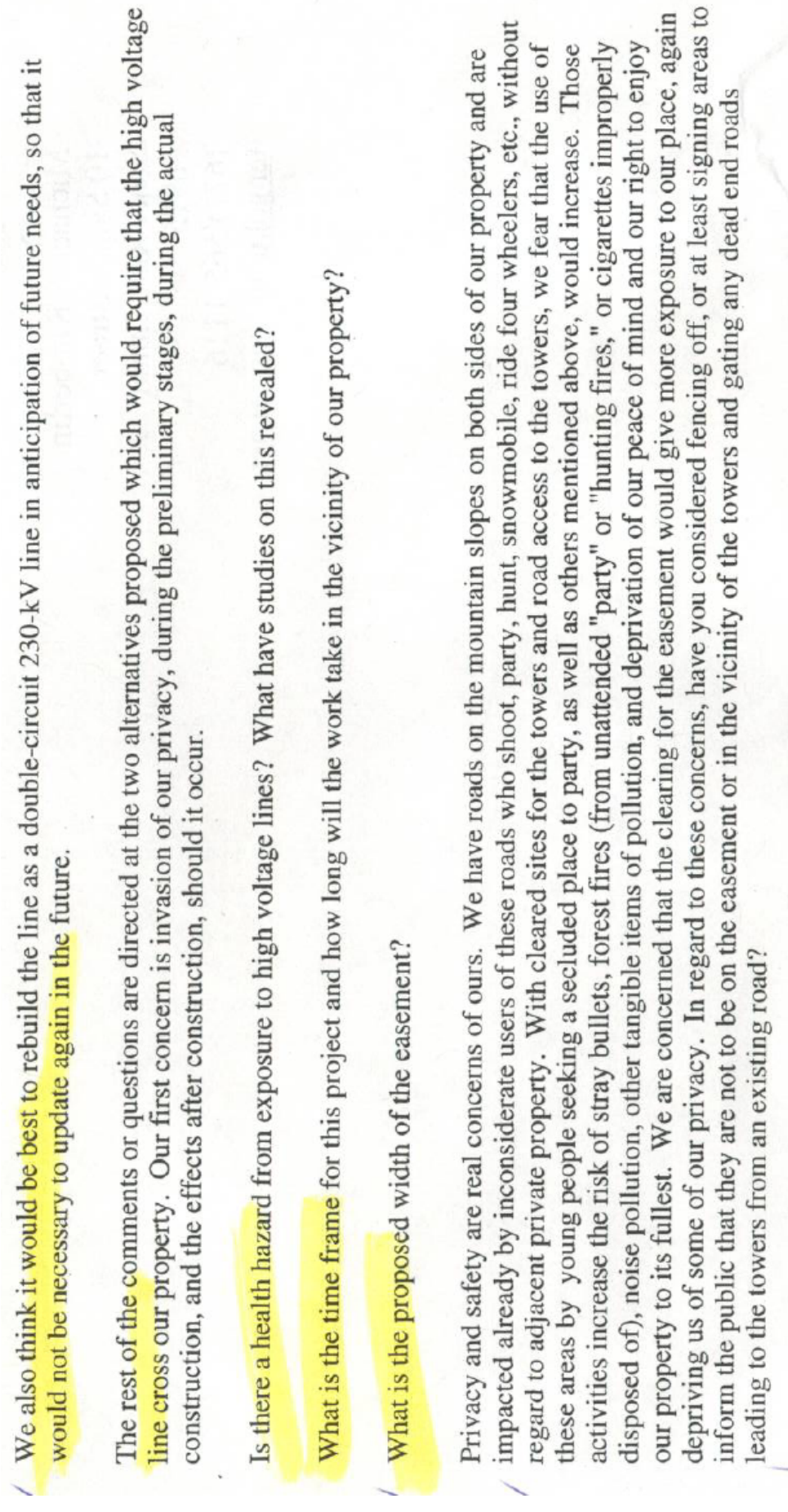

Figure 13: Textural Document Snippet of Stakeholder Concerns and Needs 
All stakeholder concerns were captured in their own words in a data repository using Microsoft Excel, as depicted Table 11. The document ID is the primary reference for traceability back to the original document. In the situation where no document ID was available, the stakeholder name and date of the document served as the reference.

\begin{tabular}{|c|c|c|c|c|c|c|}
\hline Stakeholder Group & Stakeholder & $\begin{array}{c}\text { Doc } \\
\text { ID }\end{array}$ & $\begin{array}{c}\text { Date } \\
\text { Received }\end{array}$ & Cause Concept & Causal & Effect Concept \\
\hline Pipe Creek Residents & Lena Whitson & LTS-018 & $7 / 27 / 2005$ & $230 \mathrm{KV}$ & + & future use \\
\hline Pipe Creek Residents & Lena Whitson & LTS-018 & $7 / 27 / 2005$ & alternatives & + & cleared sites \\
\hline Pipe Creek Residents & Lena Whitson & LTS-018 & $7 / 27 / 2005$ & cleared sites & + & $\begin{array}{l}\text { inconsiderate } \\
\text { users }\end{array}$ \\
\hline Pipe Creek Residents & Lena Whitson & LTS-018 & 7/27/2005 & $\begin{array}{l}\text { inconsiderate } \\
\text { users }\end{array}$ & + & stray bullets \\
\hline Pipe Creek Residents & Lena Whitson & LTS-018 & $7 / 27 / 2005$ & $\begin{array}{l}\text { inconsiderate } \\
\text { users }\end{array}$ & + & Fires \\
\hline Pipe Creek Residents & Lena Whitson & LTS-018 & $7 / 27 / 2005$ & $\begin{array}{l}\text { inconsiderate } \\
\text { users }\end{array}$ & + & noise \\
\hline
\end{tabular}

Table 11: Data Repository for Stakeholder Concerns and Needs

The research did not have direct access to stakeholders; therefore, the process of inferring the degree of influence was not possible. A practical approach to dealing with this issue was to assign only a positive or a negative and not infer any degree of influence from the text (B. Kosko, 1988), as shown in the casual relationship column in Table 11 


\subsubsection{BPA Expert Knowledge Capture: Draft EIS Phase}

During the draft EIS phase, BPA experts had identified the consequences resulting from each alternative as either an impact or benefit to the environment, society, and the economy. BPA interests spanned the entire project area and also included the stakeholder concerns and needs documented in the scoping comments, as defined in Table 12. The description of the characteristics are adapted from the draft EIS (Bonneville Power Administration, 2007). The extraction process was similar in nature as to stakeholder comments, but differed in several ways. First, the extraction process captured the text describing the impact of the alternatives: replacing the existing $115 \mathrm{kV}$ line, replacing the existing $115 \mathrm{kV}$ line with a $230 \mathrm{kV}$, and three realignment options: Pipe Creek, Quartz Creek and Kootenai River. The experts defined the degree of influence as either harmful effect to the environment/society or as a benefit. A negative causal relationship was determined if the causal concept increased harmful impact, such as more construction of structures that caused more soil destruction. A positive causal relationship was given if the causal concept increased the effect such as $230 \mathrm{kV}$, causing a wider ROW or creating a benefit. The experts used a Likert scale of high, medium to high, medium, low to medium, and low to describe the harmful effect to the environment/society or as a benefit effect. The research converted these fuzzy values into edge weights of "0.9" (high), "0.7" (medium high), "0.5" (medium), "0.3" (medium low), "0.1" (low). The reasoning for these values was based on equal distance between 
each value. Furthermore, " 0 " is no impact and " 1 " is destruction (total impact), of which none was found by the experts.

The impacts identified by the experts were captured and documented in a data repository using Microsoft OneNote. The experts defined the impacts according to 17 EIS areas, as defined in Table 12.

\section{CHARACTERISTICS}

\section{EIS AREAS}

1. Soil Disturbance and Erosion Quality
- Construction activities affect the soils due to ground surface and subsurface soil disturbance, soil compaction, and vegetation removal.

- Soil disturbances can increase soil erosion and mass movement, and could alter soil productivity and physical characteristics associated with soils.

- Construction activities could increase runoff, which could impair water quality.

- Increased runoff into streams could also increase bank erosion and scouring, which would also increase sedimentation.

- Soil erosion can increase sediment into streams.

- Sediment can cause a decrease in water quality.

3. Water Quantity

- Sediment can cause an undesirable increase in water quantity.

4. Land Use

- $\quad$ Land potentially affected by the proposed project is currently owned by the Kootenai National Forest, Confederated Salish and Kootenai Tribes, the state of Montana, Lincoln County, the city of Libby, private timber companies, and other private landowners.

- $\quad$ Existing land uses within the project area include residential, commercial (federal and private timber production), industrial, recreational, tribal, and resource protection for wildlife habitat and cultural resources.

5. Vegetation

- Removal of existing and construction of new structures affects endangered, forest sensitive plants, old growth and noxious weeds as well as for the common vegetation.

- $\quad$ Right-of-way and the existing and proposed access roads can affect the viability of sensitive plants and the potential for spread of noxious weed. 
6. Wetland

7. Floodplains

8. Wildlife
- Wetlands can be biologically productive and help maintain or improve water quality, contribute to flood control, provide wildlife habitat, and have recreational or aesthetic value.

- Removal of existing and building of new structures located in the Pipe Creek, Bobtail Creek, and Kootenai River floodplains.

- Removal of existing and building of new structures across lands that provide habitat to a wide variety of wildlife.

- Several species known to occur in the vicinity of the transmission line are considered to have a special status protected under the Endangered Species Act (ESA) of 1973, being listed under federal or state laws or having a special designation under the Kootenai National Forest Plan or as assigned by the regional forester.

9. Fish, Amphibians and Reptiles

- Removal of existing and building of new structures crosses the following fish bearing streams: Pipe Creek, Bobtail Creek, Quartz Creek, China Creek and the Kootenai River.

- Several species known to occur in the vicinity of the transmission line are considered to have a special status protected under the Endangered Species Act (ESA) of 1973, "Forest Sensitive" by the USFS Regional Forester, and as a "Species of Concern" or "Species of Greatest Concern" by the State of Montana.

10. Visual Resources

- The new structures cross or obstruct natural features, including mountains, massive rock outcrops, and valley bottoms.

11. Cultural Resources

- Cultural resources are related to American history, architecture, archaeology, engineering, and culture, and they are nonrenewable.

- They are characterized as prehistoric, pre-dating European settlement.

12. Recreational Resources

13. Noise

- Noise is unwanted sound that disrupts normal human activities or diminishes the quality of the human environment.

- Noise is characterized as transient (short duration), stationary (long duration) and ambient (typical of the area). 
14. Public Health and Safety

15. Social and Economic Resources

16. Transportation
- Transmission facilities and lines can potentially harm if not kill humans if contact is made.

- Structures could interfere and harm aircraft.

- Transmission lines produce and emit electric and magnetic (EMF) voltage.

- Toxic and hazardous waste associated with removal of existing structures and maintenance of corridors.

- Removal and building of transmission lines could impact local business due to construction; however, it could improve the economy with housing and other business services such as retail.

- Social conditions include public services supported by the tax base and property values.

- Removal of existing and building of new structure require improvements to existing access roads and building of new roads.

- Construction could affect traffic on local roads, airports and railroads.
- Construction equipment to remove existing and build new structures and roads emits air pollutants.

\section{Table 12: EIS Areas}

\subsubsection{Development of Causal Cognitive Maps Using Common Ontology}

The goal for the research is to create individual stakeholder group and BPA expert causal cognitive maps. Research commonly captures individual stakeholder perceptions in causal cognitive maps (A. J. Jetter \& Kok, 2013; Mouratiadou \& Moran, 2007; Uygar Özesmi \& Özesmi, 2004) when conducting individual or group modeling sessions or extracting from text (K. M. Carley, 1997; Nakamura, et al., 1982; Taber, 1991). These individual cognitive maps are then integrated into a stakeholder group causal cognitive map. However, individual comments within a group represent a partial view of the overall problem and most likely represent only how the alternative affects them 
individually; therefore, stakeholder perceptions are more than likely to vary from one another (B. Kosko, 1988). Given that 58 documents were used in the scoping phase, this would result in 58 individual causal cognitive maps, where many of them would vary by four or five concepts. Furthermore, stakeholders and experts, for the most part, documented their concerns and needs using different terminology. As a result, it was necessary to establish common semantics for the various concepts.

A review of the stakeholder concepts determined that their cause-and-effect concepts were represented by the expert's concepts; therefore, the expert's concepts became the basis for the common ontology. All stakeholders' concepts were translated to the common ontology (see Appendix D - Common Ontology for all the concepts). As shown in Table 13, the common cause concept and common effect concept columns represent the translation. The concepts "Stray Bullets" and "Fires" were translated as "General Safety, Fire and Injury," which is an EIS area. Because of this change, the causal relationship between "Inconsiderate Users" and "General Safety, Fire and Injury" was decreased. Furthermore, the gray-filled cells indicate there was no translatable concept from the expert's view; therefore, these concepts were added to the common ontology. This method established consistency in the cognitive maps. 


\begin{tabular}{|c|c|c|c|c|c|c|}
\hline Stakeholder Group & Stakeholder & $\begin{array}{c}\text { Doc } \\
\text { ID }\end{array}$ & $\begin{array}{c}\text { Date } \\
\text { Received }\end{array}$ & $\begin{array}{c}\text { Common Cause } \\
\text { Concept }\end{array}$ & Causal & $\begin{array}{c}\text { Common Effect } \\
\text { Concept }\end{array}$ \\
\hline Pipe Creek Residents & Lena Whitson & LTS-018 & $7 / 27 / 2005$ & "Existing 230 KV" & + & future use \\
\hline Pipe Creek Residents & Lena Whitson & LTS-018 & $7 / 27 / 2005$ & "Existing 230 KV" & + & $\begin{array}{l}\text { "Vegetation } \\
\text { Clearing/Tree } \\
\text { Removal Soil } \\
\text { Disturbance" }\end{array}$ \\
\hline Pipe Creek Residents & Lena Whitson & LTS-018 & $7 / 27 / 2005$ & $\begin{array}{l}\text { "Vegetation } \\
\text { Clearing/Tree } \\
\text { Removal Soil } \\
\text { Disturbance" }\end{array}$ & + & $\begin{array}{l}\text { "Inconsiderate } \\
\text { Trespassers/Hunters/ } \\
\text { ORV" }\end{array}$ \\
\hline Pipe Creek Residents & Lena Whitson & LTS-018 & $7 / 27 / 2005$ & $\begin{array}{l}\text { "Inconsiderate } \\
\text { Trespassers/Hunters/ } \\
\text { ORV" }\end{array}$ & + & $\begin{array}{l}\text { "General Safety - Fire } \\
\text { and Injury" }\end{array}$ \\
\hline Pipe Creek Residents & Lena Whitson & LTS-018 & $7 / 27 / 2005$ & $\begin{array}{l}\text { "Inconsiderate } \\
\text { Trespassers/Hunters/ } \\
\text { ORV" }\end{array}$ & + & $\begin{array}{l}\text { "General Safety - Fire } \\
\text { and Injury" }\end{array}$ \\
\hline Pipe Creek Residents & Lena Whitson & LTS-018 & $7 / 27 / 2005$ & $\begin{array}{l}\text { "Inconsiderate } \\
\text { Trespassers/Hunters/ } \\
\text { ORV" }\end{array}$ & + & people nose \\
\hline
\end{tabular}

Table 13: Translation to Common Terms

The final step in the process was developing the stakeholder group and the BPA expert causal cognitive models. For the stakeholder group causal cognitive maps, the research used a tool called Mental Modeler, a cognitive mapping tool. By filtering the data repository using the stakeholder group column, only stakeholder comments that were affiliated to that group were available. The mapping process required only unique concepts; therefore, the next step was to sort the data by the common cause concept column, and then by the common effect concept column within the common cause concept. This made duplicate concepts obvious. Figure 14 depicts the cognitive map for the Pipe Creek Residents (see Appendix C - Cognitive Models for the other stakeholder and expert models). There are two alternatives: implementing the Pipe Creek realignment using either $115 \mathrm{kV}$ or $230 \mathrm{kV}$ voltage. These alternative concepts are on the 
left side. To the right of the alternatives is the network of cause and effects that result from each alternative. The degree of causal influence between the cause-and-effect concept is defined as either " + " or "-“. A " + " indicates there is an increase or beneficial value, and a "_" is a decrease or impact. For example, the Pipe Creek realignment 115kV caused the right-of-way (ROW) to be cleared of vegetation, thus increasing the number of inconsiderate trespassers, hunters or over-the-road (ORV) vehicles, which increased the noise from people.

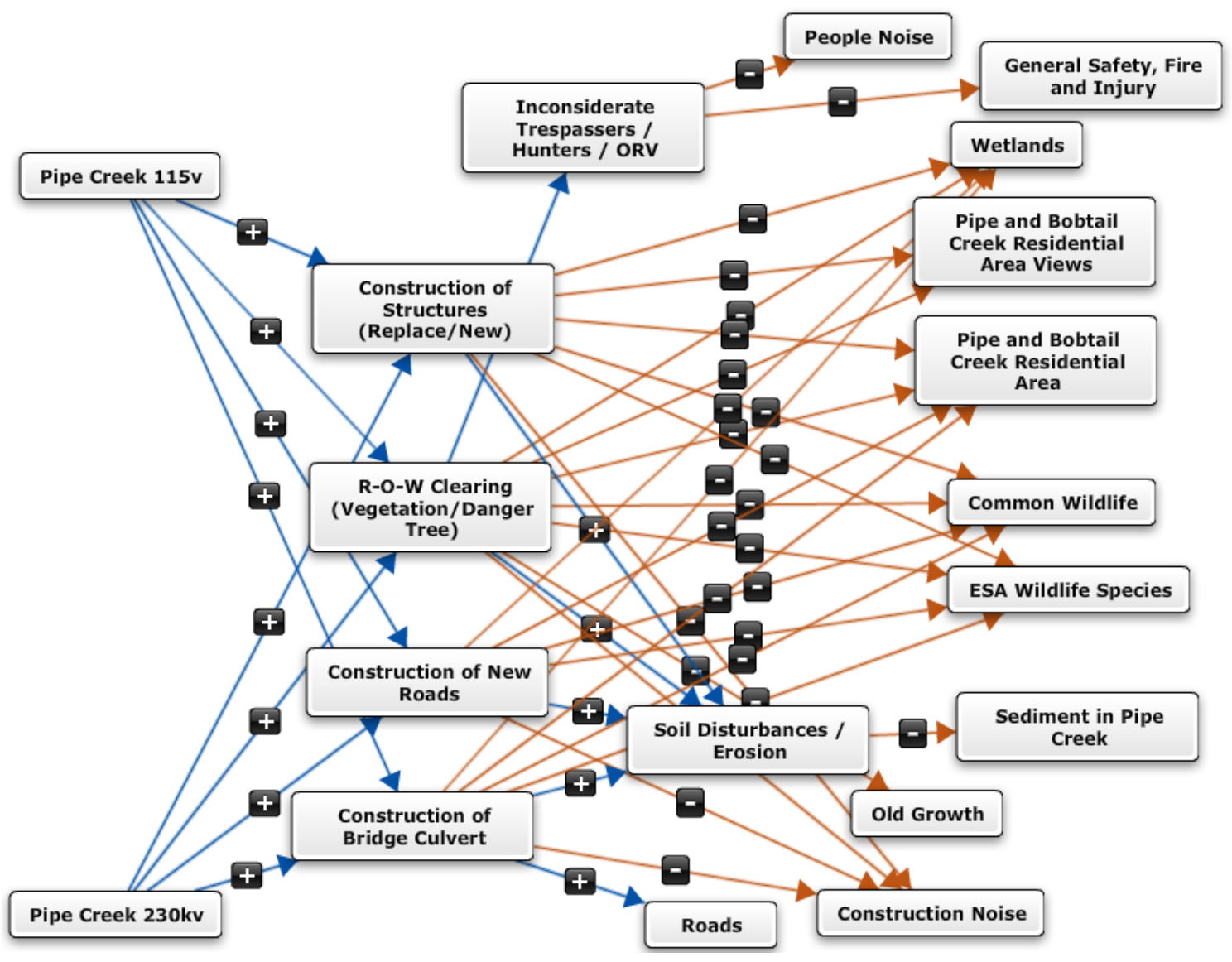

Figure 14: Pipe Creek Residents Cognitive Map 
The process for developing the expert cognitive map was different. The process used the Pajek social network analysis tool instead of Mental Modeler because it could not handle the number of concepts identified by the BPA experts. The process identified 93 cause-and-effect concepts for the 17 EIS. Figure 15 shows a subset of the entire cognitive map (see Appendix C - Cognitive Models for view).

Solid lines indicate an increase or beneficial value, and a dotted line indicates a decrease or impact. The eight alternative concepts are at the bottom, and the 17 EIS area concepts are at the top. In between are the networks of cause and effect concepts. Again, all eight alternatives are defined as transmitter concepts at the bottom. At the top are three EIS area concepts: Water Quantity, Soil Disturbances/Erosion and Sediment and Water Quality. Each alternative increases the ROW clearing, Construction of Structures, Construction of Staging Areas, Corridor Maintenance, Construction of Tensioning Areas, Construction of New Roads, Construction of Road Improvements, and Construction of Bridge Culverts. The construction activities cause soil disturbances and erosion and also impact creeks due to sediment. Corridor maintenance also impacts the creeks due to runoff of chemicals used to maintain the corridor. 


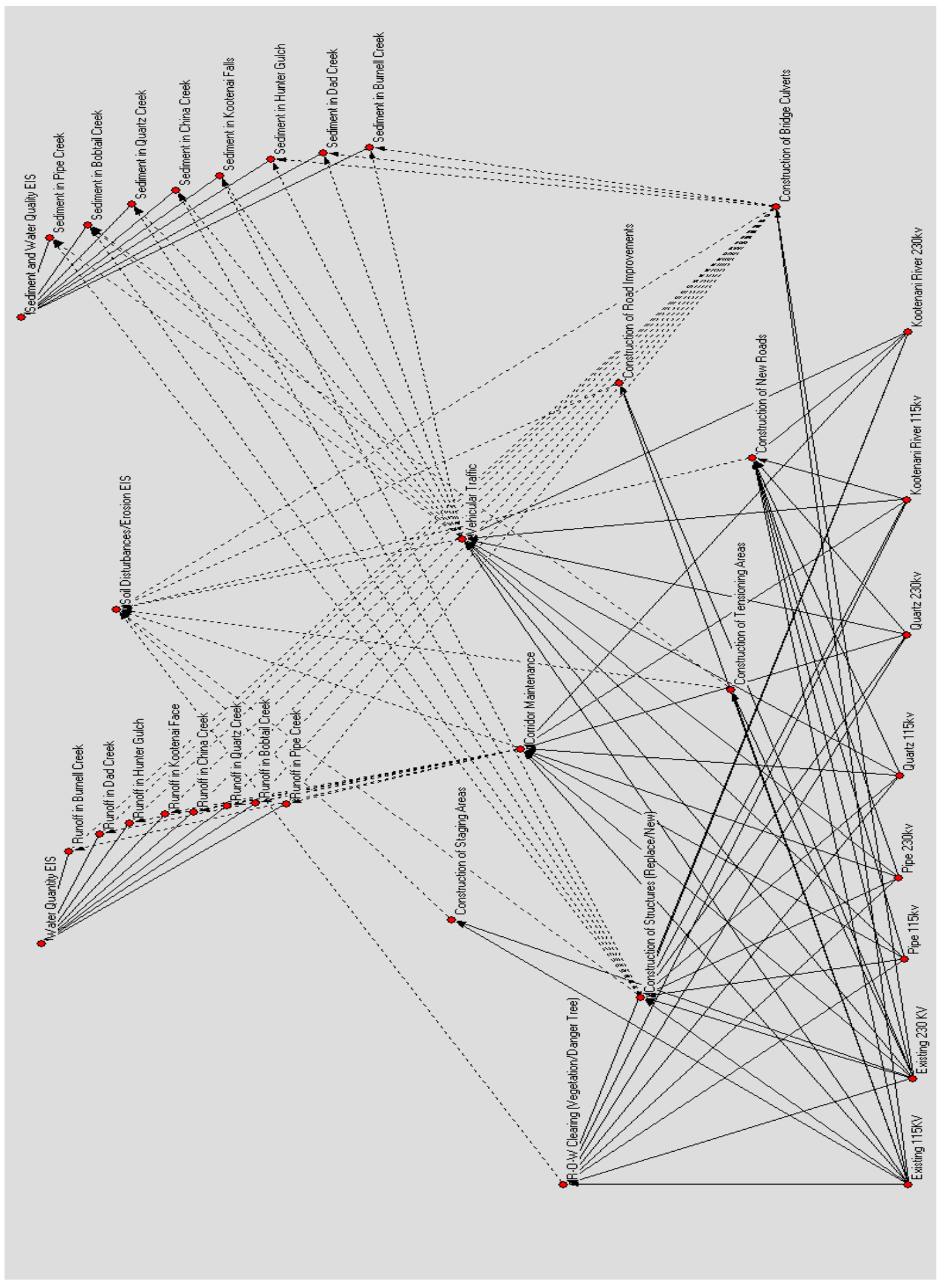

Figure 15: Three EIS Areas Define by the BPA Expert 


\subsection{TRanslate Cognitive MaPS in FCM Models}

\subsubsection{Methods for Translation to FCM Models}

Figure 16 depicts the methodology for translating causal cognitive maps into FCM models, which is the foundation for transparency and understanding stakeholder concerns and needs. This requires a model structure that is capable of evaluating value or desirability of the possible outcome of each decision alternative in the context of an objective. Cognitive models have been used successfully to assess strategic goals (Bryson, et al., 2004) and have been translated into FCM models to assess the environmental impacts of product development alternatives (A. J. Jetter \& Sperry, 2013).

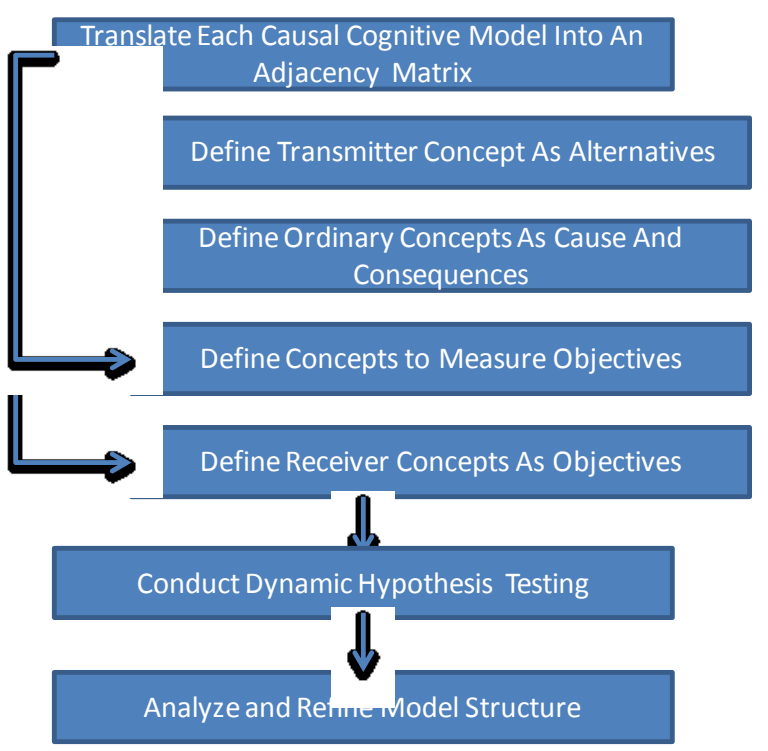

Figure 16: Methodology for FCM Modeling

Structural elements of the FCM model include transmitter concepts for the alternatives, ordinary concepts for the network of cause-and-effect concepts, and receiver concepts 
for objectives. This structure allows for toggling alternatives on and off to assess the impacts through a network of cause-and-effect concepts in a non-linear function that transfers the weighted input into output values using a squashing function directed to the objectives. Dynamic hypothesis testing is used to validate the structure of the model, which is described in detail in section 3.4.1.1. A thorough analysis of the results will determine whether the model needs to be refined due to concepts and causal links that created computational problems as discussed in section 2.6.1.

\subsubsection{Development of Stakeholder and Expert FCMs}

All stakeholder and expert cognitive models were translated into an FCM to understand and evaluate the perceived desirability of the alternatives being considered by BPA and the consequences (positive or negative) on stakeholders. In all there were seven FCM models for the scoping/draft EIS phases (6 stakeholders and 1 expert) and nine FCM models for the final EIS phase (8 stakeholders and 1 expert).

The first step was to convert each cognitive causal map into a weighted adjacency matrix as discussed in section 2.6.1. All FCMs were built using a common structure of concepts. As discussed in section 5, two objectives at the very left are related to the decision-making in the context of this research. Also discussed in section 5 , the project needs to evaluate eight alternatives. The preferred alternative is replacing the existing $115 \mathrm{kV}$ transmission line. Under this alternative, BPA would make use of the existing corridor and replace the deteriorating $115 \mathrm{kV}$ single circuit wood structure with a similar 
single circuit wood $115 \mathrm{kV}$ structure in the same place. Alternatively, BPA could replace the $115 \mathrm{kV}$ with a $230 \mathrm{kV}$ transmission line. This requires removing the old $115 \mathrm{kV}$ single circuit structure with a larger $230 \mathrm{kV}$ double circuit steel structure. Because of the size of these structures, the capacity to support the transmission cable required fewer structures than the $115 \mathrm{kV}$ alternative; but a wider corridor is needed. In addition to these two alternatives, BPA identified three re-alignment options: Pipe Creek, Quartz Creek and Kootenai River. Each of these realignments needed to consider new right-ofway easements for the corridor for either $115 \mathrm{kV}$ or $230 \mathrm{kV}$. In all, the project needs to evaluate eight alternatives.

As shown in Figure 17, each FCM contained eight alternatives that were structured as transmitter concepts. This allows for toggling alternatives on and off to assess the impacts though a network of cause-and-effect concepts in a non-linear fashion that transfers the weighted input into output value using a squashing function. The causeand-effect concepts were comprised of the 97 concepts in the common ontology (94 concepts that were identified in scoping/draft EIS phases and an additional three more were identified in final EIS). These concepts were represented as a network of ordinary concepts that included feedback loops. Finally, two objective concepts, Minimize Environmental Impact and Minimize Cost, were structured as receiver concepts. 


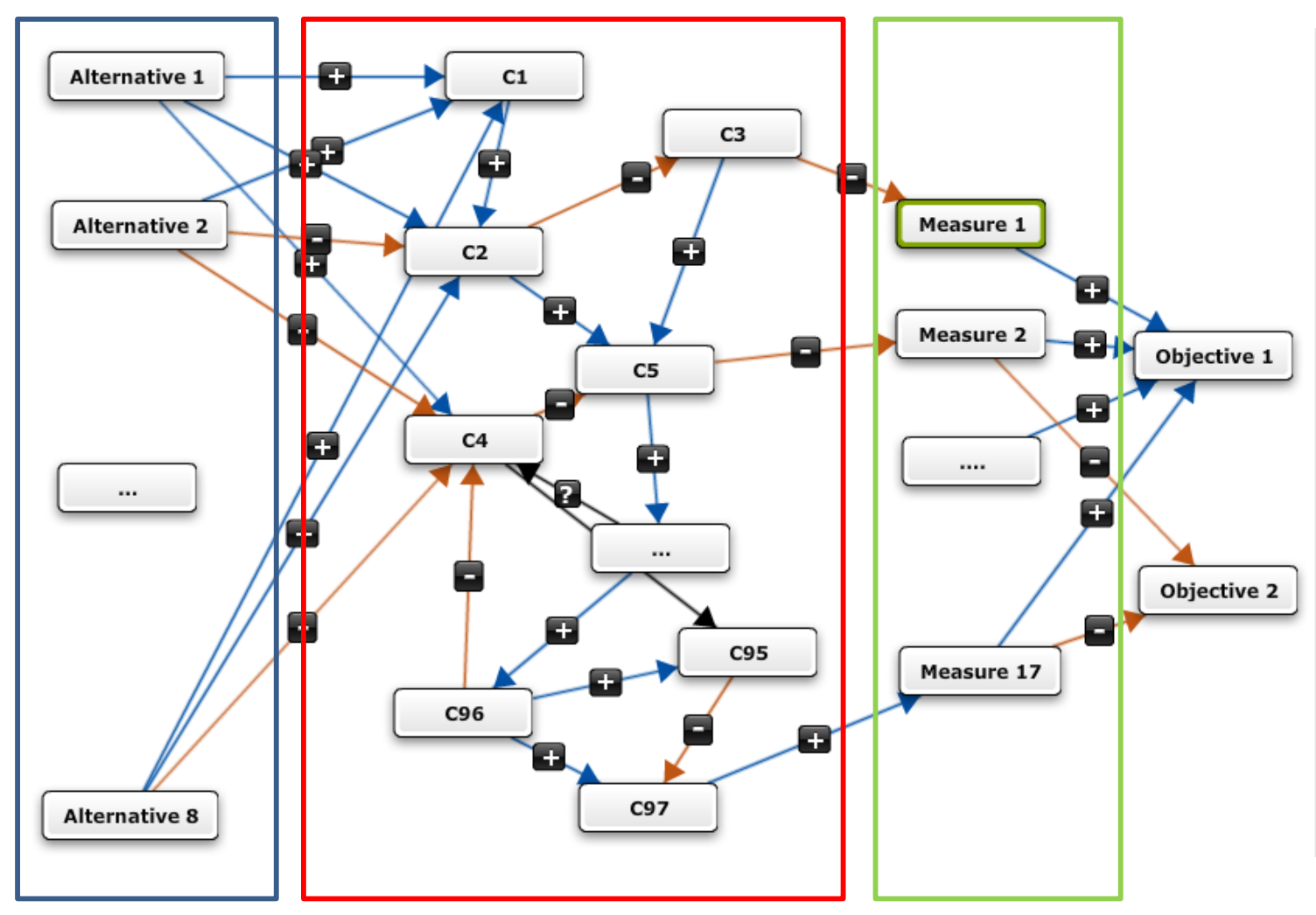

Figure 17: Common FCM Structure

The research assumed decision-making is based on two premises. The first premise is that more than one criterion may be used to evaluate the objective for each alternative. The second premise assumes that the stakeholder and expert may share the same interests (symmetrical) or they may be in conflict (asymmetrical); therefore, it is assumed that the criteria used to measure and evaluate the stakeholder or expert's desirability of the possible outcome of each decision alternative will also vary. The model handled these two assumptions by establishing the 17 EIS areas defined in Table 12 as the criteria concepts used to measure the objective. The causal assertions represented by the 94 concepts were the input into the 17 EIS area concepts. The eight 
stakeholders and one expert were each modeled in their own FCM, thereby preserving individual interest.

The analysis and refinement of the models was done in tandem with the dynamic hypothesis using FCM simulation. The common structure used in all FCM models facilitated consistency in measuring the objectives, and the dynamic hypotheses served as the basis for validating the internal structure. To ensure inclusiveness for the objective concepts, it was necessary to synchronize EIS area concepts so that they fire at the same time. As result, the model included a dummy concept to synchronize the firing.

The stakeholder group models were tested to assure that causal relationships and structure matched cognitive models. The BPA expert model was tested in accordance with the record of decisions regarding the reasoning for selecting the alternative (reference Appendix D - Common Ontology for details). The input vector determined which alternative is to be tested. The alternatives were defined as the first eight concepts. To test replacing the $115 \mathrm{kv}$ alternative and no realignment options, a "1" was placed in the input vector to activate the "Existing $115 \mathrm{kV}$ " concepts as shown in Figure 18 , and all other concepts were set to zero. Furthermore, the concept was clamped by placing the "fix" into the state vector. This would simulate the project activities that took place over the duration of time, not just a one-time event. When testing the three 115kV realignment alternatives (Pipe Creek, Quartz Creek and Kootenai River) a "1" was 
placed in the input vector for the specified alternative, while leaving $115 \mathrm{kv}$ at " 1. " The same process was used for testing $230 \mathrm{kV}$ and its three realignment alternatives. The hyperbolic tangent sigmoid threshold squashing function was used for testing the four hypotheses.

FCM Model

write 'fix' to clamp concept

Startvector (shows start states of conce

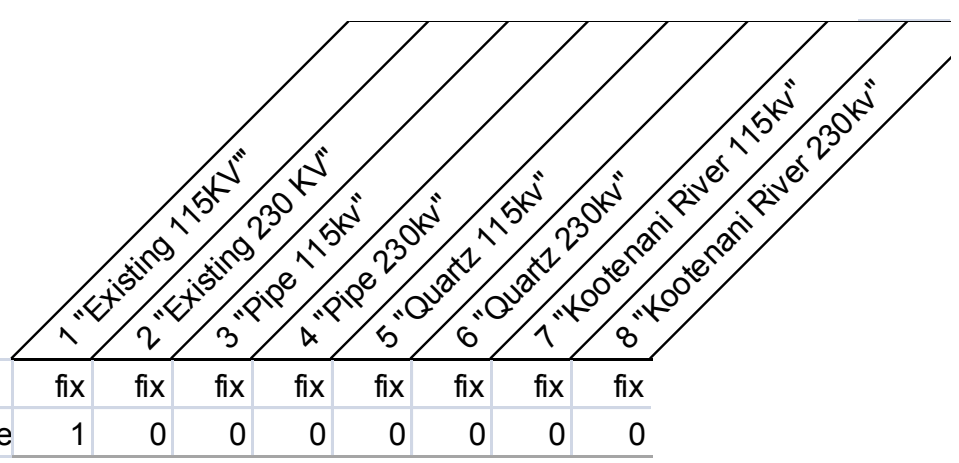

Figure 18: Input Vector

The first hypothesis viewed the proposed $115 \mathrm{kV}$ as the most environmentally friendly of all the alternatives because it was replacing structures within the existing ROW. Furthermore, there are impacts from widening right-of-way (ROW), improving existing access roads and constructing new roads. To test this hypothesis, two scenarios were executed: replacing the existing $115 \mathrm{kV}$ and $230 \mathrm{kV}$. As shown in Table 14 , the $115 \mathrm{kV}$ voltage has less of an impact than the $230 \mathrm{kV}$ voltage. A negative value represents an impact, and a positive value represents a benefit - the closer to "- 1 " the greater the impact, and the closer to "1" the greater benefit. 


\begin{tabular}{|c|c|c|}
\hline ALTERNATIVE & 115kV & $230 \mathrm{kV}$ \\
\hline Environmental Impact from Existing Corridor & -0.20 & -0.27 \\
\hline Environmental Impact from Existing Corridor plus Pipe Creek & -0.26 & -0.33 \\
\hline Environmental Impact from Existing plus Corridor Quartz Creek & -0.27 & -0.33 \\
\hline $\begin{array}{l}\text { Environmental Impact from Existing Corridor plus Kootenai } \\
\text { River }\end{array}$ & -0.24 & -0.3 \\
\hline
\end{tabular}

Table 14: Environmental Impact Dynamic Hypothesis

There are two primary factors regarding why the degree of interest appears to be minimal (e.g., -0.20 versus -0.27 ). First, there are many concepts that are input into the EIS concepts, and each concept has equal weighting. For example, if there were five concepts, each concept would contribute "0.2" weight. Secondly, the 17 EIS concepts are also equally weighted; therefore, each EIS area contributes "0.6" to the objective. Nonetheless, the outcome can still predict the desirability.

In the second hypothesis, BPA indicated that the Pipe Creek alternative would have greater impacts on the soil and water resources, land use, vegetation (old growth trees and weeds), wetland, floodplains, wildlife, visual resources, and cultural resources than just building on the existing corridor. To test this hypothesis, two scenarios were executed: replacing the existing $115 \mathrm{kv}$ by itself and then testing the existing $115 \mathrm{kV}$ with the Pipe Creek 115kv alternative. As shown in Table 15, the Pipe Creek realignment does create more impact than just the $115 \mathrm{kV}$ alone. 


\begin{tabular}{|l|c|c|}
\hline \multicolumn{1}{c}{ RESOURCE } & 115kV & Pipe 115kV \\
\hline \hline Soil & -0.17 & -0.28 \\
\hline Water Resources & -0.12 & -0.19 \\
\hline Land-Use & -0.13 & -0.19 \\
\hline Old-growth trees/Vegetation & -0.18 & -0.23 \\
\hline Wetlands & -0.32 & -0.42 \\
\hline Floodplains & 0.11 & -0.19 \\
\hline Visual Resources & -0.29 & -0.35 \\
\hline Wildlife & -0.28 & -0.32 \\
\hline Cultural & -0.49 & -0.53 \\
\hline Noise & -0.20 & -0.31 \\
\hline Public Health and Safety & -0.10 & -0.19 \\
Air Quality & -0.16 & -0.25 \\
\hline \hline
\end{tabular}

Table 15: Pipe Creek Dynamic Hypothesis

In the third hypothesis, BPA indicated that the Quartz Creek alternative would have greater impacts on soil, land-use, old-growth trees, other vegetation, visual resources, wildlife and cultural resources. In addition, the construction creates noise and presents public health, safety, and air quality issues. To test this hypothesis, two scenarios were executed: replacing the existing $115 \mathrm{kv}$ by itself and then testing the existing $115 \mathrm{kV}$ with the Quartz Creek 115kv alternative. As shown in Table 16, the Quartz Creek realignment does create more impact than just the $115 \mathrm{kV}$ alone. 


\begin{tabular}{|l|c|c|}
\hline \hline \multicolumn{1}{|c|}{ RESOURCE } & 115kV & Quartz 115kV \\
\hline \hline Soil & -0.17 & -0.33 \\
\hline Water Resources & -0.12 & -0.19 \\
\hline Land-Use & -0.13 & -0.19 \\
\hline Old-growth trees/Vegetation & -0.18 & -0.23 \\
\hline Visual Resources & -0.29 & -0.26 \\
\hline Wildlife & -0.28 & -0.46 \\
\hline Cultural & -0.49 & -0.53 \\
\hline Noise & -0.2 & -0.31 \\
\hline Public Health and Safety & -0.10 & -0.19 \\
Air Quality & -0.16 & -0.25 \\
\hline \hline
\end{tabular}

Table 16: Quartz Creek Dynamic Hypothesis

In the fourth hypothesis, BPA indicated that the impacts would mainly come from the new transmission corridor and road clearing with Kootenai River alternative. A beneficial effect of removing the line crossing from the view shed of the Kootenai Falls, which is a culturally significant area, is voiding a new replacement bridge over China Creek. However, it would have adverse impacts on vegetation, wildlife, amphibians and visual resources. To test this hypothesis, two scenarios were executed: replacing the existing $115 \mathrm{kv}$ by itself and then testing the existing $115 \mathrm{kV}$ with the Kootenai River $115 \mathrm{kv}$ alternative. As shown Table 17, the Kootenai River realignment reduces the impact on cultural resource but creates more impact on other resources than just the $115 \mathrm{kV}$ alone, with the exception of visual resources, which was lessened. 


\begin{tabular}{lcc}
\hline \multicolumn{1}{c}{ RESOURCE } & 115kV & Kootenai River 115kV \\
\hline \hline Wildlife & -0.28 & -0.41 \\
Amphibians & -0.08 & -0.21 \\
China Creek & -0.15 & -0.14 \\
Visual resources -Kootenai Falls & -0.10 & 0.00 \\
Cultural & -0.49 & -0.44 \\
\hline \hline
\end{tabular}

Table 17: Kootenai River Dynamic Hypothesis

\subsection{FCM SIMULATION}

\subsubsection{Methods for FCM Simulation}

Figure 19 depicts the methodology for setting up and conducting simulation with FCM. FCM simulation supports the planning and decision-making process by assessing the positive and negative impacts of the eight alternatives on stakeholders and how these alternatives satisfy BPA's objectives ((A. J. Jetter \& Sperry, 2013; Mouratiadou \& Moran, 2007). Particularly, the process shows how stakeholders perceive the value or harm associated with the technology alternatives, how stakeholders share the same perceptions, and how strongly the perception of value or harm differs, and regarding what aspects about the alternatives over time (Brooks \& Harris, 2008; J. C. M. Van Eijndhoven, 1997). Furthermore, it shows how experts perceive the value or harm associated with the alternatives and how experts assess the value or harm of the alternatives for stakeholders (Glasson, et al., 1994). It also shows the degree to which expert and stakeholder perspectives are in support or in conflict with the project 
objectives, and the direct and indirect consequences associated with the decision (Hart \& Sharma, 2004; Linstone, 1999).

FCM simulation is predicated on the configuration of the plausible states in the initial input vector (A. J. Jetter \& Kok, 2013). The input vector triggers the activation of a network of causal relationships step-by-step until the FCM reaches a stable state. Furthermore, the choice of threshold squashing function controls the simulation to either a fixed state vector, called fixed-point attractor, or cycles between a number of fixed state values called a limit cycle (refer to equations 2, 3, and 4 section Step 2 - FCM Modeling for details.)

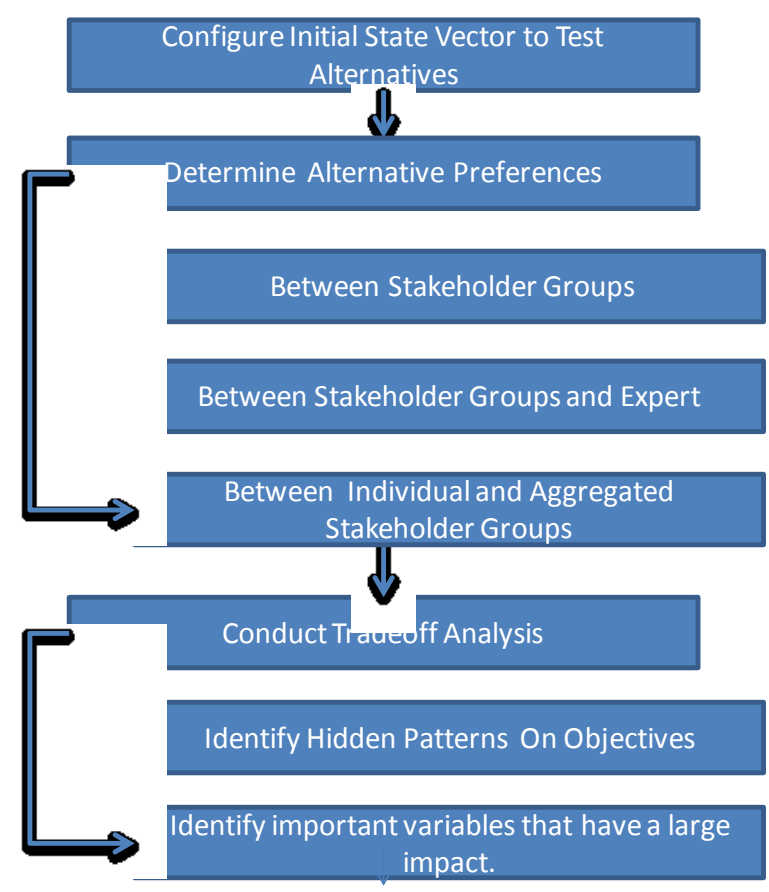

Figure 19: FCM Methodology for Simulation 
Conducting tradeoff analysis requires executing multiple scenarios that simulate the alternatives selected and interpreting the conclusions drawn from the hidden patterns in the resulting stable state in order to assess the impacts (B. Kosko, 1988). Centrality is a method drawn from structural analysis (Mouratiadou \& Moran, 2007; Uygar Özesmi \& Özesmi, 2004) that provides a quantitative approach for determining those concepts that influence the downstream concepts the most. Specifically, those concepts with the highest degree of "in-degree" and "out-degree" weights, that is, the summation of the concept's input arc edge weights (in-degree) and concept's output edge weights (out-

degree). For example, if concept 1 has three input arc-edge weights, "0.5," “0.7," and "0.3," the in-degree is "1.5." And if the concept provides input to three other concepts and those arc-edge weights are "0.2," "0.8" and "0.5," the out-degree is "1.5." Concept 2 has two input arc-edge weights, "0.5", and " 0.3 ", so the in-degree is "0.8." And if this concept provides input to three other concepts and those arc-edge weights are "0.2," "0.8" and "0.5," the out-degree is "1.5." When comparing the centrality between concept 1 , which is "3.0," and centrality for concept 2 is "2.3," concept 1 has more influence than concept 2.

\subsubsection{FCM Simulation for Libby to Troy}

\subsubsection{Analysis Between Stakeholder Groups}

The purpose of assessing alternative preferences between stakeholder groups is to understand how symmetrical and asymmetrical interests affect the perceptions of consequences associated with the eight alternatives. All stakeholder FCMs used the 
hyperbolic tangent sigmoid threshold squashing function for simulation. The FCM output in Table 18 shows the eight alternatives and how they impact the stakeholder groups. This table reflects both impacts identified in scoping and draft EIS comments (see section Identifying New or Changing Information for details below). Eight scenarios were executed for each stakeholder group, one for each alternative, for a total of 64 scenarios. The gray columns represent the initial state vector, and white columns indicate the desirability of the alternatives. The values produced by the FCM output are used to compare and contrast symmetrical and asymmetrical interest between stakeholders. The FCM output values range from a "-1" to " 1. " A positive value is viewed as a benefit, and a negative index value is viewed as a harmful impact. The higher the value the more desirable the alternative is to the stakeholder. Conversely, the lower the number, the less desirable the alternative is to the stakeholder.

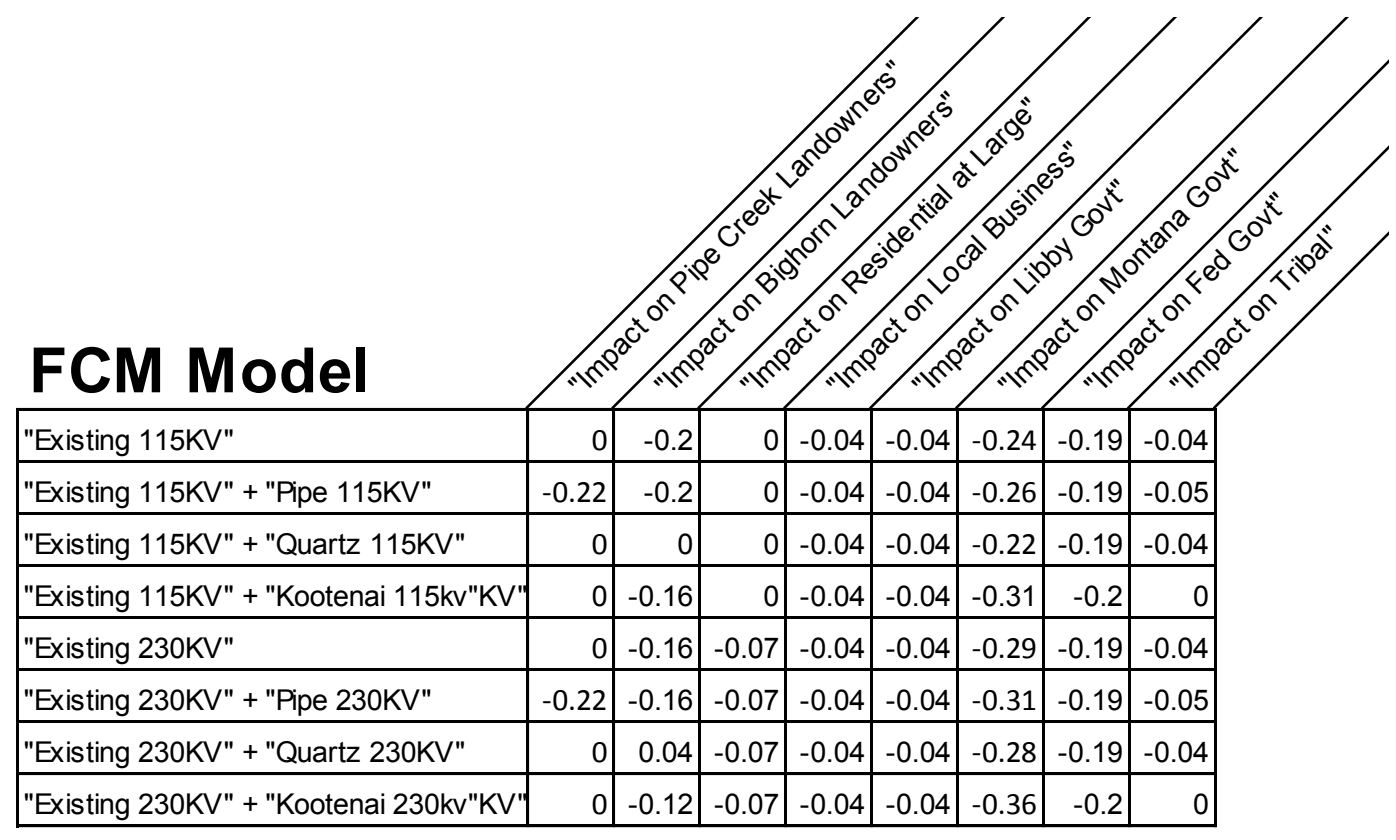

Table 18: Stakeholder Perceptions on Impacts of Alternatives 
The FCM results show that the Pipe Creek alternative causes the most impact with a value of "-0.22," and stakeholders were indifferent to all other alternatives. On the other hand, Bighorn Terrace residents saw the existing $115 \mathrm{kV}$ line with quartz realignment as beneficial with a value of " 0.0 ," and if the line was $230 \mathrm{KV}$, that was even better with a value of "0.4." Residents at large were concerned about the impacts associated with any of $230 \mathrm{kV}$ alternatives with a value of "-0.07," and they were indifferent to any of the $115 \mathrm{kV}$ alternatives with a value of " 0. " Local business and Libby city government were indifferent to all alternatives; however, they were impacted with value "-0.4." The state of Montana viewed the Existing Line with the Quartz Creek realignment as having the least impact with a value of "-0.22" and viewed the Existing Line with $230 \mathrm{kV}$ and Kootenai River realignment as having the most impact with a value of "-0.36." The federal government viewed Existing line with Kootenai River realignment with either $115 \mathrm{kV}$ or $230 \mathrm{kV}$ voltage as having the most impact and were indifferent to all other alternatives. Conversely, the tribal communities viewed Existing Line with Kootenai River with either $115 \mathrm{kV}$ or $230 \mathrm{kV}$ voltage as no impact, but they viewed Pipe Creek realignment with either $115 \mathrm{kV}$ or $230 \mathrm{kV}$ voltage as having the most impact.

One of the premises of the research is that stakeholders' interests vary, which is why there is a difference in perceived desirability for each alternative. Understanding how stakeholder interests affect the BPA objectives requires understanding the most central concepts (gray columns) among the stakeholder and the downstream effects (white columns) of these concepts, as shown Table 19, which is derived from each of the 
individual stakeholder group FCMs. The majority of the stakeholders viewed the rightof-way and construction of the new structures as the most central concepts, show in gray. Given that any realignment alternative and replacement of the existing line with $230 \mathrm{kV}$ requires acquiring land to widen the right of way (ROW), this makes sense. Furthermore, because $115 \mathrm{kV}$ uses the same right of way for the most part, it also makes sense as to why stakeholders primarily viewed $115 \mathrm{kV}$ alternatives over $203 \mathrm{kV}$, as defined in Table 18. The use of the symmetrical and asymmetrical stakeholders utilities as shown in Table 19 are concepts that can be used to test the assumptions that ultimately affect BPA's objectives, which is discussed in the next section. 


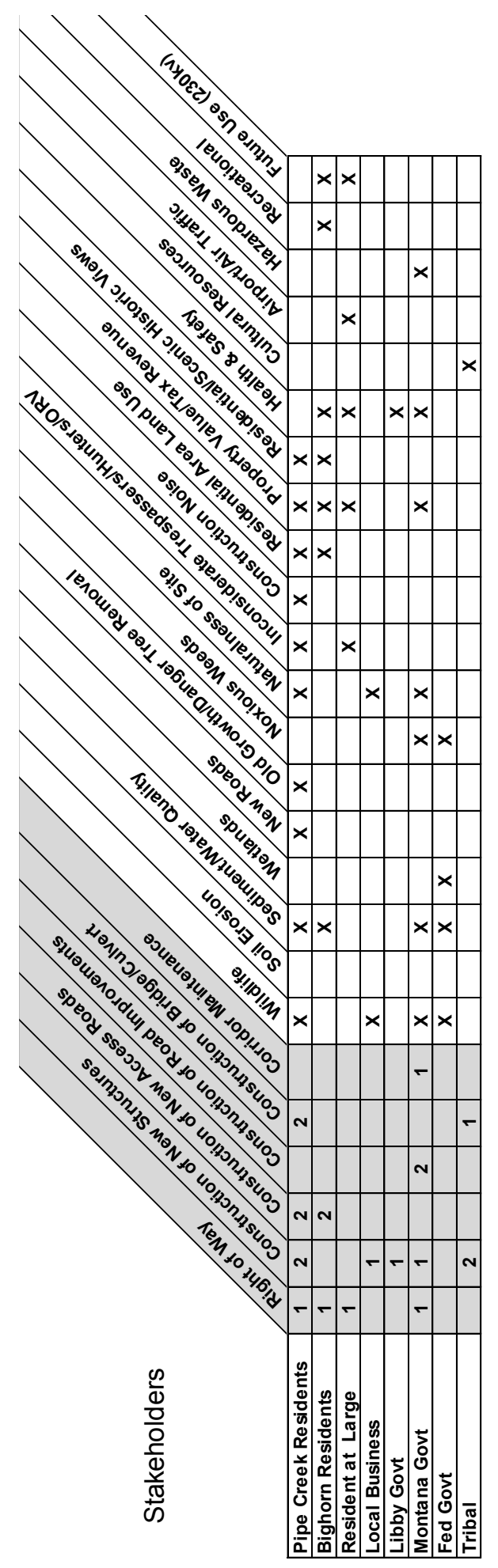

Table 19: Central Concepts that Affect Utility 


\subsubsection{Analysis of the Expert's Views}

BPA experts conduct a long and detailed process for understanding the environmental, social and economic consequences (positive or negative) resulting from each alternative's impacts. The expert FCM also used a hyperbolic tangent sigmoid threshold squashing function for simulation. As shown Table 20, the FCM shows how the BPA views the consequences from each of the alternatives on the 17 EIS areas, which are the input into BPA's objectives. This required executing the eight alternative scenarios, just as was done with the stakeholders. Upon observation, ground surface soil disturbances/erosion, wetlands, wildlife, visual impacts and cultural resources are what the stakeholders are mostly concerned about as these values range from "-0.4" to "0.68." Also shown in Table 20, the replacement of the existing line with 115kV has the least impact on minimizing environmental impacts. This was accomplished by equally weighing each of the EIS area concepts' input into the objective concept. Furthermore, the replacement of the existing $115 \mathrm{kV}$ line with $115 \mathrm{kV}$ was also the least expensive among the Pipe Creek and Kootenai River realignment alternatives. The project cost objective was based on edge-weight for each alternative as a percentage of the overall costs for all alternatives. BPA defined the costs for each alternative in draft and final EIS documents. 


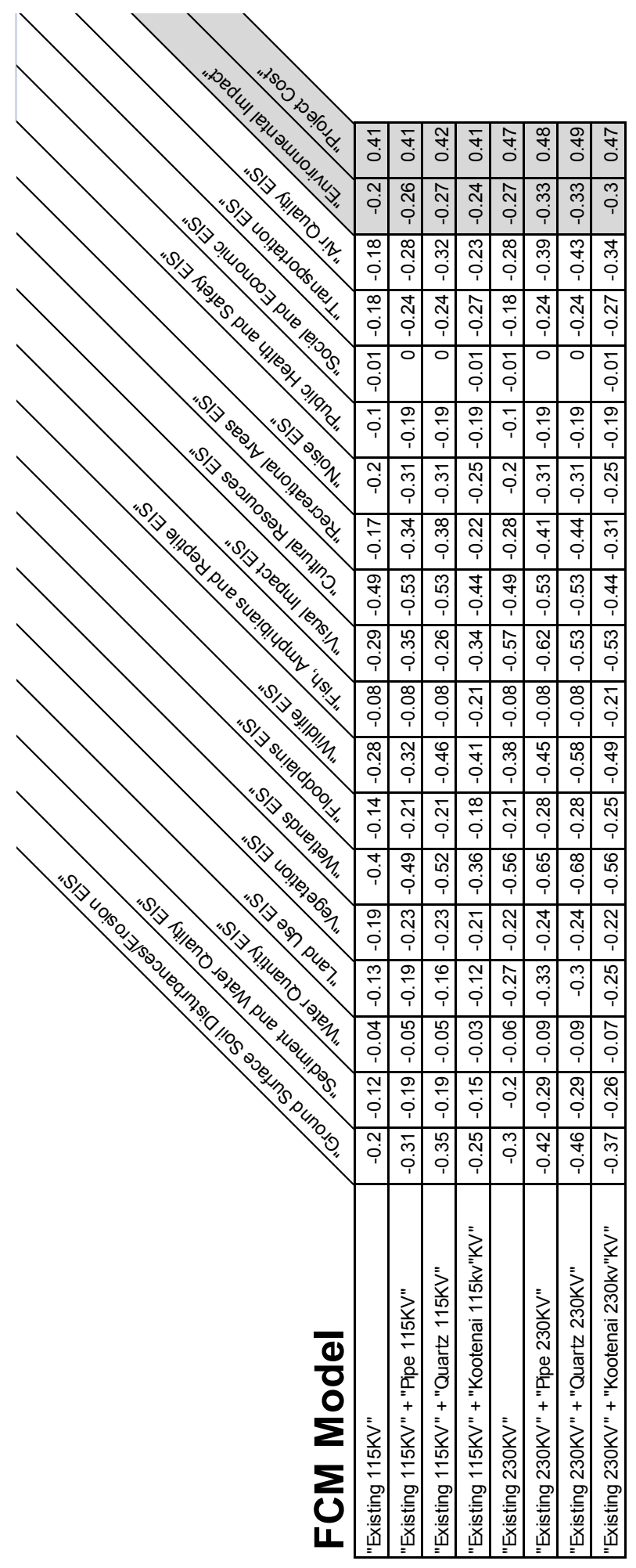

Table 20: How Experts View Affects BPA Objectives 
To assess how the experts view the consequences (positive or negative) on stakeholders, it was necessary to map the concepts that stakeholders view as impacts (see Table 19) on the applicable EIS areas. Using those EIS that each stakeholder group was concerned about, equal weights were given as input to each stakeholder group objective concept, and the eight scenario alternatives were executed as above. As shown in Table 21, the experts not only viewed replacing the existing $115 \mathrm{kV}$ lines as having the least impact on the environment, but it also had the least impact on all stakeholders, with the exception of the tribal communities. Also shown in Table 19 is that cultural resources are their only concern, and when compared to the EIS areas in Table 20, Kootenai River has the least impact on cultural resource. Therefore, when the Kootenai River alternative is included, the cultural resource impacts associated with the existing $115 \mathrm{kV}$ are mitigated. This was the justification and decision made in the Record of Decision (Bonneville Power Administration, 2008). However, when comparing the expert's view on stakeholders in Table 21 with the stakeholder view in Table 18, Bighorn Terrace, State of Montana and Federal Government disagreed with the experts because they view the impacts with Kootenai River alignment more impactful. 


\begin{tabular}{|c|c|c|c|c|c|c|c|c|}
\hline "Existing 115KV" & -0.22 & -0.14 & -0.1 & -0.14 & -0.1 & -0.24 & -0.31 & -0.45 \\
\hline "Existing 115KV" + "Pipe 115KV" & -0.33 & -0.16 & -0.15 & -0.16 & -0.19 & -0.31 & -0.38 & -0.48 \\
\hline "Existing 115KV" + "Quartz 115KV" & -0.28 & -0.14 & -0.15 & -0.23 & -0.19 & -0.35 & -0.39 & -0.48 \\
\hline "Existing 115KV" + "Kootenai 115kv"KV" & -0.28 & -0.19 & -0.15 & -0.2 & -0.19 & -0.31 & -0.31 & -0.41 \\
\hline "Existing 230KV" & -0.22 & -0.2 & -0.14 & -0.19 & -0.1 & -0.35 & -0.38 & -0.45 \\
\hline "Existing 230KV" + "Pipe 230KV" & -0.35 & -0.21 & -0.19 & -0.22 & -0.19 & -0.41 & -0.51 & -0.48 \\
\hline "Existing 230KV" + "Quartz 230KV" & -0.3 & -0.17 & -0.19 & -0.28 & -0.19 & -0.42 & -0.51 & -0.48 \\
\hline "Existing 230KV" + "Kootenai 230kv"KV" & -0.27 & -0.22 & -0.19 & -0.24 & -0.19 & -0.38 & -0.4 & -0.41 \\
\hline
\end{tabular}

Table 21: How the Experts View Impacts on Stakeholders

\subsection{AggREgATE FCM MODELS}

\subsubsection{Methods for Aggregating FCMs}

Figure 20 depicts the methodology for integrating FCMs. Individual stakeholder group FCMs are combined to create a holistic view (Mouratiadou \& Moran, 2007; Uygar Özesmi, 1999). Furthermore, integrating individual FCMs provides the capability of uncovering hidden patterns (B. Kosko, 1988) among the stakeholder groups otherwise not seen in individual FCMs. The methodology begins with defining the criteria for integration, such as common interests. Establishing the framework for integration using common ontology provides the foundation for augmenting individual FCMs and normalizing edge weights as discussed in Section 2.6.1. 


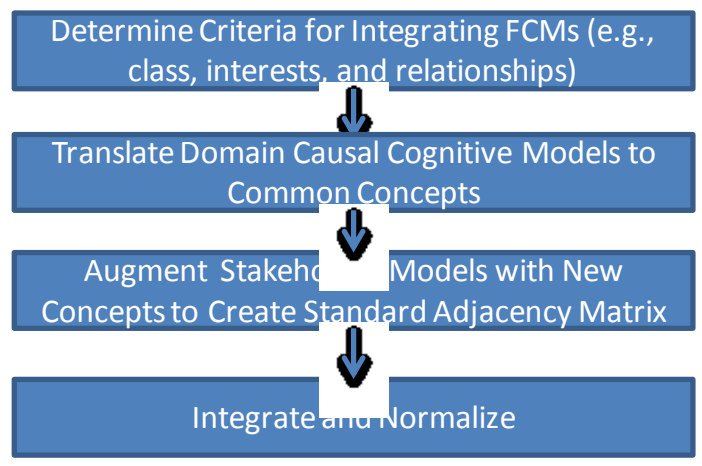

Figure 20: FCM Methodology for Integrating FCMs

In addition to common interest, power is another attribute commonly discussed in stakeholder literature (Mitchell, et al., 1997) as well as the creation of strategic relationships or collations (Fran Ackermann \& Eden, 2011; Hart \& Sharma, 2004; King, 2007). Allowances for power can be made by applying credibility weighting factor to the edge weights in the adjacency matrix before normalizing the matrices (B. Kosko, 1988). The research will first conduct non-weighted assessments to understand the difference among stakeholders. Once differences are understood, weighting factors can be applied in order to assess if the differences change based on power and influence.

\subsubsection{Aggregating Stakeholder Group FCMs}

This research aggregated stakeholder groups using the criteria as shown in Table 22. The thought process of aggregating like entities was founded on the same principle of grouping stakeholders from past research, where Özesmi (1999) grouped villagers to understand the impacts as a whole and Mouratiadou and Moran (2007) grouped stake holders by farmers, local people, water experts, researchers-ecologists and government 
officials. The second criteria was based on the principle of mutually benefiting relationships (Fran Ackermann \& Eden, 2011) or coalitions (Hart \& Sharma, 2004). Mutually benefiting relationships is where two or more stakeholders stand to gain an advantage by joining forces, thereby creating a collation.

\begin{tabular}{|c|c|}
\hline STAKEHOLDER GROUP TO BE INTEGRATED & CRITERIA FOR INTEGRATION \\
\hline $\begin{array}{l}\text { Pipe Creek Residents, Bighorn Terrace } \\
\text { Residents, and Residents at Large }\end{array}$ & $\begin{array}{l}\text { - Common interest among all } \\
\text { residents }\end{array}$ \\
\hline $\begin{array}{l}\text { City of Libby, State of Montana, and Federal } \\
\text { Government }\end{array}$ & $\begin{array}{l}\text { - Common interest among all } \\
\text { governmental agencies and } \\
\text { departments }\end{array}$ \\
\hline $\begin{array}{l}\text { Pipe Creek Residents, Bighorn Terrace } \\
\text { Residents, and Residents at Large, Local } \\
\text { Business, City of Libby, State of Montana, and } \\
\text { Federal Government, Tribal Communities }\end{array}$ & $\begin{array}{l}\text { - Common interest among all } \\
\text { stakeholders }\end{array}$ \\
\hline $\begin{array}{l}\text { State of Montana and US Federal } \\
\text { Government }\end{array}$ & $\begin{array}{l}\text { - Mutually benefiting relationship } \\
\text { in Kootenai River realignment } \\
\text { where power may be exploited }\end{array}$ \\
\hline $\begin{array}{l}\text { Bighorn Terrace, State of Montana, and } \\
\text { Federal Government }\end{array}$ & $\begin{array}{l}\text { - Mutually benefiting relationship } \\
\text { in Quartz Creek realignment } \\
\text { where power may be exploited }\end{array}$ \\
\hline
\end{tabular}

Table 22: Integrated Stakeholders

As shown in Table 23, when aggregating Pipe Creek, Bighorn Terrace and Residents at Large, replacing the existing line with $115 \mathrm{kV}$ and Quartz Creek Alternative has a positive benefit at "0.2." This required integrating the Pipe Creek, Bighorn Terrace and Residents at Large individual FCMs and normalizing the edge weights by three, thereby creating a new FCM. Then eight scenarios were executed, one for each alternative. The threshold squashing function used was the hyperbolic tangent function. 
When integrating the city of Libby, state of Montana and the federal government agencies, they were now indifferent about replacing the existing Line with $115 \mathrm{kV}$ and the Pipe Creek or Quartz Creek. However, they viewed the replacing the existing line with $115 \mathrm{kV}$ and Kootenai River alternative as having the most harmful impact. This required integrating the city of Libby, state of Montana and the federal government individual FCMs and normalizing the edge weights by three, thereby creating a new FCM. Then eight scenarios were executed, one for each alternative. The threshold squashing function used was the hyperbolic tangent function.

Integrating all stakeholders reveals that replacing the existing line with $115 \mathrm{kV}$ and Quartz Creek realignment has the least impact at "-0.04." This required integrating all eight individual FCMs and normalizing the edge weights by eight, thereby creating a new FCM. Then eight scenarios were executed, one for each alternative. The threshold squashing function used was the hyperbolic tangent function.

The result of integrating the state of Montana and US Federal Government, whose land use is affected by the Kootenai River alignment, was the same as the three governments combined. This required integrating the state of Montana and US Federal Government individual FCMs and normalizing the edge weights by two, thereby creating a new FCM. Then eight scenarios were executed, one for each alternative. The threshold squashing function used was the hyperbolic tangent function. 


\begin{tabular}{|c|c|c|c|c|c|}
\hline "Existing 115KV" & -0.08 & -0.09 & -0.06 & -0.17 & -0.18 \\
\hline "Existing 115KV" + "Pipe 115KV" & -0.15 & -0.09 & -0.08 & -0.18 & -0.2 \\
\hline "Existing 115KV" + "Quartz 115KV" & 0.02 & -0.09 & -0.04 & -0.17 & -0.12 \\
\hline "Existing 115KV" + "Kootenai 115kv"KV" & -0.06 & -0.15 & -0.07 & -0.22 & -0.22 \\
\hline "Existing 230KV" & -0.13 & -0.11 & -0.08 & -0.19 & -0.19 \\
\hline "Existing 230KV" + "Pipe 230KV" & -0.18 & -0.11 & -0.09 & -0.21 & -0.22 \\
\hline "Existing 230KV" + "Quartz 230KV" & -0.05 & -0.1 & -0.06 & -0.19 & -0.14 \\
\hline "Existing 230KV" + "Kootenai 230kv"KV" & -0.12 & -0.16 & -0.09 & -0.25 & -0.23 \\
\hline
\end{tabular}

Table 23: Impact on Aggregated Stakeholders

Bighorn Terrace contracted its state senator to help fight against BPA replacing the existing line through the neighborhood and instead moving the line over the mountaintop, as proposed by the Quartz realignment. What is interesting is that not only did that alternative have the least impact at "-0.12", but also the Kootenai River Realignment became the most impactful alternative at "-0.22". This required integrating Bighorn Terrace and state of Montana individual FCMs and normalizing the edge weights by two, thereby creating a new FCM. Then eight scenarios were executed, one for each alternative. The threshold squashing function used was the hyperbolic tangent function. 


\subsection{IDENTIFYING NEW OR ChANGING INFORMATION}

\subsubsection{Methods for Identifying New or Changing Information}

Learning from feedback allows the decision maker to reassess decisions that were made previously and to bring the model's perceptions closer to reality by showing how new or changing perceptions by experts and stakeholders affect the outcome of the decision (J. D. Sterman, 2000b). As shown in Figure 21, the method for soliciting feedback is to identify new or changing perceptions. This is achieved by adding new or changed information to the existing causal cognitive maps in Step 1 and then translating the updated causal cognitive map into a new FCM in Step 2 and conducting FCM simulation in Step 3.

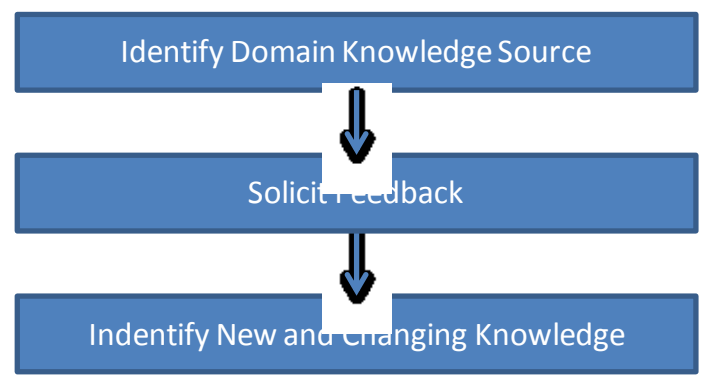

Figure 21: FCM Methodology for Soliciting Feedback

\subsubsection{Identifying New or Changing Information in Libby to Troy}

\subsubsection{Stakeholder Knowledge Capture: Draft EIS Phase}

During the scoping phase only six stakeholder groups commented, but after the draft EIS phase, the city of Libby and federal government indicated their interest and concerns in 22 documents that are listed in Appendix B - Documents Used. Extracting the stakeholder comments used a confirmatory approach because the research had already 
established a common ontology. It used the same methods as described in step 1 and built a new data repository for capturing the stakeholder comments after the release of the draft EIS. At the completion, three new concepts were indentified and were added to the common ontology. Next, copies of the scoping causal cognitive maps were created. The new or changed stakeholder perceptions were added to the individual stakeholder group causal cognitive map (i.e., copy), thereby preserving the scoping cognitive maps. In the case of the city of Libby and US Federal Government, new cognitive maps were created. In total, there were eight stakeholder group causal cognitive maps for this phase, which were then translated into FCMs using the same methods in step 2.

Table 24 shows how stakeholders perceived the value or harm of the alternatives from the scoping phase to when the draft EIS was release. The left side of Table 24Error! Reference source not found. shows the impacts indentfied from the scoping comments, and the right-hand side shows the same assessment, but only after the draft EIS was issued, which is a composite of both scoping and draft EIS comments. Each side required executing eight scenarios, one for each alternative for each stakeholder group. During the scoping phase, six stakeholder groups provide comments: Pipe Creek residents, Bighorn Terrace residents, residents at large, local businesses, state of Montana, and tribal communities. After the draft EIS was released, two new stakeholder groups were indentified: city of Libby and the US Federal Government. In total, 112 scenarios were required, 64 for the scoping phase and another 64 after the draft EIS was released. All 
scenarios used the hyperbolic tangent sigmoid threshold squashing function for simulation.

Table 24 shows a shift in some opinions: For example, Bighorn Terrace residents, who had initially viewed the impacts from the Kootenai River alternative as harmful in the scoping phase, changed their opinion and actually felt neutral toward the 115KV option and even positive about the $230 \mathrm{kV}$ alternative because they realized that both options gave them land use back. The state of Montana view also changed. They too viewed Kootenai River as the most impactful, but lessened their view of the Kootenai River after the draft EIS was released due to the mitigation measures being taken. Residents at large, local business, and tribal communities did not shift.

\section{FCM Model}

\begin{tabular}{|c|c|c|c|c|c|}
\hline "Existing 115KV" & -0.17 & 0 & -0.04 & -0.02 & -0.04 \\
\hline "Existing 115KV" + "Pipe 115KV" & 0.17 & 0 & -0.04 & -0.02 & -0.05 \\
\hline "Existing 115KV" + "Quartz 115KV" & -0.03 & 0 & -0.04 & 0.02 & -0.04 \\
\hline "Existing 115KV" + "Kootenai 115kv"KV" & $\begin{array}{ll}0 & -0.17 \\
\end{array}$ & & -0.0 & -0.11 & 0 \\
\hline "Existing 230KV" & \begin{tabular}{l|l|}
0 & -0.16 \\
\end{tabular} & 02 & -0.04 & -0.07 & -0.04 \\
\hline "Existing 230KV" + "Pipe 230KV" & 016 & .02 & -0.04 & -0.07 & -0.05 \\
\hline "Existing 230KV" + "Quartz 230KV" & -0.02 & .02 & -0.04 & -0.03 & -0.04 \\
\hline "Existing 230KV" + "Kootenai 230kv"KV" & $\begin{array}{lll}0 & -0.16 \\
\end{array}$ & בח & -0.04 & -0.16 & 0 \\
\hline
\end{tabular}

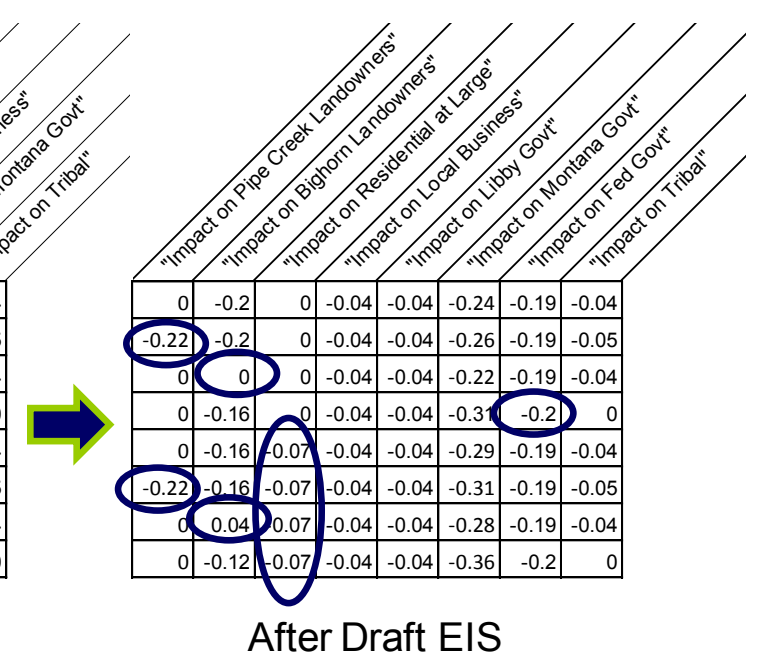

Table 24: Stakeholder Preferences over Time 


\subsubsection{BPA Expert Knowledge Capture: Final EIS Phase}

As indicated previously, the NEPA process seeks public involvement as to its concerns during the scoping phase. These concerns became input in to the draft EIS process where BPA experts address the stakeholders concerns. The expert FCM used the hyperbolic tangent sigmoid threshold squashing function for simulation. Table 25 shows how the BPA experts view impacts on the environment, including the concerns of the stakeholders in the draft EIS. This required executing eight scenarios, one for each alternative.

The process continues whereby stakeholders are again encouraged to voice their concerns after the draft EIS was released, which then become input into the final EIS. Changes from the draft EIS to the final EIS are redlined in the final EIS. The research modified the BPA expert draft EIS FCM with the redlines marked up in the BPA expert final EIS FCM. FCM simulation used the hyperbolic tangent sigmoid threshold squashing function for simulation. Table 26 now shows how the BPA experts view the impacts on the environment. This also required executing eight scenarios, one for each alternative. Fundamentally, there are no differences in experts' perceptions, with the exception of the Quartz Creek realignment. The impact was reduced by " 0.01 " for both $115 \mathrm{kV}$ and $230 \mathrm{kV}$ because impact from the construction of the new structure was reduced from medium-high " 0.7 " to medium "0.5." 


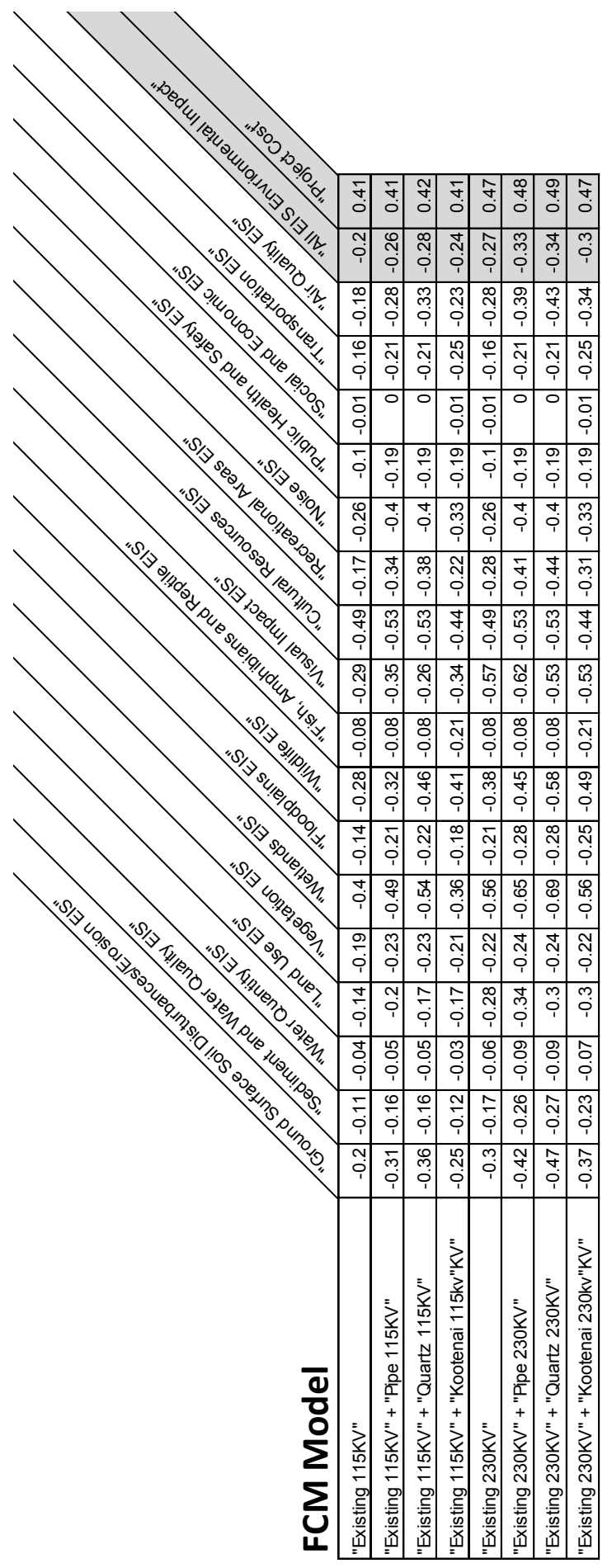

Table 25: BPA Expert Draft EIS Assessment 


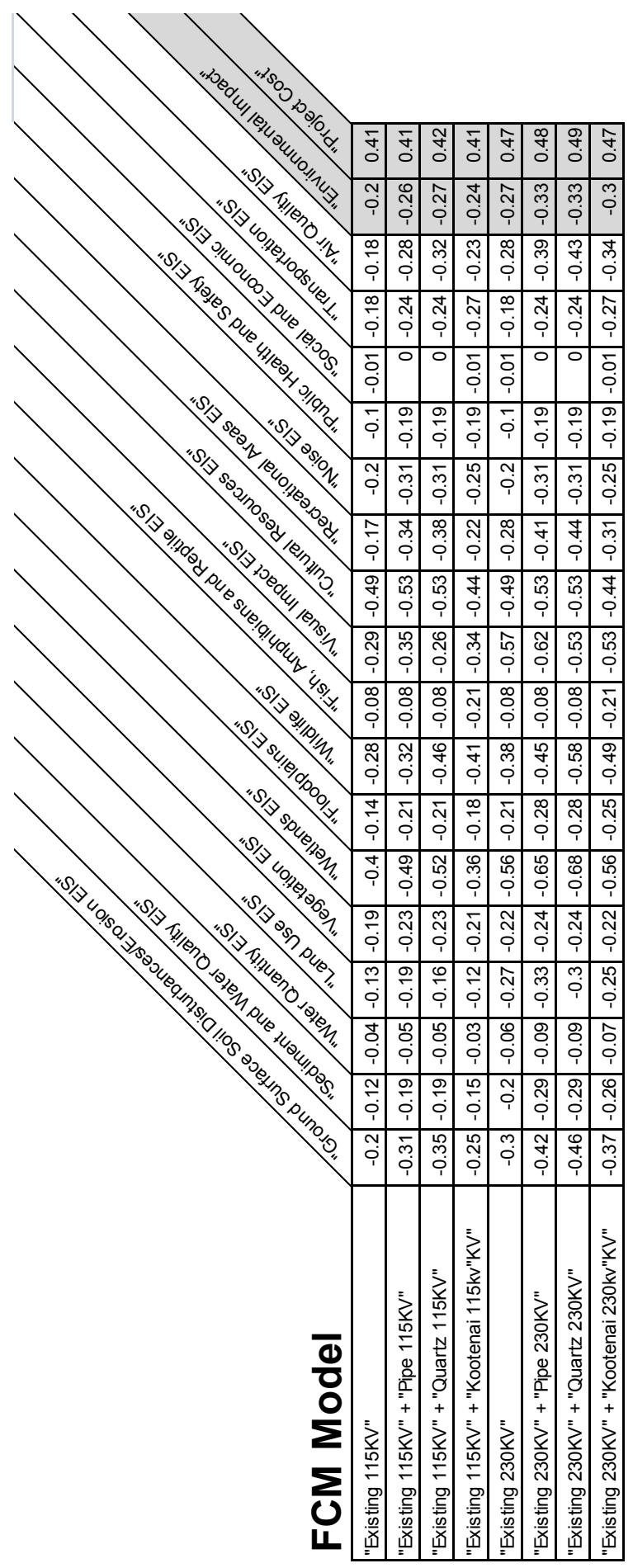

Table 26: BPA Expert Final EIS Assessment 


\subsection{SUMmARY OF CASE INSIGHTS}

The Libby to Troy transmission upgrade case study provided several insights. First, the research considered how the different stakeholder groups perceive the eight alternatives and how strongly their perceptions agree or disagree. It was clear that residents do not want the line in their backyard. Bighorn Terrace residents favor the Quartz Realignment because it removes the existing line from their neighborhood, and Pipe Creek Residents do not want the line coming in. Residents at large are indifferent to $115 \mathrm{kV}$, but they do not want $230 \mathrm{kV}$. The state of Montana and US Federal Government view the Kootenai River realignment as most impactful, whereas the tribal communities view it as the least impactful. Local business and the city of Libby are indifferent. Furthermore, there were changes in perceptions from scoping to when the draft EIS was released to the public for review; in particular, stakeholders' desirable option increased, Bighorn Terrace residents felt the draft EIS addressed some their concerns with the Kootenai River Realignment, and the city of Libby and US Federal Government voiced their concerns after the draft EIS was released.

Next, the research considered how the BPA experts assess the impacts of the eight alternatives. It was clear that replacing the existing line with $115 \mathrm{kV}$ is preferred becuase it was the most environmental friendly and it had the lowest cost. However, BPA went with Kootenai realignmentz because of cultural concerns with the tribal 
communities. Finally, how do aggregated stakeholder groups perceive the eight alternatives? When all residents and all stakeholders views are considered, the Quartz Creek is the preferred alternative. Furthermore, there were two potential coalitions becuase of like interests. The US Federal Government and state of Montana viewed impacts with the Kootenai River as most impactful, and the state of Montana and Bighorn Terrace residents saw the Quartz Creek option as the most favorable. 


\section{EVALUATION AND ASSESSMENT}

\subsection{Evaluation of Methodology}

The objective of the research is to develop a new Fuzzy Cognitive Based TA (FCTA) methodology using a historical case study that models environmental impacts of the Libby to Troy transmission upgrade project. As discussed in Section 3.2, an evaluation determines that the model adequately represents the real world, which is determined through quality control during modeling and by investigating assumptions and limitations of the model (Borenstein, 1998). This requires adherence to the logical tests to validate the research methods for data collection and model development (Yin, 2003) and investigations into how sensitive the model is when assumptions change (J. D. Sterman, 2000b).

\subsubsection{Validation and Quality Control of Research Methods}

\subsubsection{Validation of the Construct}

The purpose of construct validity is to establish the correct operational measures for the concepts under study and to confirm that the data collected is objective and interpretational (Yin, 2003). The research identified two strategies: 1) establish a chain of evidence and 2) have key informants review the results. The research collected stakeholder input from publically available documents that included 80 stakeholder documents, as well as Appendix A in the Draft and Final EIS, which focus on tribal 
communities' comments. All stakeholder concerns and needs were initially captured in the stakeholders' own words using Microsoft Excel, which served as the data repository. Three key pieces of information provide the capability to trace the stakeholder comments back to the original document. The document ID was used as the primary reference. In the situation where no document ID was available, the stakeholder name and date of the document served as the reference. The stakeholder comments were then translated into common concepts that are defined in the common ontology. This required adding two new columns to the data repository, Common Cause Concept and Common Effect Concept, thereby providing backward traceability to the original document and forward traceability to the stakeholder group causal cognitive map and FCM.

The experts' input was collected from two publically available documents: Draft EIS and Final EIS. The experts identified the impacts associated with the alternatives from an environmental and socio-economic perspective. The impacts were identified and collected for each of 17 EIS areas. Within each EIS area, the impacts associated with each of the eight alternatives are documented in Microsoft One Note. This allows traceability back to the EIS documents.

The second strategy was to have the BPA project team identify which stakeholder group particular respondents belong to. This was not necessary because the research was able to identify all stakeholder affiliations through information provided in the documents. 
When the document did not give specific information, the comments contained sufficient geographic information, such as the area that is affected by the transmission alternative, to identify the location of the stakeholder using a mapping tool, such as www.Zillow.com or Bing.

With regard to the construct validity of the core concepts and the environmental and organizational objectives represented in the FCM models, the research consistently used the concepts explicitly identified in the Draft EIS as the basis for the common ontology. The EIS provided 91 common concepts; and an additional 6 concepts were identified by the stakeholders and represented in their language.

\subsubsection{Validation of the Internal Structure}

Internal validity establishes confidence in the truth of the research analysis and, in particular, it establishes the causal relationships to show how certain conditions lead to other conditions (Yin, 2003). Three strategies were used: 1) dynamic hypotheses testing;

2) explanation building; and 3) address rival explanations. The model confirmed all four of the dynamic hypotheses. ROD provided the basis for explanation and rival building, as previously discussed in section 6.3.

\subsubsection{Validation of External Structure for General Use}

External validity establishes if the findings can be applied to other contexts and settings (Yin, 2003). In the context of this research, generalization is possible for the FCTA methodology but not the models themselves because those are case-specific. As 
discussed in section 4, the strategy for achieving external validity of this research is to use methods that have been used and validated by other researchers in previous FCM studies. For example, the data collection methods used to extract stakeholder and expert perceptions from documents are well researched and have been used by other researchers (K. Carley, 1986; K. M. Carley, 1997; Nakamura, et al., 1982; Roberts, 1989), though existing literature typically only focuses on stakeholders and rarely on experts. Similarly, the methods for translating causal cognitive maps into FCMs and using FCM simulation to assess environmental impacts on stakeholders to support decision making have been used in several case studies (R Giordano, et al., 2007; R. Giordano, et al., 2005; Mouratiadou \& Moran, 2007; Uygar Özesmi, 1999; Uygar Özesmi \& Özesmi, 2003). Moreover, the method for quantitatively integrating FCM is adopted from prior research (B. Kosko, 1988; Taber, 1991), even though the majority of FCM studies qualitatively integrate causal cognitive maps and then create the FCM (A. Jetter \& Schweinfort, 2011; Mouratiadou \& Moran, 2007; Uygar Özesmi, 1999; Uygar Özesmi \& Özesmi, 2004). Earlier research has also provided a structure for using objectives in causal cognitive maps (Bryson, et al., 2004), which was adapted for the purpose of this study.

\subsubsection{Validation of the Reliability of the Research Data and Processes}

Reliability measures the degree of consistency in the collection of the data to minimize errors and biases so that other researchers can repeat the same experiments and get the same results (Yin, 2003). The validation strategy used in this research was to 
develop a case study protocol that documents the procedures for collecting data, build FCM models, and conduct FCM simulation. First, the research used publically available documents from BPA's website, with the exception of the stakeholder comments. These comments were prepared by BPA for the purpose of this research. The research documented the steps taken for developing causal cognitive maps, translating them into FCMs in sections 6.2 and 6.3. The steps for using FCM simulation to assess the impacts on stakeholders, examine how experts perceive the impacts on stakeholders, and look at the differences between the stakeholders and experts are discussed in section 6.4. Procedures for integrating stakeholder FCMs to assess the impacts on aggregated stakeholders are documented in section 6.5. Finally, the procedure for identifying new or changing information was documented in section 6.6.

\subsubsection{Investigation into the Assumptions and Results of the Model}

Model simulation is used for problem solving, such as assessing the state of affairs compared to the organization's goals; however, there is always uncertainty with simulations regarding formulations and parameter assumptions (J. D. Sterman, 2000b). This raises two questions: 1) can the output of the model be trusted and 2) if the output of the model is to aid the decision maker, how sensitive are the results to changes in assumptions (Moxnes, 2005; J. D. Sterman, 2000b)? The research used numerical and policy sensitivity for answering these two questions. 


\subsubsection{Numerical Sensitivity}

Numerical sensitivity is used to analyze the change of model outputs when model assumptions change. Numerical sensitivity analysis was performed to investigate the impact of various squashing functions. The research tested bivalent, trivalent, and pentavalent squashing functions - see Appendix F details. Bivalent squashing functions produce outputs that are either " 0 " or " 1 ", trivalent functions produce outputs of "-1"," 0 " or " 1 ", and pentavalent shows negative and positive outcomes of " -1 ", "- 0.5 ", " 0 ", " 0.5 " or " 1 ". The test revealed that the binary squashing function indicated that all alternatives were positively impacted equally, and trivalent and pentavalnet squashing functions show all alternatives were negatively impacted. By their very nature, these three threshold squashing functions did not provide any ranking among the eight alternatives.

Logistic threshold squashing functions, namely sine, hyperbolic sine, and arc tangent, produce the same ranking for impacts on stakeholders as the hyperbolic tangent squashing function that was used in this research. The alternative to keep the existing $115 \mathrm{kV}$ was always the best alternative, followed by $115 \mathrm{kV}$ Kootenai River and Pipe Creek and Quartz Creek.

\subsubsection{Policy Sensitivity Analysis}

Policy sensitivity tests the desirability of the proposed alternatives when model assumptions, such as those about causal relationships, change (J. D. Sterman, 2000b). The dynamic hypothesis testing conducted in section 6.3.2 showed that the expert FCM 
model generated the same policy conclusions that the BPA arrived at in the ROD. Is the FCM model sensitive enough to lead to different policy decisions if model assumptions are changed? To test policy sensitivity, assumptions about each alternative were modified to represent a situation in which environmental impacts can be successfully mitigated, for example, through improved technology or design.

Alternative 1 - upgrading the existing $115 \mathrm{kV}$ transmission line - was perceived to be the best alternative because it replaces the old structures with new structures of similar size, which requires some road improvements but no large additional ROW. To test sensitivity, the model assumes that the impact of new structures, buildings, roads, and ROW can also be minimal for other alternatives. This condition was tested by zeroing the weights for "R-O-W Clearing (Vegetation/Danger Tree)," "Construction of Structures (Replace/New)," "Construction of New Roads," and "Construction of Road Improvements" concepts, thereby indicating that there is no impact. As shown in Table 27 , replacing the existing structure with $115 \mathrm{kV}$ voltage is still the best solution over $230 \mathrm{kV}$. Furthermore, Kootenai River realignment is still the next best solution. Pipe Creek and Quartz Creek, which were once different in their environmental impacts, are now equal. The model upheld the policy decision when the assumptions regarding ROW clearing, construction of new structures, and building new and improving roads were negated. 


\begin{tabular}{|l|c|c|c|c|}
\hline \hline \multicolumn{1}{|c|}{ ALTERNATIVE } & \multicolumn{2}{c|}{ DH1 } & \multicolumn{2}{c|}{$\begin{array}{c}\text { TEST FOR POLICY } \\
\text { SENSITIVTY. }\end{array}$} \\
\cline { 2 - 5 } & $\mathbf{1 1 5 k V}$ & $\mathbf{2 3 0 k V}$ & $\mathbf{1 1 5 k V}$ & $\mathbf{2 3 0 k V}$ \\
\hline \hline Environmental Impact From Existing Corridor & -0.20 & -0.27 & -0.17 & -0.22 \\
Environmental Impact From Existing Corridor plus & -0.26 & -0.33 & -0.21 & -0.27 \\
$\begin{array}{l}\text { Pipe Creek } \\
\text { Environmental Impact From Existing plus Corridor } \\
\text { Quartz Creek }\end{array}$ & -0.27 & -0.33 & -0.21 & -0.27 \\
$\begin{array}{l}\text { Environmental Impact From Existing Corridor plus } \\
\text { Kootenai River }\end{array}$ & -0.24 & -0.30 & -0.19 & -0.24 \\
\hline \hline
\end{tabular}

Table 27: Policy Sensitivity Analysis for Dynamic Hypothesis 1

The second dynamic hypothesis indicated that the Pipe Creek alternative would have greater impacts on the soil and water resources, land use, vegetation (old growth trees and weeds), wetland, floodplains, wildlife, visual resources, and cultural resources than just building in the existing corridor. The basis for this argument is that there is no existing corridor with the Pipe Creek realignment. Therefore, it requires acquiring a new ROW, thus impacting land use. Clearing the ROW to place the new structures and build roads would impact the old growth trees and vegetation, and the disturbances from the construction would impact water and cultural resources. Furthermore, the new corridor would increase the noise level from hunters and off-road vehicles, as well as the emissions from the construction equipment. To test the policy, sensitivity, the weights for "Construction of Structures (Replace/New)," "Construction of New Roads," "Construction of Road Improvements," and "R-O-W Clearing (Vegetation/Danger Tree)" concepts were set to " 0 " for the Pipe Creek alternative, thereby indicating no impact. 
As shown in Table 28, the impacts with "Soil," "Water Resources," "Old-growth trees/Vegetation," "Wetlands," "Floodplains," and "Air Quality" are lesser; however, "Land Use," "Visual Resources," "Wildlife," "Cultural," and "Noise" remain the same. Therefore, the policy decision was still upheld; however, there were still some other factors not considered.

\begin{tabular}{lcccc}
\hline \multicolumn{1}{c}{ RESOURCE } & \multicolumn{2}{c}{ DH2 } & \multicolumn{2}{c}{ POLICY SENSITIVITY } \\
& $\mathbf{1 1 5 k V}$ & PIPE 115kV & $\mathbf{1 1 5 k V}$ & PIPE 115kV \\
\hline \hline Soil & -0.17 & -0.28 & -0.18 & -0.22 \\
Water Resources & -0.12 & -0.19 & -0.11 & -0.15 \\
Land-Use & -0.13 & -0.19 & -0.13 & -0.19 \\
Old-growth trees/Vegetation & -0.18 & -0.23 & -0.18 & -0.20 \\
Wetlands & -0.32 & -0.42 & -0.37 & -0.42 \\
Floodplains & 0.11 & -0.19 & -0.11 & -0.15 \\
Visual Resources & -0.29 & -0.35 & -0.29 & -0.35 \\
Wildlife & -0.28 & -0.32 & -0.28 & -0.32 \\
Cultural & -0.49 & -0.53 & -0.49 & -0.53 \\
Noise & -0.20 & -0.31 & -0.20 & -0.31 \\
Public Health and Safety & -0.10 & -0.19 & -0.1 & -0.19 \\
Air Quality & -0.16 & -0.25 & -0.17 & -0.20 \\
\hline \hline
\end{tabular}

Table 28: Policy Sensitivity Analysis for Dynamic Hypothesis 2

The third hypothesis indicated that the Quartz Creek alternative would have greater impacts on the soil, land use, old-growth trees, other vegetation, visual resources, wildlife and cultural resources. The basis for this argument is similar to hypothesis 2 : 
there is no existing corridor with the Quartz Creek realignment; therefore, it requires acquiring a new ROW and impacting land use. It also requires clearing the ROW to place the new structures and build roads, thereby impacting the old growth trees and vegetation, and the disturbances would impact water resources and cultural resources.

\begin{tabular}{lcccc}
\hline \hline & DYNAMIC HYPOTHESIS & \multicolumn{2}{c}{ POLICY SENSITIVITY } \\
TEST
\end{tabular}

Table 29: Policy Sensitivity Analysis for Dynamic Hypothesis 3

Furthermore, the new corridor would increase the noise level from hunters and off-road vehicles, as well as the emissions from the construction equipment. To test policy sensitivity, weights for "Construction of Structures (Replace/New)," "Construction of New Roads," "Construction of Road Improvements," and "R-O-W Clearing (Vegetation/Danger Tree)" concepts were set to " 0 " for the Quartz Creek alternative, 
thereby indicating that there is no impact. As shown in Table 29, the impacts on "Soil," "Water Resources," "Land Use," and "Old-growth trees/Vegetation" are lesser; however, "Visual Resources," "Wildlife," "Cultural," "Noise," "Public Health and Safety" and "Air Quality" remain the same. Therefore, the policy decision was still upheld; however, there were still other factors not considered.

The fourth hypothesis indicated that the impacts would mainly occur from construction of the new transmission corridor and road clearing with the Kootenai River alternative. This alternative was to move the location where the line would cross to the north of the Kootenai River and west of China Creek from its current location. This realignment would not require having to build a culvert in China Creek, thus protecting cultural resources. Also, the visual resources would improve because the line would be further away from Kootenai Falls. To test policy sensitivity, weights for "Construction of Structures (Replace/New)," "Construction of New Roads," "Construction of Road Improvements," "Bridge/Culvert," and "R-O-W Clearing (Vegetation/Danger Tree)" concepts were set to " 0 " for the Kootenai River alternative, thereby indicating that there is no impact. As shown in Table 30, the impacts on China Creek actually increased. This is because the Kootenai River alternative would avoid the construction impacts from building the bridge and culverts, hence the model indicated a positive wedge weight; and by placing a zero in the concept, that actually indicated an impact, thus the reason for why the impact increased. However, "Wildlife," "Fish and Amphibians," 
"Visual Resources - Kootenai Falls" and "Cultural" remain the same. Therefore, there was no change in policy.

\begin{tabular}{lcccc}
\hline \multicolumn{1}{c}{ Resource } & DYNAMIC HYPOTHESIS & \multicolumn{2}{c}{$\begin{array}{c}\text { POLICY SENSITIVITY } \\
\text { TEST }\end{array}$} \\
& $\mathbf{1 1 5 k V}$ & $\begin{array}{c}\text { KOOTENAI } \\
\text { RIVER } \\
\mathbf{1 1 5 k V}\end{array}$ & $\mathbf{1 1 5 k V}$ & $\begin{array}{c}\text { KOOTENAI } \\
\text { RIVER 115kV }\end{array}$ \\
\hline \hline Wildlife & -0.28 & -0.41 & -0.28 & -0.41 \\
Fish and Amphibians & -0.08 & -0.21 & -0.08 & -0.21 \\
China Creek & -0.15 & -0.14 & -0.11 & -0.17 \\
Visual resources - Kootenai Falls & -0.10 & 0.00 & -0.10 & 0.00 \\
Cultural & -0.49 & -0.44 & -0.49 & -0.44 \\
\hline \hline
\end{tabular}

Table 30: Policy Sensitivity Analysis for Dynamic Hypothesis 4

The $115 \mathrm{kV}$ option was still the best alternative. EIA deals with the impacts on the environment and society; therefore, the decision-maker has an understanding of the issues, and by focusing on the best policy, the decision-maker can determine if he/she can make the policy better (Moxnes, 2005), in this case $115 \mathrm{kV}$. As a result, the research conducted sensitivity testing on the $115 \mathrm{kV}$ alternative to understand what changes occur in the output when the assumptions change. This was tested by zeroing the weights for each of the construction concepts and maintenance concepts one by one by clamping the concept at activation with " 0 ," thereby indicating that there is no impact. As shown in Table 31, minimizing impacts that would result from the construction of bridges and culverts reduces the overall impact of the $115 \mathrm{kV}$ alternative by $10 \%$, 
thereby indicating that this concept provides the optimum reduction. This indicates that if BPA was able to mitigate the impacts of the bridge/culvert in China Cree, there would no justification for implementing the Kootenai River alternative, as described by the ROD, thereby minimizing the impacts on the environment and reducing costs even more. Furthermore, BPA would be supporting the concerns of the tribal communities and avoiding a potential conflict with the state of Montana and US federal government.

\begin{tabular}{lc}
\hline \hline & POLICY SENSITIVITY \\
\multicolumn{1}{c}{ CONSTRUCITON \& MAINTENANCE } & TEST \\
& $\mathbf{1 1 5 k V}$ \\
\hline \hline Construction of Structures (Replace/New) & -0.19 \\
Construction of Staging Areas & -0.20 \\
Construction of Tensioning Areas & -0.19 \\
Construction of New Roads & -0.19 \\
Construction of Road Improvements & -0.19 \\
Construction of Bridge Culverts & -0.18 \\
R-O-W Clearing (Vegetation/Danger Tree) & -0.20 \\
Corridor Maintenance & -0.19 \\
Vehicular Traffic & -0.20 \\
\hline \hline
\end{tabular}

Table 31: Policy Sensitivity Analysis with Best Alternative - 115kV

\subsection{Assessment OF the Methodology}

The research followed up with the BPA project team using the predefined script in Appendix E - Interview Script for Evaluation of the Research. There were four openended questions with several probing questions for each question to assess the 
methodology. The focus of the questions was to see how well FCTA identified and grouped stakeholders, captured and understand concerns, isolated changes in perceptions over time, and isolated potential issues with the implementation. The interview was tape recorded with the team's permission, and the comments by team members, as identified in Table 32, were documented and time stamped for traceability.

\begin{tabular}{|c|c|}
\hline NAME & TITLE/JOB RESPONSIBILITY \\
\hline Lydia Grimm & Manager \\
\hline Tish Eaton & Environmental lead (planning/analysis) \\
\hline Sunshine Schmidt & Archaeologist \\
\hline Erich Orth & $\begin{array}{l}\text { Transmission Project Lead (and overall team lead-he took over the project } \\
\text { and brought it to completion) }\end{array}$ \\
\hline Kevin George & $\begin{array}{l}\text { Environmental lead (for the permitting and implementation/construction } \\
\text { phase) }\end{array}$ \\
\hline Dustin Smith & Realty \\
\hline Jamie Murray & Realty \\
\hline
\end{tabular}

Table 32: BPA Project Team

Question 1 set out to validate if the method for stakeholder identification and analysis used for aggregation was appropriate. For the most part, BPA agreed with the eight stakeholder groups: Pipe Creek residents, Bighorn residents, residents at large, local businesses, city of Libby, Montana State Government, US Federal Government, and tribal communities, as defined in Table 10 . However, BPA indicated that local businesses are treated as if there were residents. Furthermore, state and federal governments are very complex and often give conflicting views among agencies, and as a result, they would not have placed all agencies into one group, but rather they would 
have kept each agency as its own group. However, BPA did not indicate that the grouping was detrimental to the research findings. Aggregating stakeholder groups by like entities, such as all residents, did not provide much value to BPA. However, aggregating by like interests did. This was supported because BPA indicated that Bighorn Terrace residents got together with the city of Libby officials and asked them to be more involved. Furthermore, BPA indicated that the state of Montana (i.e., state senators) did join forces with Bighorn Terrace, thereby giving Bighorn Terrace residents more power.

Question 2 set out to understand if the causal cognitive mapping method was able to capture concerns accurately, which BPA indicated yes. However, BPA also indicated that there was a lot of one-on-one dialogue in meetings with stakeholders which is not documented. For example, tribal communities do not publically document their specific concerns but rather discuss them in person. It was the same for the federal government agencies. As a result, the research could not capture the discussions because there was no direct access to the stakeholders.

Question 3 set out to ask the project team whether or not the research captured and isolated changes in stakeholder perceptions between scoping and final EIS. The results of stakeholder concerns for each of the alternatives were discussed, and there were no objections to the results. The project team was asked about the issues they encountered during implementation. The premise was to determine if the model could isolate potential areas of conflict when stakeholder views differed from the experts' 
view. The research indicated that there could be potential issues with the state of Montana, Bighorn Terrace and federal government. The team acknowledged that there were issues initially with Bighorn Terrace because the residents had a relationship with the senator and governor, but eventually the residents quieted down once the more vocal person moved. Although BPA tried to resolve all issues prior to releasing the record of decision (ROD), they indicated that there were issues with the state of Montana and federal government over land use and ROW permits. Furthermore, when BPA started construction, they also found cultural issues with the Kootenai River realignment, the state of Montana, tribal communities and the US Forest Service. 


\section{SUMMARY OF FINDINGS AND LIMIATIONS}

\subsection{INTRODUCTION TO SUMMARY OF FINDINGS}

This chapter provides a summary of the findings presented in Chapters 6 and 7 based on the five research questions identified in Chapter 3. It also discusses the limitations of the research.

\subsection{MAJOR FINDINGS}

\subsubsection{Research Question 1}

Research question 1 investigates how FCM can be used to systematically integrate a wide range of stakeholder and expert input into the technology assessment and decision-making process while preserving their individual perceptions. The research identified several approaches for integrating stakeholder/expert input into FCMs and aggregating these FCMs into social cognitive maps that represent multiple stakeholder groups and expert views together.

For the case study, BPA identified approximately 300 stakeholders whose concerns were captured in 80 stakeholder documents, as well in the Appendix of the Draft and Final EIS. In all, the research captured knowledge from 64 individual stakeholders, six public forums, 10 local, state and federal government agencies, and two tribal communities. Stakeholder concerns were captured for eight stakeholder groups: Pipe Creek residents, Bighorn Terrace residents, residents at large, city of Libby, state of Montana, US Federal Government, and tribal communities. A causal cognitive map was developed for each 
stakeholder group in the exact words of the stakeholder group. Once captured, the stakeholders' exact words were translated using a common ontology of concepts. Furthermore, each causal cognitive map was converted into a common FCM structure. This ensured that all stakeholder models were comparable and could be mathematically aggregated, while also ensuring that there was traceability between the exact comment of the stakeholder and the FCM modeling. This approach provides an extension of previous research, whereby most prior research creates individual causal cognitive maps for each stakeholder group and combines them qualitatively into a single social cognitive map (Uygar Özesmi \& Özesmi, 2004) by relabeling stakeholder concepts and integrating them into bigger categories of meaning. This social cognitive map and the resulting FCM do not directly map to the individual cognitive maps that went into them, thereby reducing traceability and producing a risk for incorrectly interpreting stakeholder perceptions.

This research created 14 causal maps that represent stakeholder perceptions and two causal maps that show expert opinions. While this allows the assessments of alternatives in a pluralistic approach, decision-makers may want to further aggregate stakeholder groups. Appropriate means for aggregating stakeholder groups are discussed in the literature (A. J. Jetter \& Kok, 2014): quantitative approaches are highly traceable but can cover up important insights because opposing opinions can offset each other. For example, when one stakeholder assumes positive causality between two concepts and another stakeholder assumes a negative one, those two insights can offset 
each other and the information is lost. In this research, this effect has occurred when all stakeholder views were aggregated and led to the conclusion that the Quartz Creek realignment was the least impactful, which covers up the fact that the tribal communities, whose perceptions went into the aggregated model, viewed the Kootenai River realignment alternative as the least impactful.

An attempt to address this issue is by applying a weighting factor to the edge weights in the adjacency matrix before aggregating and normalizing the matrices (B. Kosko, 1988). Thus, the tribal communities' view could have been counted with a higher weight. However, the purpose of the FCTA methodology is to use stakeholder input to gain an empathic understanding of all the needs and concerns, not just those who - for whatever reasons - are deemed more important, impactful, or credible. For this reason, this research did not apply weights. It also kept stakeholder and expert FCM separate and preserved stakeholder group views in individual stakeholder models.

In summary, FCM is a vehicle that systematically integrates the technology assessment with the decision-making process, and it is capable of handling a wide range of stakeholder and expert input. To do this, it is best to create a common FCM structure based on a common ontology before creating the FCM. Furthermore, it is best to create small and granular stakeholder group FCMs and then aggregate them quantitatively to provide a more holistic view depending on the level of analysis. For example, agencies and departments within the state of Montana, such as the Department of Wildlife and 
Department of Environmental Quality, could be aggregated to create the state of Montana category, if desired. Individual influences are preserved in the individual FCM; therefore, they are not lost, and applying credibility weights defeats the purpose of making stakeholder input transparent.

\subsubsection{Research Question 2}

Research question 2 investigates how FCM models can be used to assess the positive and negative effects of alternative technologies on stakeholders. Prior to this study, research had shown that translating a causal cognitive map into an FCM provides the basis for conducting FCM simulation, which reveals hidden patterns (B. Kosko, 1988) and insights into stakeholders' perceptions of desirability for each of the alternatives. Where the research was limited, however, was on how to structure the FCM to assess technology alternatives and their impacts on stakeholders. In this research, each FCM was built using a common structure consisting of alternatives, cause-and-effect concepts that connected the alternatives to the EIS area concepts that measured of environmental impact objective. This provides the first general model for representing stakeholder views, EIS categories, and project alternatives in an integrated model.

Stakeholder interests can be asymmetrical and in conflict with one another or symmetrical and mutually reinforcing. The approach used in this research was to understand these pluralistic views by studying each stakeholder group separately. This was achieved by simulating the positive and negative impacts of each alternative for 
each stakeholder group and expert view, resulting in a total of 112 FCM scenarios. The hidden patterns in the EIS area concepts revealed the series of desirability outcomes for each alternative ranging from a "- 1 " to " 1 ". A positive value is viewed as a benefit and negative values are viewed as a harmful impact. The closer to " 1 " the more harm. Conversely, the closer to "1" the less harm (or more benefit). The same value meant that the stakeholder was indifferent to the alternatives. These values, which can be interpreted as preference or desirability, allowed the research to rank the alternatives for individual stakeholder groups and compare relative rankings across stakeholder groups.

In summary, this research provides a common FCM modeling framework and ontology used within the models to enable the assessment of the relative desirability of each alternative for each stakeholder group. This provides an understanding of the preference or dislike for each alternative from the perspective of each stakeholder group and in comparison to other groups. Moreover, the common FCM structure allows for comparison of factors that contribute to the dislike or preference of an alternative in each stakeholder group.

\subsubsection{Research Question 3}

Research question 3 investigates how FCM can be used to identify the potential for stakeholder coalitions. The research identified the potential stakeholder coalition among stakeholder groups that share the same concerns about the technology 
alternatives. One such coalition was identified by comparing the preference structure of the Bighorn Terrace residents and the state of Montana, who both preferred the Quartz Creek alternative. Bighorn Terrace was a very vocal group but did not have much power. However, the analysis showed that their interest in the Quartz Creek alternative was shared with the state of Montana, which does have power. By teaming up with the state, Bighorn Terrace could potentially become a salient stakeholder. In the assessment study with the BPA project team, the researcher therefore asked about the relationship between these two stakeholder groups and learned that Bighorn Terrace did engage the governor of Montana and a state senator, thereby giving its residents power and making their signals stronger.

A comparison of stakeholder perceptions also revealed that the state of Montana and the federal government both viewed the impacts associated with the Kootenai River to be harmful. However, the tribal communities, who the BPA project team characterized to be very salient, viewed the Kootenai River as the best of all alternatives because it eliminated the impacts on cultural resources that were associated with the existing transmission line. BPA indicated that after construction started, it was continually dealing with both the state and federal agencies regarding permitting and regulatory concerns. Although BPA did not indicate that the state of Montana and US federal government actually teamed up, the possibility of a shared strategy of both stakeholders certainly made the project more difficult. 
In summary, the research aggregated the two stakeholder relationships to uncover new insights from a holistic point of view. Their rankings did not change; therefore, the research did not discern any new insights, especially regarding power. However, the research did predict that coalitions based on like interests. In addition, the research aggregated like entities, such as all residents, governments, and stakeholders. The results revealed what alternative was best across multiple stakeholder groups and what concerns they have in common. While that may be of value, aggregating stakeholder groups also runs the risk of negating one group's positive interests with another group's negative interests as discussed in Research Question 1.

\subsubsection{Research Question 4}

Research question 4 investigates how FCM can be used to resolve conflicts between stakeholder interests and organizational objectives. To understand how stakeholder perceptions are in conflict with the organizational objectives, it is necessary to assess how the BPA experts assessed the value (or harm) of the alternatives and how these alternatives support or negate the organizational objectives. Furthermore, is necessary to understand how experts perceive the environmental value or harm of the alternatives to the stakeholders and how their perceptions differ from the stakeholders. As done in the previous research questions, FCM simulation is used to assess the eight alternatives when configuring the plausible states in the input vector. The $17 \mathrm{EIS}$ areas serve as BPA's way to measure the impacts on the environment. Project costs, which are 
based on the costs associated with each alternative, are provided in the draft and final EIS documents.

Policy sensitivity analysis was the process used to conduct tradeoff analysis. First, the research re-tested the four dynamic hypotheses as described in Section 7.1.2.2. BPA experts determined that replacing the existing $115 \mathrm{kV}$ was the least impactful on the environment and least costly, which the research shows to be true. BPA also decided to implement the Kootenai River realignment alternative because it had fewer impacts on cultural resources; however, it had more impacts on other resources such as amphibians. Again, the research proved this true. The research also showed that the Kootenai River realignment alternative was favored by the tribal communities, but not by the state of Montana and US federal government. The major factor for this decision was the impact to cultural resources associated with the construction activities that included placing a new culvert on the bridge over China Creek.

The policy sensitivity testing with the Kootenai River realignment alternative indicated that there were factors other than construction of new structures, roads and ROW clearing as indicated by BPA in the ROD. Policy sensitivity revealed it was the bridge/culvert, and the analysis revealed that it reduced impacts associated with replacing exiting $115 \mathrm{kV}$ line by $10 \%$. This analysis indicates that if BPA could have avoided or mitigated the impacts on China Creek, it would have not needed to implement the Kootenai River realignment. This would not only have supported the 
tribal communities' concerns about cultural resources, it would have also avoided the conflicts with the state of Montana and US federal government. Moreover, it would have reduced the overall cost of the project.

In summary, resolving conflicts between stakeholder interests and the organizational objectives requires understanding the differences in how the organization perceives the impacts of the alternatives on stakeholders and how stakeholders perceive impacts. When they differ, there is a potential area of conflict, and tradeoff analysis can be performed to test sensitivity on polices with various assumptions in the FCM model to reduce the impacts on stakeholders while meeting or improving the organizational objectives.

\subsubsection{Research Question 5}

Research question 5 investigates how new or changing stakeholder and expert input can be integrated into the FCM to reassess the technology alternatives. This was achieved by making the scoping FCMs the baseline and then making a copy of them before adding or changing the perceptions. This allows the research to compare perceptions between the two states, specifically, using research question 2 to assess the impacts of the alternatives at scoping and re-executing research question 2 after the draft EIS comments are included in the new FCM.

The research found that Bighorn Terrace and the state of Montana viewed the Kootenai River alternative as having the most impact during scoping, but after the draft EIS was 
released, Bighorn Terrace residents changed their view and indicated it was not impactful. For the most part, stakeholder group perceptions were stronger for their preferred alternative after the draft EIS was released. In addition, after the draft EIS was released, two new stakeholder groups viewed the concerns of the federal government and city of Libby. The US federal government also felt the Kootenai River alternative was most impactful.

In summary, understanding new perceptions or changes in perceptions requires identifying them and adding them to a copy of the previous FCM, thereby maintaining separate FCM models. The comparison process is simply a matter of assessing the impacts for each FCM and comparing the outcomes. When the value goes up, then the impacts that were previously thought to be harmful are lessened, and the reverse is true when the value goes down.

\subsection{LIMITATIONS}

The research demonstrated that FCM is a robust and useful approach for assessing the impacts of technology alternatives on stakeholders; analyzing conflicting interests with organizational objectives; and dynamically adjusting the conclusions when learning about new, or changes in, stakeholder perceptions and/or expert input. However, the research did have some limitations. First, the research did not have direct access to the stakeholders; therefore, the degree of influence could not be obtained. As a result, the causal relationships were represented by either a positive "1" or negative "-1". Although 
this did not present a problem in the development of FCM, the research was not able to discern the priority of the stakeholder's concerns. Furthermore, the researcher learned that not all information was disclosed in the publically available documents. For example, BPA indicated that there were several privately held meetings between BPA and tribal communities. As a result, the researcher was not able to incorporate this information into the model.

Second, the model could only compare the relative ranking of alternative preferences across stakeholder groups. As a result, the research could not compare how strongly one stakeholder group felt about the positive or negative effects of an alternative over another stakeholder group, only within the stakeholder group. Finally, the researcher did not have access to the true decision maker to evaluate the FCTA methodology from their perspective. Although the research received positive feedback from the BPA project team members, they are not the decision maker. 


\section{CONCLUSION, CONTRIBUTIONS AND FUTURE RESEARCH}

This research set out to resolve common problems with technology assessmentnamely, a lack of integration of stakeholder engagement activities and decisionmaking-by developing FCTA, an FCM-based technology assessment and decisionmaking methodology. To fulfill the methodological requirements identified in section 2.7 of this dissertation, FCTA needed to be capable of capturing a wide range of stakeholder and expert input in order to assess and anticipate the effects of the technology on stakeholders; analyze conflicting interests with organizational objectives; and dynamically adjust the conclusions when learning about new, or changes in, stakeholder perceptions and/or expert input.

FCTA demonstrated that it is capable of capturing a wide range of knowledge from stakeholders and experts, and it can be accomplished using existing stakeholder engagement practices. Preserving individual stakeholder group and expert perceptions requires capturing these perceptions in their own causal cognitive maps and developing a common ontology to translate the unique meaning of concepts into a shared understanding across all stakeholders and experts.

FCTA uses a common FCM structure that augments all common concepts. FCTA uses FCM simulation to assess the direct impacts associated with alternatives. By comparing rankings and assessing the hidden patterns found in the EIS areas, similar and pluralistic differences become visible. Similar interests between stakeholder groups are 
candidates for potential coalitions. Therefore, the individual FCMs can be aggregated into one FCM to understand these relationships holistically. Aggregating individual stakeholder group FCMs that are like entities also supports a holistic understanding at any desired level of analysis, while still preserving the individual perceptions and transparency. FCTA is also capable of identifying differences between stakeholder and expert perceptions as causes for potential problems. Furthermore, FCTA-based tradeoff analysis is achieved by changing the assumptions of the central concepts that affect the outcome in order to determine when the rankings of alternatives change. Finally, FCTA shows changes in perceptions over time to reassess decisions made.

Table 33 lists the contributions of this study to the research community and to practitioners of FCTA. It extends the TA and EIS research by developing a novel methodology - FCTA - that uses FCM modeling to integrate assessment and decision making; it provides a novel approach for using the stakeholder insights commonly generated during the NEPA process; and it applies FCTA to a complex real-world process and evaluates it with practitioners, demonstrating the applicability and usefulness. It extends the FCM research by capturing a wider range of experts and stakeholder inputs; supporting tradeoff analysis; and reassessing decisions in light of new information. Finally, it demonstrates applicability to the BPA project by providing new insights to the project team regarding government pushback over Kootenai River realignment and predicting stakeholder coalitions. 
FCTA would benefit from future research that includes developing and using FCM models with real-time projects and having access to the decision maker. Furthermore, the research would benefit greatly by modeling the power of a coalition to learn how that would affect the analysis and decision-making process and, finally, capturing stakeholder and expert perceptions using a technique called "crowd sourcing," whereby users would create their own causal cognitive maps using the Internet. This could increase the range of stakeholders and expert input.

\section{GAPS WITH CURRENT METHODS...}

RG1-... do not preserve the perceptions of stakeholders and experts

RG2 ... do integrate the assessment and decision-making

\section{FINDINGS AND CONTRIBUTION TO RESEARCH}

- Demonstrated FCM is capable of capturing a wider range of expert and stakeholder inputs and preserving individual perceptions

- Extended TA by developing a novel methodology - FCTA - that uses FCM modeling to integrate assessment and decision making

- Extended EIA by providing a novel approach using the stakeholder insights commonly generated during the NEPA process

- $\quad$ Extended TA and FCM by applying FCTA to a complex real-world process and evaluated it with practitioners, demonstrating the applicability and usefulness

RG3 ... do not support decision makers in understanding far-reaching and indirect effects of their decisions on stakeholders
- Provided new insights to the BPA project team regarding government pushback over Kootenai River realignment

- Predicted project stakeholder coalition

RG4 ... do not make transparent how stakeholder and expert inputs impact decisions

RG5-...do not assess tradeoffs between organizational objectives and stakeholder impacts

RG6 ... are static or have limited capacity to incorporate new or changing stakeholder perspectives
- Extended TA by demonstrating how stakeholders are impacted and how experts assess the impacts on stakeholders

- Extended FCM by demonstrating that policy sensitivity can be achieved using hypothesis testing and policy sensitivity analysis

- $\quad$ Extended FCM by reassessing decisions in light of new information

Table 33: Summary of Research Contributions 
In conclusion, the research bridges theory with practicality in the development of a Fuzzy Cognitive-based Technology Assessment methodology (FCTA). The methodology integrates a wide range of stakeholder and expert input into the assessment and decision-making process of a large infrastructure project. It is capable of assessing the impacts of alternative technologies on stakeholders; analyzing conflicting interests with organizational objectives; and dynamically adjusting the conclusions when learning about new, or changes in, stakeholder perceptions and/or expert input. Finally, it makes transparent how stakeholder and expert input influence the decision. 


\section{REFERENCES}

AccountAbility Institute (2005a). From Words to Action, Volume 1: Practitioners' Perspectives on Stakeholder Engagement.

AccountAbility Institute (2005b). From Words to Action, Volume 2: Practitioners' Pesrpectives on Stakeholder Engagement.

AccountAbility Institute (2008). AA1000 Assurance Standard (pp. 1-28).

Ackermann, F., \& Eden, C. (2005). Using Causal Mapping with Group Support Systems to Elicit an Understanding of Failure in Complex Projects: Some Implications for Organizational. Group Decision and Negotiation 14(5), 355-376.

Ackermann, F., \& Eden, C. (2005). The practice of making strategy. London, Thousand Oaks, New Delhi: Sage

Ackermann, F., \& Eden, C. (2011). Strategic Management of Stakeholders: Theory and Practice. Long Range Planning, 44(3), 179-196.

Ackermann, F., Eden, C., \& Williams, T. (1997). Modeling for Litigation: Mixing Qualitative and Quantitative Approaches. Interfaces, 27(2), 48-65.

Agle, B. R., Donaldson, T., Freeman, R. E., Jensen, M. C., Mitchell, R. K., \& Wood, D. J. (2008). Dialogue: Toward Superior Stakeholder Theory. Business Ethics Quarterly, 18(2), 153-190.

Agle, B. R., Micthell, R. K., \& Sonnedfeld, J. (1999). Who Matters to CEOs? An Investigation of Stakeholder Attributes And Salience, Corpate Performance, and CEOo Values. Academy of Management Journal, 42(5), 507-525.

Axelrod, R. (1976). Structure of Decision. The Cognitive Maps of Political Elites. Princeton: Princeton University Press.

Axelrod, R. (1976). Structure of Decision: The Cognitive Maps of Political Elites. . Princeton: Princeton University Press

Azzone, G., \& Manzini, R. (2008). Quick and dirty technology assessment: The case of an Italian Research Centre. Technological Forecasting and Social Change, 75(8), 1324-1338.

Baird, B. F. (1989). Managerial Decisions Under Uncertainty: John Wiley \& Sons.

Bass, R. E., \& Herson, A. I. (1993). Mastering NEPA: A Step-By-Step Approach. Point Arena: Solano Press Books.

Bonneville Power Administration (2007). Rebuild of the Libby (FEC) to Troy Seciton of $B P A$ 's Libby to Bonners Ferry 115-kilovolt Transmission Line: Draft Envrionmental Impact Study.

Bonneville Power Administration (2008). Rebuild of the Libby (FEC) to Troy Seciton of BPA's Libby to Bonners Ferry 115-kilovolt Transmission Line Project Record of Decision.

Borenstein, D. (1998). Towards a practical method to validate decision support systems. Decision Support Systems, 23(3), 227-239.

Brezet, H., \& van Hemel, C. (1997). ECODESIGN: a promising approach to sustainable production and consumption. Paris: United Nations Publications. 
Brooks, R. W. S., \& Harris, G. R. (2008). Citizen Participation, NEPA, and Land-Use Planning in Northern New York, USA. Envrionmental Practice, 10(4), 140-151.

Bryson, J. M., Ackermann, F., Eden, C., \& Finn, C. B. (2004). Visible Thinking Unlocking Causal Mapping for Practical Business Results. Chichester: John Wiley \& Sons Ltd.

Carley, K. (1986). Knowledge acquisition as a social phenomenon. Instructional Science, 14(3), 381-438.

Carley, K., \& Palmquist, M. (1992). Extracting, Representing, and Analyzing Mental Models. Social Forces, 70(3), 601-636.

Carley, K. M. (1997). Extracting Team Mental Models through Textual Analysis. Journal of Organizational Behavior, 18, 533-558.

Carroll, A. B. (1974). Corporate social responsibility: Its managerial impact and implications. Journal of Business Research, 2(1), 75-88.

Carroll, A. B. (1979). A Three-Dimensional Conceptual Model of Corporate Performance. Academy of Management Review, 4(4), 497-505.

Chambers, R. (1994a). The origins and practice of participatory rural appraisal. World Development, 22(7), 953-969.

Chambers, R. (1994b). Participatory rural appraisal (PRA): Challenges, potentials and paradigm. World Development, 22(10), 1437-1454.

Checkland, P. (2000). Soft Systems Methodology: A Thirty Year Retrospective(a). Systems Research and Behavioral Science, S11.

Chen, L., Liu, J., \& Chih-Chen (2001). An eco-innovative design approach incorporating the TRIZ method without contradiction analysis. The Journal of Sustainable Product Design, 1(4), 263-272.

Clarkson, M. E. (1995). A Stakeholder Framework for Analyzing And Evaluating Corporate Social Performance. Academy of Management Review, 20(1), 92-117.

Coase, R. (1998). The New Institutional Economics. American Economic Review, 88(2), 72-74.

Collins, K. M. T., \& Onwuegbuzie, A. J. (2007). A typology of mixed methods sampling designs in social science research. The Qualitative Report, 12, 281+.

Cristofari, M., Deshmukh, A., \& Wang, B. (1996). Green quality function deployment. Paper presented at the 4th International Conference on Environmentally Conscious Design and Manufacturing, Cleveland, OH, pp. 297-304.

D'Arcy, R. (2009). The Road to Product Stewardship: Local Government as Catalysts Retrieved 7/8/2011, 2011, from http://www.calpsc.org/solution/whatis EPR.html

Dellinger, A. B., \& Leech, N. L. (2007). Toward a Unified Validation Framework in Mixed Methods Research. Journal of Mixed Methods Research, 1(4), 309-332.

Dickerson, J., \& Kosko, B. (1994). Virtual Worlds as Fuzzy Dynamical Systems. In B. Sheu (Ed.), Technology for Multimedia (pp. 1-35): IEEE Press.

Dickerson, J. A., \& Kosko, B. (1993, 18-22 Sep 1993). Virtual worlds as fuzzy cognitive maps. Paper presented at the Virtual Reality Annual International Symposium, 1993., 1993 IEEE. 
Donaldson, T., \& Dunfee, T. W. (1994). Toward a Unified Conception of Business Ethics: Integrative Social Contracts Theory. Academy of Management Review, 19(2), 252-284.

Dresner, S., \& Gilbert, N. (1999). Decision-Making Processes for Projects Requiring Environmental Impact Assessment: Case Studies in Six European Countries. Journal of Environmental Assessment Policy \& Management, 1(1), 105.

Eccleston, C. H. (2001). Effective Envrionmental Assessments: How to Manage and Pepare NEPS EAs. Boca Raton: Lewis Publishers.

Eden, C. (1988). Cognitive mapping. European Journal of Operational Research, 36(1), 113.

Eden, C. (1992). On the Nature of Cognitive Maps. Journal of Management Studies, 29(3), 261-265.

Eden, C., \& Ackermann, F. (2002). A Mapping Framework for Strategy Making In A. S. Huff \& M. Jenkins (Eds.), Mapping Strategic Knowledge (pp. 173-195 ). London, Thousand Oaks, New Delhe Sage.

Eden, C., \& Ackermann, F. (2002). A Mapping Framework for Strategy Making. In A. S. Huff \& M. Jenkins (Eds.), Mapping Strategic Knowledge (pp. 173-195). London, Thousand Oaks, New Delhi: Sage.

Eden, C., Ackermann, F., \& Cropper, S. (1992). The analysis of cause maps. Journal of Management Studies, 29(3), 309-324.

Fiksel, J. (1996a). Achieving Eco-Efficiency Through Design for Environment. Total Quality Environmental Management, Summer, 47-54.

Fiksel, J. (1996b). Conceptual Principles of DfE. In J. Fiksel (Ed.), Design For Environment: Creating Eco-Efficient Products and Processes. New York: McGraw-Hill.

Fiksel, J. (2003). Designing Resilient, Sustainable Systems. Environmental Science \& Technology, 37(23), 5330-5339.

Fisher, E. (2005). Lessons learned from the Ethical, Legal and Social Implications program (ELSI): Planning societal implications research for the National Nanotechnology Program. Technology in Society, 27(3), 321-328.

Freeman, R. E. (1984). Strategic Management: A Stakeholder Approach. Boston: Pitman/Ballinger.

Freeman, R. E. (2004). The Stakeholder Approach Revisited. Argument, 5(3), 228-254.

Freeman, R. E., Harrison, J. S., Wicks, A. C., Parmar, B. L., \& deColle, S. (2010). Stakeholder Theory - The State of the Art. Cambridge, UK: Cambridge University Press.

Frooman, J. (1999). Stakeholder Influence Strategies. Academy of Management Review, 24(2), 191-205.

Gass, S. I. (1983). Decision-aiding models: validation, assessment, and related issues for policy analysis. Operations Research, 31(4), 603-631.

Genus, A. (2006). Rethinking constructive technology assessment as democratic, reflective, discourse. Technological Forecasting and Social Change, 73(1), 13-26. 
Giordano, R., Passarella, G., Uricchio, V., \& Vurro, M. (2007). Integrating conflict analysis and consensus reaching in a decision support system for water resource management. Journal of Environmental Management, 84(2), 213-228.

Giordano, R., Passarella, G., Uricchio, V. F., \& Vurro, M. (2005). Fuzzy cognitive maps for issue identification in a water resources conflict resolution system. Physics and Chemistry of the Earth, 30, 463-469.

Glasson, J., Therivel, R., \& Chadwick, A. (1994). Introduction to Envrionmental Impact Assessment. London: UCL Press Unlimited.

GRI (2000-2011). Sustainability Reporting Guidelines v3.1 (pp. 195).

Grin, J., \& van de Graaf, H. (1996). Technology Assessment as Learning. Science, Technology \& Human Values, 21(1), 72-99.

Guston, D. (2013). Understanding'Anticipatory Governance'. Social Studies of Science, 0306312713508669.

Guston, D. H. (1999). Evaluating the First U. S. Consensus Conference: The Impact of the Citizens' Panel on Telecommunications and the Future of Democracy. Science, Technology, \& Human Values, 24(4), 451-482.

Guston, D. H. (2001, June 14). Science and Technology Advice for the Congress: Insights from the OTA Experience. Paper presented at the Creating Institutional Arrangements to Provide Science and Technology Advice to Congress, Washington, DC.

Guston, D. H., \& Sarewitz, D. (2002). Real-time technology assessment. Technology in Society, 24(1-2), 93-109.

Harary, F., Norman, R. Z., \& Cartwright, D. (1965). Structural models: an introduction to the theory of directed graphs. New York: John Wiley \& Sons.

Harrison, J. S., Bosse, D. A., \& Phillips, R. A. (2010). Managing for stakeholders, stakeholder utility functions, and competitive advantage. Strategic Management Journal, 31(1), 58-74.

Harrison, J. S., \& Freeman, R. E. (1999). Stakeholders, Social Responsibility, and Performance: Empirical Evidence and Theoretical Perspectives. Academy of Management Journal, 42(5), 479-485.

Harrison, J. S., \& St. John, C. H. (1996). Managing and partnering with external stakeholders. Academy of Management Executive, 10(2), 46-60.

Hart, S. L. (1997). Beyond Greening: Strategies for a Sustainable World. Harvard Business Review, 75(1), 66-76.

Hart, S. L., \& Sharma, S. (2004). Engaging Fringe Stakeholders for Competitive Imagination. The Academy of Management Executive (1993-2005), 18(1), 7-18.

Hauser, J. R., \& Clausing, D. (1988). The House of Quality. Harvard Business Review, 66(3), 63-73.

Hildebrand, S. G., \& Cannon, J. B. (1993). Envrionmental Analysis. Boco Raton: Lewis Publishers.

Huff, A. S. (Ed.). (1990). Mapping Strategic Thought. Chichester: John Wiley \& Sons. ISO (2010). ISO 26000: Guidance on Social Responsibility. . 
Jensen, M. C. (2002). Value Maximization, Stakeholder Theory, and the Corporate Objective Function. Business Ethics Quarterly, 12(2), 235-256.

Jetter, A., \& Schweinfort, W. (2011). Building Scenarios with Fuzzy Cognitive Maps: An Exploratory Study of Solar Energy. Futures, 43, 52-66.

Jetter, A. J. (2006, 8-13 July 2006). Fuzzy Cognitive Maps for Engineering and Technology Management: What Works in Practice? Paper presented at the Technology Management for the Global Future, 2006. PICMET 2006.

Jetter, A. J. (2011). Integrating Multiple Stakeholder Perspectives with Fuzzy Cognitive Maps - A Tutorial. Department of Engineering and Technology Management, Portland State University.

Jetter, A. J., \& Kok, K. (2013). Fuzzy Cognitive Maps for Futrues Studies - A Methodological Assessment of Concepts and Methods. Unpublished WIP. Portland State Unicersity, Department of Engineering and Technology Management and Wageningen University, Land Dynamics Group, the Netherlands.

Jetter, A. J., \& Kok, K. (2014). Fuzzy Cognitive Maps for Futrues Studies - A Methodological Assessment of Concepts and Methods. [WIP]. Futures (in print).

Jetter, A. J., \& Sperry, R. (2013). Fuzzy Cognitive Maps for Product Planning: Using Stakeholder Knowledge to AchCorporate Responsibility. Paper presented the 46th Hawaii International Conference.

Jetter, A. J. M. (2003, 20-24 July 2003). Educating the guess: strategies, concepts and tools for the fuzzy front end of product development. Paper presented at the Management of Engineering and Technology, 2003. PICMET '03. Technology Management for Reshaping the World. Portland International Conference on.

Jetter, A. J. M., \& Sperry, R. C. (2011). Realizing Corporate Social Responsibility in Product Planning - The Potential of Fuzzy Cognitive Map Modeling. Paper presented at the 5th Annual International Conference on Business and Sustainability.

Johnson, R. B., Onwuegbuzie, A. J., \& Turner, L. A. (2007). Toward a Definition of Mixed Methods Research. Journal of Mixed Methods Research, 1(2), 112-133.

Jones, B. (1995). Institutional Change: Theory and Empirical Findings. Journal of Management Studies, 32(2), 249-251.

Jones, S. R. H. (1997). Transaction Costs and the Theory of the Firm: The Scope and Limitations of the New Institutional Approach. Business History, 39(4), 9-25.

Kardaras, D., \& Mentzas, G. (1997). Using Fuzzy Cognitive Maps to Model and Analyse Business Performance Assessment. Paper presented at the 2nd Annual International Conference on Industrial Engineering Applications and Practice San Diego, CA.

Kiesler, S., \& Sproull, L. (1982). Managerial Response to Changing Environments: Perspectives on Problem Sensing from Social Cognition. Administrative Science Quarterly, 27(4), 548-570. 
Kim, J., \& Courtney, J. F. (1988). A survey of knowledge acquisition techniques and their relevance to managerial problem domains. Decision Support Systems, 4(3), 269284.

King, A. (2007). Cooperation between Corporations and Environmental Groups: A Transaction Cost Perspective. Academy of Management Review, 32(3), 889-900.

Kok, K. (2009). The potential of Fuzzy Cognitive Maps for semi-quantitative scenario development, with an example from Brazil. Global Environmental Change, 19(1), 122-133.

Kosko, B. (1986). Fuzzy Cognitive Maps International Journal of Man-Machine Studies 24(1), 65-75.

Kosko, B. (1986). Fuzzy Cognitive Maps. International Journal of Man-Machine Studies, 24(1), 65-75.

Kosko, B. (1988). Hidden patterns in combined and adaptive knowledge networks. International Journal of Approximate Reasoning, 2(4), 377-393.

Kosko, B. (1988). Hidden patterns in combined and adaptive knowledge networks. International Journal of Approximative Reasoning, 2(4), 377-393.

Kosko, B. (1993). Adaptive Inference in Fuzzy Knowledge Networks. In D. Dubois, H. Prade \& R. R. Yager (Eds.), Readings in Fuzzy Sets for Intelligent Systems. San Mateo: Morgan Kaufman.

Krefting, L. (1991). Rigor in Qualitative Research: The Assessment of Trustworthiness. Am J Occup Ther, 45(3), 214-222.

Lengwiler, M. (2008). Participatory approaches in science and technology historical origins and current practices in critical perspective. Science, Technology \& Human Values, 33(2), 186-200.

Linstone, H. A. (1999). Decision Making for Technology Executives. Boston: Artech House.

Lopolito, A., Prosperi, M., \& Sisto, R. (2009). Socio-Economic Implicatons of the Development of a Bio-Refinery: An Analysis with Fuzzy Cognitive Maps. Retrieved from http://unifg.academia.edu/AntonioLopolito/Papers/1053338/SocioEconomic Implications of The Development of A BioRefinery An Analysis With Fuzzy Cognitive Maps

Masui, K., Sakao, T., Kobayashi, M., \& Inaba, A. (2003). Applying Quality Function Deployment to environmentally conscious design. International Journal of Quality \& Reliability Management, 20(1), 90-106.

Miao, Y., Liu, Z.-Q., Tao, X. H., Shen, Z. Q., \& Li, C. W. (2002). Simplification, Merging and Division of Fuzzy Cognitive Maps. International Journal of Computational Intelligence \& Application, 2(2), 185.

Mitchell, R. K., \& Agle, B. R. (1997). Stakeholder Identification and Salience: Dialogue and Operationalization. Paper presented at the International Association for Business and Society, Destin, FL. 
Mitchell, R. K., Agle, B. R., \& Wood, D. J. (1997). Toward a Theory of Stakeholder Identification and Salience: Defining the Principle of Who and What Really Counts. Academy of Management Review, 22(4), 853-886.

Modak, P., \& Biswas, A. K. (1999). Conducting Envrionmental Impact Assessment for Developing Countries. Tokyo: United Nations University Press.

Mouratiadou, I., \& Moran, D. (2007). Mapping public participation in the Water Framework Directive: A case study of the Pinios River Basin, Greece. Ecological Economics, 62(1), 66-76.

Moxnes, E. (2005). Policy sensitivity analysis: simple versus complex fishery models. System Dynamics Review, 21(2), 123-145.

Nakamura, K., Iwai, S., \& Sawaragi, T. (1982). Decision Support Using Causation Knowledge Base. Systems, Man and Cybernetics, IEEE Transactions on, 12(6), 765-777.

Nooy, W. d., Mrvar, A., \& Batagelj, V. (2005). Exploratory Social Network Analysis with Pajek. Cambridge: Cambridge University Press.

Nourry, M. (2008). Measuring sustainable development: Some empirical evidence for France from eight alternative indicators. Ecological Economics, 67(3), 441-456.

Özesmi, U. (1999). Conservation Strategies for Sustainable Resource Use in the Kizilirmak Delta in Turkey. University of Minnesota, Minneapolis.

Özesmi, U., \& Özesmi, S. L. (2003). A Participatory Approach to Ecosystem Conservation: Fuzzy Cognitive Maps and Stakeholder Group Analysis in Uluabat Lake, Turkey. Environmental Management, 31(4), 0518-0531.

Özesmi, U., \& Özesmi, S. L. (2004). Ecological models based on people's knowledge: a multi-step fuzzy cognitive mapping approach. Ecological Modeling, 176(1-2), 4364.

Palm, E., \& Hansson, S. O. (2006). The case for ethical technology assessment (eTA). Technological Forecasting and Social Change, 73(5), 543-558.

Pennington, D. W., Potting, J., Finnveden, G., Lindeijer, E., Jolliet, O., Rydberg, T., et al. (2004). Life cycle assessment Part 2: Current impact assessment practice. Environment International, 30(5), 721-739.

Porter, M. E. (1980). Competitive Strategy: Techniques for Analyzing Industries and Competitors. New York: The Free Press.

Porter, M. E., \& Kramer, M. R. (2006). Strategy \& Society: The Link Between Competitive Advantage and Corporate Social Responsibility. Harvard Business Review, 84(12), 78-92.

Prasad, B. (1998). Review of QFD and Related Deployment Techniques. Journal of Manufacturing Systems, 17(3), 221-234.

Pretty, J. N. (1995). Participatory learning for sustainable agriculture. World Development, 23(8), 1247-1263.

Probst, G., \& Gomez, P. (1989). Thinking in Networks to Avoid Pitfalls of Managerial Thinking. Human Systems Management, 8(3). 
Project Management Institute (2013). A Guide to the Project Management Body of Knowledge (PMBOK ${ }^{\circledR}$ Guide) -Fifth Edition. Newton Square, PA: Project Management Institute, Inc. .

Rahimi, M., \& Weidner, M. (2002). Integrating Design for Environment (DfE) Impact Matrix into Quality Function Deployment (QFD) Process. The Journal of Sustainable Product Design, 2(1), 29-41.

Rebitzer, G., Ekvall, T., Frischknecht, R., Hunkeler, D., Norris, G., Rydberg, T., et al. (2004). Life cycle assessment: Part 1: Framework, goal and scope definition, inventory analysis, and applications. Environment International, 30(5), 701-720.

Roberts, C. W. (1989). Other Than Counting Words: A Linguistic Approach to Content Analysis. Social Forces, 68(1), 147-177.

Runliang, D., \& Hui, Z. (2009, 21-23 Oct. 2009). Model of design for energy saving of products based on the integration of TRIZ/AD/QFD. Paper presented at the Industrial Engineering and Engineering Management, 2009. IE\&EM '09. 16th International Conference on.

Saling, P., Kicherer, A., Dittrich-Krämer, B., Wittlinger, R., Zombik, W., Schmidt, I., et al. (2002). Eco-efficiency analysis by basf: the method. The International Journal of Life Cycle Assessment, 7(4), 203-218.

Salomon, M., \& Seegers, S. (1996). Rapid Appraisal of Agricultural Knowledge Systems (RAAKS) and its Use in Irrigation Management Report: International Irrigation Management Institute, Pakistan.

Schmidt, I., Meurer, M., Saling, P., Kicherer, A., Reuter, W., \& Gensch, C.-O. (2004). SEEbalance: Managing Sustainability of Products and Processes with the SocioEco-Efficiency Analysis by BASF. Greener Management International(45), 79-94.

Schot, J., \& Rip, A. (1997). The past and future of constructive technology assessment. Technological Forecasting and Social Change, 54(2-3), 251-268.

Shonnard, D. R., Kicherer, A., \& Saling, P. (2003). Industrial Applications Using BASF EcoEfficiency Analysis: Perspectives on Green Engineering Principles. Environmental Science \& Technology, 37(23), 5340-5348.

Soler, L. S., Kok, K., Camara, G., \& Veldkamp, A. (2012). Using fuzzy cognitive maps to describe current system dynamics and develop land cover scenarios: a case study in the Brazilian Amazon. Journal of Land Use Science, 7(2), 149-175.

Stach, W., Kurgan, L., Pedrycz, W., \& Reformat, M. (2005). Genetic learning of fuzzy cognitive maps. Fuzzy Sets and Systems, 153(3), 371-401.

Sterman, J. D. (2000a). Business Dynamics: System Thinking and Modeling for a Complex World. Boston: Irwin McGraw-Hill.

Sterman, J. D. (2000b). Business Dynamics: System Thinking and Modeling for a Complex World Boston: Irwin McGraw-Hill.

Sterman, J. D. (2001). System Dynamics Modeling: Tools for Learning in a Complex World. California Management Review, 43(4), 8-25.

Stitzhal, D. (2011). Product stewardship: Can it drive green design? Environmental Quality Management, 20(3), 25-41. 
Taber, R. (1991). Knowledge processing with Fuzzy Cognitive Maps. Expert Systems with Applications, 2(1), 83-87.

Thorn, M. J., Kraus, J. L., \& Parker, D. R. (2011). Life-cycle assessment as a sustainability management tool: Strengths, weaknesses, and other considerations. Environmental Quality Management, 20(3), 1-10.

Tsadiras, A. K. (2008). Comparing the inference capabilities of binary, trivalent and sigmoid fuzzy cognitive maps. Information Sciences, 178(20), 3880-3894.

Van Eijndhoven, J. C. M. (1997). Technology assessment: Product or process? Technological Forecasting and Social Change, 54, 269-286.

Van Eijndhoven, J. e. C. M. (1997). Technology assessment: Product or process? Technological Forecasting and Social Change, 54(2â€“3), 269-286.

van Vliet, M., Kok, K., \& Veldkamp, T. (2010). Linking stakeholders and modellers in scenario studies: The use of Fuzzy Cognitive Maps as a communication and learning tool. Futures, 42(1), 1-14.

Voinov, A., \& Bousquet, F. (2010). Modelling with stakeholders. Environmental Modelling \&amp; Software, 25(11), 1268-1281.

Wartick, S. L., \& Cochran, P. L. (1985). The Evolution of the Corporate Social Performance Model. Academy of Management Review, 10(4), 758-769.

Wildenberg, M., Bachhofer, M., Adamescu, M., De Blust, G., Diaz-Delgadod, R., Isak, K. G. Q., et al. (2010). Linking thoughts to flows - Fuzzy cognitive mapping as tool for integrated landscape modeling Retrieved 3/13/2012, 2012, from http://www.symposcience.org/exl-doc/colloque/ART-00002419.pdf

Wilkins, H. (2003). The need for subjectivity in EIA: discourse as a tool for sustainable development. Environmental Impact Assessment Review, 23(4), 401-414.

Williamson, O. E. (1979). Transaction-Cost Economics: The Governance of Contractual Relations. Journal of Law and Economics, 22(2), 233-261.

Wood, D. J. (1991). Corporate Social Performance Revisited. Academy of Management Review, 16(4), 691-718.

Wood, F. B. (1997). Lessons in Technology Assessment Methodology and Management of OTA. Technological Forecasting and Social Change, 54, 145-162.

Woodward, D. G. (1997). Life cycle costing--Theory, information acquisition and application. International Journal of Project Management, 15(6), 335-344.

Wrightson, M. T. (1966). The Documentary Coding Method. In R. Axelrod (Ed.), Stucture of Decision (pp. 291-332): Princeton University Press.

Xirogiannis, G., \& Glykas, M. (2004). Fuzzy cognitive maps in business analysis and performance-driven change. Engineering Management, IEEE Transactions on, 51(3), 334-351.

Yin, R. K. (Ed.). (2003). Case Study Researh Design and Methods (3 ed.). Thousand Oaks: Sage Publications.

Zhang, Y., Wang, H. P., \& Zhang, C. (1999). Green QFD-II: a life cycle approach for environmentally conscious manufacturing by integrating LCA and LCC into QFD matrices. International Journal of Production Research, 37(5), 1075. 


\section{APPENDIX A - LIBBY TO TROY UPGRADE PROJECT}

The following information is from the Final EIS, pp. S1-S7, which can be found at BPA's website http://efw.bpa.gov/environmental services/Document Library/Libby/

\section{PuRPose AND NEED FOR ACTION}

Historically, BPA has served electrical loads in northwestern Montana and northern Idaho with transmission facilities from Libby Dam east of Libby, Montana, through Bonners Ferry Substation west of Bonners Ferry, Idaho, to Albeni Falls Dam near the Idaho-Washington border. These facilities include a 17-mile section of 115-kilovolt (kV) transmission line that extends from a Flathead Electric Cooperative (FEC) substation near the town of Libby, Montana, to a BPA substation near Troy. This line section, referred to as the Libby-Troy line, is an integral part of the larger $115-\mathrm{kV}$ transmission loop in the area that provides electrical service to Libby, Bonners Ferry, Sandpoint, and many smaller communities.

The Libby-Troy line section originally belonged to Pacific Power and Light and was purchased by FEC in November 1998. It was the only section of this transmission loop that BPA did not own. In 2003, BPA purchased this section from FEC because BPA was concerned that the line's deteriorating condition could threaten the reliability of the regional transmission system. The transmission line is supported by wooden structures (Figure S-2). Most of the cross-arms that carry the line on the structures are rotting and metal parts, electric current) fell to the ground, starting a fire. 
The Libby-Troy transmission line provides backup service (redundant load service) to the area if another transmission line is out of service. This means service to the area is maintained because the Libby-Troy line provides an electrical connection to Libby and Albeni Falls dams. Without the Libby-Troy line, this level of service would be reduced, and the area could lose power if another line failed. BPA has taken steps to prevent the line from failing in the near term, but these measures cannot solve the problem for the long term. BPA needs to rebuild or reinforce this section of its transmission system to provide stable and reliable transmission service to northwestern Montana. In addition, electrical load for the communities served by the Libby Dam-Albeni Falls Dam transmission system is projected to grow at an average of 1 percent per year. Over time this load growth will increasingly strain the existing electrical system.

BPA must decide whether to rebuild the Libby-Troy transmission line. If BPA's decision is to rebuild the transmission line, BPA must choose among alternative voltages and alternative routing options in certain locations, and among various measures to mitigate construction and operational impacts. Additionally, the United States Forest Service (USFS) must decide whether to grant BPA a permit for additional corridor areas across the Kootenai National Forest beyond what has been granted under the Special Use permit for the existing transmission line. In making these decisions, BPA and the Kootenai National Forest will consider the following purposes or objectives: 
- Maintain transmission system reliability to industry standards;

- Continue to meet BPA's contractual and statutory obligations;

- Minimize environmental impacts; and

- Minimize costs

\section{Public Involvement}

During the development of this EIS, BPA solicited input from the public, agencies, interest groups, and others to help determine what issues should be studied in the EIS. BPA requested comments through publishing notices in the Federal Register, mailing letters to about 300 people and agencies requesting comments, holding four public meetings (including one devoted to electric and magnetic fields), and meeting with state agencies. Most scoping comments received by BPA focused on potential impacts to fish, wildlife, visual resources, and cultural resources; public health and safety; residential land use and property values; and proposed realignment options near Pipe Creek, Quartz Creek and across the Kootenai River.

\section{Cooperating Agencies}

BPA is the lead agency for the Libby-Troy Project EIS. The USFS - Kootenai National Forest, the U.S. Army Corps of Engineers, and the Montana Department of Environmental Quality (DEQ) are cooperating agencies in the development of this EIS because of their roles as managers of lands crossed by the Libby- Troy line, or because the agencies need to make findings on the project. 


\section{Tribal Involvement}

Throughout the EIS process, BPA has strived to involve the potentially affected tribes in the proposed project area: the Kootenai Tribe of Idaho and the Confederated Salish and Kootenai Tribes. Representatives from both tribes participated in site trips conducted in 2002 and 2004 and provided advice and perspective in developing project alternatives. In 2005, BPA sent a letter to these tribes that outlined a process for initiating a formal government-to-government consultation process when or if desired. To date, the tribes have not requested formal government-to-government consultation meetings. Throughout 2007 and 2008, BPA has met with tribal representatives to discuss project specifics, including the proposed road work at Black Eagle Rock.

\section{Alternatives}

BPA is considering two alternatives to meet the purpose and need: the Proposed Action (115-kV single-circuit rebuild) and Alternative 1 (230-kV double-circuit rebuild). Both of these alternatives include rebuilding the existing 17-mile-long Libby-Troy section of the $115-\mathrm{kV}$, Libby-Bonners Ferry transmission line. BPA is also considering the No Action Alternative. Under the No Action Alternative, the existing line would not be rebuilt but would continue to be operated and maintained in its current location. 


\section{Proposed Action - 115-kV Single-Circuit Rebuild}

Under the Proposed Action, BPA would rebuild the Libby-Troy section at the same voltage $(115-\mathrm{kV})$, with the same number of circuits (one) as currently exists. The line would be rebuilt in the same location as the existing line.

\section{Removal of Existing Wood-Pole Structures}

The 186 existing wood pole structures would be removed. In most cases, the structures would be removed using a backhoe or line truck/crane and would be disposed of by the contractor according to the regulations required for handling hazardous materials (structures contain preservatives that are considered hazardous). In culturally sensitive areas, such as the Kootenai Falls area, the poles would be cut off at the ground line and transported off site via trailer or helicopter. A helicopter also would likely be used to remove poles in inaccessible areas along portions of Sheep Range Road and the historic Highway 2 trail.

\section{Line Routing and Corridor}

BPA's existing Libby-Troy transmission line corridor crosses a combination of private, City of Libby, county, state, tribal, and federal (USFS) land. BPA holds right-of-way easements, agreements and permits that give BPA the right to clear vegetation a certain width out from the centerline of the corridor; the right to cut and remove trees beyond the stated width if they might endanger the transmission line; and the right to access, 
operate, and maintain the line along most of the corridor. In some areas, additional right-of-way easements or permits would be acquired because either the existing corridor is not wide enough to accommodate the rebuilt $115-\mathrm{kV}$ line or because BPA moving the centerline requiring new easements or permits. Easements or permits giving BPA the rights to construct, operate, rebuild, access, and maintain the line would be needed in the following areas.

- Structures $15 / 181$ to $17 / 5,28 / 7$ to $29 / 1$, and $30 / 2$ to $31 / 1$ cross National Forest System lands where the existing Special Use Permit limits the clearing width to 60 feet. Additional width would be needed.

- Structures $17 / 15$ to $18 / 8$ cross private land along Kootenai River Road near Bobtail Road. BPA would need to acquire right-of-way easements for an additional width if the centerline of the transmission line is moved to the north about 2 feet between structures 18/1 and 18/6. Between structures 17/15 and $17 / 18$, a new easement would be needed if the centerline is moved to the north side of Kootenai River Road to eliminate the road crossings. If the transmission line remains in the current location between $17 / 15$ and $17 / 18$, additional width easements would need to be acquired on the south side of the road. No additional easements would be needed between $17 / 18$ and $18 / 1$ because the current width is sufficient. Additional right-of-way easements would be needed between $18 / 6$ and $18 / 8$ to provide for a 60 - to 80 - foot wide corridor. 
- Land under structures $26 / 1$ to $26 / 8$ is currently owned by Lincoln County; the land rights were originally acquired as an agreement for a license and permit for a power line across property owned by Great Northern Railroad Company. BPA would be acquiring easement rights from Lincoln County.

- Structures $28 / 3$ to $28 / 7,29 / 1$ to $30 / 2$, and $31 / 1$ to BPA's Troy Substation cross private lands where the fixed clearing width was limited to 60 feet. Additional easement width would be needed.

BPA does not permit any use of its rights-of-way that are unsafe or might interfere with constructing, operating, or maintaining the transmission facilities.

\section{Transmission Structure Design}

About 171 transmission structures would be needed to carry the transmission line conductors for the proposed rebuild on the existing corridor. Wood or colorized steel Hframe structures would be used for about 14.6 miles of the 17-mile-long line. This includes the areas inaccessible to motor vehicles along the historic U.S. Highway 2 west of Kootenai Falls, and along Sheep Range Road. About 1.6 miles of the line would be constructed with single wood poles, and the remaining 0.8 miles would be constructed using colorized steel single-pole structures. The wood or steel $\mathrm{H}$-frame structures and the single wood poles would about 20 inches in diameter at the base and about 60 to 80 feet tall. Poles would be spaced about 12 feet apart for $\mathrm{H}$-frame structures. The steel poles would be about 30 inches in diameter at the base and range from 70 to 105 feet tall. The 
steel structures would be colorized a dark gray to blend with the surrounding environment as much as possible.

\section{Structure Footings}

At each structure site, an area about 75 feet by 75 feet would be temporarily disturbed

during construction, depending on the terrain and structure type. Structures without guy wires would permanently use an area about 15 feet by 15 feet; structures with guy wires would use an area about 30 feet by 50 feet. New structures would be constructed in the same holes used for the existing structures where possible, although some new holes may be needed. New footing holes would either be hand dug (in inaccessible areas), augered, or dug with a small backhoe excavator, depending on subsurface conditions. The wood or steel poles would be placed directly in the holes (directembedded) and then backfilled with native material or gravel (crushed rock). Concrete could be used as backfill for some structures.

\section{Fiber Optics}

Although there is no operational need at this time to install fiber optic cable between Libby and Troy substations, BPA would provide space on the transmission structures for future BPA installation should the need arise. 


\section{Conductor, Fiber Optic Cable, and Pulling/Tensioning Sites}

Conductors are suspended from structures with insulators. Insulators are bell-shaped devices that prevent electricity from jumping from the conductors to the structure and going to the ground. The proposed project would most likely use a combination of ceramic and non-ceramic polymer insulators. Two smaller wires (0.5-inch diameter), called overhead ground wires, would also be attached to the top of the transmission structures for about a half mile coming out of Libby and Troy substations to protect the substations from lightning damage. Overhead ground wires might also be strung in other areas of high lightning exposure. A fiber optic cable may be installed either as the overhead ground wire or independently on the structure.

Every two to three miles a conductor pulling and/or tensioning site is needed so trucks can pull the conductor to the correct tension during construction. These temporary sites typically disturb an area of about one acre.

\section{Vegetation Clearing}

Clearing of tall-growing vegetation would take into account line voltage, vegetation species height and growth rates, ground slope, conductor location, span length (which influences conductor swing), stringing requirements, and the clearance distance required between the conductors and other objects. Because most vegetation within the existing corridor is low-growing shrubs or young trees and most of the corridor is already 80 feet wide, additional clearing of tall-growing vegetation would be minimal. 
However, in areas where BPA proposes to acquire additional width, many larger trees would be removed. On either side of both the existing and new right-of-way, danger trees that pose a hazard to construction activities and reliable operation of the transmission line would be removed.

\section{Access Roads}

Much of BPA's road system for the existing corridor would be used for rebuilding the line, although roads would need to be improved in most areas. Many of the structures located along the historic U.S. Highway 2 section and a few located along the north side of the Kootenai River are inaccessible except by helicopter.

The proposed transmission line rebuild would require improving about 14 miles of existing access road on and off the existing transmission corridor and constructing about 4.5 miles of new access road on and off the existing corridor. Improvement and construction would consist of the following activities: widening existing roads; installing or improving an estimated 20 culverts, drain dips and water bars; installing one bridge at China Creek; constructing an access road for bridge approaches to China Creek; clearing and disposal of brush and trees; soil excavation and embankment placement for new roads (except roads constructed west of the gate at the end of Kootenai River Road); placing sub-grade reinforcement special rock embankment material (approximately 15,000 cubic yards); and placing crushed rock (approximately 25,000 cubic yards). Special rock embankment material would consist of well-graded crushed, 
partially crushed, or naturally occurring granular material free of wood waste or other extraneous or objectionable materials. The exception to no soil excavation on roads west of the gate would be for proposed work to widen Sheep Range Road along the face of Black Eagle Rock. BPA proposes to widen the roadbed by constructing retaining walls at the road/river edge to allow safe passage of large construction equipment past a series of narrow turns. Placing rock next to the Kootenai River at the edge of the road would eliminate the need to remove rock from the face of Black Eagle Rock.

To protect cultural resources, access road construction and improvement in the area west of the gate at the end of Kootenai River Road would be accomplished primarily by hauling and placing borrow sub-grade reinforcement (fill) material and not by normal soil cutting and filling practices. Normal cut and fill practices could damage or disturb subsurface deposits of cultural materials. Where BPA needs to acquire rights for access roads, a 50-foot-wide easement would be acquired for new roads and a 20 -foot-wide easement would be acquired for existing roads. The 50-foot-wide easement would allow the agency to cut and remove trees and build road cuts and fills. These activities would not be needed on existing roads.

\section{Construction Schedule and Work Crews}

Construction would take place during two seasons, the first would be between July and November 2008 and the second would be between May and November 2009. One or more construction crews would clear vegetation, improve/construct access roads, and 
construct the line. A typical crew can usually construct about 10 miles of transmission line in 3 months. In the inaccessible areas along historic U.S. Highway 2 and north of the Kootenai River, construction could take longer due to difficult terrain and limited access. Helicopters could be used for clearing and would be used intermittently for 6 to 7 months during removal of the existing line and construction of the new line. Helicopters would not be used to remove poles in the Big Horn Terrace or Pipe Creek residential areas or where the line parallels or crosses well traveled roads (such as Kootenai River Road) because the line is easily accessible from the ground.

\section{Maintenance and Vegetation Management}

During the life of the project, BPA would perform routine, periodic maintenance and emergency repair of electrical equipment, structures, and conductors. BPA would detour around the Big Horn Terrace and Pipe Creek residential areas during helicopter inspections of the transmission line. Pilots would be instructed to fly around, rather than over, these areas during routine inspections. These areas would be inspected from the ground.

Tall-growing vegetation would be removed from the corridor and from around structures so as not to interfere with the conductors. Access roads would be graded, seeded, ditched, and rocked to reduce soil erosion as needed. Noxious weed control is also part of BPA's vegetation management program. BPA works with the county weed boards and landowners on area-wide plans for noxious weed control. 


\section{Estimated Project Cost}

The estimated cost for rebuilding the Libby to Troy transmission line as a $115-\mathrm{kV}$ singlecircuit line is approximately $\$ 17$ million. Annual maintenance costs would be about $\$ 10,000$ to $\$ 20,000$.

\section{Alternative 1 - 230-kV Double-Circuit Rebuild}

Under Alternative 1, BPA would remove the existing Libby to Troy transmission line and rebuild the line as a 230-kV double-circuit transmission line for its full 17-mile length.

\section{Line Routing and Corridor}

Additional transmission line right-of-way easements and permitted areas would need to be acquired to accommodate a $230-\mathrm{kV}$ transmission line. BPA would need to acquire an additional 10 to 20 feet from each edge of existing right-of-way easement (on private, county, state, and tribal lands) or permitted area (on National Forest and former Great Northern Railroad lands) so that the cleared width would extend 50 feet on each side of the center conductor, for a total right-of-way easement width or permitted area width of 100 feet.

\section{Transmission Structure Design}

The structures for the proposed $230-\mathrm{kV}$ rebuild would be single tubular steel pole structures 90 to 110 feet tall with spans of 800 to 900 feet between structures. Typical steel pole diameter is about 40 inches at the base. Three types of structures 
(suspension, angle, and dead-end) would be used. The steel in all the structures would be colorized a dark gray to blend with the surrounding environment as much as possible. About 120 transmission structures would be needed to carry the conductors for this alternative.

\section{Structure Footings}

Concrete shaft or direct-embed footings would be used for the $230-\mathrm{kV}$ rebuild, depending on the terrain and tower type. Footing holes would either be hand dug, drilled or augered, or dug with an excavator, depending on subsurface conditions. At each structure site, an area about 100 feet by 100 feet would be temporarily disturbed during construction, depending on the terrain and type of structure. An average area of 10 feet by 10 feet would be permanently occupied by the structure.

\section{Conductor, Fiber Optic Cable and Pulling/Tensioning Sites}

The 230-kV double-circuit structures would hold six conductors or two circuits. The conductors for the proposed transmission line would be dulled to reduce the shininess

of the metal. Conductors are attached to the $230-\mathrm{kV}$ structures in the same manner as the 115-kV single-circuit alternative, with about the same number and size of pulling/tensioning sites required. Ground wires and counterpoise would be installed with this alternative. The structures also could accommodate fiber optic cable, as for the 115-kV alternative. 


\section{Vegetation Clearing}

Because the existing corridor would need to be widened to 100 feet to accommodate the higher voltage line, all tall-growing vegetation on the additional right-of-way and permitted areas would be cleared, except where the vegetation would not interfere with construction or operation of the line. Additionally, danger trees located outside the 100foot right-of-way would also be cleared.

\section{Access Roads, Staging Areas, Removal of Existing Structures, Maintenance and Vegetation Management}

The $230-\mathrm{kV}$ rebuild alternative would require the same work on existing and new roads as for the $115-\mathrm{kV}$ alternative. Temporary staging areas, wood pole removal processes, and maintenance activities also would be the same.

\section{Construction Schedule and Work Crews}

The construction schedule and work crews would be similar to those for the Proposed Action.

\subsubsection{Estimated Project Cost}

The estimated cost for rebuilding the Libby to Troy transmission line as a $230-\mathrm{kV}$ doublecircuit line is $\$ 30$ million. Since steel structures require less maintenance than wood structures, annual maintenance costs would be about $\$ 7,000$ to $\$ 9,000$. 


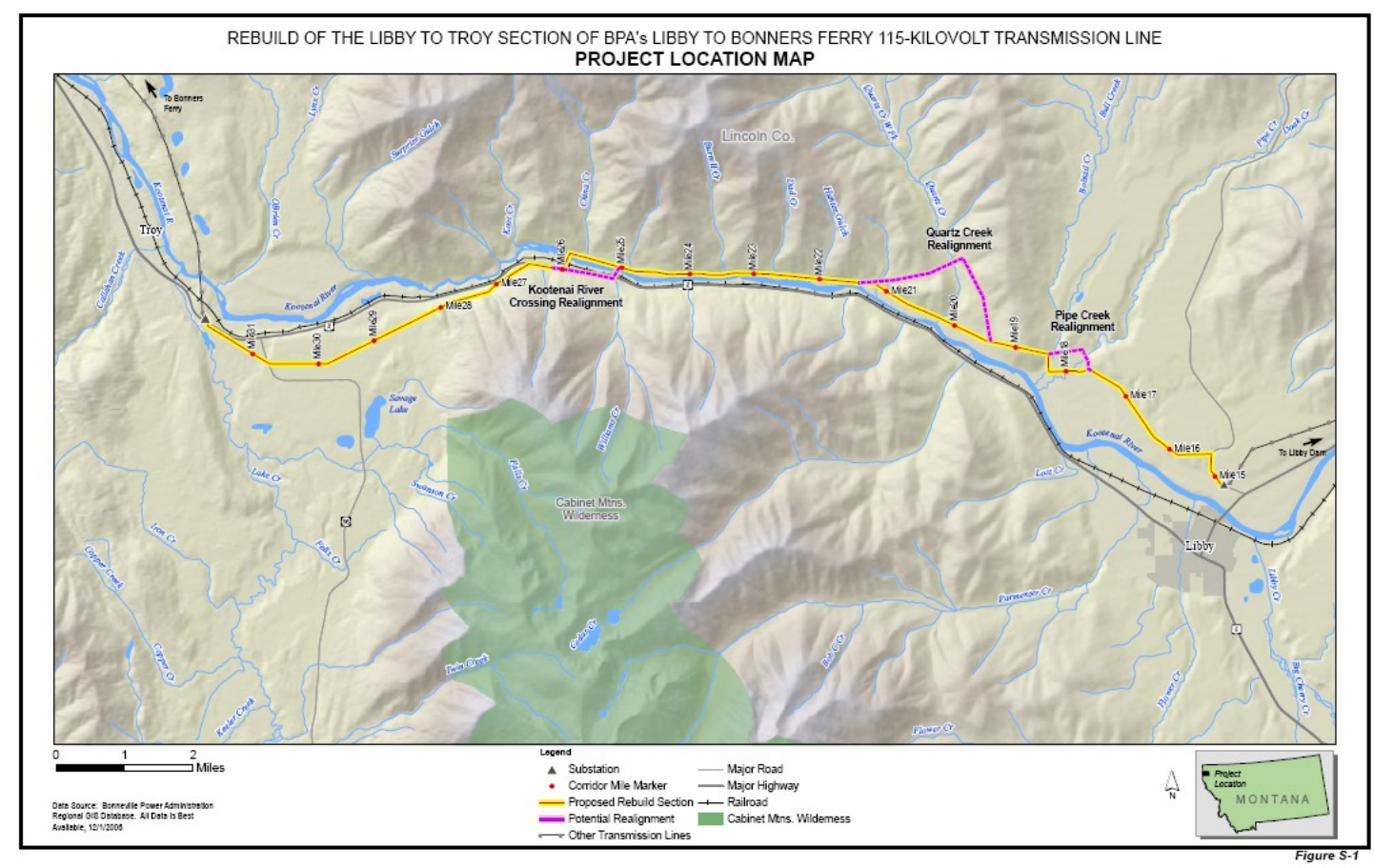

Figure 22: Rebuild of Libby to Troy System Upgrade Project 


\section{APPENDIX B - DOCUMENTS USED}

\begin{tabular}{|c|c|c|}
\hline & Document ID & Stakeholder Name \\
\hline 1 & LTS-044 & (Jerry and Helen Gould) Paul and Patricia Mammano \\
\hline 2 & LTS-004 & (no name) \\
\hline 3 & LTS-022 & (no name) \\
\hline 4 & LTS-026 & (no name) \\
\hline 5 & LTS-038 & Alfred and Wilberta Dearth \\
\hline 6 & LTS-027 & Alice Robison and Joe Cielak \\
\hline 7 & LTS-001 & Barbara Dutro \\
\hline 8 & & Barbara Dutro \\
\hline 9 & LTS-010 & Barbara Dutro (Solar/Wind Energy Conversion) \\
\hline 10 & LTS-003 & Carolyn Fera \\
\hline 11 & LTS-037 & Carolyn Fera \\
\hline 12 & LTS-049 & Dale Swapinksi \\
\hline 13 & LTS-009 & Dan Martin \\
\hline 14 & LTS-041 & Dan Ooley \\
\hline 15 & LTS-029 & Darcy and Mark \\
\hline 16 & & Denna Watson \\
\hline 17 & & Department of Energy (reply to Barbara Dutro) \\
\hline 18 & & Don and Lena Whitson \\
\hline 19 & LTS-018 & Don W. and Lena Whitson \\
\hline 20 & LTS-109 & Fred Sturgess \\
\hline 21 & & Fred Sturgess (email of the phone call) \\
\hline 22 & LTS-046 & Gale Lammers \\
\hline 23 & LTS-030 & George Anderson \\
\hline 24 & LTS-034 & George Baker \\
\hline 25 & & Jerry and Helen Gould \\
\hline 26 & LTS-028 & Joe Cielak and Alice Robinson \\
\hline 27 & LTS-006 & Joel Chvilicek and Gelna Young \\
\hline 28 & LTS-039 & John \& Myrtle Jeldnser \\
\hline 29 & & John and Margret Smith \\
\hline 30 & LTS-021 & Karen Ross \\
\hline 31 & LTS-020 & Kevin Christensen \\
\hline 32 & LTS-038 & Kevin Christensen \\
\hline 33 & LTS-035 & Larry Kelly \\
\hline 34 & LTS-047 & Lena Whitson \\
\hline 35 & LTS-040 & Margret Smith \\
\hline 36 & LTS-042 & Margret Smith \\
\hline 37 & LTS-005 & Mark Contor (Northern Lights) \\
\hline 38 & LTS-015 & Mary Mitchell \\
\hline 39 & LTS-017 & Michael Kimberlin \\
\hline 40 & LTS-103 & Montana Dept of Environmental Quality \\
\hline 41 & & Montana Fish, Wildlife \& Parks \\
\hline 42 & LTS-032 & Paul \& Maria Eanes \\
\hline 43 & LTS-007 & Paul A. Leimbach \\
\hline 44 & LTS-025 & Paul E Mannand \\
\hline
\end{tabular}




\begin{tabular}{lll}
45 & LTS-002 & Paul Eanes \\
46 & LTS-031 & Paul Eanes \\
47 & LTS-043 & Ralph Heinert - Montana House of Representatives \\
48 & LTS-036 & Randy Buckner \\
49 & LTS-016 & $\begin{array}{l}\text { Richard and Nancy Young } \\
50\end{array}$ \\
51 & LTS-033 & Senator Aubyn Curtis - Montana State Senate \\
52 & LTS-023 & Town Hall meeting \\
53 & LTS-011 & Town hall meeting - May 18 \\
54 & LTS-012 & Town hall meeting - May 19 \\
55 & LTS-014 & Town hall meeting - May 20 \\
56 & & Tribal Project Briefing - 11/14 Kootenai Culture Advisory \\
& & Committee \\
57 & LTS-008 & US Environmental Protection Agency \\
58 & LTS-045 & Vince and Becky Silverstri \\
\hline \hline
\end{tabular}

Table 34: Scoping Stakeholder Comments

\begin{tabular}{rll}
\hline \hline & Document ID & Stakeholder Name \\
\hline 1 & LTD-0001 & Fred Sturgess \\
3 & LTD-0002 & Paul Leimbach \\
4 & LTD-0003 & Jean Riley - Montana Dept. of Transportation \\
5 & LTD-0000 & Lena Whitson \\
6 & LTD-0006 & Robert Stewart - Us Dept. of Interior \\
7 & LTD-0007 & Rich Young \\
8 & LTD-0008 & Paul and Patricia Mammano \\
9 & LTD-0009 & John Wardell - US EPA \\
10 & LTD-0010 & John Smith \\
11 & LTD-0011 & Carolyn Fera \\
12 & LTD-0012 & Public Meeting \\
13 & LTD-0013 & Warren McCullough - Montana Dept. of Env. of. Quality \\
14 & LTD-0014 & Residents of Kootenai River Road \\
15 & LTD-0015 & John Smith \\
16 & LTD-0016 & Tom Ring - Montana Dept. of Env. Quality \\
17 & LTD-0017 & John Smith \\
18 & LTD-0018 & John Smith \\
19 & LTD-0019 & John Smith \\
20 & LTD-0020 & John Smith \\
21 & LTD-0021 & John Smith \\
22 & LTD-0022 & John Smith \\
\hline \hline
\end{tabular}

Table 35: Draft EIS Stakeholder Comments 


\section{APPENDIX C- COGNITIVE MODELS}

The Stakeholders models were built using Mental Modeler, and the BPA Expert Model was built using Pajek. Pajek is a mature social network analysis tool capable of handling hundreds of concept, whereas Mental Modeler is a new tool and is currently limited in the number of concepts that can fit in the user interface window. Therefore, it could not handle modeling the BPA expert.

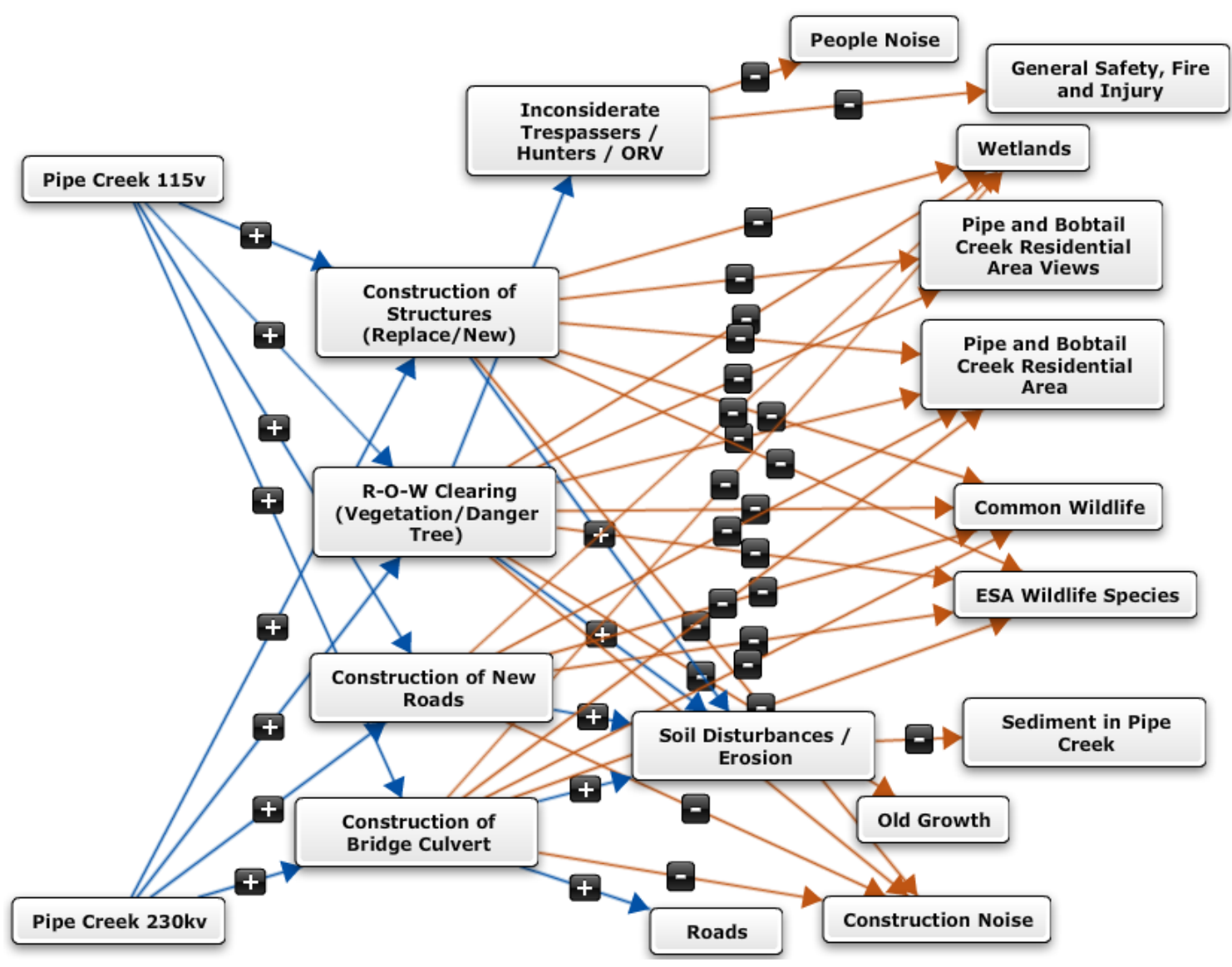

Figure 23: Pipe Creek 


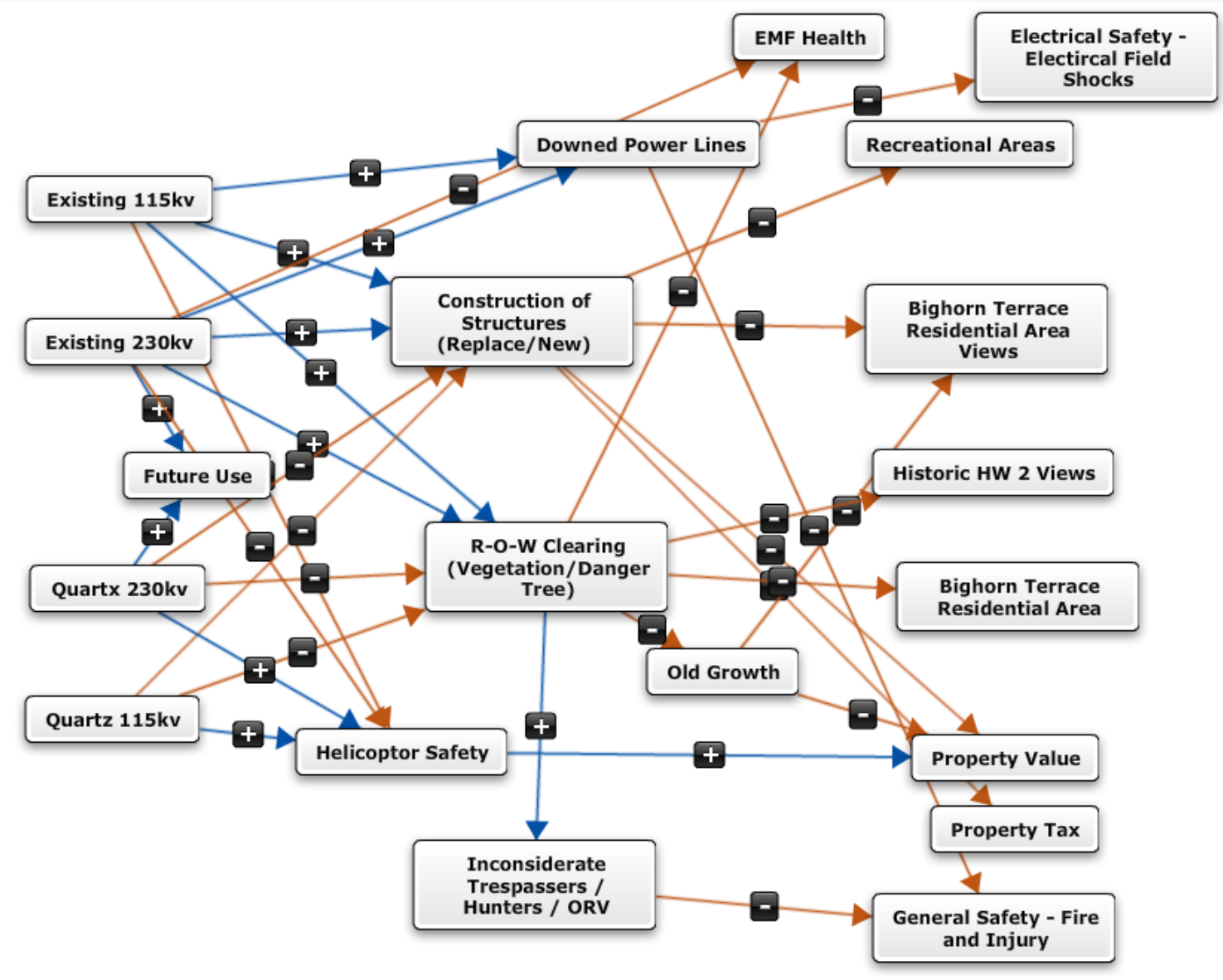

Figure 24: Bighorn Terrace 


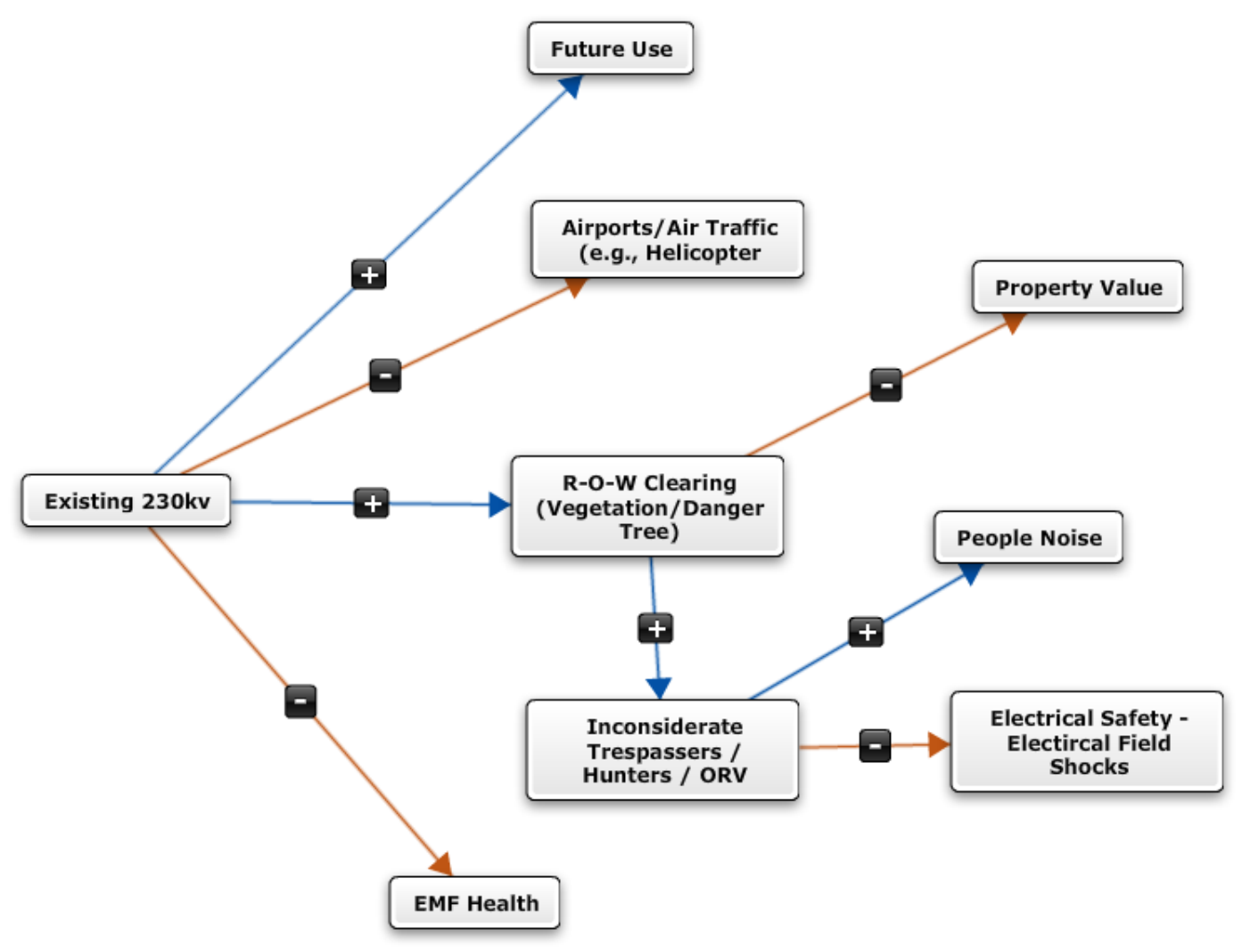

Figure 25: Residents at Large

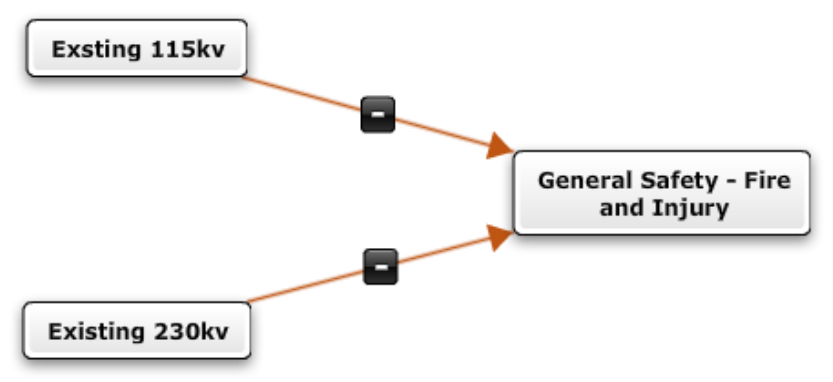

Figure 26: City of Libby 


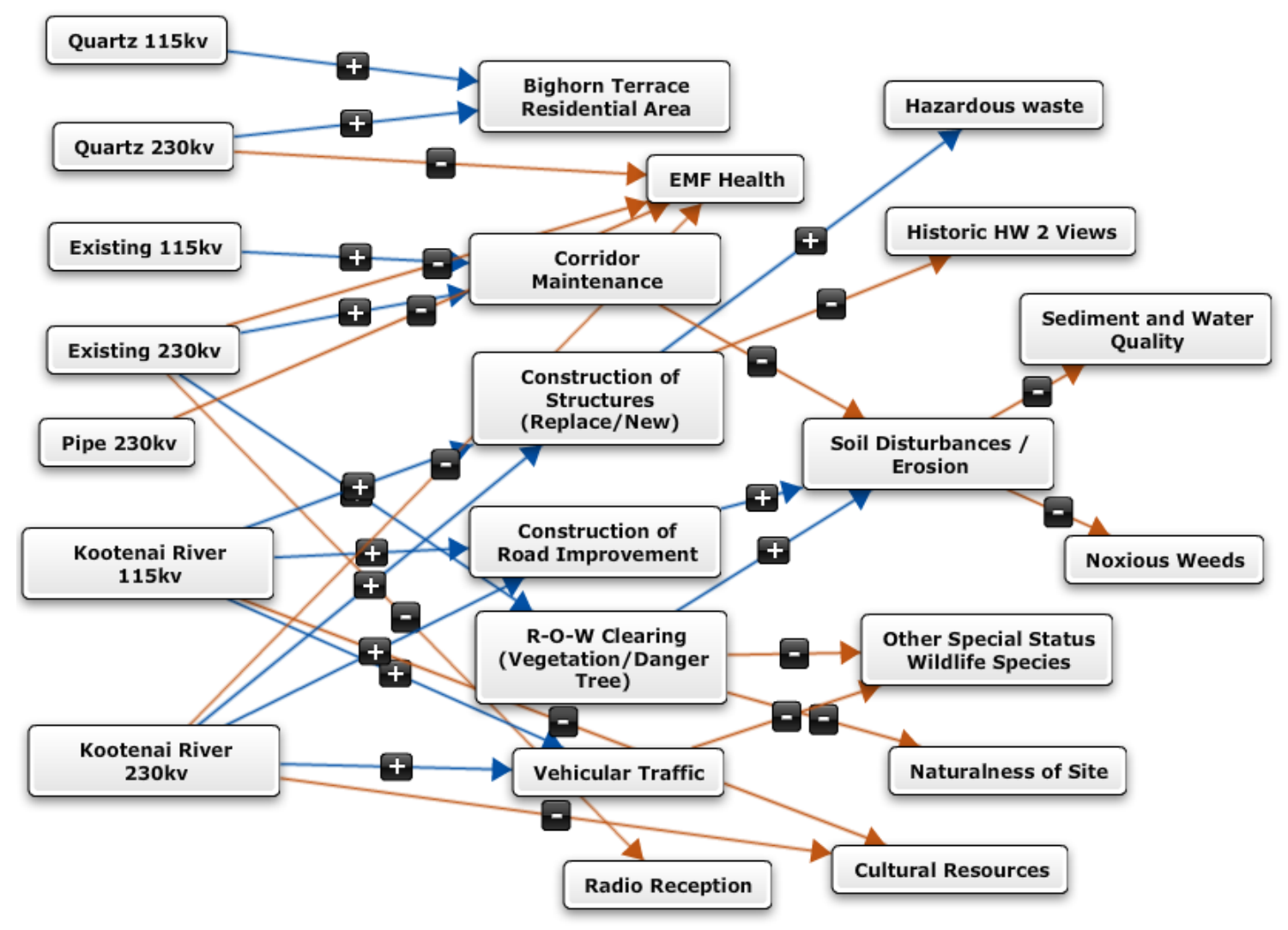

Figure 27: State of Montana 


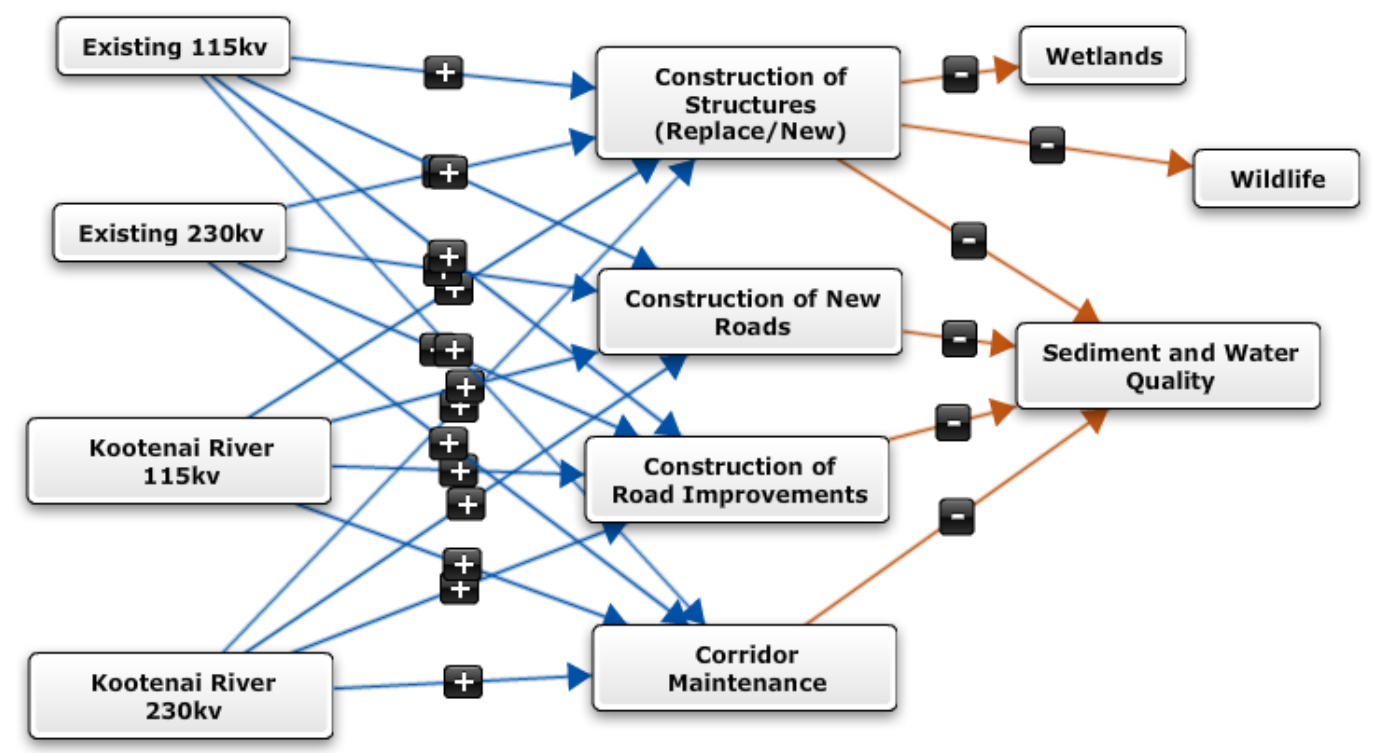

Figure 28: Federal Government 


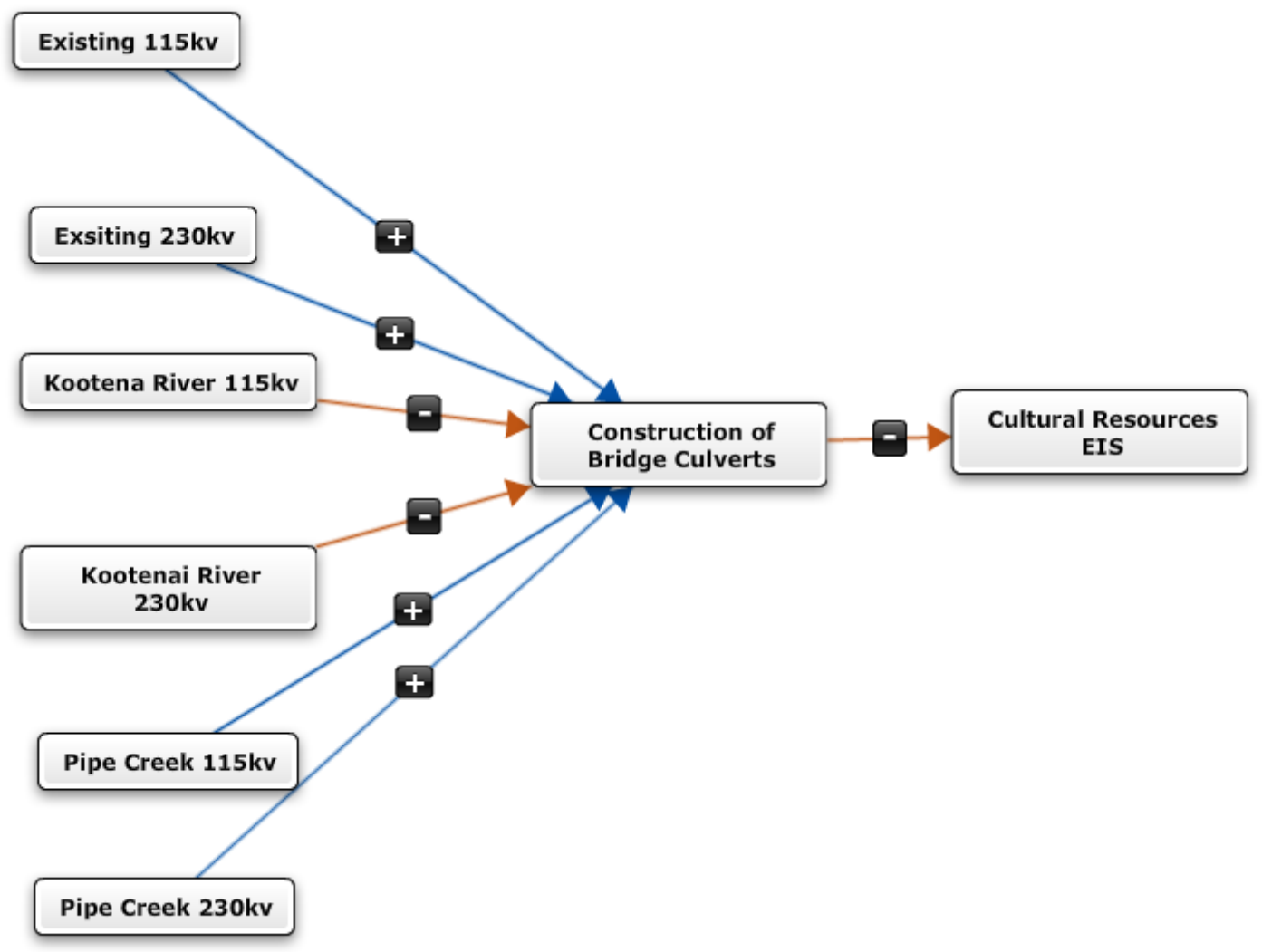

Figure 29: Tribal Communities 


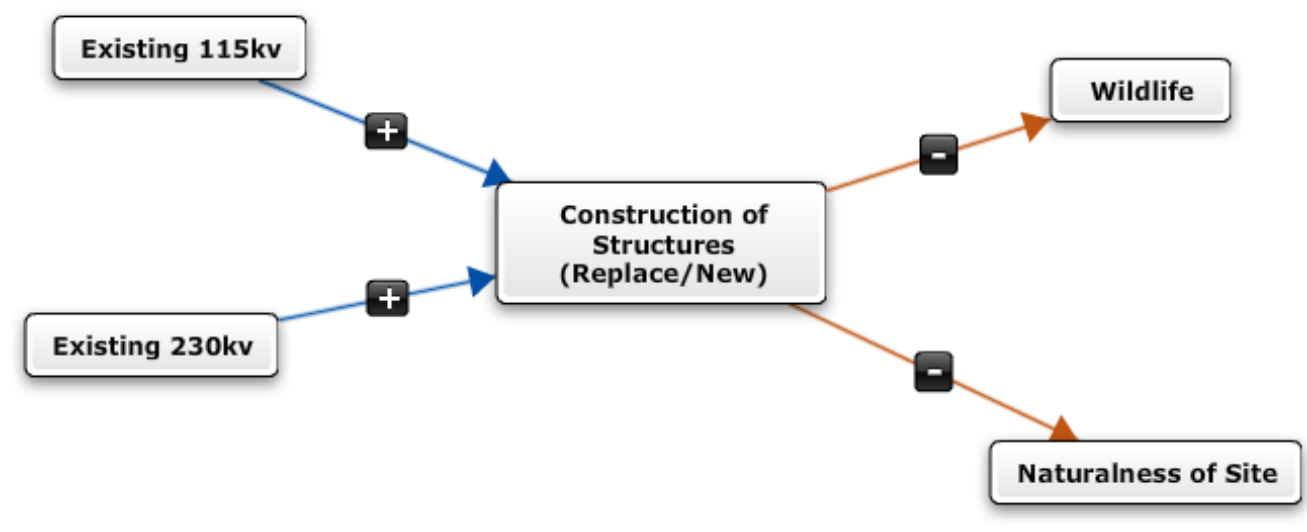

Figure 30: Local Business 


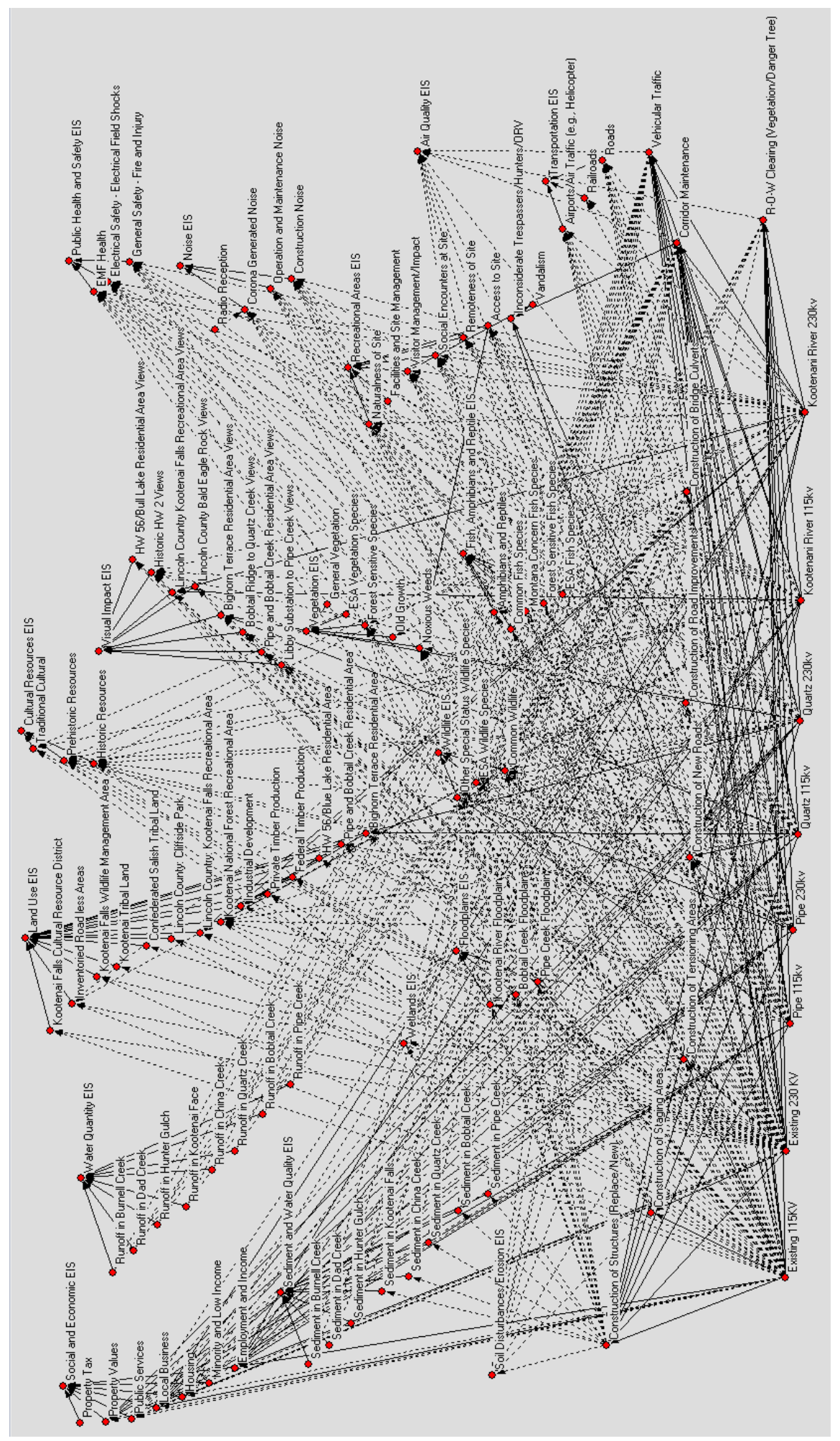

Figure 31: BPA Expert Cognitive Map 


\section{APPENDIX D - COMMON ONTOLOGY}

\begin{tabular}{|c|c|}
\hline "Construction of Structures (Replace/New)" & "Common Wildlife" \\
\hline "Construction of Staging Areas" & "ESA Wildlife Species" \\
\hline "Construction of Tensioning Areas" & "Other Special Status Wildlife Species" \\
\hline "Construction of New Roads" & "Wildlife EIS" \\
\hline "Construction of Road Improvements" & "ESA Fish Species" \\
\hline "Construction of Bridge Culverts" & "Forest Sensitive Fish Species" \\
\hline " R-O-W Clearing (Vegetation/Danger Tree)" & "Montana Concern Fish Species" \\
\hline "Corridor Maintenance" & "Common Fish Species" \\
\hline "Vehicular Traffic" & "Amphibians and Reptiles" \\
\hline "Soil Disturbances/Erosion EIS" & "Fish, Amphibians and Reptile EIS" \\
\hline "Sediment in Pipe Creek" & "Libby Substation to Pipe Creek Views" \\
\hline "Sediment in Bobtail Creek" & "Pipe and Bobtail Creek Residential Area Views" \\
\hline "Sediment in Quartz Creek" & "Bobtail Ridge to Quartz Creek Views \\
\hline "Sediment in China Creek" & "Bighorn Terrace Residential Area Views" \\
\hline "Sediment in Kootenai Falls" & "Lincoln County Bald Eagle Rock Views" \\
\hline "Sediment in Hunter Gulch" & $\begin{array}{l}\text { "Lincoln Country Kootenai Falls Recreational Area } \\
\text { Views" }\end{array}$ \\
\hline "Sediment in Dad Creek" & "Historic HW 2 Views" \\
\hline "Sediment in Burnell Creek" & "HW 56/Bull Lake Residential Area Views" \\
\hline "Sediment and Water Quality EIS" & "Visual Impact EIS" \\
\hline "Runoff in Pipe Creek" & "Prehistoric Resources" \\
\hline "Runoff in Bobtail Creek" & "Historic Resources" \\
\hline "Runoff in Quartz Creek" & "Traditional Cultural" \\
\hline "Runoff in China Creek" & "Cultural Resources EIS" \\
\hline "Runoff in Kootenai Face" & "Vandalism" \\
\hline "Runoff in Hunter Gulch" & "Inconsiderate Trespassers/Hunters/ORV" \\
\hline "Runoff in Dad Creek" & "Access to Site" \\
\hline " Runoff in Burnell Creek" & "Remoteness of Site" \\
\hline "Water Quantity EIS" & "Social Encounters at Site" \\
\hline "Pipe and Bobtail Creek Residential Area" & "Visitor Management/Impact" \\
\hline "Bighorn Terrace Residential Area" & "Facilities and Site Management" \\
\hline "HW 56/Blue Lake Residential Area" & "Naturalness of Site" \\
\hline "Federal Timber Production" & "Recreational Areas EIS" \\
\hline "Private Timber Production" & "Construction Noise" \\
\hline "Industrial Development" & "Operation and Maintenance Noise" \\
\hline "Kootenai National Forest Recreational Area" & "Corona Generated Noise" \\
\hline "Lincoln Country: Kootenai Falls Recreational Area" & "Radio Reception" \\
\hline
\end{tabular}




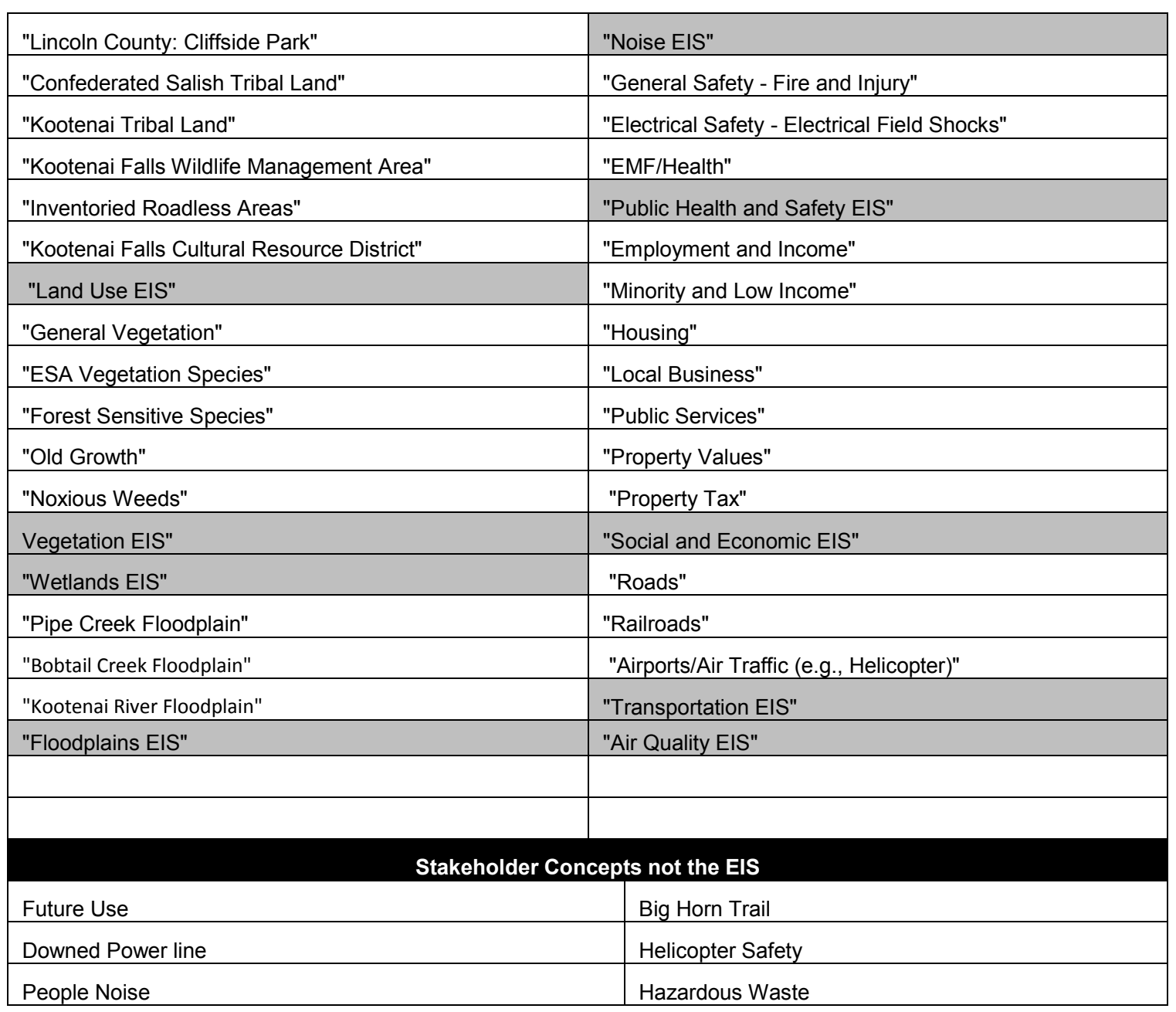

Table 36: Common Ontology 


\section{APPENDIX E - INTERVIEW SCRIPT FOR EVALUATION OF THE RESEARCH}

Thank you for participating in our study and agreeing to be interviewed.

The purpose of the interview is to validate the methods used in research and instill confidence in the research results. Meaning, did the methods used determine the impacts of alternatives under investigation on stakeholders.

Over the past 9 months, I have been researching stakeholder concerns with the Libbyto-Troy transmission upgrade project. The purpose of the research is to develop methodology for evaluating technology alternatives and making decisions that are sociably responsible and align to the organizational objectives using fuzzy cognitive mapping. The Libby-to-Troy project was chosen because BPA conducted a lengthy stakeholder engagement process to consider the impact of multiple alternatives on all stakeholders as part the NEPA EIS process. Furthermore, all information was publically available.

There are four (4) areas to the interview.

1. Stakeholder grouping and aggregation.

2. Stakeholders' concerns with the alternatives.

3. Changes in stakeholder concerns between scoping and final EIS.

4. Implementation issues.

These are open-ended questions so that we can learn from your experiences and perceptions. Do you have any questions before we begin? If not or after questions are answered - Let us begin

\section{Interview Questions}

\#1a - The research identified eight stakeholder groups: Pipe Creek residents, Bighorn residents, Residents at large, local businesses, City of Libby, Montana state government, US federal government, and tribal communities (pass out the handout Appendix A). 
The purpose of the following question(s) is to validate the method for stakeholder identification and analysis used for aggregation.

Question 1a - We want to learn how you identify and group stakeholders and whether our grouping is aligned to how you grouped stakeholders? If not, why?

- Optional probe:

- Do you group stakeholders?

- If not, why?

- If yes, what criteria do you use to group stakeholders?

\#1b - The research aggregated stakeholder groups based on demographics, for example, residents and government. Furthermore, the research also aggregated stakeholder groups based on common interests regarding concerns with the alternatives, for example, Bighorn Terrace and Montana state government favored Quartz Creek realignment. These two and the US federal government did not favor Kootenai River realignment.

Question $1 \mathrm{~b}$ - How do relationships among stakeholders affect the way you analyze stakeholder concerns, and is our analysis aligned to how you view aggregated stakeholders?

- Optional probe:

- Do you prioritize stakeholders (for example, power, interests)?

- Do stakeholders ever team up with one another?

- If so, what brought them together?

- What are the effects when they team up?

\#2 - The research captured stakeholder concerns in the form of causal cognitive maps, which are a collection of beliefs, experiences and information people use to orient themselves within an environment such as social setting.

The purpose of the following question(s) is to validate the method for analyzing stakeholder concerns.

Question 2a - Do the concerns captured reflect your understanding of the stakeholder's concerns based on your experience? 
An introduction to causal cognitive mapping is required prior to discussing the models. Upon completion, three models will be reviewed: Bighorn Terrace, Montana State Government, and Tribal Communities.

- - Optional probe (for each model):

- Would you look at their concerns in this way?

- Did I miss any concerns?

- If so, what were they?

- How and when did you learn of those concerns (e.g., scoping, draft EIS).

- Were they documented in the comments?

- Were they concerned about other alternatives?

- Did I include a concern that they were not concerned about?

\#3 - The research captured stakeholder concerns from the comments at scoping and after the draft EIS was released to determine if their perceptions changed over time regarding the impacts of the alternatives.

The purpose of the following question(s) is to validate that the method was capable of isolating changes in perceptions over time.

Two of three stakeholder groups from question 2 had changes in their perceptions and one did not. Bighorn Terrace: added Helicopter Safety and effect on property value if the helicopter crashed and impact on cultural resources from the Kootenai River realignment were lessened, but now they identified the visual impact HW2. Montana state government added hazardous waste, (GPS) radio reception, naturalness of site, EMF health, and sediment and water quality as impacts. Tribal communities' views did not change; they are only concerned with cultural resources from China Creek culvert resulting from only replacing the existing $115 \mathrm{kv}$ line and Pipe Creek realignment.

Question 3a - Of the three stakeholders, did stakeholder views change from scoping to release of the draft EIS?

- Optional probe (for each model):

- If so, what caused the change in perceptions?

- If so, did their change in perception cause your priority to change?

- Did their change in perception cause new relationships? 
- If so, what brought them together or apart?

- What are the effects of these new relationships?

\#4 - The research captured the stakeholders' perceptions of the concerns resulting from the alternatives under investigation. The research also captured how the expert viewed impacts of stakeholders. Differences in perceptions are areas for potential issues to occur.

The purpose of the following question(s) is to validate that the method was capable of isolating potential issues with the implementation.

Question $4 \mathrm{a}-$ BPA chose to replace the existing $115 \mathrm{kv}$ line with the same voltage to avoid the environmental impacts resulting with wider ROW associated with $230 \mathrm{kv}$. In addition, it also chose to realign the transmission line around China Creek to avoid impacts to cultural resources resulting from the construction of a culvert. What stakeholder issues did BPA encounter during the implementation?

- Optional probe:

- Did you underestimate the power of stakeholders?

- Did their power increase though relationships with other stakeholders?

- Did you underestimate the impact of the alternatives selected on stakeholders?

- What were the real concerns stakeholders had with the known alternatives?

- What would you have done differently?

- Did you make any changes to the alternatives as a result of the issues? 


\section{APPENDIX F - SENSITIVITY ANALYSIS}

Sensitivity analysis was performed using various linear and non-linear threshold squashing functions. The output of each of the threshold squashing functions are shown below.

Bivalent formula: greater than " 0 ", then " 1 ", Else " 0 "

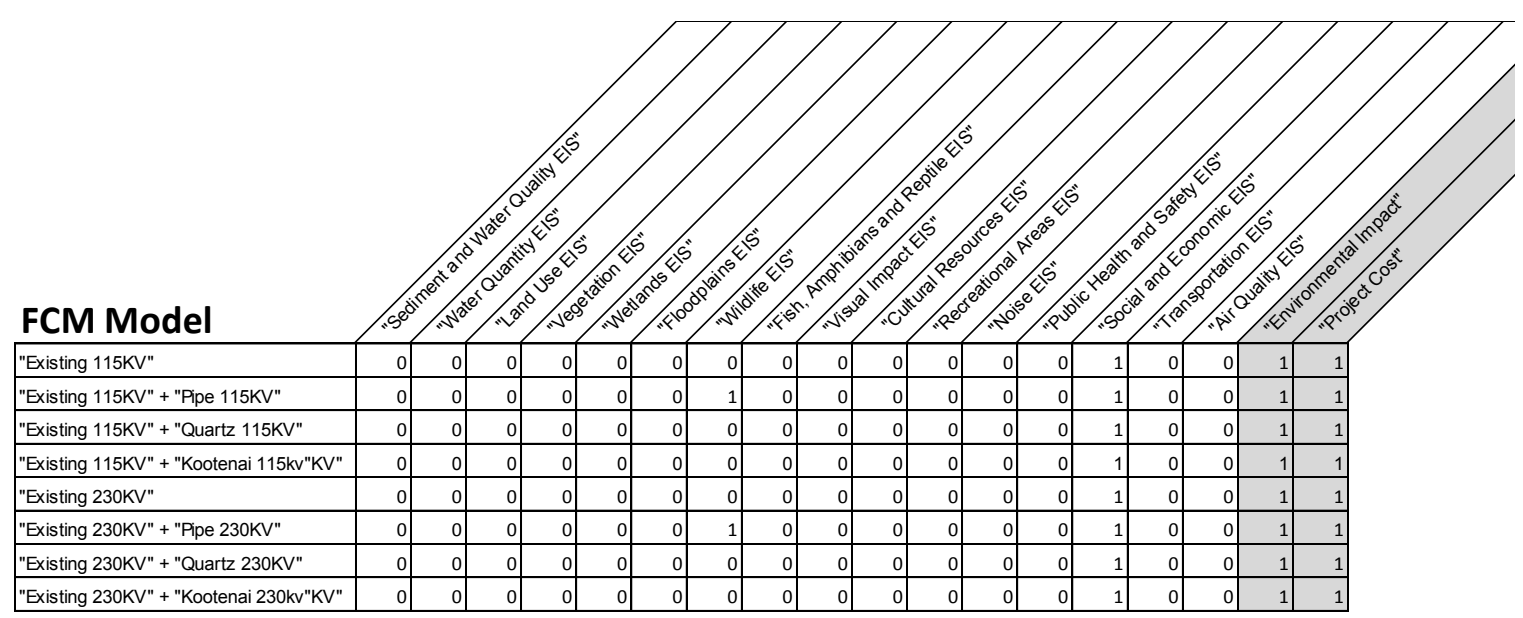

Table 37: Bivalent Threshold Squashing Function

Trivalent formula: greater than or equal to " 0.5 ", then " 1 ", less than or equal to " 0.5 " then "-1", Else " 0 "

FCM Model

\begin{tabular}{|c|c|c|c|c|c|c|c|c|c|c|c|c|c|c|c|c|c|}
\hline & & & & & & & & & & & & & & & & & \\
\hline "Existing 115KV" & -1 & -1 & -1 & -1 & -1 & -1 & -1 & -1 & -1 & -1 & -1 & -1 & -1 & -1 & -1 & -1 & 0 \\
\hline "Existing 115KV" + "Pipe 115KV" & -1 & -1 & -1 & -1 & -1 & -1 & -1 & -1 & -1 & -1 & -1 & -1 & -1 & -1 & -1 & -1 & 0 \\
\hline "Existing 115KV" + "Quartz 115KV" & -1 & -1 & -1 & -1 & -1 & -1 & -1 & -1 & -1 & -1 & -1 & -1 & -1 & -1 & -1 & -1 & 0 \\
\hline "Existing 115KV" + "Kootenai 115kv"KV" & -1 & 0 & -1 & -1 & -1 & -1 & -1 & -1 & -1 & -1 & -1 & -1 & -1 & -1 & -1 & -1 & 0 \\
\hline "Existing 230KV" & -1 & -1 & -1 & -1 & -1 & -1 & -1 & -1 & -1 & -1 & -1 & -1 & -1 & -1 & -1 & -1 & 1 \\
\hline "Existing 230KV" + "Pipe 230KV" & -1 & -1 & -1 & -1 & -1 & -1 & -1 & -1 & -1 & -1 & -1 & -1 & -1 & -1 & -1 & -1 & 1 \\
\hline "Existing 230KV" + "Quartz 230KV" & -1 & -1 & -1 & -1 & -1 & -1 & -1 & -1 & -1 & -1 & -1 & -1 & -1 & -1 & -1 & -1 & 1 \\
\hline "Existing 230KV" + "Kootenai 230kv"KV" & -1 & -1 & -1 & -1 & -1 & -1 & -1 & -1 & -1 & -1 & -1 & -1 & -1 & -1 & -1 & -1 & 1 \\
\hline
\end{tabular}

Table 38: Trivalent Threshold Squashing Function 
Pentavalent Formula: greater than " 1 " then " 1 ", greater or equal to" 0.5 " then " 0.5 ", if less than "- 1 ", then "- 1 ", if less than or equal to "-0.5" then "- .5 ", Else " 0 ".

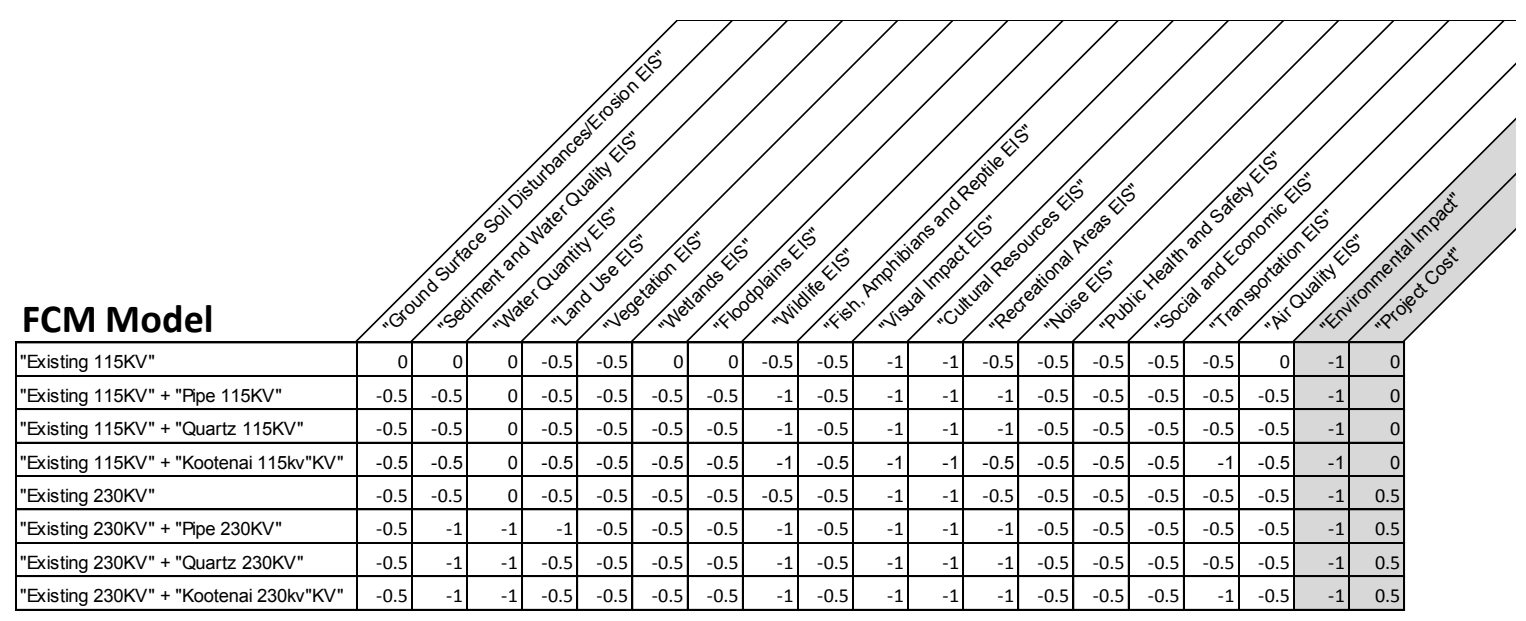

Table 39: Pentaivalent Threshold Squashing Function

\section{FCM Model}

\begin{tabular}{|c|c|c|c|c|c|c|c|c|c|c|c|c|c|c|c|c|c|c|}
\hline & -012 & & 012 & ד? & 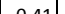 & $011 / 1^{1}$ & 0,20 & 2001 & 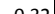 & $0=5 \mid$ & 010 & & 0.11 & & 01010 & & & \\
\hline "Existing 115KV" + "Pipe 115KV" & -0.2 & $-0.05]$ & -0.2 & -0.23 & -0.52 & -0.23 & -0.36 & $-0,08 \mid$ & -0.37 & $-0.59 l-100$ & -0.37 & -034 & $-0,2$ & 0 & -0.25 & -03 & $-0.28 \mid$ & 0.43 [ \\
\hline & & & & & & & & & & & & & & & & & & \\
\hline "EXIsting TISKV + "Quartz TISKV & -0.2 & -0.05 & -0.17 & -0.23 & -0.56 & -0.23 & -0.51 & $-0.08 \mid$ & -0.28 & -0.59 & -0.41 & -0.34 & -0.2 & 0 & -0.25 & -0.35 & -0.3 & 0.43 \\
\hline "Existing 115KV" + "Kootenai 115kv"KV" & -0.15 & -0.03 & -0.12 & -0.23 & -0.37 & -0.19 & -0.45 & -0.23 & -0.37 & -0.48 & -0.23 & -0.28 & -0.2 & -0.01 & -0.28 & -0.23 & -0.25 & 0.42 \\
\hline "Existing 230KV" & -0.2 & -0.06 & -0.28 & -0.23 & -0.62 & -0.22 & -0.41 & -0.08 & -0.64 & -0.54 & -0.29 & -0.21 & -0.1 & -0.01 & -0.19 & -0.29 & -0.29 & 0.49 \\
\hline "Existing 230KV" + "Pipe 230KV" & -0.32 & -0.09 & -0.36 & -0.19 & -0.74 & -0.31 & -0.52 & -0.08 & -0.71 & -0.59 & -0.45 & -0.34 & -0.2 & 0 & -0.25 & -0.42 & $\mid-0.36$ & 0.5 \\
\hline "Existing 230KV" + "Quartz 230KV" & -0.32 & -0.09 & -0.32 & -0.19 & -0.77 & -0.31 & -0.66 & -0.08 & -0.6 & -0.59 & -0.49 & -0.34 & -0.2 & 0 & -0.25 & -0.47 & $|-0.37|$ & 0.51 \\
\hline "Existing 230KV" + "Kootenai 230kv"KV" & -0.28 & -0.07 & -0.27 & -0.22 & -0.62 & -0.27 & -0.54 & -0.23 & -0.6 & -0.48 & -0.33 & -0.28 & -0.2 & $|-0.01|$ & -0.28 & -0.36 & $-0.33 \mid$ & 0.49 \\
\hline
\end{tabular}

Table 40: Sine Threshold Squashing Function 


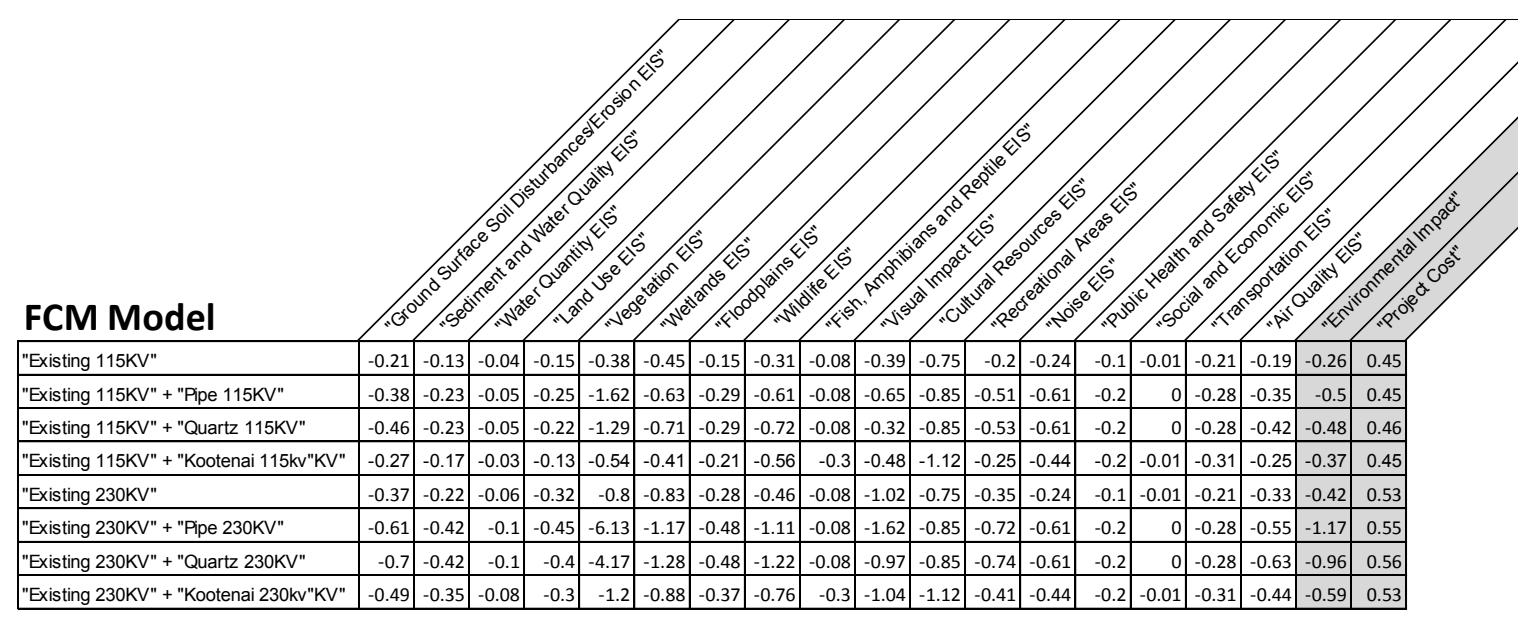

Table 41: Hyperbolic Sine Threshold Squashing Function

FCM Model

\section{"Existing 115KV"}

"Existing 115KV" + "Ripe 115KV"

"Existing 115KV" + "Quartz 115KV"

"Existing 115KV" + "Kootenai 115kv"KV"

"Existing 230KV" + "Pipe 230KV"

\begin{tabular}{|l|r|r|r|r|r|r|r|r|r|r|r|r|r|r|r|r|r|r|}
\hline "Existing 230KV" + "Quartz 230KV" & -0.3 & -0.09 & -0.3 & -0.27 & -0.7 & -0.28 & -0.6 & -0.08 & -0.54 & -0.54 & -0.45 & -0.32 & -0.19 & 0 & -0.24 & -0.43 & -0.34 & 0.49 \\
\hline "Existing 230KV" + "Kootenai 230kv"KV" & -0.26 & -0.07 & -0.25 & -0.24 & -0.57 & -0.25 & -0.5 & -0.21 & -0.55 & -0.46 & -0.31 & -0.26 & -0.19 & -0.01 & -0.27 & -0.34 & -0.31 & 0.47 \\
\hline
\end{tabular}

Table 42: Arc Tangent Threshold Squashing Function 


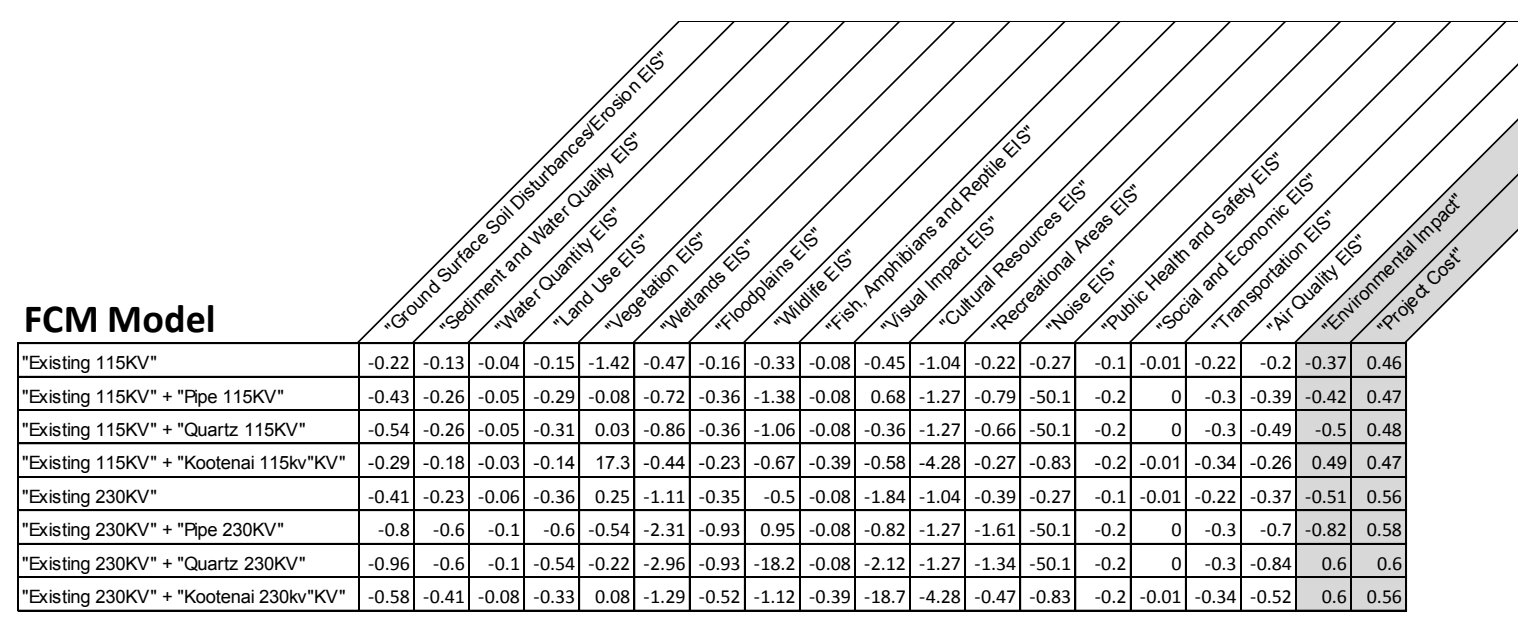

Table 43: Tangent Threshold Squashing Function 